\title{
Identifikation und funktionelle Analyse von Xdach1 und Xeya 3 als morphogenetische Faktoren der Kopfentwicklung von Xenopus laevis
}

\author{
Dissertation \\ zur Erlangung des Doktorgrades \\ der Mathematisch-Naturwissenschaftlichen Fakultäten \\ der Georg-August-Universität zu Göttingen
}

\author{
vorgelegt von \\ Martin Kriebel \\ aus Jane-Furse-Hospital/Südafrika
}

Göttingen 2004 


\section{D7}

Referent: Prof. Dr. Tomas Pieler

Korreferent: Prof. Dr. Rüdiger Hardeland

Tag der mündlichen Prüfung: 26.01.2005 




\section{Inhaltsverzeichnis}

Inhaltsverzeichnis

Abbildungsverzeichnis

VII

Abkürzungsverzeichnis

$\mathrm{X}$

\section{Einleitung}

1.1 Die Bildung neuralen Ektoderms am Beispiel der frühen Embryonalentwicklung des südafrikanischen Krallenfrosches Xenopus laevis

1.1.1 Neurale Induktion als Folge der Inhibition des Bmp4-vermittelten Signalweges

1.1.2 Anterior-posteriore Musterbildung innerhalb des neuralen Ektoderms

1.2 Frühe Augenentwicklung als Spezifikation von Bereichen anterioren neuralen

Ektoderms

1.3 Vertebraten-Homologe der Drosophila Gene Eyes absent (eya) und Dachshund (dac) 7

1.3.1 Die Eyes absent Familie von Proteinen

1.3.2 Die Dachshund Familie von Proteinen

1.4 Organogenese und Aufbau des Linsenauges der Vertebraten 10

1.5 Musterbildung im Hinterhirn und Neuralrohr von Xenopus laevis 11

$\begin{array}{ll}\text { 1.6 Ziel der Arbeit } & 14\end{array}$

2.1 Versuchstiere

2.2 Bakterienstämme

2.3 Genbanken

2.4 Medien und Lösungen $\quad 15$

2.4.1 Nährmedien 16

$\begin{array}{ll}\text { 2.4.2 Antibiotika } & 16\end{array}$

2.4.3 Puffer und (Stamm-)Lösungen 16

2.5 Antikörper und Chemikalien 17

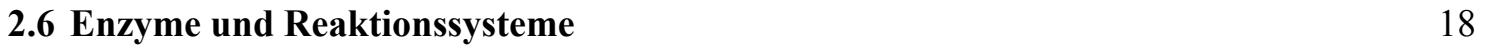

$\begin{array}{ll}2.6 .1 \text { Enzyme } & 18\end{array}$

$\begin{array}{ll}\text { 2.6.2 Reaktionssysteme } & 18\end{array}$ 
2.7 Oligonukleotide 19

2.8 Vektoren und cDNA-Klone 20

2.8.1 Vektoren 20

2.8.2 cDNA-Klone 21

2.9 Geräte 27

3. Methoden 31

3.1 Präparation von Xenopus laevis Embryonalstadien 31

3.1.1 Präparation einer Spermiensuspension aus Xenopus laevis Testis 31

3.1.2 Stimulation der Eiablage 31

3.1.3 In vitro Fertilisation 31

3.1.4 Entfernen der Gallerte, Vitalfärbung und Entwicklung 31

3.1.5 Fixierung von Xenopus laevis Embryonen $\quad 32$

3.2 Mikromanipulation von Xenopus laevis Embryonen 32

3.2.1 Mikroinjektion von Xenopus laevis Embryonen $\quad 32$

3.2.2 Hydroxyurea-/Aphidicolin-(„HUA“) Behandlung von Xenopus laevis Embryonen 33

3.2.3 Präparation und Kultivierung von animalen Gewebeexplantaten (animal caps) 33

3.3 RNA Methoden 33

3.3.1 Präparation von Gesamt-RNA aus Xenopus laevis 33

3.3.1.1 Embryonalstadien 34

3.3.1.2 Adulte Gewebe und Organe 34

3.3.1.3 Animale Gewebeexplantate (animal caps) 34

3.3.2 Reverse-Transkriptase-Polymerase-Ketten-Reaktion (RT-PCR) 35

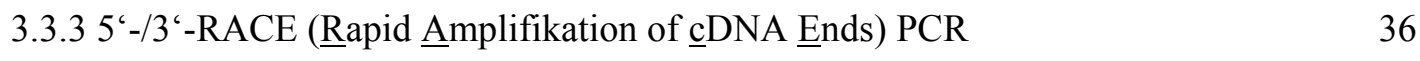

3.3.3.1 Herstellen von 5'-/3'-RACE-Ready cDNA 36

3.3.3.2 Amplifikation von 5'-/3'-cDNA Enden (RACE-PCR) 37

3.3.4 In vitro Synthese von Cap-mRNA für Mikroinjektionen 38

3.3.5 In vitro Synthese markierter RNA-Sonden 39

3.3.6 Aufreinigung synthetisch hergestellter RNA 39

$\begin{array}{ll}\text { 3.4 DNA Methoden } & 40\end{array}$

3.4.1 Bestimmung der optischen Dichte (OD) von Bakterien-Flüssigkulturen $\quad 40$

3.4.2 Herstellung kompetenter Bakterienzellen für die chemische Transformation $\quad 40$

3.4.3 Herstellung kompetenter Bakterienzellen für die elektrische Transformation $\quad 40$

3.4.4 Transformation kompetenter Bakterienzellen 41

3.4.5 Elektrische Transformation kompetenter Bakterienzellen 41

3.4.6 Isolierung von Plasmiden im analytischen Maßstab 42 
3.4.7 Isolierung von Plasmiden im präparativen Maßstab 42

3.4.8 Konzentrationsbestimmung von Nukleinsäuren 43

3.4.9 PCR-vermittelte in vitro-Mutagenese 43

3.4.10 Nachweis der Integration klonierter DNA-Fragmente 43

3.4.10.1 PCR auf Flüssigkultur-Aliquots („Colony-PCR“) 43

3.4.10.2 Restriktionsanalyse $\quad 44$

3.4.11 DNA-Sequenzierung und Sequenzanalyse $\quad 44$

3.4.12 Plasmidlinearisierung 45

3.4.13 Restriktionsspaltung von Vektor-DNA und DNA-Fragmenten 46

3.4.14 Agarosegelelektrophorese 46

3.4.15 Aufreinigung von DNA-Fragmenten $\quad 47$

3.4.15.1 Aufreinigung von PCR-Produkten und linearisierten Plasmiden 47

3.4.15.2 Isolierung von PCR-Produkten aus Agarosegelen 47

$\begin{array}{ll}\text { 3.4.16 Ligation von DNA-Fragmenten } & 47\end{array}$

3.4.17 Durchmustern einer cDNA-Bank 48

3.4.17.1 Identifikation positiver Phagenfraktionen 48

3.4.17.2 Phagenplattierung $\quad 49$

3.4.17.3 Amplifikation spezifischer 5'-Fragmente 49

3.5 Protein Methoden $\quad 50$

3.5.1 In vitro Translation $\quad 50$

3.5.2 Nachweis von Fusionsproteinen in vivo $\quad 50$

$\begin{array}{ll}\text { 3.5.2.1 Immunpräzipitation } & 50\end{array}$

3.5.2.2 SDS-Polyacrylamid-Gelelektrophorese (SDS-PAGE) 51

3.5.2.3 Western Blot $\quad 52$

3.5.3 Nachweis der subzellulären Lokalisation von Fusionsproteinen 53

3.5.3.1 „Whole mount“ Immunfärbung 53

3.5.3.2 Immunfärbung an Paraffinschnitten 53

3.5.4 Nachweis von proliferierenden oder apoptotischen Zellen $\quad 54$

3.5.4.1 Nachweis von proliferierenden Zellen durch Detektion von phosphoryliertem Histon 3 ( $p H 3$ ) 54

3.5.4.2 Nachweis von proliferierenden Zellen durch Inkorporation von BrdU 54

3.5.4.3 Nachweis von apoptotischen Zellen durch TUNEL-Analyse 55

3.6 „Whole mount” in situ Hybridisierung $\quad 56$

3.6.1 Rehydrieren der Embryonen $\quad 56$

3.6.2 Proteinase-K Behandlung 56

3.6.3 Acetylierung und Refixierung $\quad 57$

$\begin{array}{ll}\text { 3.6.4 Hybridisierung } & 57\end{array}$ 
3.6.5 Waschen $\quad 57$

3.6.6 Antikörper-Inkubation 58

$\begin{array}{ll}\text { 3.6.7 Farbentwicklung } & 59\end{array}$

3.6.7.1 NBT/BCIP-Färbung $\quad 59$

3.6.7.2 FAST RED-Färbung $\quad 59$

3.6.8 Abstoppen der Färbung und Auswertung $\quad 60$

$\begin{array}{ll}\text { 3.6.9 Doppelfärbungen } & 60\end{array}$

3.7 Anfertigung von Gewebeschnitten 61

3.7.1 Vibratomschnitte 61

3.7.2 Kunststoffschnitte $\quad 62$

3.7.3 Paraffinschnitte 63

4. Experimente und Ergebnisse $\quad 65$

4.1 Die Klonierung des Eyes absent Homologs 3 aus Xenopus laevis (Xeya3) 65

4.2 Das Xenopus Eya-Homolog Xeya3 ist in eine C-terminale „PST“- und eine

N-terminale Eya-Domäne gegliedert 68

4.3 Xeya3 besitzt eine Phosphatase-Aktivität im Bereich der Eya-Domäne 69

4.4 Xeya3 wird in anterioren neuralen Strukturen exprimiert 72

4.5 Das Xeya3-Protein ist ausschließlich nukleär lokalisiert 75

4.6 Ein Xeya3-Funktionsverlust verursacht massiven Verlust anterioren neuralen

Gewebes $\quad 76$

4.7 Ein Xeya3-Funktionsverlust führt anterior zur Suppression neuraler

$\begin{array}{ll}\text { Markergene } & 78\end{array}$

4.8 Ein Xeya3-Funktionsverlust führt zur Apoptose von neuralen Vorläuferzellen $\quad 79$

4.9 Eine Xeya3-Überexpression führt zu Neoplasie anterioren neuralen Gewebes 81

4.10 Eine Xeya3-Überexpression verursacht eine Expansion der vorderen

Neuralplatte $\quad 83$

4.11 Zellen einer durch Xeya3-Überexpression vergrößerten Retina durchlaufen den Differenzierungsprozess $\quad 84$

4.12 Die Überexpression von Xeya3 bewirkt eine Expansion dorsaler Hirnbereiche sowie die Ausweitung von Zentren der Neurogenese 86

4.13 Eine Xeya3-Überexpression stimuliert die Zellproliferation innerhalb neuralen

Gewebes

4.14 Ein Verlust der Phosphatase-Aktivität von Xeya3 führt zu einer gesteigerten $\begin{array}{ll}\text { Aktivität des Xeya3-Proteins } & 90\end{array}$

4.15 Die Klonierung des dachshund Homologs 1 aus Xenopus laevis (Xdach1) 
4.16 Xdach1-A und Xdach1-B besitzen zwei konservierte „Dachshund-Domänen“ und zeigen Sequenzverwandtschaft zu den Proto-Onkogenen Ski und Sno

4.17 Xdach1 wird in neuralen und mesodermalen Geweben exprimiert 101

4.18 Das Xdach1-B-Protein ist im Zellkern lokalisiert

4.19 Ein Xdach1-Funktionsverlust führt zu Defekten in der embryonalen Augenentwicklung

4.20 Ein Funktionsverlust von Xdach1 hat Defekte der Musterbildung während der Augenentwicklung zur Folge

4.21 Ein Xdach1-Funktionsverlust verhindert Neurogenese in Bereichen des zentralen Nervensystems

4.22 Eine Überexpression von Xdach1-B führt zur Vergrößerung von Derivaten neuralen Ektoderms

4.23 Die Überexpression von Xdach1-B hat einen stark neuralisierenden Effekt

4.24 Xdach1-B inhibiert den Xbmp4-Signaltransduktionsweg

4.25 Eine Ko-Injektion von Xdach1-B und Msix6 führt zu positiven synergistischen Effekten bezüglich retinalen Wachstums

\section{Diskussion}

5.1 Xeya3 als Mitglied der Eyes absent-Familie von Proteinen

5.2 Xeya3 als trophischer Faktor der Spezifikation und Determination anterioren neuralen Gewebes

5.3 Das Xeya3-Protein besitzt möglicherweise zusätzlich eine transdeterminierende Funktion

5.4 Die Phosphatase-Aktivität des Xeya3-Proteins hat möglicherweise autoregulatorische Funktion

5.5 Die Zellkernlokalisation des Xeya3-Proteins

5.6 Xdach1 als Mitglied der Dachshund-Familie von Proteinen

5.7 Xdach1 in Morphogenese und Musterbildung des Amphibienauges

5.8 Xdach1 in Entwicklung und Differenzierung von Hirngewebe

5.9 Die Zellkernlokalisation des Xdach1-Proteins

5.10 Der Synergismus zwischen Xdach1-B und Msix6

$5.11 X d a c h 1$ als Inhibitor der Xbmp4 induzierten Signaltransduktion 
7. Literaturverzeichnis

Danksagungen

Lebenslauf 


\section{Abbildungsverzeichnis}

Abbildung 1.1: $\quad$ Lebenszyklus des südafrikanischen Krallenfrosches Xenopus laevis

Abbildung 1.2: $\quad$ Modell der Funktion des Spemann-Organisators und anterior-posteriore Musterbildung innerhalb des Neuroektoderms

Abbildung 1.3: $\quad$ Die Entwicklung der Augen als Strukturen des Vorderhirns

Abbildung 1.4: $\quad$ Das genetische Netzwerk der Komplexaugendifferenzierung in

Drosophila melanogaster

Abbildung 1.5: $\quad$ Organogenese des Linsenauges der Vertebraten 10

Abbildung 1.6: $\quad$ Anatomie des Vertebratenauges 11

Abbildung 1.7: $\quad$ Musterbildung und sekundäre Neurogenese im Neuralrohr von Xenopus laevis

Abbildung 2.1: $\quad$ Der Klonierungsvektor $p G E M-T$

Abbildung 2.2:

Der Expressionsvektor $p C S 2+$

Abbildung 2.3:

Der Expressionsvektor $p C S 2+M T$

Abbildung 4.1: $\quad$ Nukleotid- und Aminosäuresequenz des offenen Leserahmens von Xeya 3

Abbildung 4.2: $\quad$ Xeya3 als Mitglied der Eya3-Subklasse innerhalb der Eyes absent-Familie von Proteinen

Abbildung 4.3: $\quad$ Vergleich der Aminosäuresequenzen von Xeya3 und Eya3-

Proteinen anderer Vertebraten

Abbildung 4.4: $\quad$ Vergleich der Aminosäuresequenzen von Xeya3 und Eyes absent aus Drosophila melanogaster

Abbildung 4.5: $\quad$ Räumliche und zeitliche Expression von Xeya3 während der

Embryonalentwicklung von Xenopus laevis

Abbildung 4.6: $\quad$ Expressions-Niveau von Xeya 3 in Embryonalstadien und adulten Geweben von Xenopus laevis 74

Abbildung 4.7: $\quad$ Subzelluläre Lokalisation von Xeya3 75

Abbildung 4.8: $\quad$ Reduktion neuralen Gewebes durch Funktionsverlust von Xeya3 77

Abbildung 4.9: $\quad$ Suppression neuraler Markergene durch Funktionsverlust von Xeya3 79

Abbildung 4.10: $\quad$ Apoptose neuraler Vorläuferzellen nach Funktionsverlust von Xeya3 80

Abbildung 4.11: $\quad$ Translation von Xeya3-myc in vivo 81

Abbildung 4.12: $\quad$ Neoplasie anterioren neuralen Gewebes als Folge einer

Überexpression von Xeya3

Abbildung 4.13: $\quad$ Expansion der vorderen Neuralplatte unter dem Einfluss einer Überexpression von Xeya 3 
Abbildung 4.14: $\quad$ Retinaler Größenzuwachs und atypisches retinales

Differenzierungsmuster nach Überexpression von Xeya 3

Abbildung 4.15: $\quad$ Veränderung des Expressionsmusters von Markergenen des zentralen Nervensystems nach einer Überexpression von Xeya3 87

Abbildung 4.16: $\quad$ Stimulation der Zellproliferation durch Xeya3-Überexpression

Abbildung 4.17: $\quad$ Repression der durch Xeya3-Überexpression induzierten Phänotypen durch „HUA“-Behandlung

Abbildung 4.18: $\quad$ Aktivitätssteigerung von Xeya3 nach Inaktivierung seiner Phosphatase-Aktivität

Abbildung 4.19: $\quad$ Nukleotid- und Aminosäuresequenz des offenen Leserahmens von Xdach1-B

Abbildung 4.20: $\quad$ Xdach1-A/-B als Mitglied der Dach1-Subklasse innerhalb der Dachshund-Familie von Proteinen

Abbildung 4.21: $\quad$ Vergleich der Aminosäuresequenzen von Xdach1-B und Xdach1-A mit denen von Dach1-Proteinen anderer Vertebraten

Abbildung 4.22: $\quad$ Vergleich der Aminosäuresequenzen von Xdach1-B und Xdach1-A mit der des Dachshund (dac) Proteins aus Drosophila melanogaster

Abbildung 4.23: $\quad$ Räumliche und zeitliche Expression von Xdachl während der Embryonalentwicklung von Xenopus laevis

Abbildung 4.24: $\quad$ Expressions-Niveau von Xdach1-A und Xdach1-B in Embryonalstadien und adulten Geweben von Xenopus laevis

Abbildung 4.25: Subzelluläre Lokalisation von Xdach1-B

Abbildung 4.26: Defekte der Augenentwicklung nach Funktionsverlust von Xdach1

Abbildung 4.27: $\quad$ Fehlerhafte Musterbildung im Zuge der Augenentwicklung nach Funktionsverlust von Xdach1

Abbildung 4.28: $\quad$ Gestörte Neurogenese nach Funktionsverlust von Xdach1 108

Abbildung 4.29: $\quad$ Translation von Xdach1-B-myc in vivo 109

Abbildung 4.30: Ausdehnung von Hirngewebe nach Überexpression von Xdachl-B 110

Abbildung 4.31: Transdeterminierung nicht-neuralen in neurales Gewebes nach Überexpression von Xdachl-B

Abbildung 4.32: $\quad$ Xdachl-B als Inhibitor der Xbmp4-Signaltransduktion

Abbildung 4.33: $\quad$ Synergismus zwischen Xdach1-B und Msix6

Abbildung 5.1: Räumliches Expressionsmuster von Eyes absent-Homologen außerhalb Drosophila melanogaster 
Abbildung 5.2: $\quad$ Rezeptor-Tyrosin-Kinase (RTK)-vermittelte, $R A S / M A P K$ -

abhängige Signaltransduktion und transaktivierende Funktion von Xeya3

Abbildung 5.3: $\quad$ Räumliches Expressionsmuster von Dachshund-Homologen außerhalb Drosophila melanogaster

Abbildung 5.4: $\quad T G F-\beta$ Signaltransduktion

Abbildung 5.5: $\quad$ Modell der Wirkungsweise von Xdach1 als Antagonist der Bmp-Signaltransduktion 


\section{Abkürzungsverzeichnis}

\section{Aminosäuren:}

$\begin{array}{ll}\text { A } & \text { Alanin } \\ \text { C } & \text { Cystein } \\ \text { D } & \text { Aspartat } \\ \text { E } & \text { Glutamat } \\ \text { F } & \text { Phenylalanin } \\ \text { G } & \text { Glycin } \\ \text { H } & \text { Histidin } \\ \text { I } & \text { Isoleucin } \\ \text { K } & \text { Lysin } \\ \text { L } & \text { Leucin } \\ \text { M } & \text { Methionin } \\ \text { N } & \text { Asparagin } \\ \text { P } & \text { Prolin } \\ \text { Q } & \text { Glutamin } \\ \text { R } & \text { Arginin } \\ \text { S } & \text { Serin } \\ \text { T } & \text { Threonin } \\ \text { V } & \text { Valin } \\ \text { W } & \text { Tryptophan } \\ \text { Y } & \text { Tyrosin }\end{array}$

$\begin{array}{ll}\text { A } & \text { Adenosin } \\ \text { Abb. } & \text { Abbildung } \\ \text { ad } & \text { Auffüllen } \\ \text { AP } & \text { Alkalische Phosphatase } \\ \text { BCIP } & \text { 5-Brom-4-Chlor-3-Indolyl Phosphat } \\ \text { bp } & \text { Basenpaare } \\ \text { BSA } & \text { Rinderserumalbumin } \\ \text { C } & \text { Cytidin } \\ { }^{\circ} \text { C } & \text { Grad Celsius } \\ \text { cDNA } & \text { „Complementary“ = komplementäre DNA } \\ \text { dATP } & \text { Desoxyadenosin 5“ triphosphat } \\ \text { dCTP } & \text { Desoxycytidin 5“ triphosphat } \\ \text { dGTP } & \text { Desoxyguanosin 5' triphosphat }\end{array}$




\begin{tabular}{|c|c|}
\hline $\mathrm{dH}_{2} \mathrm{O}$ & destilliertes Wasser \\
\hline DTT & Dithiothreitol \\
\hline dTTP & Desoxythymidin 5' triphosphat \\
\hline E. coli & Escherichia coli \\
\hline EDTA & Ethylendiamintetraacetat \\
\hline EGTA & Ethylenglykol-bis(2-aminoethylether)-N,N'-tetraacetat \\
\hline et al. & et altera \\
\hline $\mathrm{Fab}$ & Antigen bindendes Fragment \\
\hline $\mathrm{g}$ & Gramm \\
\hline G & Guanosin \\
\hline $\mathrm{h}$ & Stunden \\
\hline Hepes & N-(2-Hydroxymethyl)piperazin, $\mathrm{N}^{`}-3$-propansulfonsäure \\
\hline $\mathrm{k}$ & Kilo \\
\hline $\mathrm{kb}$ & Kilobasenpaare \\
\hline 1 & Liter \\
\hline$\lambda$ & Lambda \\
\hline M & Molar \\
\hline$\mu$ & Mikro \\
\hline $\mathrm{m}$ & Meter, Milli \\
\hline $\min$ & Minute \\
\hline $\mathrm{n}$ & Gesamtanzahl (hier: Embryonen), Nano \\
\hline NBT & Nitro-Blau-Tetrazolium \\
\hline OD & Optische Dichte \\
\hline PBS & Phosphat gepufferte Salinenlösung \\
\hline PCR & Polymerase-Kettenreaktion \\
\hline $\mathrm{ph}$ & negativer dekadischer Logarithmus der Protonenkonzentration \\
\hline RACE & 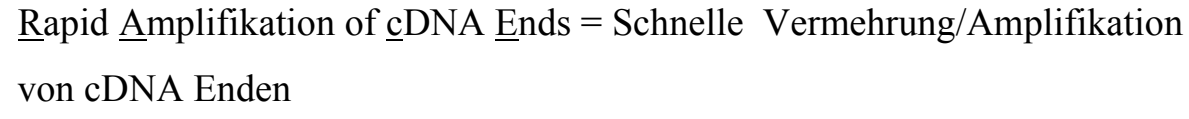 \\
\hline RNA & Ribonukleinsäure \\
\hline RNase & Ribonuklease \\
\hline RT & Raumtemperatur, Reverse Transkriptase \\
\hline RT-PCR & Reverse Transkriptase-Polymerase-Kettenreaktion \\
\hline SDS & Natriumdodecylsulfat \\
\hline sec & Sekunde \\
\hline $\mathrm{T}$ & Thymin \\
\hline tet & Tetracyclin \\
\hline Tris & Trishydroxymethylaminomethan \\
\hline
\end{tabular}




$\begin{array}{ll}\text { U } & \text { Einheiten (Units) der Enzymaktivität } \\ \text { ü.N. } & \text { über Nacht } \\ \text { Upm } & \text { Umdrehungen pro Minute } \\ \text { UTP } & \text { Uridintriphosphat } \\ \text { V } & \text { Volt } \\ \text { Vol. } & \text { Volumen } \\ \text { w/v } & \text { Gewicht (weight) pro Volumen } \\ \text { v/v } & \text { Volumen pro Volumen }\end{array}$




\section{Einleitung}

Das Spektrum neuraler Systeme innerhalb des Tierreichs erstreckt sich vom einfachen, dezentralisierten Netzwerk früher Wirbelloser bis hin zum hochkomplexen, cranial lokalisierten Gehirn der Vertebraten. Erst durch die Entwicklung zentralisierter Nervensysteme mit klar erkennbarer Hierarchie und spezialisierten Sinnesorganen ist im Verlauf der Evolution die Aufnahme und Verarbeitung einer Vielzahl von Sinnesreizen sowie die hochkomplexe Steuerung darauf fein abgestimmter Verhaltensweisen möglich geworden. Das Verständnis der Entstehung dieser neuralen Strukturen im Zuge der Ontogenese stellt eine der zentralen Fragestellungen der modernen Entwicklungsbiologie dar und kann als Modell dabei helfen, allgemeingültige Prinzipien der Organogenese zu erkennen.

\subsection{Die Bildung neuralen Ektoderms am Beispiel der frühen Embryonalentwicklung des südafrikanischen Krallenfrosches Xenopus laevis}

Voraussetzung für die Entwicklung neuraler Organe ist die Bildung des Neuroektoderms als Teil des ektodermalen Keimblattes. Durch anschließende Musterbildung entlang seiner anteriorposterioren Achse enstehen definierte Bereiche, die sich im weiteren Verlauf der Embryogenese zu Bestandteilen des zentralen Nervensystems und davon abgeleiteten Sinnesorganen wie den Augen entwickeln. Die zugrunde liegenden molekularen Prozesse der Entstehung des Neuroektoderms und dessen Regionalisierung sollen im Folgenden kurz erläutert werden.

\subsubsection{Neurale Induktion als Folge der Inhibition des Bmp4-vermittelten Signalweges}

Die primäre Neurogenese in Xenopus laevis ist das Ergebnis der Inhibition einer durch das Morphogen Bmp4 ( Bone Morphogenetic Protein 4) vermittelten Induktion des Ektoderms in Richtung eines epidermalen Schicksals. In Abwesenheit der Bmp4-Aktivität entsteht aus Zellen des Ektoderms neuroektodermales Gewebe. In diesem Zusamenhang besagt das sogenannte „default model of neural induction“, dass für Zellen des Ektoderms ein neurales Entwicklungsschicksal vorgegeben ist und die Bildung weiterer ektodermaler Derivate, wie beispielsweise der Epidermis, erst durch induktive Vorgänge, wie z.B. durch Bmp4 vermittelt, ermöglicht wird (Munoz-Sanjuan und Brivanlou, 2002; Weinstein und Hemmati-Brivanlou, 1999; Wilson und Hemmati-Brivanlou, 1995).

$\mathrm{Zu}$ Beginn der Gastrulationsbewegungen (NF Stadium 10; Abb. 1.1), der Bildung und Ausrichtung der drei Keimblätter Ektoderm, Mesoderm und Endoderm, kommt es in der prospektiven dorsalen Region des Embryos zur Ausbildung der dorsalen Urmundlippe, des sogenannten Spemann-Organisators (Harland und Gerhart, 1997; Spemann und Mangold, 2001). 


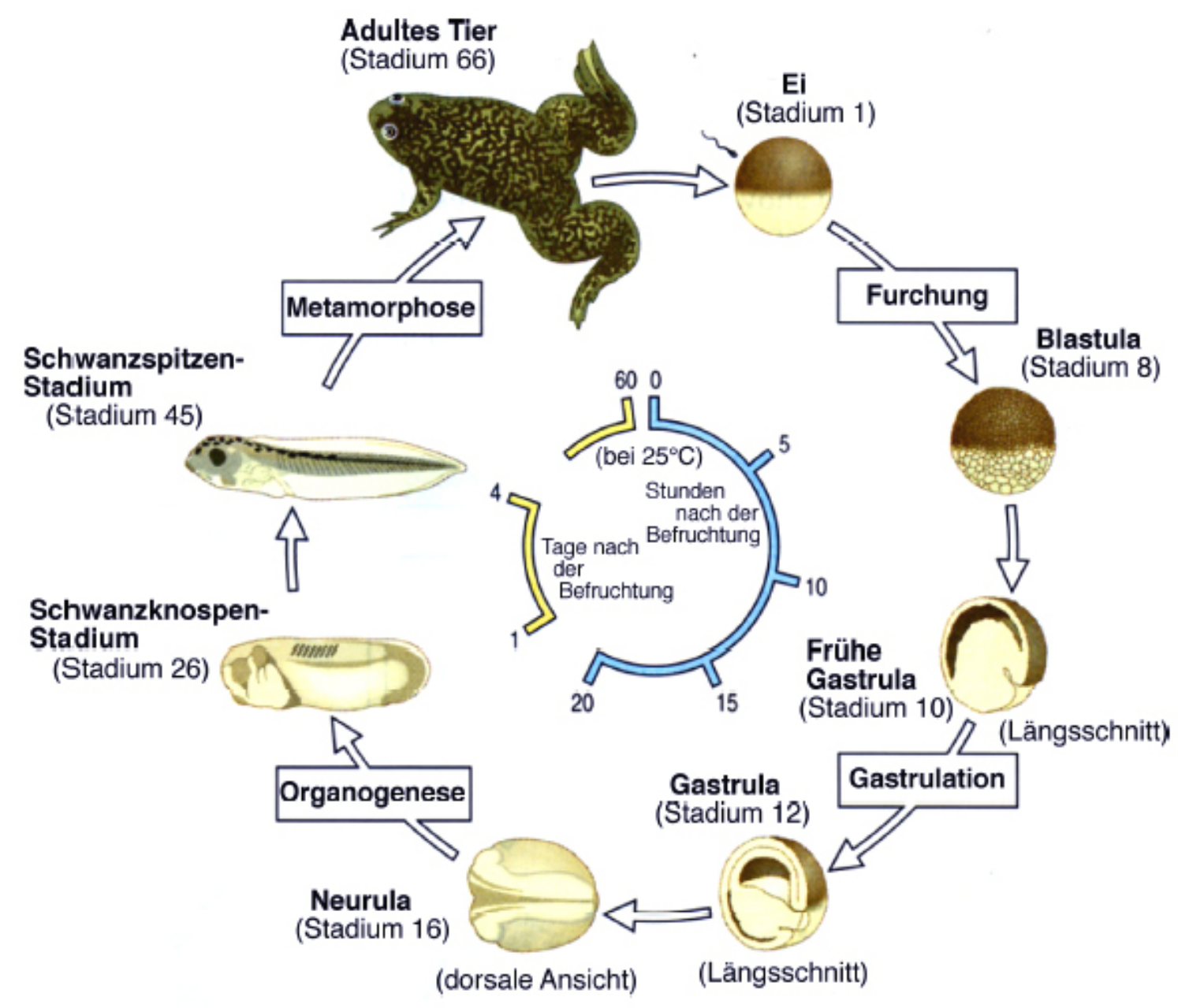

Abb. 1.1: Lebenszyklus des südafrikanischen Krallenfrosches Xenopus laevis. Nach der Fertilisation des Eies folgen Furchungsteilungen, die zur Bildung einer vielzelligen Blastula und der Entstehung der primären Leibeshöhle führen (NF Stadium 8). Zu diesem Zeitpunkt setzt die zygotische Transkription ein („Mid Blastula Transtition“). Während der anschließenden Gastrulationsbewegungen kommt es zur Invagination präsumtiven Meso- und Endoderms, der Spezifikation neuralen Ektoderms und der Ausbildung der sekundären Leibeshöhle (NF Stadium 10, 12). Im Verlauf der Neurulation entwickelt sich aus der offenen Neuralplatte durch dorsalen Schluss das Neuralrohr des Embryos (NF Stadium 16). Mit Abschluss der Neurulation beginnt der Embryo zu elongieren und die Organogenese setzt ein. Durch Schlupf aus der Befruchtungsmembran (NF Stadium 26) und Auswachsen des Schwanzes entwickelt sich eine freischwimmende Larve (NF Stadium 45). Während der Metamorphose werden larvale Strukturen wie Kiemen und Schwanz zurück- und Lunge und Extremitäten des adulten Tieres ausgebildet (NF Stadium 66). Bis zur Geschlechtsreife des Tieres vergeht anschließend noch etwa ein Jahr. Die Zuordnung der verschiedenen Entwicklungsstufen zu Stadien erfolgt nach Nieuwkoop und Faber (1967). Nach Wolpert, 1998. 
Dieser ist Quelle sezernierter Moleküle wie Chordin, Noggin und Follistatin (Fainsod et al., 1997; Knecht et al., 1995; Lamb et al., 1993; Piccolo et al., 1996; Sasai et al., 1995; Zimmerman et al., 1996). Alle verhindern die Bindung des Xbmp4-Proteins an seinen Zelloberflächenrezeptor und somit die Aktivierung der Transkription von Xbmp4-Zielgenen durch die nachgeschaltete Signaltransduktionskaskade (Abb. 1.2). Im weiteren Verlauf der Gastrulation wandert dorsales Mesoderm über die Urmundlippe ins Innere des Embryos ein und kommt unterhalb des Ektoderms zu liegen (NF Stadium 12; Abb. 1.1). Durch die Wirkung der genannten Xbmp4-Antagonisten, die vom so gebildeten Notochord, einem axialen Derivat dorsalen Mesoderms des Spemann Organisators, in das darüberliegende Ektoderm sezerniert werden, kommt es zur Ausbildung der Neuralplatte des Embryos. Die Zellen der Neuralplatte unterliegen keiner Xbmp4-Aktivität mehr und schlagen das vorgegebene neurale Entwicklungsschicksal ein. Dies ist durch den Beginn der Expression von panneuralen Markergenen wie etwa Xsox3 gekennzeichnet (Penzel et al., 1997).

\subsubsection{Anterior-posteriore Musterbildung innerhalb des neuralen Ektoderms}

Die Bildung neuraler Strukturen des späteren Kopfbereiches wie Gehirn und Augen im Verlauf der Organogenese (NF Stadium 26; Abb. 1.1) erfordert neben einer Inhibition von Bmp4Signalen zusätzliche Antagonisten der kanonischen $W n t$-Signaltransduktionskaskade, welche $\beta$ Catenin zur intrazellulären Signalweiterleitung verwendet (Behrens et al., 1996; Cadigan und Nusse, 1997). Zu den in Xenopus laevis bekannten Wnt-Antagonisten zählen die Moleküle Cerberus und Dickkopf1, beides extrazelluläre Inhibitoren von sowohl Xbmp4 und Xwnt8, und Frzb, das eine lösliche Form des Wnt-Membranrezeptors Frizzled darstellt und somit WntMoleküle an der Bindung an ihren Rezeptor hindern kann (Glinka et al., 1998; Glinka et al., 1997; Leyns et al., 1997; Piccolo et al., 1999). Die alleinige Inhibition von Bmp4-Signalen durch Einsatz eines dominant-negativen Bmp4-Rezeptormoleküls ( $t B R)$ erzeugte zwar eine zweite Körperachse, diese wies jedoch keine Kopfstrukturen auf (Glinka et al., 1997). Erst die gemeinsame Überexpression von $t B R$ und Dickkopfl führte zur Bildung eines zweiten Kopfes als Teil der duplizierten Körperachse (Glinka et al., 1998). Die Wnt-Inhibitoren werden vom sogenannten Mesendoderm sezerniert, das sich bereits vor Beginn der Gastrulation an der Grenze zwischen Mesoderm und Endoderm befindet. Im Zuge der Invagination von Gewebe während der Gastrulationsbewegungen gelangen Zellen des Mesendoderms ans anteriore Ende des Embryos und kommen unterhalb prospektiven anterioren Neuroektoderms zu liegen, welches in der weiteren Entwicklung Kopfstrukturen ausbildet.

Die Funktion der Wnt-Signaltransduktionskaskade im Zusammenhang mit anterioposteriorer Musterbildung des Neuroektoderms konnte auch in Experimenten gezeigt werden, in denen es durch Überexpression von Mitgliedern der Wnt-Familie, Xwnt3a bzw. Xwnt8, zur verstärkten Ausbildung posteriorer Zellidentitäten auf Kosten anteriorer Zellidentitäten des 
Neuroektoderms kam (Kiecker und Niehrs, 2001; McGrew et al., 1995). Die Blockierung des Wnt-Signalwegs durch Verwendung einer dominant negativen Form von Xwnt8 (dnWnt8) führte im Gegensatz dazu zur Anteriorisierung des Neuroektoderms, analog zur weiter oben beschriebenen Wirkungsweise der Wnt-Inhibitoren (McGrew et al., 1995).

Einen weiteren, neurales Ektoderm posteriorisierenden Faktor stellt der embryonale Fgf (eFgf; Fibroblast $\underline{\text { Growth }}$ Factor) aus Xenopus laevis dar, der bei Überexpression in Explantaten der anterioren Neuralplatte die Expression von Markergenen des Hinterhirns induziert (Cox und Hemmati-Brivanlou, 1995; Lamb und Harland, 1995). Damit im Einklang steht, dass es bei Inhibition des Fgf-Signalwegs durch Überexpression des dominant-negativen Fgf-Rezeptors-1 $(X F D)$ zur Repression von Markergenen des posterioren Neuroektoderms kommt (Holowacz und Sokol, 1999).

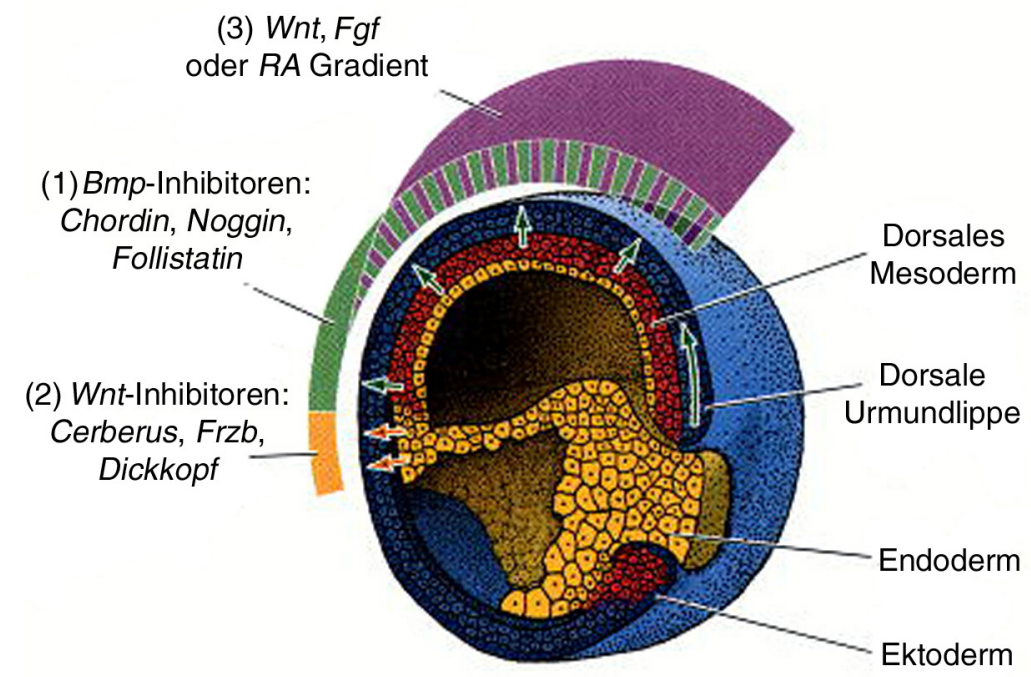

Abb. 1.2: Modell der Funktion des Spemann-Organisators und anterior-posteriore Musterbildung innerhalb des Neuroektoderms. (1) Bmp-Inhibitoren des dorsalen Mesoderms verhindern die Bildung von Epidermis im darüberliegenden Ektoderm (grüne Pfeile). (2) Wnt-Inhibitoren des anterior lokalisierten Mesendoderms erlauben die Entwicklung von Kopfstrukturen wie Augen und Vorderhirn (orange Pfeile). (3) Durch einen Gradienten posteriorisierender Faktoren wie Wnt, Fgf und RA erfolgt die Musterbildung entlang der anterior-posterioren Achse. Nach Gilbert, 2000.

Ebenso kommt es bei Behandlung von Xenopus laevis Neurulae mit Retinsäure $(R A)$ zum Verlust bzw. zu Entwicklungsdefekten des Vorder- und Mittelhirns, was ihr posteriorisierendes Potential zeigt (Papalopulu et al., 1991). RA liegt während der Gastrulation innerhalb des Mesoderms in einem posterior-anterioren Gradienten vor, der durch die komplementäre 
Aktivität des $R A$-produzierenden Enzyms $R a l D H 2$ und des $R A$-metabolisierenden Enzyms Cyp26 gebildet wird (Chen et al., 2001; Hollemann et al., 1998; Niederreither et al., 1997). RA ist sowohl innerhalb des Ektoderms als auch Mesoderms aktiv, da weder mit $R A$ behandeltes anteriores dorsales Mesoderm die Induktion anterioren neuralen Gewebes induzieren (Ruiz i Altaba und Jessell, 1991a; Ruiz i Altaba und Jessell, 1991b), noch mit $R A$ behandeltes anteriores neurales Ektoderm auf Induktionsvorgänge ausgehend vom anterioren dorsalen Mesoderm reagieren kann (Sive et al., 1990). Die Vorgänge während der Induktion und anterior-posterioren Musterbildung des neuralen Ektoderms in Xenopus laevis sind in Abb. 1.2 zusammengefasst.

\subsection{Frühe Augenentwicklung als Spezifikation von Bereichen anterioren neuralen Ektoderms}

Im Zuge der Regionalisierung des Neuroektoderms entlang der anterioren-posterioren Achse entsteht am vorderen Ende der Neuralplatte ein Bereich, aus dem im Verlauf der weiteren Embyronalentwicklung anteriore neurale Strukturen wie Vorderhirn und Augen, als Evagination des Diencephalons, entstehen (s. Abb. 1.3).

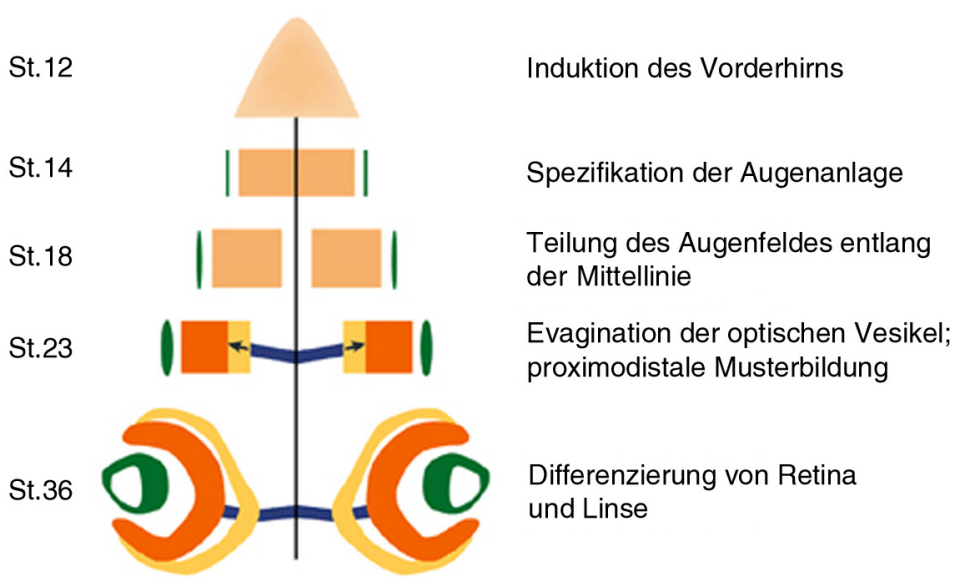

Abb. 1.3: Die Entwicklung der Augen als Strukturen des Vorderhirns. Nach Spezifikation der Augenanlage als Teil des prospektiven Vorderhirns kommt es durch Teilung entlang der Mittellinie zur Bildung der zwei retinalen Primordien. Mit Evagination der optischen Vesikel erfolgt

eine erste Musterbildung entlang der proximodistalen Achse. In der weiteren Entwicklung enstehen optischer Becher und Linsenvesikel, und es kommt zur Differenzierung von optischem Nerv (blau), Retinalem Pigmentepithel (gelb), neuraler Retina (orange) und Linsenfasern (grün). Nach Wittbrodt et al., 2002.

Molekular ist die anteriore Neuralplatte in späten Gastrulastadien u.a durch die Expression des Homöodomänen-Transkriptionsfaktors Xotx2 (Pannese et al., 1995) gekennzeichnet. Dessen Deletion führt in der Maus zur Reduktion des Kopfes (Acampora et al., 1995). Innerhalb des Bereiches der Xotx2-Domäne wird die Augenanlage induziert, die durch die Expression weiterer 


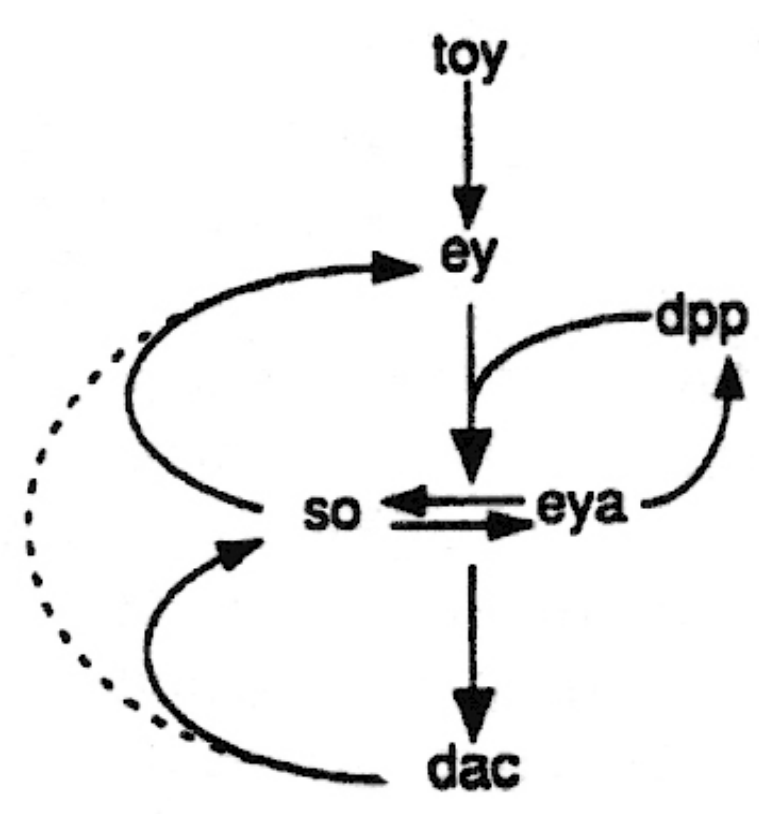

Abb. 1.4: Das genetische Netzwerk der Komplexaugendifferenzierung in Drosophila melanogaster. Twin of eyeless (Toy) induziert die Expression von eyeless (ey), Ey bewirkt zusammen mit Decapentaplegic (Dpp) die Expression von sine oculis (so) und eyes absent (eya). Eya und So interagieren auf Proteinbasis und bewirken eine Expression von dac. Eya stabilisiert zusätzlich die Expression von $d p p$ innerhalb der Augen-Imaginalscheibe. Bis auf $d p p$ stehen alle genannten Gene in einer positiven Rückkopplunsschleife mit ey, so das sich ein regulatorisches Netzwerk ergibt. Nach Wawersik und Maas, 2000.

Transkriptionsfaktoren wie Xpax6, Xsix3, Xsix6 (Xoptx2) und Xrx1 gekennzeichnet ist. Ihre Funktionen haben sich als essentiell für die Entwicklung der Augen herausgestellt und treiben die Spezifikation retinalen Vorläufergewebes weiter voran. Analog dazu existieren in Drosophila melanogaster Homologe zu Pax6 [Twin of eyeless (Toy), Eyeless (Ey)], Six3, Six6 [Sine oculis (So)] und Rxl (Drx) mit einer Funktion bezüglich der Entwicklung der Komplexaugen bzw. Strukturen des Kopfes. Eyeless und sine oculis sind zudem Teil eines regulatorischen Netzwerkes, dass im Zuge der Differenzierung der Ommatidien des Komplexauges eine zentrale Rolle einnimmt (s. Abb. 1.4; Wawersik und Maas, 2000). Mutationen innerhalb des Pax6-Gens der Maus verursachen den small-eye Phänotyp (sey), der bei Homozygotie zum vollständigen Verlust der Augen führt (Hill et al., 1991; Hogan et al., 1988). Im Menschen ist eine Haploinsuffizienz bezüglich $P A X 6$ Ursache der Aniridie, einer Hypoplasie der Iris sowie der Fovea. Homozygote Genotypen sind lethal (Glaser et al., 1994; Glaser et al., 1992). Durch eine Überexpression von Pax6 in Xenopus laevis konnte zudem die ektopische Bildung von Retina und Linsengewebe innerhalb prospektiver Hirnregionen induziert werden (Altmann et al., 1997; Chow et al., 1999). Wie oben erwähnt, finden sich Homologe von Pax6 auch außerhalb der Vertebraten, wie z.B. in der Taufliege Drosophila melanogaster in Form des ey-Gens. Das hier eine Konservierung im Verlauf der Evolution nicht nur auf Ebene der Primärstruktur besteht, zeigt die Tatsache, dass etwa die Überexpression von Pax6 der Maus wie auch von Eyeless aus Drosophila melanogaster die Bildung ektopischer Komplexaugen aus Derivaten der Imaginalscheiben der Taufliege verursacht (Halder et al., 1995). Die Reduzierung des Augen-induzierenden Potentials auf bestimmte Gewebe weist dabei auf die Notwendigkeit einer Kompetenz des transdeterminierten Gewebes hin, wie sie z.B. durch das innerhalb der anterioren Neuralplatte exprimierte Xotx2 bereitgestellt wird. 
Die Überexpression von Rxl in Xenopus laevis induziert die Bildung ektopischen Retinalen Pigmentepithels sowie eine durch Hyperproliferation der Vorläuferzellen vergrößerte neurale Retina (Mathers et al., 1997). In $R x 1$-Nullmutanten $\left(R x 1^{-/}\right)$der Maus kommt es zur fehlerhaften Ausbildung der Augenvesikel als Folge einer gestörten Entwicklung retinaler Vorläuferzellen (Zhang et al., 2000).

Die Funktionen der Homöobox-Gene Six3 und Six6 im Zusammenhang mit der embryonalen Augenentwicklung werden durch bei Überexpression in Xenopus laevis stark vergrößerte neurale Retinae deutlich. Ursache ist zum einen die Konvertierung von Hirn- zu Retinagewebe, zum anderen eine deutlich gesteigerte Proliferationsrate retinaler Vorläuferzellen (Bernier et al., 2000; Zuber et al., 1999). Im Fall von Six6 konnte gezeigt werden, dass letzteres die Folge einer aktiven transkriptionellen Repression von Inhibitoren Cyclin-abhängiger Kinasen ist, was ein Voranschreiten des Zellzyklus ermöglicht. Diese Repression erfolgt durch einen multimeren Transkriptionsfaktor-Komplex unter Beteiligung von Six6 (Li et al., 2002).

\subsection{Vertebraten-Homologe der Drosophila Gene Eyes absent (eya) und Dachshund (dac)}

Neben Eyeless und Sine oculis sind die Transkriptionsfaktoren Eyes absent (Eya) (Bonini et al., 1993) und Dachshund (Dac) (Mardon et al., 1994) Bestandteile des regulatorischen Netzwerkes, das die Differenzierung des Komplexauges von Drosophila melanogaster vorantreibt (Abb. 1.3). Analog zu den bereits angesprochenen Transkriptionsfaktoren mit einer Rolle bezüglich der Augenentwicklung sowohl im Insekt als auch im Wirbeltier finden sich auch hinsichtlich Eya und Dac Homologe innerhalb der Vertebraten. Über eine Funktion im Zusammenhang mit der Entwicklung des Linsenauges der Vertebraten ist bis heute jedoch nur wenig bekannt.

\subsubsection{Die Eyes absent Familie von Proteinen}

Zu Eyes absent aus Drosophila melanogaster existieren in Vertebraten vier Homologe, Eyal-4 (Abdelhak et al., 1997; Duncan et al., 1997; Mishima und Tomarev, 1998; Vincent et al., 1997; Zimmerman et al., 1997) (Borsani et al., 1999; David et al., 2001; Sahly et al., 1999; Wayne et al., 2001; Xu et al., 1997). Die enge Verwandtschaft zeigt sich durch einen zwischen den Mitgliedern der Protein-Familie hochkonservierten Sequenzabschnitt im Bereich des CTerminus, der als Eya-Dömane bezeichnet wird. Eyes absent aus Drosophila melanogaster ist als Teil des in Abbildung 1.3 dargestellten regulatorischen Netzwerkes im Zuge der Differenzierung der Komplexaugen unerlässlich. Fliegen mit einem Funktionsverlust von Eya entwickeln keine Augen und es kommt zu einer erhöhten Apoptoserate von Zellen der Augenimaginalscheibe, die die Vorläufer differenzierter, ommatidialer Zellen darstellen (Bonini et al., 1993). Eine Überexpression von Eya in anderen Imaginalscheiben führt hingegen zur Bildung ektopischen Komplexaugengewebes (Bonini et al., 1997). 
Die verschiedenen Eya-Homologe der Vertebraten zeigen Expression innerhalb von Augenstrukturen wie Linse und Retina, Bereichen des Gehirns, ektodermalen Plakoden, Derivaten der cranialen Neuralleiste, der Nierenanlage sowie innerhalb myogenen Mesoderms der Somiten. Dabei kommt es zu Überschneidungen der Expressionsmuster innerhalb sowie zwischen den verschiedenen Spezies. Die bis heute bekannten Eya-Homologe aus Xenopus laevis, Xeyal und Xeya2, werden allerdings, im Gegensatz zu anderen bekannten Eyal oder Eya2 Homologen (Mishima und Tomarev, 1998; Zimmerman et al., 1997), zu keinem Zeitpunkt der Embryonalentwicklung in Retina- oder Linsengewebe exprimiert (David et al., 2001) (Kriebel, Diplomarbeit 2001). Ein Verlust der Eyal-Funktion in Eyal ${ }^{-/-}$-Mäusen führt im Verlauf der Embryogenese zum Verlust der Niere sowie der Ohren, beides Organe mit einer Expression von Eyal. Als Ursache wurde, analog zu den Verhältnissen bei einem Funktionsverlust von Eya in Drosophila melanogaster, eine erhöhte Apoptoserate der Zellen des betroffenen Gewebes festgestellt. Defekte in der Augenentwicklung wurden hingegen nicht beobachtet (Xu et al., 1999). Ähnliche Phänotypen ergeben sich in Patienten mit der sogenannten Branchio-Oto-(BO) oder Branchio-Oto-Renalen-Dysplasie (BOR), die durch eine Kombination branchialer, renaler und otischer Anomalien gekennzeichnet ist, und durch Mutationen innerhalb des humanen EYAl ausgelöst wird (Vincent et al., 1997). Mutationen des EYA1-Gens sind daneben zusätzlich Ursache für die Ausbildung kongenitaler Katarakte, Trübungen der Linse (Azuma et al., 2000).

Im Bereich der Eya-Domäne wurde eine Phosphatase-Aktivität mit Zugehörigkeit zur Familie der Haloacid-Dehalogenase ähnlichen Phosphohydrolasen (HAD) beschrieben (Li et al., 2003; Rayapureddi et al., 2003; Tootle et al., 2003). Mutationen im katalytischen Motiv der Hydrolase beeinträchtigten in Zellkultur die Funktion von murinem Eya3 im Hinblick auf eine positive Regulation der Zellproliferation von Muskelvorläuferzellen (Li et al., 2003). Ebenso war das Potential von Eya aus Drosophila melanogaster in Rescue-Experimenten sowie im Zuge von Überexpressionsstudien stark reduziert, war die Phosphatase-Aktivität durch Mutationen innerhalb des aktiven Zentrums der Hydrolase-Domäne herabgesetzt (Tootle et al., 2003).

In Drosophila melanogaster kommt es zwischen Eya und So sowie zwischen Eya und Dac zu direkten Protein-Protein Wechselwirkungen, die über die konservierte Eya-Domäne vermittelt werden (Chen et al., 1997; Pignoni et al., 1997). Im Einklang damit hat die gemeinsame Überexpression von Eya und So bzw. Eya und Dac synergistische Effekte bezüglich der Bildung ektopischer Komplexaugen zur Folge. Ein ähnliches Zusammenspiel ist im Hühnerembryo beschrieben worden, wo Sixl, Eya2 und Dach2 (Dac-Homolog; s.u.) einen multimeren Transkriptionsfaktor-Komplex ausbilden und die Muskelentwicklung regulieren (Heanue et al., 1999). Somit erstreckt sich die evolutionäre Konservierung nicht nur auf die jeweiligen Gene sondern auch auf die zwischen den Genprodukten bestehenden Interaktionen und Wechselwirkungen. 


\subsubsection{Die Dachshund Familie von Proteinen}

Zu Dachshund aus Drosophila melanogaster sind drei Homologe in Vertebraten, Dach1, Dach2 und DachB bekannt, wobei letzteres bis jetzt nur im Zebrafisch isoliert wurde (Caubit et al., 1999; Davis et al., 1999; Davis et al., 2001b; Hammond et al., 1998; Hammond et al., 2002; Hammond et al., 1999; Heanue et al., 1999; Kida et al., 2004; Kozmik et al., 1999). Alle Dachshund-Proteine sind durch zwei evolutionär konservierte Domänen gekennzeichnet: Die Dachshund Domäne 1 (DD1) im N-terminalen Bereich und die Dachshund Domäne 2 (DD2) im C-terminalen Bereich des Proteins (Wawersik und Maas, 2000). Zusätzlich existiert ein Sequenzabschnitt mit Homologie zu den Proto-Onkogenen Ski und Sno, der grösstenteils mit der DD1 überlappt (Hammond et al., 1998). Eine funktionelle Analyse von möglichen Dachshund-Homologen aus Xenopus laevis hat bis heute nicht stattgefunden. Wie auch im Fall von Ey, So und Eya aus Drosophila melanogaster kommt es bei einem Funktionsverlust des Dac-Proteins zu einem vollständigen Verlust der Komplexaugen der Imago (Mardon et al., 1994). Eine Überexpression löst hingegen die Bildung ektopischer Augen im Kopf- und Thorax-Bereich sowie an den Beinen aus (Shen und Mardon, 1997). Dabei kommt es durch positive Rückkopplungsschleifen zur ektopischen Etablierung des durch Ey initiierten regulatorischen Netzwerkes (Abb. 1.3; Shen und Mardon, 1997).

Expression von Dach1 bzw. Dach2 findet sich in Vertebraten innerhalb des Auges in Linse und Retina, in Vorder-, Mittel-, und Hinterhirnbereichen, im Rückenmark, innerhalb neurogener cranialer Plakoden, in der Niere sowie in myogenem Mesoderm. Damit ähnelt das räumliche Expressionsmuster dem der Eya-Familie, und es kommt, wie bereits weiter oben angeführt, zu Interaktionen und Wechselwirkungen zwischen Mitgliedern der Dach- und Eya-Familie im Kontext der Muskelentwicklung des Hühnerembryos (Heanue et al., 1999). Eine Funktionsverluststudie in der Maus $\left(\right.$ Dachl $\left.^{-/}\right)$führte zur postnatalen Lethalität der neugeborenen Tiere, u.a. ausgelöst durch eine schwere Zyanose (Davis et al., 2001a). Zugrunde liegende Entwicklungsdefekte konnten allerdings nicht festgestellt werden. Möglicherweise besteht in der Maus eine Redundanz zwischen Dach1 und Dach2, so dass der Dach1-Verlust während der Embryogenese zum Teil durch Dach2 ausgeglichen werden kann.

Im Zusammenhang mit der durch Six6 gesteuerten Zellproliferation retinaler Vorläuferzellen konnte gezeigt werden, dass Dach1 und Six6 einen nukleären Repressorkomplex ausbilden, wobei Dach1 für die Rekrutierung von Ko-Repressoren zum multimeren Komplex verantwortlich ist (Li et al., 2002). Eine ähnliche Funktion des Dach1-Proteins besteht auch im Zusammenhang mit TGF- $\beta$ ( Transforming Growth Factor- $\beta$ )-vermittelter Signaltransduktion, wo Dach1 als intrazellulärer Inhibitor der Transkription von TGF- $\beta$-Zielgenen auftritt. Als Ursache für die beobachtete transkriptionelle Repression konnte eine Bindung an Mitglieder der Smad-Familie von Transkriptionsfaktoren und die Rekrutierung von Ko-Repressoren zum ansonsten transkriptionell aktivierend wirkenden nukleären Komplex ermittelt werden (Wu et 
al., 2003). Dies trifft auch auf Zielgene des Bone Morphogenetic Protein 4 (Bmp4) zu, das zur $T G F-\beta$ Familie gehört. In Experimenten zur Extremitätenentwicklung im Hühnerembryo konnte gezeigt werden, das Dach1 als Antagonist des Bmp-vermittelten Signalwegs so u.a. zur Musterbildung entlang der proximodistalen Achse beiträgt (Kida et al., 2004).

\subsection{Organogenese und Aufbau des Linsenauges der Vertebraten}

Morphologisch wird die Organogenese des Linsenauges der Vertebraten mit der Evagination der optischen Vesikel sichtbar (Abb. 1.5A). Diese entwickeln sich aus den beiden retinalen Primordien, die sich während der Neurulation des Embryos durch Signale des median liegenden Notochords aus dem frühen Augenfeld der anterioren Neuralplatte gebildet haben (vgl. Abb. $1.3)$.

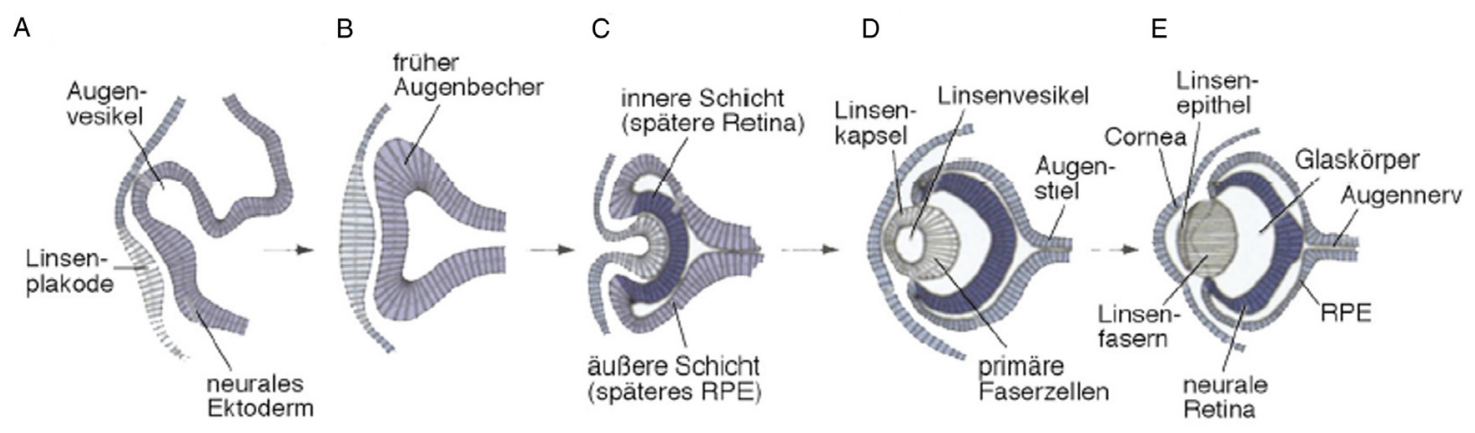

Abb. 1.5: Organogenese des Linsenauges der Vertebraten. (A) Der Augenvesikel tritt in Kontakt zu nicht-neuralem Ektoderm, das daraufhin zur Linsenplakode verdickt. (B) Beginn der Ausbildung des Augenbechers aus Gewebe des optischen Vesikels. (C) Invagination des Linsenektoderms. Der optische Becher hat seine konkave Form angenommen und es sind zwei retinale Schichten erkennbar; RPE, Retinales Pigmentepithel. (D) Entstehung des Linsenvesikels. (E) Reifung der Linse und Ausdifferenzierung der Retina zu den Zellschichten der neuralen Retina und zum Retinalen Pigmentepithel. Proximal entsteht aus dem Augenstiel der Augennerv. Nach Gilbert, 2000.

Durch Wechselwirkungen des neuralen Gewebes der optischen Vesikel mit distal liegendem nicht-neuralen Kopfektoderm kommt es zur Bildung der Linsenplakode, einer subepidermalen, ektodermalen Verdickung. Dabei bedarf es einer Kompetenz des Kopfektoderms, auf die vom optischen Vesikel ausgehenden Signale reagieren zu können, wobei diesbezüglich dem Homöoprotein Pax6 eine wichtige Rolle zugesprochen wird (Fujiwara et al., 1994; Hirsch und Harris, 1997). In der weiteren Entwicklung entsteht aus dem Augenvesikel der konkav geformte optische Becher, der die invaginierende Linsenplakode aufnimmt. Dadurch entstehen bereits 
zwei retinale Schichten, distal die prospektive neurale Retina, proximal das zukünftige Retinale Pigmentepithel (Abb. 1.5B, C). Das invaginierte Linsenektoderm bildet den Linsenvesikel aus, auf den distal das Ektoderm der späteren Cornea folgt (Abb. 1.5D). Über die Elongation primärer Faserzellen der Linse in Richtung des Zentrums des Linsenvesikels sowie durch die Bildung sekundärer Linsenfasern durch die Proliferation von Zellen des Linsenepithels reift die Linse heran. Die beiden retinalen Schichten differenzieren zu den verschiedenen Zelltypen der Retina aus (Abb. 1.5E). Dabei entsteht ein charakteristisches Muster, das die Anordnung der verschiedenen Zelltypen und ihrer Fortsätze wiederspiegelt (Abb. 1.6).

A

B

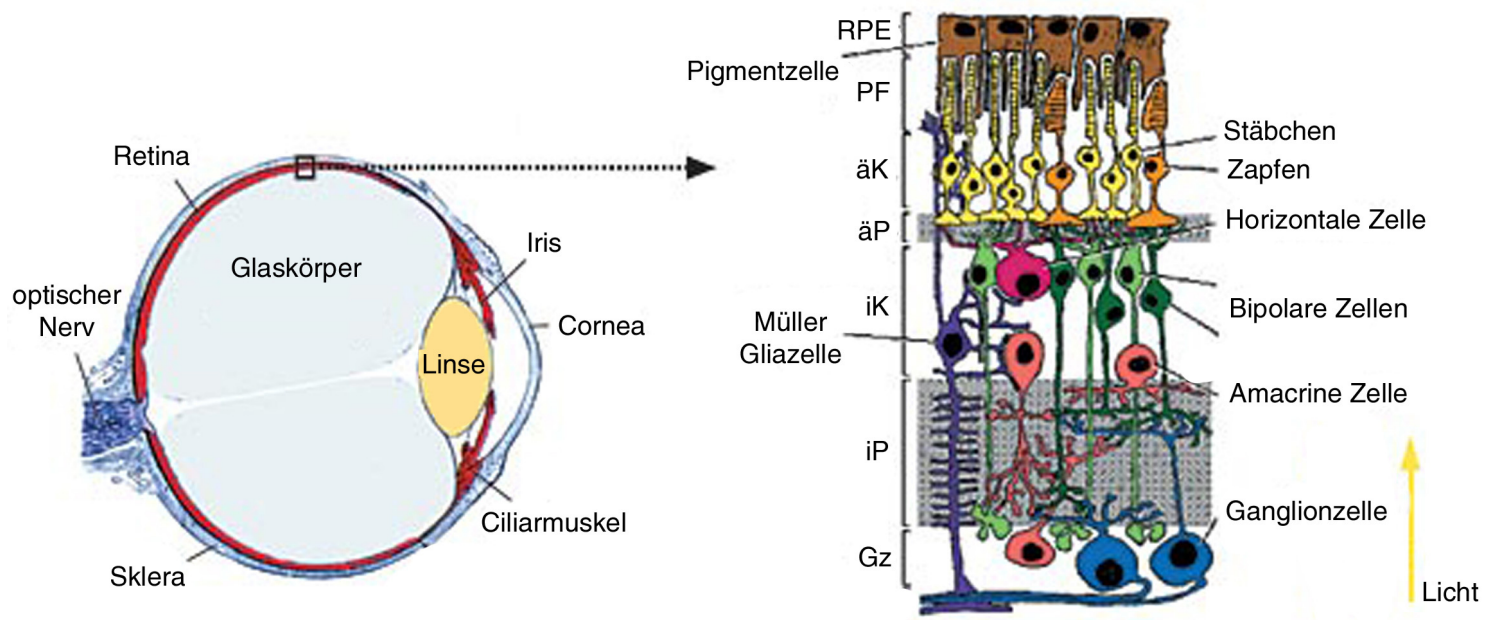

Abb. 1.6: Anatomie des Vertebratenauges. (A) Schematischer Längsschnitt durch das Linsenauge eines Vertebraten. (B) Vergrößerung des in (A) gekennzeichneten Bereiches der Retina. Lichtreize treffen von der Seite der Ganglionzellen auf die Retina; äK, äussere Körnerschicht; äP, äussere plexiforme Schicht; Gz, Ganglionzellschicht; iK, innere Körnerschicht; iP, innere plexiforme Schicht; PF, Zellfortsätze der Photorezeptoren; RPE, Retinales Pigmentepithel. Nach Ashery-Padan et al., 2001.

\subsection{Musterbildung im Hinterhirn und Neuralrohr von Xenopus laevis}

Bereiche des Neuroektoderms der Neuralplatte, die während der frühen Embryogenese unter dem Einfluss posteriorisierender Faktoren wie $e F G F$ oder $R A$ gestanden haben (s. 1.1.2 und Abb. 1.2), bilden in der weiteren Entwicklung Hinterhirn und Neuralrohr des Tieres aus. Schon während der primären Neurogenese in Neuralplatten-Stadien kommt es in Xenopus laevis zur Ausbildung eines charakteristischen Musters der Anordnung differenzierter Neurone, die durch die Expression von $N$-Tubulin, das spezifisch in differenzierten Nervenzellen exprimiert wird, 

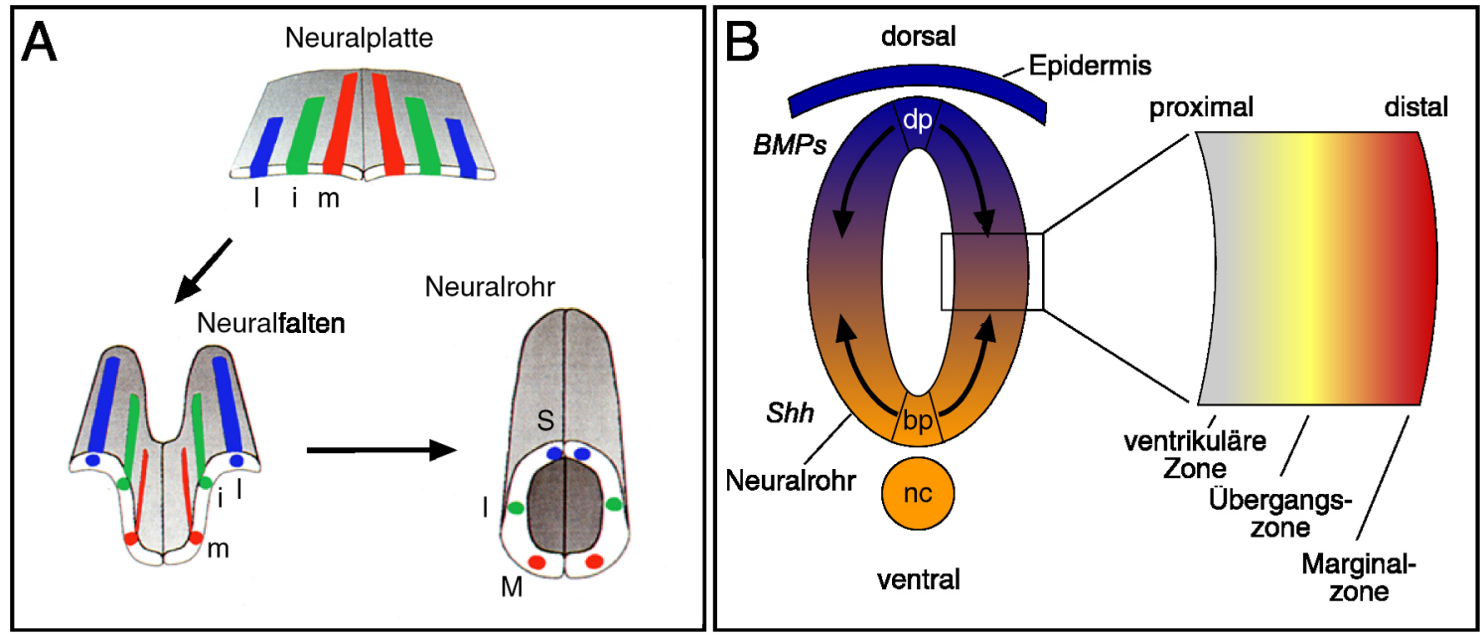

Abb. 1.7: Musterbildung und sekundäre Neurogenese im Neuralrohr von Xenopus laevis. (A) Bildung des Neuralrohres aus der offenen Neuralplatte im Zuge der Neurulation in Xenopus laevis. Bereits im Stadium der offenen Neuralplatte entstehen primäre Neurone in einem charakteristischen Muster, das die Orientierung der verschiedenen Nervenzelltypen im späteren Neuralrohr wiederspiegelt; i, intermediärer Streifen; 1, lateraler Streifen; m, medialer Streifen; I, Interneurone; M, Motorneurone; S, sensorische Neurone. Nach Chitnis und Kintner, 1996. (B) Dorsoventrale und proximodistale Musterbildung im Hinterhirn und Neuralrohr von Xenopus laevis. Durch Expression der sezernierten Morphogene Bmp4, Bmp7 und Sonic Hedgehog (Shh) in der Dach- (dp) bzw. Bodenplatte (bp) des Neuralrohres entstehen dorsoventrale bzw. ventrodorsale Gradienten der Proteine, die zur Ausbildung spezifischer Zelltypen in Abhängigkeit der vorliegenden Konzentration an Morphogen führen. Innerhalb des Neuralrohres besteht ausserdem eine proximodistale Organisation in Form der ventrikulären-, Übergangs- und Marginalzone. Neuroblasten der ventrikulären Zone bilden durch Teilung determinierte Zellen neuralen Schicksals der Übergangszone, die in ihrer weiteren Entwicklung zu distal lokalisierten Neuronen ausdifferenzieren; nc, Notochord.

gekennzeichnet sind (Oschwald et al., 1991). So sind zukünftige sensorische-, Inter- und Motorneurone innerhalb der Neuralplatte beidseitig der Mittellinie in drei longitudinalen Streifen angeordnet, die bereits die dorsoventrale Orientierung der verschiedenen Neurone im späteren Neuralrohr wiederspiegeln (Abb. 1.7A; Chitnis und Kintner, 1996). Grundlage für die Etablierung dieses Musters sind Wechselwirkungen zwischen Faktoren, die die Entwicklung von Nervenzellen hemmen, z.B. Zic-2 (Brewster et al., 1998), bzw. vorantreibenden, wie etwa X-Ngnr-1 (Ma et al., 1996). Der Prozess der lateralen Inhibition, vermittelt durch die Membranproteine X-Delta1 und X-Notch1, entscheidet zudem innerhalb der erwähnten Streifen der primären Neurogenese über ein Entwicklungsschicksal hin zur Glia- oder Nervenzelle (Chitnis und Kintner, 1996). Im Verlauf der Neurulation kommt es zur Einsenkung der Neuralplatte entlang der Mittellinie und ihrem dorsalen Schluss durch Verschmelzung zuvor 
lateral gelegener Bereiche (NF Stadium 16, Abb.1.1; Abb. 1.7A). Dadurch entstehen Strukturen wie Hinterhirn und Neuralrohr, die im weiteren Verlauf ihrer Entwicklung ein spezifisches Muster neuraler Zelltypen sowohl entlang der dorsoventralen als auch proximodistalen Achse erkennen lassen (Abb. 1.7). Ein in diesem Zusammenhang wichtiger Faktor ist das Morphogen Sonic Hedgehog (Shh) (Ekker et al., 1995), das zunächst vom Notochord sezerniert wird und die Ausbildung der Bodenplatte induziert. Diese exprimiert und sezerniert in der Folge selbst Shh, was zur Ausbildung eines ventrodorsalen Konzentrations-Gradienten von Shh im Neuralrohr führt (Briscoe und Ericson, 1999; Roelink et al., 1995). Verschiedene Konzentrationen an Shh haben dabei die Aktivierung unterschiedlicher Transkriptionsfaktoren innerhalb der betroffenen Zellen zur Folge, die die Differenzierung zu bestimmten neuronalen Subtypen, etwa verschiedenen Klassen von Motor- bzw. Interneuronen, auslösen (Briscoe und Ericson, 1999).

Mit Bmp4 und Bmp7 konnten im Gegensatz dazu dorsalisierende Faktoren identifiziert werden (Liem et al., 1997; Liem et al., 1995). Nach Ausbildung des Neuralrohres kommt es durch darüberliegendes epidermales Gewebe, das Bmp4 und Bmp7 sezerniert, zur Ausbildung der Dachplatte, die ihrerseits beginnt, Bmp4 zu exprimieren. Der dorsoventrale Gradient von Bmp4, mit höchster Konzentration innerhalb der Dachplatte, führt, analog zu den für Shh beschriebenen Beobachtungen, zur Induktion der Expression unterschiedlicher Zielgene in Abhängigkeit der vorliegenden Konzentration an Morphogen. Dabei werden u.a. auch Mitglieder der TGF- $\beta$-Familie wie Bmp7 und Activin aktiviert, die ihrerseits einen Konzentrationsgradienten aufbauen und zur Musterbildung entlang der dorsoventralen Achse beitragen.

Auch in proximodistaler Orientierung lässt sich eine Organisation des Neuralrohres und Hinterhirns von Xenopus laevis erkennen, die in diesem Fall die verschiedenen Stadien sekundärer Neurogenese wiederspiegelt (Bellefroid et al., 1996). So finden sich proximal in Nähe des Hirnventrikels, innerhalb der sogenannten ventrikulären Zone, neurale Vorläuferzellen, die aktiv proliferieren und so zur Entstehung determinierter neuraler Zellen der in Richtung distal lokalisierten Übergangszone beitragen (Abb. 1.7B). Neurale Zellen der Übergangszone durchlaufen den Differenzierungsprozess weiter und bilden als ausdifferenzierte Neurone die distal gelegene Marginalzone. Die angesprochenen Zonen sind dabei durch die Expression molekularer Marker charakterisiert. So exprimieren Zellen der ventrikulären Zone das auch früh während der primären Neurogenese detektierbare X-Ngnr1 (Ma et al., 1996), Zellen der Übergangszone das mit Prozessen der neuronalen Differenzierung in Verbindung gebrachte $X-M y T 1$ (Bellefroid et al., 1996) und differenzierte Neurone der Marginalzone den Differenzierungsmarker N-Tubulin (Oschwald et al., 1991). 


\subsection{Ziel der Arbeit}

Bezüglich einer Funktion von Homologen der Eya- und Dac-Proteine aus Drosophila melanogaster ist im Zusammenhang mit der Entwicklung des Nervensystems und der Augen in Vertebraten bis heute nur wenig bekannt. Mit dem südafrikanischen Krallenfrosch als Modellorganismus soll zunächst versucht werden, Homologe von Eya und Dac zu klonieren, die eine Genexpression innerhalb der embryonalen Augen- und Hirnanlagen zeigen. Durch Mikroinjektion synthetischer mRNA in Xenopus laevis Embyronalstadien können anschließend Funktionsgewinnstudien im Sinne einer Überexpression der entsprechenden Gene durchgeführt werden. Die Verfügbarkeit von Morpholino-Antisense-Oligonukleotiden (Morpholinos) erlaubt zudem die Durchführung von Funktionsverluststudien durch eine spezifische Inhibition der Translation endogener mRNAs. Mit Hilfe der in Xenopus laevis etablierten Methode der ,whole mount" in situ Hybridisierung können weiter die Auswirkungen eines Funktionsgewinns bzw. Funktionsverlustes der untersuchten Proteine auf die Expression von Markergenen getestet werden, um Hinweise auf Veränderungen molekularer Natur während der Embryonalentwicklung zu erhalten. Mit Hilfe der gewonnenen Daten soll eine Einordnung der neu identifizierten Faktoren in Prozesse der Entwicklung von Gehirn und Auge versucht werden. 


\section{Material}

\subsection{Versuchstiere}

Der afrikanische Krallenfrosch (Xenopus laevis) gehört zur Familie der zungenlosen Froschlurche (Pipidae) der Ordnung Anura. Pigmentierte- und Albino-Frösche wurden von Dipl.-Ing. Horst Kähler (Hamburg) sowie den Firmen Xenopus I (Ann Arbor, USA) und Nasco (Ft. Atkinson, USA) erworben. Die Tiere wurden gemäß den Tierschutzbestimmungen gehalten und behandelt. Die Bestimmung der Embryonalstadien erfolgte nach Nieuwkoop und Faber (1967).

\subsection{Bakterienstämme}

XL1-Blue

(Stratagene GmbH, Heidelberg)

XL1-Blue MRF,

(Stratagene GmbH, Heidelberg)
recA1, endA1, gyrA96, thi-1, hsdR17, supE44, relA1, lac[F’ proAB, $\left.\operatorname{lacI}^{\mathrm{q}} \mathrm{Z} \Delta \mathrm{M} 15, \operatorname{Tn} 10\left(\mathrm{Tet}^{\mathrm{r}}\right)\right]^{\mathrm{c}}$; (Bullock et al., 1987)

$\mathrm{D}$ (mcrA)183, $\quad \Delta$ (mcrCB-hsdSMR-mrr)173, endA1， supE44, thi-1, recA1, gyrA96, relA1 lac[F' proAB, $\left.\operatorname{lacI}^{\mathrm{q}} \mathrm{Z} \Delta \mathrm{M} 15, \operatorname{Tn} 10\left(\mathrm{Tet}^{\mathrm{r}}\right)\right]^{\mathrm{c}}$

\subsection{Genbanken}

$\lambda$-Zap Express cDNA-Bank

(Stratagene GmbH, Heidelberg)
Erstellt von T. Hollemann (1995); enthaltene cDNA repräsentiert Transkriptom aus präparierten Köpfen der Xenopus laevis NF Stadien 28-31

\subsection{Medien und Lösungen}

Die im Folgenden aufgeführten Medien und Lösungen wurden mit doppelt destilliertem Wasser angesetzt und durch Autoklavieren für 20 min bei $121^{\circ} \mathrm{C}$ sterilisiert. Hitzelabile Substanzen wurden durch Membranfilter (0,2 $\mu \mathrm{m}$ Porendurchmesser; Sartorius AG, Göttingen) in zuvor autoklavierte Flaschen sterilfiltriert. 


\subsubsection{Nährmedien}

Luria-Bertani (LB)-Medium: 2\% (w/v) LB Broth Base (Invitrogen GmbH, Karlsruhe)

LB-Agar: 3,2\% (w/v) LB Agar (Invitrogen GmbH, Karlsruhe)

NZY-Medium: 1\% (w/v) NZ-Amin (Casein Hydrolysat); 0,5\% (w/v) Hefeextrakt (DIFCO); $0,5 \%(\mathrm{w} / \mathrm{v}) \mathrm{NaCl} ; 8,1 \mathrm{mM} \mathrm{MgSO}{ }_{4} \cdot 7 \mathrm{H}_{2} \mathrm{O}, \mathrm{pH} 7,5$

\subsubsection{Antibiotika}

Ampicillin: $100 \mathrm{mg} / \mathrm{ml}$ in $\mathrm{dH}_{2} \mathrm{O}$, Lagerung bei $-20^{\circ} \mathrm{C}$; verwendete Endkonzentration $(100 \mu \mathrm{g} / \mathrm{ml})$

Tetracyclin: $5 \mathrm{mg} / \mathrm{ml}$ in $100 \%$ Ethanol (p.A.), Lagerung bei $-20^{\circ} \mathrm{C}$; verwendete Endkonzentration 12,5 $\mu \mathrm{g} / \mathrm{ml}$

\subsubsection{Puffer und (Stamm-)Lösungen}

Tris- $\mathrm{HCl}(\mathrm{pH} 7,5$ bzw. 9,5)

TE $(10 \mathrm{x}, \mathrm{pH} 7,5)$

$\mathrm{MgCl}_{2}$

$\mathrm{MgSO}_{4}$

$\mathrm{NaCl}$

EDTA

EGTA

PBS $(10 \mathrm{x}, \mathrm{pH} 7,3)$

Natrium-Acetat

Triethanolamin

$\operatorname{TBE}(10 \mathrm{x})$

Maltose

Denhardt's (100 x)

Ethidiumbromid

SDS-Lösung
$1 \mathrm{M}$ Tris-HCl; $\mathrm{pH}$ 7,5 bzw. 9,5

100 mM Tris- $\mathrm{HCl}(\mathrm{pH}$ 7,5); 10 mM EDTA

$1 \mathrm{M} \mathrm{MgCl}_{2} \cdot 6 \mathrm{H}_{2} \mathrm{O}$

$1 \mathrm{M} \mathrm{MgSO}_{4} \cdot 7 \mathrm{H}_{2} \mathrm{O}$

$5 \mathrm{M} \mathrm{NaCl}$

0,5 M EDTA; $\mathrm{pH} 8,0$

0,2 M EGTA; $\mathrm{pH} 8,0$

$1,75 \mathrm{M} \mathrm{NaCl} ; 18 \mathrm{mM} \mathrm{NaH} \mathrm{PO}_{4} ; 75 \mathrm{mM}$ $\mathrm{Na}_{2} \mathrm{HPO}_{4} \cdot 12 \mathrm{H}_{2} \mathrm{O} ; \mathrm{pH} 7,3$

$3 \mathrm{M} \mathrm{NaCH}_{3} \mathrm{COO} ; \mathrm{pH} 5,2$

0,1 M Triethanolamin; $\mathrm{pH}$ 7,5

0,9 M Tris Base; 0,9 M Borsäure; $20 \mathrm{mM}$ EDTA

$20 \%(\mathrm{w} / \mathrm{v})$ Maltose; sterilfiltriert

2\% (w/v) BSA; 2\% (w/v) PVP; 2\% (w/v)

Ficoll

$10 \mathrm{mg} / \mathrm{ml}$ Ethidiumbromid

$10 \%(\mathrm{w} / \mathrm{v})$ Natriumdodecylsulfat 


\subsection{Antikörper und Chemikalien}

anti-Digoxigenin/AP (Roche Diagnostics GmbH, Mannheim): Fab-Fragmente von Digoxigenin-spezifischen, polyklonalen Antikörpern (aus Ziege), konjugiert mit Alkalischer Phosphatase

anti-Fluoreszein/AP (Roche Diagnostics GmbH, Mannheim): Fab-Fragmente von Fluoreszeinspezifischen, polyklonalen Antikörpern (aus Ziege), konjugiert mit Alkalischer Phosphatase

anti-Flag (Sigma-Aldrich Chemie GmbH, Deisenhofen): Flag-Epitop spezifischer, polyklonaler Primär-Antikörper (aus Kaninchen)

anti-c-myc (Sigma-Aldrich Chemie GmbH, Deisenhofen): c-Myc-Epitop spezifischer, monoklonaler Primär-Antikörper (aus Maus)

anti-phosphorylated-Histon 3 (Santa Cruz Biotechnology, Heidelberg): Phosphoryliertes Histon 3 spezifischer, polyklonaler Primär-Antikörper (aus Kaninchen)

anti-rabbit/AP (Sigma-Aldrich Chemie GmbH, Deisenhofen): Kaninchen spezifischer, polyklonaler Sekundär-Antikörper (aus Ziege), konjugiert mit Alkalischer Phosphatase

anti-rabbit/Fitc (Sigma-Aldrich Chemie $\mathrm{GmbH}$, Deisenhofen): Kaninchen spezifischer, polyklonaler Sekundär-Antikörper (aus Ziege), konjugiert mit Fluoreszeinthiocyanat (Fitc)

anti-mouse/Cy3 (Dianova GmbH, Hamburg): Maus spezifischer, polyklonaler SekundärAntikörper (aus Ziege), konjugiert mit $\mathrm{Cy} 3$

anti-rabbit/HRP (Santa Cruz Biotechnology, Heidelberg): Kaninchen spezifischer, polyklonaler Sekundär-Antikörper (aus Ziege), konjugiert mit Horseradish-Peroxidase

anti-mouse/HRP (Amersham Pharmacia Biotech, Freiburg): Maus spezifischer, polyklonaler Sekundär-Antikörper (aus Schaf), konjugiert mit Horseradish-Peroxidase

Biochemische Feinchemikalien wurden von den Firmen Roche Diagnostics, Fluka, SigmaAldrich und Serva bezogen. Alle anderen Chemikalien stammten von den Firmen Fluka, Baker, Gibco, Roth oder Merck und wiesen den höchsten Reinheitsgrad (p.A.) auf. 


\subsection{Enzyme und Reaktionssysteme}

\subsubsection{Enzyme}

Restriktionsendonukleasen

$\operatorname{TdT}(15 \mathrm{U} / \mu \mathrm{l})$

RNase A

RNase T1

Proteinase K

T4 DNA-Ligase (3 U/ $\mu \mathrm{l})$

SP6 RNA-Polymerase (50 U/ $\mu \mathrm{l})$

T3 RNA-Polymerase (50 U/ $\mu \mathrm{l})$

T7 RNA-Polymerase (50 U/ $\mu 1)$

Taq DNA-Polymerase (5 U/ $\mu \mathrm{l})$

\subsubsection{Reaktionssysteme}

mMESSAGE mMACHINE ${ }^{\text {TM }}$ SP6

Dye Terminator Cycle Sequencing Kit

Gene Amp RNA PCR Core Kit

ECL+ plus Western Blotting Detection System

SMART $^{\mathrm{TM}}$ RACE cDNA Amplification Kit

Nucleobond AX

$\mathrm{TnT}^{\circledR}$-Coupled Reticulocyte Lysate System

Wizard Plus SV-Minipreps

QIAquick ${ }^{\circledR}$ PCR Purification Kit

QIAprep ${ }^{\circledR}$ Spin Miniprep Kit

QIAGEN ${ }^{\circledR}$ Plasmid Midi Kit

QIAEX $^{\circledR}$ Gel Extraction Kit

RNase-Free DNase Set

RNeasy Mini Kit

BrdU-Labeling and Detection Kit II

QuikChange ${ }^{\mathrm{TM}}$ Site-Directed Mutagenesis Kit
New England Biolabs GmbH, Schwalbach;

Roche Diagnostics GmbH, Mannheim;

Fermentas GmbH, St. Leon-Rot

Invitrogen $\mathrm{GmbH}$, Karlsruhe

Sigma-Aldrich Chemie GmbH, Deisenhofen

Sigma-Aldrich Chemie GmbH, Deisenhofen

Merck KGaA, Darmstadt

Promega Deutschland GmbH, Mannheim

Stratagene $\mathrm{GmbH}$, Heidelberg

Stratagene GmbH, Heidelberg

Stratagene $\mathrm{GmbH}$, Heidelberg

Qbiogene, Heidelberg

Ambion Ltd., Huntingdon (UK)

Applied Biosystems $\mathrm{GmbH}$, Weiterstadt Applied Biosystems GmbH, Weiterstadt

Amersham Pharmacia Biotech, Freiburg

BD Biosciences Clontech, Heidelberg Macherey-Nagel GmbH \& Co. KG, Düren

Promega Deutschland GmbH, Mannheim

Promega Deutschland GmbH, Mannheim

Qiagen $\mathrm{GmbH}$, Hilden

Qiagen $\mathrm{GmbH}$, Hilden

Qiagen GmbH, Hilden

Qiagen $\mathrm{GmbH}$, Hilden

Qiagen GmbH, Hilden

Qiagen GmbH, Hilden

Roche Diagnostics GmbH, Mannheim

Stratagene GmbH, Heidelberg 


\subsection{Oligonukleotide}

Oligonukleotide wurden von der Firma MWG-Biotech (Ebersberg) sowie Sigma-Genosys (Steinheim), Morpholino-Antisense-Oligonukleotide (Morpholinos) von der Firma Gene Tools (Philomath, USA) bezogen. Die Sequenzen sind in $5^{\text {‘ }} \rightarrow 3^{\text {‘ }}$ Richtung wiedergegeben.

\section{Xdach}

Xdach-part-3'Race

Xdach-part-5'-Race

Xdach-F.b.

Xdach-R

Xdach-141

Xdach-cds-F

Xdach-R2

Xdach-F-Cla1

Xdach-R-Xho1

Xdach-F-Stu1

Xdach-Flag-R-Xho1

Xdach-Splice-F

Xdach-Splice-R

Xdach-Morpholino

\section{Хеуа3}

Xeya3-3'-Race

Xeya $3-c d s-F 2$

Xeya3-cds-R

Xeya3-F-Cla1

Xeya3-R-Xho1

Хeya3-F-Stu1

Xeya3-Flag-R-Xho1

Xeya3-wob-F-1 ${ }^{\text {st }}$

Xeya3-wob-F-fin

Xeya3-mut1-F

Xeya3-mut1-R

Xeya3-mut2-F
GGCATGGGCAACCTCTACCTCCTGGCTACCCATCTCC

GTCTTCGACCCTCTTCAAGAGATGGAGCAGGAGAAGGAC

CCCATTTATGATGATGCCCCACCC

GTCCTTTCAGCATCTGTTCTGGCC

CTCCATTGTCAGAATCAGCTCCATGCTGGTTATTGCC

ATGGCTGTGCCAGCCGCTTTGATC

GTTGTAGCTTGTGCTCCATCAATAC

GCGATCGATATGGCTGTGCCAGCCGCTTTGATC

GCGCTCGAGTCAATACATCACACTGGTTTTT

GGAGGCCTATGGCTGTGCCAGCCGCTTTG

CCTCGAGTCACTTGTCATCGTCGTCCTTGTAGTCTGGATA

CATCACACTG

GGAGCTGATTCTGACAATGGAG

GATGGACAGGAATTCTGTCTGAGG

CATGGTCGCATACGACTGCCTCCCC

CACCATCTTCACCTGTTGTGCTAACATCATCAGGAGTT $\mathrm{ACC}$

ATGGAGAACGGACAGGATTTAG

TCACAAGAAGTCCAGTTCCAG

GCGATCGATATGGAGAACGGACAGGATTTAG

GCGCTCGAGTCACAAGAAGTCCAGTTCCAG

GGAGGCCTATGGAGAACGGACAGGATTTAG

CCTCGAGTCACTTGTCATCGTCGTCCTTGTAGTCTGGCAA GAAGTCCAGT

ATCGATATGGAGAATGGACAAGATTTGGCAGAGCAG

ATCGATATGGAAAATGGGCAAGACTTGGCGGAGCAG

CGTGTGTTTTTGTGGGCCTTGGATGAGACCATTATCATC

GATGATAATGGTCTCATCCAAGGCCCACAAAAACACACG

CGTGTGTTTTTGTGGGACTTGGCTGAGACCATTATCATC 


$\begin{array}{ll}\text { Xeya3-mut2-R } & \text { GATGATAATGGTCTCAGCCAAGTCCCACAAAAACACACG } \\ \text { Xeya3-mut3-F } & \text { CGTGTGTTTTTGTGGGCCTTGGCTGAGACCATTATCATC } \\ \text { Xeya3-mut3-R } & \text { GATGATAATGGTCTCAGCCAAGGCCCACAAAAACACACG } \\ \text { Xeya3-RT-F } & \text { CATCAGGAGTTACCAGCAGCC } \\ \text { Xeya3-RT-R1 } & \text { GATTCCACCACCAATGTAGGGTC } \\ \text { Xeya3-Morpholino } & \text { CTGCTAAATCCTGTCCGTTCTCCAT }\end{array}$

Sonstige Oligonukleotide

$C M V$-F

CGCGCCTGCAGGTCGACACTA

H4-F

CGGGATAACATTCAGGGTATCACT

H4-R

ATCCATGGCGGTAACTGTCTTCCT

Xmsxl-F

GCTAAAAATGGCTGCTAA

Xmsxl-R

AGGTGGGCTGTGTAAAGT

Xsox3-RT-F

GCGCACATGAACGGCTGGACTA

Xsox3-RT-R

GTGTGGGAGGTGATGGCTGGAG

SP6-Seq

TTTAGGTGACACTATAGAATAC

T7-Seq $(p G E M-T)$

TAATACGACTCACTATAGGGCGA

T7-Seq $(p C S 2+)$

TCTACGTAATACGACTCACTATAG

T3-Seq

ATTAACCCTCACTAAAGGGA

\subsection{Vektoren und cDNA-Klone}

\subsubsection{Vektoren}

p $\boldsymbol{G E M - T}$ (Abb. 2.1): Zur direkten, ungerichteten Klonierung von durch PCR erhaltenen DNAFragmenten und zur Herstellung markierter RNA-Sonden für ,whole mount“ in situ Hybridisierungen wurde der Vektor $p G E M-T$ (Promega) verwendet. Durch einzelne, überhängende Thymidinreste wird die Effizienz der Insertion von durch Taq-Polymerase erzeugten PCR-Produkten, welche zu ca. 50\% einzelne, überhängende Adeninreste tragen, erhöht. 


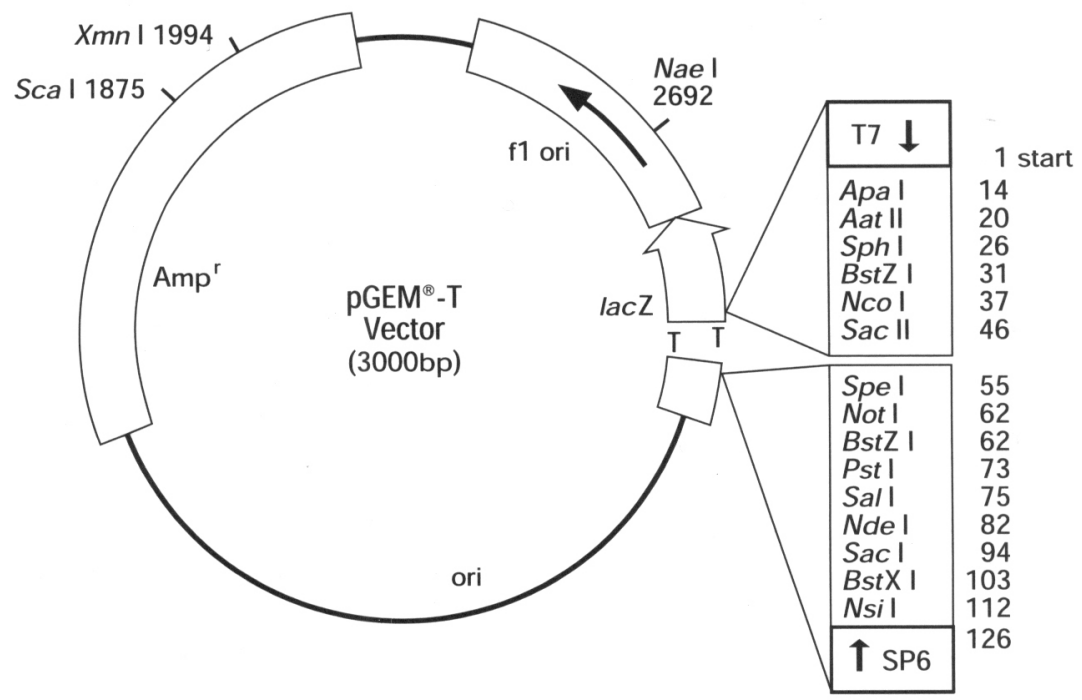

Abb. 2.1: Der Klonierungsvektor pGEM-T (Promega Deutschland GmbH, Mannheim). Der Vektor liegt als lineares Molekül vor. Zur einfachen Insertion von durch Taq-Polymerase erzeugten PCRProdukten befinden sich an den 3'-Enden einzelne, überhängende Thymidinreste.

pCS2+ (Abb. 2.2): Zur gerichteten Klonierung von DNA-Fragmenten und einer nachfolgenden in vitro Synthese synthetischer mRNAs wurde das pBluescript II $\mathrm{KS}+$-Derivat $p C S 2+$ verwendet. Mit Hilfe des SP6-Promotors und der 3' des Polylinker 1 gelegenen SV40Polyadenylierungsstelle lassen sich translatierbare mRNAs für die in vitro- oder in vivo Proteinsynthese herstellen.

pCS2+ MT (Abb. 2.3): Zur Herstellung von für c-myc-Fusionsproteine codierenden mRNAs wurde das $p C S 2+$-Derivat $p C S 2+M T$ verwendet. Dieser Vektor trägt sechs Kopien des $c-m y c-$ Epitops 3' des SP6-Promotors innerhalb des Polylinker 1. Durch die Wahl geeigneter Restriktionsschnittstellen bei der Insertion lassen sich so Konstrukte erzeugen, die sechs $c$-mycEpitope 5' oder 3' des eingefügten DNA-Fragmentes tragen.

\subsection{2 cDNA-Klone}

Xeya3/pGEM-T: Enthält den offenen Leserahmen (1698bp) der Xeya3-cDNA ligiert in $p G E M$ $T$. Für die in vitro Synthese von Antisense-RNA für „whole mount“ in situ Hybridisierungen wurde mit SphI linearisiert und mit SP6-RNA-Polymerase transkribiert. 


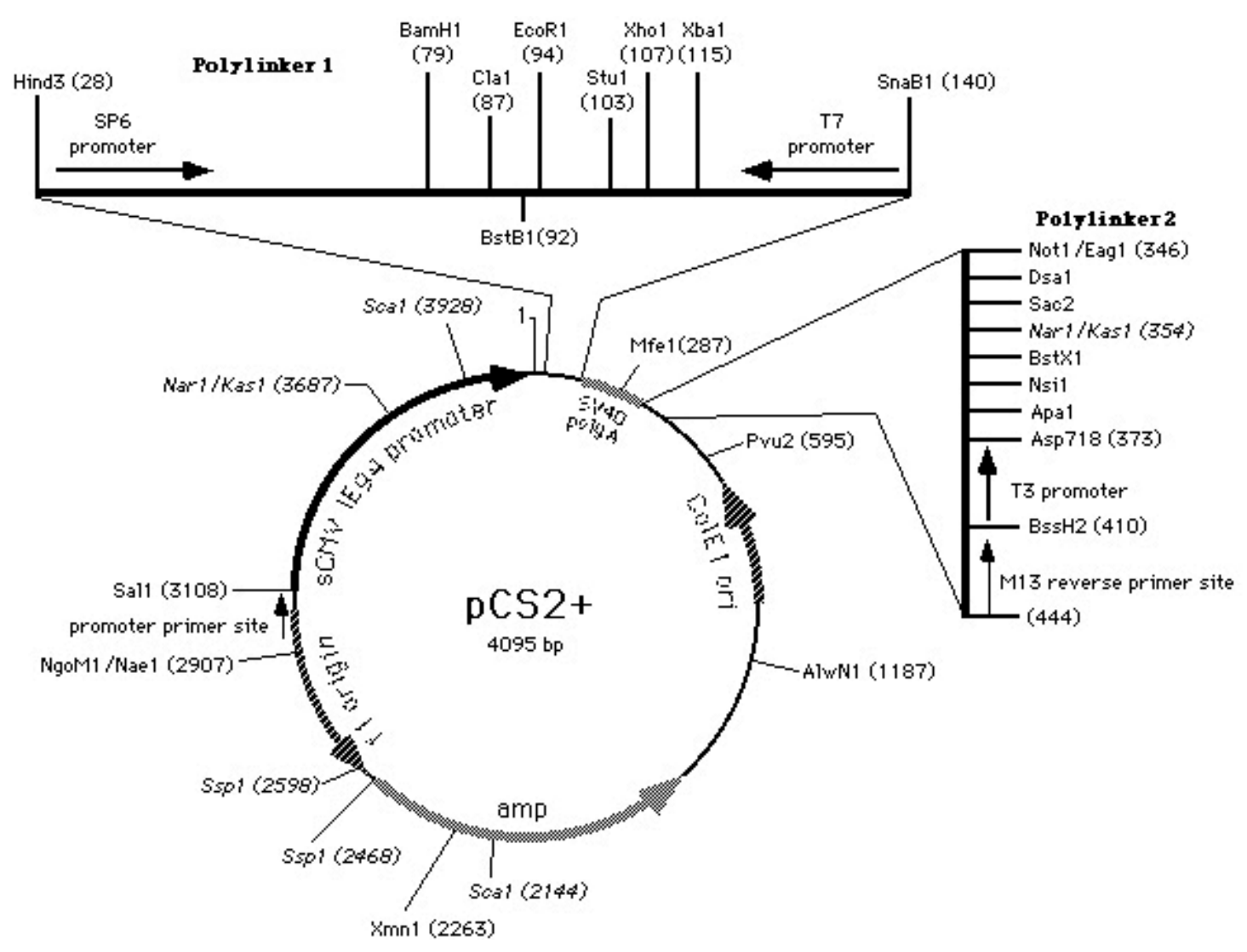

Abb. 2.2: Der Expressionsvektor $\boldsymbol{p} \boldsymbol{C S} 2+$. Der zur Herstellung von Konstrukten für die in vitro Transkription verwendete Polylinker 1 ist vergrößert dargestellt. Nach Turner und Weintraub, 1994.

Xeya3/pCS2+: Enthält den offenen Leserahmen (1698bp) der Xeya3-cDNA ligiert in pCS2+ unter Verwendung der Restriktionsschnittstellen für ClaI (5'-Ende) und XhoI (3'-Ende). Für die in vitro Synthese von synthetischer mRNA wurde mit NotI linearisiert und mit SP6-RNAPolymerase (mMessage mMachine, Ambion Ltd.) transkribiert.

Xeya3-Flag/pCS2+: Enthält den offenen Leserahmen (1698bp) der Xeya3-cDNA ergänzt durch die DNA-Sequenz für ein Flag-Epitop (27bp) am ihrem 3'-Ende. Die Insertion in $p C S 2+$ erfolgte unter Verwendung der Restriktionsschnittstellen für ClaI (5'-Ende) und XhoI (3'Ende). Für die in vitro Synthese von synthetischer mRNA wurde mit NotI linearisiert und mit SP6-RNA-Polymerase (mMessage mMachine, Ambion Ltd.) transkribiert.

Xeya3-myc/pCS2+: Enthält den offenen Leserahmen (1698bp) der Xeya3-cDNA ligiert in $p C S 2+M T$ unter Verwendung der Restriktionsschnittstellen für StuI (5'-Ende) und XhoI (3'Ende). Für die in vitro Synthese von synthetischer mRNA wurde mit NotI linearisiert und mit SP6-RNA-Polymerase (mMessage mMachine, Ambion Ltd.) transkribiert. Die resultierende 
mRNA kodiert für ein $c$-myc/Xeya3-Fusionsprotein mit sechs $c$-myc-Epitopen an seinem $\mathrm{N}$ Terminus.

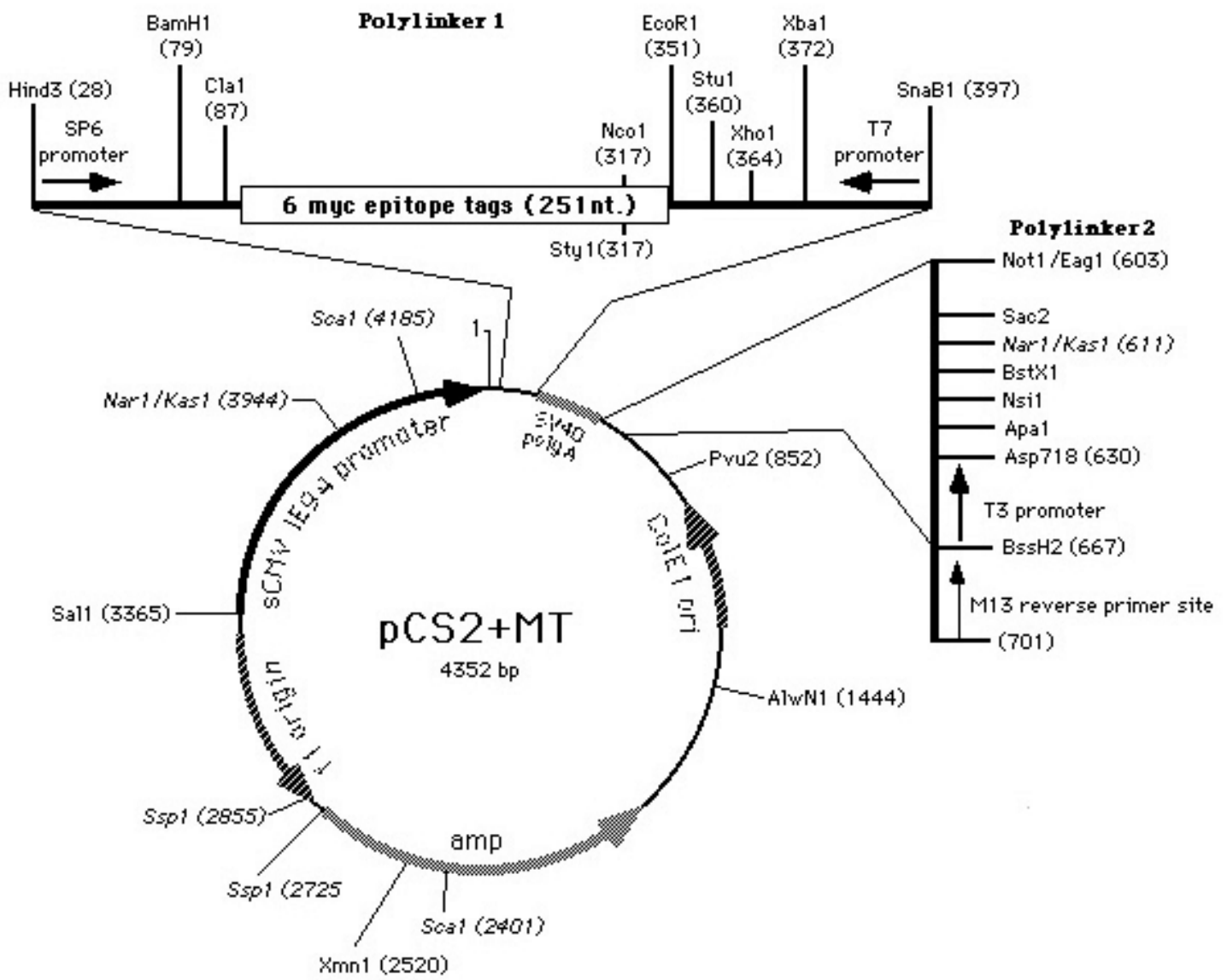

Abb. 2.3: Der Expressionsvektor $\boldsymbol{p C S} 2+\boldsymbol{M T}$. Der zur Herstellung von Konstrukten für die in vitro Transkription verwendete Polylinker 1 (inklusive der sechs $c$-myc-Epitope) ist vergrößert dargestellt. Nach Turner und Weintraub, 1994.

Xeya3-wob/pCS2+: Enthält den offenen Leserahmen (1698bp) der Xeya3-cDNA ligiert in $p C S 2+$ unter Verwendung der Restriktionsschnittstellen für ClaI (5'-Ende) und XhoI (3'-Ende). Zur Verwendung als Rescue-Konstrukt in Morpholino-Antisense-Oligonukleotid-Experimenten sind im Bereich der ersten 25bp des Xeya 3 ORF sieben „stille“ (ohne Einfluss auf die ProteinPrimärstruktur) Basenaustausche vorgenommen worden. Für die in vitro Synthese von synthetischer mRNA wurde mit NotI linearisiert und mit SP6-RNA-Polymerase (mMessage mMachine, Ambion Ltd.) transkribiert. 
Xeya3-mut1/pCS2+: Enthält den offenen Leserahmen (1698bp) der Xeya3-cDNA mit einer Punktmutation an Position $902(\mathrm{~A} \rightarrow \mathrm{C}, \mathrm{Asp} \rightarrow \mathrm{Ala})$ ligiert in $p C S 2+$ unter Verwendung der Restriktionsschnittstellen für ClaI (5'-Ende) und XhoI (3'-Ende). Für die in vitro Synthese von synthetischer mRNA wurde mit NotI linearisiert und mit SP6-RNA-Polymerase (mMessage mMachine, Ambion Ltd.) transkribiert.

Xeya3-mut2/pCS2+: Enthält den offenen Leserahmen (1698bp) der Xeya3-cDNA mit einer Punktmutation an Position $908(\mathrm{~A} \rightarrow \mathrm{C}$, Asp $\rightarrow$ Ala) ligiert in $p C S 2+$ unter Verwendung der Restriktionsschnittstellen für ClaI (5'-Ende) und XhoI (3'-Ende). Für die in vitro Synthese von synthetischer mRNA wurde mit NotI linearisiert und mit SP6-RNA-Polymerase (mMessage mMachine, Ambion Ltd.) transkribiert.

Xeya3-mut3/pCS2+: Enthält den offenen Leserahmen (1698bp) der Xeya3-cDNA mit zwei Punktmutationen an Position $902(\mathrm{~A} \rightarrow \mathrm{C}$, Asp $\rightarrow$ Ala) sowie $908(\mathrm{~A} \rightarrow \mathrm{C}, \mathrm{Asp} \rightarrow$ Ala) ligiert in $p C S 2+$ unter Verwendung der Restriktionsschnittstellen für ClaI (5'-Ende) und XhoI (3'Ende). Für die in vitro Synthese von synthetischer mRNA wurde mit NotI linearisiert und mit SP6-RNA-Polymerase (mMessage mMachine, Ambion Ltd.) transkribiert.

Xdach1-part/pGEM-T: Enthält ein 414bp Fragment innerhalb des offenen Leserahmens der $X d a c h 1-c D N A$ ligiert in $p G E M-T$.

Xdach1-900/pGEM-T: Enthält ein Fragment (939bp) des offenen Leserahmens der Xdach1cDNA ligiert in $p G E M-T$. Für die in vitro Synthese von Antisense-RNA für „whole mount“ in situ Hybridisierungen wurde mit NcoI linearisiert und mit SP6-RNA-Polymerase transkribiert.

Xdach1-A/pCS2+: Enthält den offenen Leserahmen (2088bp) der Xdach1-A-cDNA ligiert in $p C S 2+$ unter Verwendung der Restriktionsschnittstellen für ClaI (5'-Ende) und XhoI (3'-Ende). Für die in vitro Synthese von synthetischer mRNA wurde mit NotI linearisiert und mit SP6RNA-Polymerase (mMessage mMachine, Ambion Ltd.) transkribiert.

Xdach1-B/pCS2+: Enthält den offenen Leserahmen (2250bp) der Xdach1-B-cDNA ligiert in $p C S 2+$ unter Verwendung der Restriktionsschnittstellen für ClaI (5'-Ende) und Xho1 (3'-Ende). Für die in vitro Synthese von synthetischer mRNA wurde mit NotI linearisiert und mit SP6RNA-Polymerase (mMessage mMachine, Ambion Ltd.) transkribiert. 
Xdach1-B-UTR/pCS2+ (erhalten von E. Amaya, Cambridge): Enthält die vollständige Xdach1$B$-cDNA ligiert in $p C S 2+$.

Xdach1-B-Flag/pCS2+: Enthält den offenen Leserahmen (2250bp) der Xdach1-B-cDNA ergänzt durch die DNA-Sequenz für ein Flag-Epitop (27bp) am ihrem 3'-Ende. Die Insertion in $p C S 2+$ erfolgte unter Verwendung der Restriktionsschnittstellen für ClaI (5'-Ende) und XhoI (3'-Ende). Für die in vitro Synthese von synthetischer mRNA wurde mit NotI linearisiert und mit SP6-RNA-Polymerase (mMessage mMachine, Ambion Ltd.) transkribiert.

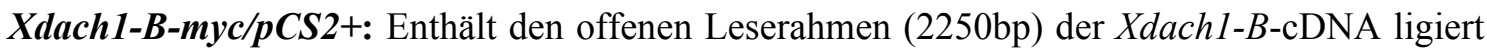
in $p C S 2+M T$ unter Verwendung der Restriktionsschnittstellen für StuI (5'-Ende) und XhoI (3'Ende). Für die in vitro Synthese von synthetischer mRNA wurde mit NotI linearisiert und mit SP6-RNA-Polymerase (mMessage mMachine, Ambion Ltd.) transkribiert. Die resultierende mRNA kodiert für ein $c-m y c / X d a c h 1-B$-Fusionsprotein mit sechs $c-m y c$-Epitopen an seinem $\mathrm{N}$ Terminus.

\section{Weitere Expressionskonstrukte}

Xbmp4 (Koster et al., 1991): Für die in vitro Synthese von synthetischer mRNA wurde mit BamHI linearisiert und mit SP6-RNA-Polymerase (mMessage mMachine, Ambion Ltd.) transkribiert.

\section{Weitere Konstrukte zur in vitro Synthese von Antisense-RNA}

$\boldsymbol{X} \boldsymbol{d l} \boldsymbol{x} 3$ (Papalopulu und Kintner, 1993): Für die in vitro Synthese von Antisense-RNA für „whole mount" in situ Hybridisierungen wurde mit EcoRI linearisiert und mit T7-RNAPolymerase transkribiert.

Xk81 (Jonas et al., 1985): Für die in vitro Synthese von Antisense-RNA für „whole mount“ in situ Hybridisierungen wurde mit EcoRI linearisiert und mit SP6-RNA-Polymerase transkribiert.

XmyT1 (Bellefroid et al., 1996): Für die in vitro Synthese von Antisense-RNA für ,whole mount" in situ Hybridisierungen wurde mit ClaI linearisiert und mit T7-RNA-Polymerase transkribiert. 
N-Tubulin (Oschwald et al., 1991): Für die in vitro Synthese von Antisense-RNA für ,whole mount" in situ Hybridisierungen wurde mit BamHI linearisiert und mit T3-RNA-Polymerase transkribiert.

Xotx2 (Pannese et al., 1995): Für die in vitro Synthese von Antisense-RNA für „whole mount“ in situ Hybridisierungen wurde mit NotI linearisiert und mit T7-RNA-Polymerase transkribiert.

Xpax3 (Davidson und Keller, 1999): Für die in vitro Synthese von Antisense-RNA für ,whole mount" in situ Hybridisierungen wurde mit BglII linearisiert und mit Sp6-RNA-Polymerase transkribiert.

Xpax6 (Hirsch und Harris, 1997): Für die in vitro Synthese von Antisense-RNA für ,whole mount" in situ Hybridisierungen wurde mit NotI linearisiert und mit T7-RNA-Polymerase transkribiert.

Xpitx3 (Pommereit et al., 2001): Für die in vitro Synthese von Antisense-RNA für „whole mount“ in situ Hybridisierungen wurde mit EcoRI linearisiert und mit T7-RNA-Polymerase transkribiert.

Xrhodopsin (Saha und Grainger, 1993): Für die in vitro Synthese von Antisense-RNA für „whole mount“ in situ Hybridisierungen wurde mit NotI linearisiert und mit T7-RNAPolymerase transkribiert.

Xrx1 (Casarosa et al., 1997): Für die in vitro Synthese von Antisense-RNA für „whole mount“ in situ Hybridisierungen wurde mit XhoI linearisiert und mit Sp6-RNA-Polymerase transkribiert.

Xshh (Ekker et al., 1995): Für die in vitro Synthese von Antisense-RNA für „whole mount“ in situ Hybridisierungen wurde mit XbaI linearisiert und mit T3-RNA-Polymerase transkribiert.

Xsix3 (Zhou et al., 2000): Für die in vitro Synthese von Antisense-RNA für „whole mount“ in situ Hybridisierungen wurde mit NotI linearisiert und mit T7-RNA-Polymerase transkribiert.

Xsox3 (Penzel et al., 1997): Für die in vitro Synthese von Antisense-RNA für ,whole mount“ in situ Hybridisierungen wurde mit EcoRI linearisiert und mit T7-RNA-Polymerase transkribiert. 
Xvax2 (Liu et al., 2001): Für die in vitro Synthese von Antisense-RNA für „,whole mount“ in situ Hybridisierungen wurde mit NotI linearisiert und mit T7-RNA-Polymerase transkribiert.

\subsection{Geräte}

Gebrauchs- und Verbrauchsmaterialien wurden von folgenden Firmen bezogen: Eppendorf AG (Hamburg), BD Falcon (Heidelberg), Qiagen GmbH (Hilden), Greiner Bio-One GmbH (Frickenhausen), Schütt Labortechnik GmbH (Göttingen), Ratiolab ${ }^{\circledR}$ GmbH (DreieichBuchschlag), Schott AG (Mainz), Biometra GmbH i.L. (Göttingen), Corning GmbH - Corning International (Wiesbaden).

\section{Mikroliterpipetten}

Pipetman P10

Pipetman P20

Pipetman P200

Pipetman P1000

\section{PCR-Cycler}

UNO II

T3 Thermocycler

\section{Zentrifugen}

Centrifuge 5415 D

Concentrator 5301

Heraeus Labofuge 400R

Heraeus Megafuge 1.0R

Sorvall RC-5B

Sorvall RC5B Plus

\section{Elektroporator}

E. coli Pulser

Elektroporationsküvetten

\section{Inkubatoren/Schüttler/Wasserbäder}

Brutschrank BM400

Brutschrank B6

Brutschrank WB $22 \mathrm{~K}$
Abimed Analysen-Technik GmbH, Langenfeld Abimed Analysen-Technik GmbH, Langenfeld Abimed Analysen-Technik GmbH, Langenfeld Abimed Analysen-Technik GmbH, Langenfeld

\author{
Biometra GmbH i.L., Göttingen \\ Biometra GmbH i.L., Göttingen
}

\author{
Eppendorf AG, Hamburg \\ Eppendorf AG, Hamburg \\ Kendro Laboratory Products GmbH, \\ Langenselbold
}

\author{
Memmert GmbH + Co.KG, Schwabach \\ Kendro GmbH, Langenselbold \\ Mytron GmbH, Heilbad Heiligenstadt
}


Thermomixer compact

Schüttler Innova 4230

Schüttler Unitron

Wasserbad GFL1002

Schüttelwasserbad GFL1092

\section{Histologie}

Vibratom Leica VT1000 S

Mikrotom Leica RM2065

Gastromaster Mikrodissektionsgerät

\section{Elektrophorese}

Netzteil E443

Netzteil E143

Model 583 Gel Dryer

Fastblot B 34

\section{Mikroinjektion}

Mikroinjektor PV820

Nadelzieher PN-30

\section{Optik}

Videodokumentationssystem Chemidoc

UV-Tisch NU-72 KL

Mikroskop Axioskop

Fluoreszenzmikroskop Axioplan 2

Stereomikroskop MZ FLIII

Stereomikroskop SZX12

Stereomikroskop Stemi 2000

Stereomikroskop SV6

DXC-950P Color Video Camera

C4742-95 Digital Camera

Evolution ${ }^{\mathrm{TM} M P}$ Digital Camera

KY-F58 3CCD Imaging Camera

Röntgenfilmentwickler Optimax Typ TR
Eppendorf AG, Hamburg

New Brunswick Scientific GmbH, Nürtingen

Infors $\mathrm{GmbH}$, Einsbach

GFL GmbH, Burgwedel

GFL GmbH, Burgwedel

Leica Mikrosysteme Vertrieb GmbH, Bensheim Leica Mikrosysteme Vertrieb GmbH, Bensheim Xenotek Engineering, Belleville (USA)

Consort nv, Turnhout (Belgien)

Consort nv, Turnhout (Belgien)

Bio-Rad Laboratories GmbH, München

Biometra GmbH i.L., Göttingen

Harry Fein World Precision Instruments, Berlin Science Products, Hofheim

Bio-Rad Laboratories GmbH, München

Konrad Benda, Wiesloch

Carl Zeiss AG, Oberkochen

Carl Zeiss AG, Oberkochen

Leica Mikrosysteme Vertrieb GmbH, Bensheim

Olympus Microscopy, Hamburg

Carl Zeiss AG, Oberkochen

Carl Zeiss AG, Oberkochen

Sony Deutschland GmbH, Köln

Hamamatsu Photonics Deutschland GmbH,

Herrsching am Ammersee

Media Cybernetics, Gleichen

JVC Deutschland GmbH, Friedberg

MS Laborgeräte Schröder OHG, Wiesloch 
Variable Mode Imager Typhoon 9400

Photometer Ultrospec 2000

Abi Prism ${ }^{\circledR} 3100$ Genetic Analyzer

\section{Computer (Hardware)}

Personal Computer

Power Macintosh G3/G4

\section{Computer (Software)}

Photoshop 7.0

Freehand 9/10

Lasergene

MacMolly ${ }^{\circledR}$ Tetra

BLAST Suchsystem für Datenbanken

Microsoft ${ }^{\circledR}$ Word 2000/XP

Microsoft $\circledast$ Excel 2000
Amersham Biosciences Europe GmbH,

Freiburg

Amersham Biosciences Europe GmbH,

Freiburg

Applied Biosystems GmbH, Weiterstadt

Avitos GmbH, Linden

Apple, Cupertino (USA)

Adobe Systems GmbH, Unterschleißheim Macromedia Central Europe, München

GATC Biotech AG, Konstanz

Mologen AG, Berlin

http://www.ncbi.nlm.nih.gov/BLAST/

(Altschul et al., 1997)

Microsoft Deutschland GmbH,

Unterschleißheim 



\section{Methoden}

\subsection{Präparation von Xenopus laevis Embryonalstadien}

\subsubsection{Präparation einer Spermiensuspension aus Xenopus laevis Testis}

Zur Herstellung einer Spermiensuspension für die in vitro Fertilisation von Xenopus laevis Eiern wurde ein Xenopus laevis Männchen nach Betäubung mit Tricaine dekapitiert und ventral aufgeschnitten. Die weißlichen, ovalen Hoden wurden in eiskalten 1 x MBS-Puffer überführt und ca. 1/5 eines Hodens mit einer Mikroschere in $1000 \mu 11$ x MBS mazeriert.

5 x MBS: 50 mM HEPES, pH 7,4; $440 \mathrm{mM} \mathrm{NaCl} ; 5 \mathrm{mM} \mathrm{KCl} ; 12 \mathrm{mM} \mathrm{NaHCO}$; 4,1 mM $\mathrm{MgSO}_{4} ; 2,05 \mathrm{mM} \mathrm{CaCl}_{2} ; 3,3 \mathrm{mM} \mathrm{KNO}{ }_{3} ; \mathrm{pH} 7,4$; sterilfiltrieren

\subsubsection{Stimulation der Eiablage}

Um die Eiablage für den folgenden Morgen zu stimulieren, wurden einem Xenopus laevis Weibchen gegen $20 \mathrm{Uhr} 800 \mathrm{U}$ humanes Gonadotropin (2000 U/ml) mittels einer $1 \mathrm{ml}-\mathrm{Spritze}$ mit G27-Kanüle in den dorsalen Lymphsack injiziert und das Tier ü.N. bei $16^{\circ} \mathrm{C}$ gehalten. War ein späterer Beginn der Eiablage erwünscht, wurde die Hormoninjektion dementsprechend zeitlich verschoben. Zur meist spontanen Eiablage wurden die Weibchen über eine leere Petrischale gehalten.

\subsubsection{In vitro Fertilisation}

Unmittelbar vor Gebrauch wurde die in 1 x MBS vorliegende Spermiensuspension mit $\mathrm{dH}_{2} \mathrm{O}$ 1/10 verdünnt und über die Gelege verteilt. Durch die so erreichte Verringerung der Ionenkonzentration erlangten die Spermien ihre volle Beweglichkeit. Nach dem Ausbreiten der Gelege zu einer Einzelschicht wurden sie 2 min zur Befruchtung inkubiert und dann mit 0,1 x MBS überschichtet.

\subsubsection{Entfernen der Gallerte, Vitalfärbung und Entwicklung}

30-40 min nach der Befruchtung wurden die aus in vitro Befruchtung erhaltenen Embryonen durch 3-5 minütige Inkubation in 2\% Cystein ( $\mathrm{pH} 8,0)$ unter Schwenken von ihrer Gallerthülle befreit und anschließend gründlich mit 0,1 x MBS gewaschen. Um Feinstrukturen von AlbinoEmbryonen besser erkennen zu können, wurden diese mit dem Vitalfarbstoff Nile-Blue angefärbt.

2\% Cystein-HCl: 2\% (w/v) L-Cysteinhydrochlorid-Monohydrat; $\mathrm{pH} 8$ 
Nile-Blue: $0,01 \%$ (w/v) Nile-Blue; $50 \mathrm{mM} \mathrm{Na}_{2} \mathrm{HPO}_{4} \cdot 2 \mathrm{H}_{2} \mathrm{O} ; 50 \mathrm{mM} \mathrm{NaH}_{2} \mathrm{PO}_{4} \cdot \mathrm{H}_{2} \mathrm{O}$; pH 7,8; mit Faltenfilter filtrieren

\subsubsection{Fixierung von Xenopus laevis Embryonen}

Hatten die Embryonen das gewünschte NF Embryonalstadium erreicht, wurden sie in $5 \mathrm{ml}$ Schraubdeckelglasröhrchen (Schütt Labortechnik GmbH, Göttingen) auf einer Wippe für 1,5 h in $1 \mathrm{x}$ MEMFA fixiert und anschließend durch eine aufsteigende Ethanolreihe (25\%EtOH/75\% $1 \mathrm{x}$ MEM, 50\%EtOH, 75\% EtOH, 100\% EtOH) dehydriert. Embryonalstadien vor dem Schlüpfen aus der Vitellinmembran wurden vor der Fixierung möglichst von dieser befreit. Die Lagerung erfolgte in $100 \% \mathrm{EtOH}$ (p.A.) bei $-20^{\circ} \mathrm{C}$.

10 x MEM: 1 M Mops; 20 mM EGTA; 10 mM MgSO 4 ; pH 7,4; sterilfiltrieren

MEMFA: 1 x MEM; 3,7\% Formaldehydlösung

\subsection{Mikromanipulation von Xenopus laevis Embryonen}

\subsubsection{Mikroinjektion von Xenopus laevis Embryonen}

Zum Transfer von Morpholino-Antisense-Oligonukleotiden (Morpholinos) oder zur Überexpression von Proteinen in Xenopus laevis Embryonen wurden Morpholino-AntisenseOligonukleotide bzw. synthetische mRNA in einzelne Blastomere von Xenopus laevis Embryonen des Zwei- bis 36-Zell-Stadiums injiziert. Mit einem Nadelziehgerät (PN-30) wurden Glaskapillaren (GC100F-10, Harvard Apparatus Ltd., Edenbridge (UK)) dünn ausgezogen. Die Morpholino-/mRNA-Lösung wurde in eine präparierte Glaskapillare pipettiert, die Nadel in eine luftdruckregulierte Mikromanipulationsapparatur (Mikroinjektor PV820) eingespannt und die Spitze mit einer Uhrmacherpinzette unter Beobachtung abgebrochen und somit geöffnet. Um mit einem geringen Durchmesser der Nadelspitze arbeiten zu können, wurde der Injektionsdruck möglichst hoch ( 2000 hPa) gehalten. Durch Variation der Injektionszeit $(0,1-$ $0,3 \mathrm{~s}$ ) wurde das zu injizierende Volumen auf ca. $5 \mathrm{nl}$ eingestellt indem der Tropfendurchmesser (d) anhand einer Mess-Skala bestimmt wurde $(\mathrm{d}=0,2 \mathrm{~mm} \approx 4,2 \mathrm{nl}$; $\mathrm{d}=0,25 \mathrm{~mm} \approx 8,2 \mathrm{nl})$. Zur Injektion wurden die Embryonen in $1 \mathrm{x}$ MBS inkubiert und auf Glas-Objektträger überführt. Nach ca. $1 \mathrm{~h}$ Inkubation in Plastikkulturschalen wurden die Embryonen in 0,5 $\mathrm{x}$ MBS umgepuffert, nach ca. $2 \mathrm{~h}$ wurde gegen $0,1 \mathrm{x}$ MBS ausgetauscht. 


\subsubsection{Hydroxyurea-/Aphidicolin-(,HUA“) Behandlung von Xenopus laevis Embryonen}

Durch Verwendung von Hydroxyurea und Aphidicolin als mitotische Inhibitoren kann die Embryonalentwicklung von Xenopus laevis in Abwesenheit von Zellproliferation untersucht werden (Harris und Hartenstein, 1991; Ikegami et al., 1978). Die Vitellinmembran von Xenopus laevis Embryonen im Gastrulastadium (NF Stadium 10,5) wurde für ca. 2 min mit Proteinase K $(10 \mu \mathrm{g} / \mathrm{ml}$ in 0,1 x MBS) angedaut, um ihre Permeabilität zu erhöhen. Anschließend wurden sie in $0,1 \times$ MBS überführt, das $20 \mathrm{mM}$ Hydroxyurea und $150 \mu \mathrm{M}$ Aphidicolin enthielt. Die Embryonen wurden in diesem Medium bis zum frühen Neurulastadium (NF Stadium 12,5-13) inkubiert und in MEMFA fixiert.

\subsubsection{Präparation und Kultivierung von animalen Gewebeexplantaten (animal caps)}

Synthethische mRNA wurde in den animalen Pol beider Blastomere von Xenopus laevis Embryonen im Zweizell-Stadium injiziert. Nach dem Erreichen des Blastula-Stadiums (NF Stadium 9-9,5) wurden die injizierten Embryonen sowie nicht-injizierte Kontrollembryonen in 0,8 x MBS (animal caps) überführt und mit Hilfe von Uhrmacherpinzetten von der Vitellinmembran befreit. Aus dem am animalen Pol befindlichen Dach des Blastocoels wurde mit Hilfe eines Mikrodissektionsgeräts (Gastromaster) ein Explantat mit einem Durchmesser von ca. $400 \mu \mathrm{m}$ herausgeschnitten und in Plastikkulturschalen mit einer Beschichtung aus 1\% Agarose in 0,8 x MBS (animal caps) überführt. Die animalen Gewebeexplantate wurden so lange kultiviert, bis unbehandelte Kontrollembryonen das gewünschte NF Stadium erreicht hatten.

5 x MBS (animal caps): $50 \mathrm{mM}$ HEPES, pH 7,4; $440 \mathrm{mM} \mathrm{NaCl} ; 5 \mathrm{mM} \mathrm{KCl} ; 12 \mathrm{mM} \mathrm{NaHCO}$; 4,1 $\mathrm{mM} \mathrm{MgSO}_{4} ; 2,05 \mathrm{mM} \mathrm{CaCl}_{2} ; 1,65 \mathrm{mM} \mathrm{Ca}\left(\mathrm{NO}_{3}\right)_{2} ; \mathrm{pH} 7,4$; sterilfiltrieren

\subsection{RNA Methoden}

Zur Inaktivierung von RNasen wurden die zum Arbeiten mit RNA bestimmten Gefäße und Lösungen autoklaviert $\left(30 \mathrm{~min}, 121^{\circ} \mathrm{C}\right)$. Hitzelabile Substanzen wurden in DEPC- $\mathrm{dH}_{2} \mathrm{O}$ gelöst. Beim Arbeiten mit RNA wurden Latex-Einmalhandschuhe getragen.

DEPC-d $\mathbf{d H}_{2} \mathbf{O}: 0,1 \%(\mathrm{v} / \mathrm{v})$ Diethylpyrocarbonat in $\mathrm{dH}_{2} \mathrm{O}$, Inkubation für $4-12 \mathrm{~h}$ bei $37^{\circ} \mathrm{C}$ und anschließendes Autoklavieren für $30 \mathrm{~min}$ bei $121^{\circ} \mathrm{C}$

\subsubsection{Präparation von Gesamt-RNA aus Xenopus laevis}

Gesamt-RNA aus Xenopus laevis wurde für RT-PCR-Analysen und 5'-/3'-RACE-PCR im Zuge von cDNA-Klonierungen verwendet. 


\subsubsection{Embryonalstadien}

Zur Extraktion von Gesamt-RNA aus Xenopus laevis Embryonalstadien wurden zuvor in flüssigem Stickstoff schockgefrorene Embryonen mit Hilfe einer $1 \mathrm{ml}$ Spritze $(0,4 \mathrm{~mm}$ Kanülendurchmesser) in TRIzol ${ }^{\circledR}$ Reagent (Invitrogen $\mathrm{GmbH} ; 1 \mathrm{ml}$ TRIzol ${ }^{\circledR}$ Reagent/100 mg Gewebe) homogenisiert. Nach Inkubation für $5 \mathrm{~min}$ bei RT wurde Chloroform $(0,2 \mathrm{ml}$ Chloroform $/ 1 \mathrm{ml}$ TRIzol ${ }^{\circledR}$ Reagent) zugesetzt, der Ansatz für $15 \mathrm{sec}$ von Hand geschüttelt, $3 \mathrm{~min}$ bei RT inkubiert und anschließend 15 min zentrifugiert $\left(12000 \mathrm{x} \mathrm{g}, 4^{\circ} \mathrm{C}\right)$. Die entstandene obere, wässrige Phase wurde in ein neues Gefäß überführt und mit Isopropanol versetzt $(0,5 \mathrm{ml}$ Isopropanol/1 ml zu Beginn eingesetztem Trizol ${ }^{\circledR}$ Reagent). Nach 10 min Inkubation bei RT wurde der Ansatz 10 min zentrifugiert $\left(12000 \mathrm{x} \mathrm{g}, 4^{\circ} \mathrm{C}\right)$ und der Überstand verworfen. Das entstandene RNA-Pellet wurde einmal mit 75\% Ethanol gewaschen $(1 \mathrm{ml} 75 \%$ Ethanol/ $1 \mathrm{ml} \mathrm{zu}$ Beginn eingesetztem Trizol ${ }^{\circledR}$ Reagent; Zentrifugation 5 min, $7500 \times$ g, $4^{\circ} \mathrm{C}$ ), luftgetrocknet und in $40 \mu \mathrm{l}$ DEPC- $\mathrm{dH}_{2} 0$ gelöst. Um kontaminierende genomische DNA zu degradieren, wurde die RNA-Lösung nach Zugabe von $2 \mu 1$ RNase-freier DNAse (20 U/ $\mu 1$, Roche), $5 \mu 110$ x DNasePuffer, $2 \mu 120 \mathrm{mM}$ Dithiothreitol und $1 \mu 1 \mathrm{RNaseOUT}$ (40 U/ $\mu$ l, Invitrogen) $30 \mathrm{~min}$ bei $37^{\circ} \mathrm{C}$ inkubiert. Anschließend wurde die RNA mittels RNeasy Mini Kit (Qiagen) aufgereinigt und die Konzentration photometrisch bestimmt.

10 x DNase-Puffer: $400 \mathrm{mM}$ Tris- $\mathrm{HCl}(\mathrm{pH} 8,0) ; 60 \mathrm{mM} \mathrm{MgCl}_{2} ; 100 \mathrm{mM} \mathrm{NaCl} ; 1 \mathrm{mM} \mathrm{CaCl} 2$ in DEPC- $\mathrm{dH}_{2} \mathrm{O}$

\subsubsection{Adulte Gewebe und Organe}

Nach der Präparation von Hoden aus Xenopus laevis Männchen wurden diesem Gewebe und Organe entnommen und mit 1 x MBS blutfrei gewaschen. Die zur RNA-Extraktion bestimmten Gewebe und Organe wurden in Flüssigstickstoff schockgefroren und mit einem in Flüssigstickstoff gekühlten Mörser pulverisiert. Das Pulver wurde in vorgekühlten 1,5 ml Eppendorfreaktionsgefäßen in $50 \mu \mathrm{l}$ Aliquots aufgeteilt und bis zur Extraktion bei $-80^{\circ} \mathrm{C}$ gelagert. Die RNA-Extraktion wurde wie unter 3.3.1.1 beschrieben durchgeführt.

\subsubsection{Animale Gewebeexplantate (animal caps)}

Die Gesamt-RNA Präparation aus animalen Gewebeexplantaten von Xenopus laevis erfolgte mit Hilfe des RNeasy Mini Kit (Qiagen). Dazu wurden jeweils 20-30 „animal caps“ in $200 \mu 1$ RLT-Puffer (incl. $10 \mu \mathrm{l} / \mathrm{ml} \beta$-Mercaptoethanol) durch Auf- und Abpipettieren (Pipetman P200) homogenisiert. Nach Zugabe von weiteren $300 \mu$ RLT-Puffer (incl. $\beta$-Mercaptoethanol) wurde 3 min bei 16000 x g zentrifugiert (Eppendorf 5415 D) und der Überstand mit $500 \mu 1$ 70\% Ethanol (p.A.) versetzt. Der Ansatz wurde in zwei Schritten á $500 \mu 1$ auf eine RNeasy-Säule pipettiert und jeweils $15 \mathrm{sec}$ bei 8000 x g zentrifugiert. Der Durchfluss wurde verworfen, $400 \mu 1$ 
RW1-Puffer auf die Säule gegeben, 5min bei RT inkubiert und $15 \mathrm{sec}$ bei $8000 \mathrm{x}$ g zentrifugiert. Zum Entfernen genomischer DNA wurde das RNase-Free DNase Set (Qiagen) verwendet. Dazu wurden je Ansatz 12,5 $\mu 1$ DNaseI und 87,5 $\mu$ 1 Puffer RDD gemischt und direkt auf die Säule pipettiert. Nach einstündiger Inkubation bei $30^{\circ} \mathrm{C}$ wurden $400 \mu 1 \mathrm{RW1-Puffer}$ auf die Säule gegeben, für $10 \mathrm{~min}$ bei RT inkubiert und der Durchfluss durch Zentrifugation für $15 \mathrm{sec}$ bei 8000 x g gesammelt. Nach zweimaligem Waschen mit jeweils $500 \mu 1$ RPE-Puffer und Zentrifugation für $15 \mathrm{sec}$ bzw. 2 min bei $8000 \mathrm{x}$ g wurde die Säule in ein 1,5 ml EppendorfGefäß überführt, die RNA mit $25 \mu 1$ RNase freiem $\mathrm{H}_{2} \mathrm{O}$ (Qiagen) eluiert und ihre Konzentration photometrisch bestimmt.

\subsubsection{Reverse-Transkriptase-Polymerase-Ketten-Reaktion (RT-PCR)}

Zur Klonierung von cDNA-Fragmenten, zur Verifizierung von durch andere Methoden erhaltener Sequenzinformation und im Zuge von ,animal cap Assays“ wurden RT-PolymeraseKettenreaktionen durchgeführt. Dabei wurde zunächst mRNA revers transkribiert und die erhaltene cDNA in der anschließenden PCR als Matrize eingesetzt.

Die reverse Transkription der RNA erfolgte mittels folgendem Ansatz:

- $1 \mu \mathrm{l} \mathrm{MgCl}$-Lösung (25 mM; Applied Biosystems GmbH)

- 0,5 $\mu 110$ x PCR-Puffer II (Applied Biosystems GmbH)

- 0,5 $\mu \mathrm{l}$ dGTP (10 mM; Applied Biosystems GmbH)

- 0,5 $\mu \mathrm{l}$ dATP (10 mM; Applied Biosystems GmbH)

- 0,5 $\mu 1$ dTTP (10 mM; Applied Biosystems GmbH)

- 0,5 $\mu \mathrm{l}$ dCTP (10 mM; Applied Biosystems GmbH)

- $0,1 \mu \mathrm{l}$ RNase Out (20 U/ $\mu 1$; Invitrogen)

- $0,25 \mu 1$ Random Hexamers (50 ng/ $\mu 1$; Invitrogen)

- 0,2 $\mu 1$ MuLV Reverse Transkriptase (50 U/ $\mu 1$, Applied Biosystems GmbH)

- bis zu 0,95 $\mu 1$ (bzw. $1 \mu \mathrm{g}$ ) total RNA

- RNase freies $\mathrm{dH}_{2} \mathrm{O}$ ad $10 \mu \mathrm{l}$

Folgendes PCR-Programm wurde verwendet (T3 Thermocycler):

- $10 \mathrm{~min}: 22^{\circ} \mathrm{C}$ (Anlagerung der Oligonukleotide)

- 15 min: $42^{\circ} \mathrm{C}$ (Reverse Transkription)

- $5 \mathrm{~min}: 99^{\circ} \mathrm{C}$ (Denaturierung)

- $5 \min : 5^{\circ} \mathrm{C}$ (Kühlung) 
Die so erhaltene cDNA wurde vollständig in einer PCR eingesetzt, der folgendes Pipettierschema zugrunde lag:

- $0,5 \mu 1 \mathrm{MgCl}_{2}$-Lösung (25 mM; Applied Biosystems GmbH)

- $2 \mu 1$ 10x PCR Puffer II (Applied Biosystems GmbH)

$\bullet 0,5 \mu 1$ genspezifisches Oligonukleotid (forward)

$\bullet 0,5 \mu 1$ genspezifisches Oligonukleotid (reverse)

• 0,125 $\mu$ 1 AmpliTaq ${ }^{\circledR}$ DNA Polymerase (5 U/ $\mu 1$; Applied Biosystems GmbH)

- $5 \mu 1 \mathrm{cDNA}$

- $16,375 \mu \mathrm{ld} \mathrm{d}_{2} \mathrm{O}$

Folgendes PCR-Programm (T3 Thermocycler) wurde verwendet, wobei die Zyklenzahl abhängig von der Häufigkeit der betreffenden cDNA, die Anlagerungstemperatur der Oligonukleotide abhängig von deren Spezifität und Schmelztemperatur und die Elongationszeit abhängig von der Länge des zu amplifizierenden cDNA-Fragmentes variiert wurde:

- $2 \min : 95^{\circ} \mathrm{C} \quad$ (Denaturierung)

$25-38 x\left[\begin{array}{ll}\bullet 45 \mathrm{sec}: 95^{\circ} \mathrm{C} & \text { (Schmelzen) } \\ \bullet 45 \mathrm{sec}: 48-68^{\circ} \mathrm{C} & \text { (Anlagerung der Primer; je nach Spezifität und Schmelzpunkt) } \\ \bullet 1-3 \mathrm{~min}: 72^{\circ} \mathrm{C} & \text { (Elongation) }\end{array}\right.$

- 10 min: $72^{\circ} \mathrm{C} \quad$ (Finale Elongation)

Nach Beendigung der Reaktion wurden $5 \mu$ des Reaktiongemisches durch Agarosegelelektrophorese aufgetrennt und analysiert.

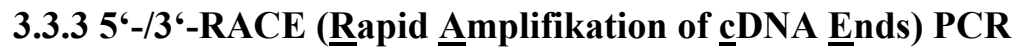

Zum Erhalt zusätzlicher cDNA-Sequenzinformation in $5^{6}$ - bzw. $3^{6}$-Richtung wurden $5^{6}-3^{6}-$ RACE Polymerase-Ketten-Reaktionen mit Hilfe des SMART TM RACE cDNA Amplifikation Kit (BD Biosciences Clontech) durchgeführt.

\subsubsection{Herstellen von 5'-/3'-RACE-Ready cDNA}

Zur Herstellung von $5^{6}-3^{6}-$ RACE-Ready cDNA, die in der anschließenden RACE-PCR als Matrize verwendet wurde, wurde wie folgt in zwei verschiedenen Ansätzen vorgegangen:

- 1-3 $\mu$ l total RNA (bis zu $1 \mu \mathrm{g}$ )

- 1 1 5'-cDNA-Synthesis-Primer

- $1 \mu$ l SMART II Oligo (nur für 5'-RACE-Ready cDNA) 
- $\mathrm{dH}_{2} \mathrm{O}$ ad $5 \mu \mathrm{l}$

Nach Mischen der Reaktionsgemische wurden diese für 2 min bei $70^{\circ} \mathrm{C}$, anschließend für $2 \mathrm{~min}$ auf Eis inkubiert. Danach wurden folgende Komponenten zu jedem der Ansätze hinzugefügt:

- $2 \mu 15$ x First-Strand Puffer

- $1 \mu 1$ DTT $(20 \mathrm{mM})$

- $1 \mu \mathrm{dNTP}$ Mix $(10 \mathrm{mM})$

- $1 \mu 1$ PowerScript Reverse Transkriptase (200 U/ $\mu \mathrm{l})$

Nach vorsichtigem Mischen der Proben erfolgte eine Inkubation bei $42^{\circ} \mathrm{C}$ für die Dauer von 1,5 h. Anschließend wurden den Reaktionsansätzen je nach eingesetzter RNA-Menge $20 \mu 1$ (< 200 ng total RNA) oder $100 \mu 1$ (> 200 ng total RNA) Tricine-EDTA-Puffer hinzugefügt. Nach einer Inkubation bei $72^{\circ} \mathrm{C}$ für 7 min konnte die so erhaltene $5^{\circ}$ - bzw. $3^{6}-\mathrm{RACE}-$ Ready cDNA bei $-20^{\circ} \mathrm{C}$ bis zu einer Dauer von 3 Monaten gelagert werden.

\subsubsection{Amplifikation von 5'-/3'-cDNA Enden (RACE-PCR)}

Für die Amplifikation von 5'- bzw. $3^{6}$-cDNA-Enden wurde wie folgt vorgegangen:

- $31 \mu$ PCR-Grade $\mathrm{H}_{2} \mathrm{O}$

- 5 l 10 x Advantage 2 PCR Puffer

- $1 \mu 1 \mathrm{dNTP}$ Mix $(10 \mathrm{mM})$

- $1 \mu 150$ x Advantage 2 Polymerase Mix

Der Ansatz wurde gemischt und 5'-RACE- bzw. 3'-RACE-spezifisch die angegebenen Komponenten hinzugefügt:

\section{5'-RACE-PCR}

- 5 시 5'-RACE-Ready cDNA

- $5 \mu 110$ x UPM (Universal Primer Mix)

- $1 \mu 1$ GSP1 (Gen spezifischer Primer 1; $10 \mu \mathrm{M}$ )

\section{3'-RACE-PCR}

- 5 ㅅ 3'-RACE-Ready cDNA

- $5 \mu 110$ x UPM

- $1 \mu 1 \mathrm{GSP} 2(10 \mu \mathrm{M})$ 
Folgendes PCR-Programm („Touchdown PCR“; Don et al., 1991; Roux, 1995) wurde verwendet (T3 Thermocycler):

- 5 sec: $94^{\circ} \mathrm{C} 75 \mathrm{x}$

- 3 min: $72^{\circ} \mathrm{C}$

- 5 sec: $94^{\circ} \mathrm{C}$

- 10 sec: $70^{\circ} \mathrm{C} \quad 5 \mathrm{x}$

- 3 min: $72^{\circ} \mathrm{C}$

- $5 \mathrm{sec}: 94^{\circ} \mathrm{C}$

- 10 sec: $68^{\circ} \mathrm{C} \quad 30-40 \mathrm{x}$

- 3 min: $72^{\circ} \mathrm{C}$

Nach Beendigung von 30 Zyklen im letzten Abschnitt der PCR wurden $5 \mu$ des Reaktionsgemisches mittels Agarosegelelektrophorese aufgetrennt. Zeigten sich keine oder nur schwache Banden, so wurden die Ansätze bis zu 10 weiteren Zyklen unterzogen.

\subsubsection{In vitro Synthese von Cap-mRNA für Mikroinjektionen}

Synthetische mRNA für Mikroinjektionen wurde mit Hilfe des „mMESSAGE mMACHINETM SP6“ Reaktionssystems (Ambion) hergestellt. Dabei wird der RNA während der in vitro Synthese am 5'-Ende eine 7-Methylguanosin-,,Kappe“ angefügt.

- $10 \mu 12$ x NTP/Cap

- $2 \mu 110$ x Reaction Buffer

- $1 \mu \mathrm{g}$ lineare DNA-Matrize

- $2 \mu$ Enzyme Mix

Nach Inkubation für $1,5 \mathrm{~h}$ bei $37^{\circ} \mathrm{C}$ wurde $1 \mu \mathrm{l}$ Rase-freie DNaseI (Ambion) hinzugefügt und der Ansatz für weitere $15 \mathrm{~min}$ bei $37^{\circ} \mathrm{C}$ inkubiert, um die DNA-Matrize abzubauen. Beinhaltete das verwendete Plasmid anstatt eines SP6- einen T7- oder T3-RNA-Polymerase Promoter, so wurde für die RNA-Synthese die entsprechende Polymerase verwendet. Zur Kontrolle einer erfolgreichen Transkription wurde $1 \mu 1$ des Reaktionsansatzes mittels Agarosegelelektrophorese analysiert. 


\subsubsection{In vitro Synthese markierter RNA-Sonden}

Zur Synthese von markierten Antisense-RNA-Sonden für in situ Hybridisierungen wurden in vitro Transkriptionen in Anwesenheit von Digoxigenin- oder Fluoreszein markiertem rUTP durchgeführt.

- $5 \mu 15$ x Transkriptionspuffer (Stratagene)

- $1 \mu 1$ DTT $(0,75 \mathrm{M})$

- $1 \mu 1$ Rnase Out (20 U/ $\mu 1$; Invitrogen)

- $3 \mu 1$ Digoxigenin-/Fluoreszein-Mix

- 1,5 $\mu 1$ RNA Polymerase (50 U/ $\mu 1)$

- $1 \mu \mathrm{g}$ lineare DNA-Matrize

- RNase freies $\mathrm{dH}_{2} \mathrm{O}$ ad $25 \mu \mathrm{l}$

Der Ansatz wurde $2 \mathrm{~h}$ bei $37^{\circ} \mathrm{C}$ inkubiert und anschließend die DNA-Matrize nach Zugabe von $1 \mu 1$ RNase-freier DNaseI (Ambion) 15 min bei $37^{\circ} \mathrm{C}$ verdaut. Zur Kontrolle einer erfolgreichen Transkription wurde $1 \mu 1$ des Reaktionsansatzes mittels Agarosegelelektrophorese analysiert.

Digoxigenin-Mix: $10 \mu \mathrm{rATP}(10 \mathrm{mM}) ; 10 \mu \mathrm{rCTP}(10 \mathrm{mM}) ; 10 \mu 1 \mathrm{rGTP}(10 \mathrm{mM}) ; 6,5 \mu 1$ rUTP (10 mM); 3,5 $\mu$ l Dig-rUTP (10 mM, Roche)

Fluoreszein-Mix: $10 \mu 1 \mathrm{rATP}(10 \mathrm{mM}) ; 10 \mu 1 \mathrm{rCTP}(10 \mathrm{mM}) ; 10 \mu 1 \mathrm{rGTP}(10 \mathrm{mM}) ; 6,5 \mu 1$ rUTP (10 mM); 3,5 $\mu$ l Flu-rUTP (10 mM, Roche)

\subsubsection{Aufreinigung synthetisch hergestellter RNA}

Um synthetische RNA von Salzen, Enzymen und Nukleotiden abzutrennen, wurden die Reaktionsansätze mit Hilfe des RNeasy Mini Kits (Qiagen) aufgereinigt. Die Probe wurde dazu mit RNase-freiem $\mathrm{dH}_{2} \mathrm{O}$ auf ein Gesamtvolumen von $100 \mu$ aufgefüllt und $350 \mu$ Puffer RLT sowie $250 \mu \mathrm{l}$ Ethanol hinzu pipettiert. Nach dem Mischen wurde die Lösung auf eine RNeasySäule übertragen und $15 \mathrm{sec}$ bei $8000 \mathrm{x}$ g zentrifugiert (Eppendorf $5415 \mathrm{D}$ ). Es wurde zweimal durch Zugabe von $500 \mu$ l Puffer RPE und anschließendes Zentrifugieren bei 8000 x g für $15 \mathrm{sec}$ gewaschen und die Säule danach durch Zentrifugation bei 8000 x g für 2 min getrocknet. Die RNA wurde anschließend mit $20 \mu 1$ RNase-freiem $\mathrm{dH}_{2} \mathrm{O}$ und 1 minütiger Zentrifugation bei $8000 \mathrm{x}$ g in ein Eppendorfgefäß eluiert. Die Lagerung erfolgte bei $-20^{\circ} \mathrm{C}$. 


\subsection{DNA Methoden}

\subsubsection{Bestimmung der optischen Dichte (OD) von Bakterien-Flüssigkulturen}

Das Wachstum von Bakterien in Flüssigkultur konnte durch Bestimmung der optischen Dichte der Zellsuspension bei einer Wellenlänge von $600 \mathrm{~nm}$ im Extinktionsbereich von 0 - 0,5 gegen einen Leerwert mit unbeimpftem Nährmedium verfolgt werden. Dazu wurden EinmalHalbküvetten $(1 \mathrm{ml})$ mit einer Schichtdicke von $\mathrm{d}=1 \mathrm{~cm}$ in einem Spektralphotometer (Ultrospec 2000) verwendet.

\subsubsection{Herstellung kompetenter Bakterienzellen für die chemische Transformation}

Zunächst wurden $5 \mathrm{ml} \mathrm{LB}$ Flüssigmedium mit einer Einzelkolonie beimpft. Nach Wachstum ü.N. bei $37^{\circ} \mathrm{C}$ im Schüttelinkubator (Unitron) wurden mit dieser Vorkultur $300 \mathrm{ml}$ LB-Medium in einem 21 Kolben beimpft. Das Wachstum der Bakterien erfolgte bis zu einer OD $_{600}$ von 0,3. $\mathrm{Ab}$ diesem Zeitpunkt wurde die Kultur bis zu einer $\mathrm{OD}_{600}$ von 0,4 bis 0,5 bei $18^{\circ} \mathrm{C}$ geschüttelt. Anschließend wurde die Kultur in $50 \mathrm{ml}$ Falconröhrchen aliquotiert und $5 \mathrm{~min}$ bei $6000 \mathrm{x} \mathrm{g}$ und $4^{\circ} \mathrm{C}$ zentrifugiert. Alle weiteren Schritte wurden auf Eis ausgeführt. Der Überstand wurde verworfen und das Pellett in $15 \mathrm{ml}$ vorgekühltem Transformationspuffer resuspendiert. Nach 15 minütiger Inkubation wurden die Suspensionen von jeweils drei Röhrchen vereinigt, wieder 5 $\min$ bei $6000 \mathrm{x} \mathrm{g}$ und $4^{\circ} \mathrm{C}$ zentrifugiert und das Zellpellett erneut in $15 \mathrm{ml}$ Transformationpuffer resuspendiert. Nach Zugabe von $525 \mu 1$ DMSO unter leichtem Schütteln, 5 min Inkubation auf Eis und wiederholter Zugabe von $525 \mu$ DMSO und 5 minütiger Inkubation wurde die Suspension in jeweils $200 \mu$ Aliquots in vorgekühlte Eppendorfgefäße verteilt, in flüssigem Stickstoff schockgefroren und bei $-70^{\circ} \mathrm{C}$ gelagert.

Transformationspuffer: $10 \mathrm{mM}$ PIPES (pH 6,7 mit $\mathrm{KOH}$ einstellen), $15 \mathrm{mM} \mathrm{CaCl} 2,250 \mathrm{mM}$ $\mathrm{KCl}, 55 \mathrm{mM} \mathrm{MnCl} \mathrm{m}_{2}\left(\mathrm{MnCl}_{2}\right.$ erst nach dem Autoklavieren dazugeben)

\subsubsection{Herstellung kompetenter Bakterienzellen für die elektrische Transformation}

Zur Anzucht von Bakterien, die kompetent für die elektrische Transformation mit PlasmidDNA waren, wurde zunächst ein Einzelkolonieausstrich des gewünschten Bakterienstammes auf LB-Agar-Platten (z.B. E. coli XL1-Blue mit 12,5 $\mu \mathrm{g} / \mathrm{ml}$ Tetracyclin) angefertigt und $20 \mathrm{ml}$ LB-Flüssigmedium mit einer einzelnen Bakterienkolonie inokuliert. Nach Inkubation über Nacht unter Schütteln bei $37^{\circ} \mathrm{C}$ (Unitron) wurden am folgenden Tag 21 LB-Flüssigmedium mit der Übernachtkultur inokuliert. Bis zum Erreichen der exponentiellen Wachstumsphase der Bakterien $\left(\mathrm{OD}_{600}=0,6-0,8\right)$ wurde erneut bei $200 \mathrm{Upm}$ und $37^{\circ} \mathrm{C}$ inkubiert und die Bakterienkultur anschließend im Eisbad gekühlt. Alle folgenden Schritte wurden mit auf $4^{\circ} \mathrm{C}$ vorgekühlten Lösungen und Geräten durchgeführt. Die Zellen wurden bei $4^{\circ} \mathrm{C}$ für 10 min und 
8000 x g (Sorvall RC-5B, GSA-Rotor) sedimentiert. Der Überstand wurde verworfen und das Sediment zunächst im Ausgangsvolumen mit sterilem $\mathrm{dH}_{2} \mathrm{O}$ resuspendiert. Nach erneuter Zentrifugation wurden die folgenden Waschschritte durchgeführt: 1 x 1 Vol. 10\% (v/v) Glycerin in $\mathrm{dH}_{2} \mathrm{O}, 1 \times$ x 0,5 x Vol. $10 \%$ (v/v) Glycerin in $\mathrm{dH}_{2} \mathrm{O}, 1$ x 1/20 Vol. 10\% (v/v) Glycerin in $\mathrm{dH}_{2} \mathrm{O}$. Das Zellpellet wurde in maximal $2 \mathrm{ml} 10 \%$ (v/v) Glycerin in $\mathrm{dH}_{2} \mathrm{O}$ resuspendiert. Aliquots von je $40 \mu \mathrm{l}$ der Zellsuspension wurden in 1,5 ml Eppendorfgefäße überführt, in flüssigem Stickstoff schockgefroren und bei $-70^{\circ} \mathrm{C}$ gelagert.

\subsubsection{Transformation kompetenter Bakterienzellen}

Zum Transfer von Plasmiden in E. coli XL1-Blue-Zellen wurde ein $200 \mu 1$ Aliquot chemisch kompetenter Bakterienzellen auf Eis aufgetaut, bis zu $20 \mu$ l Ligationsprodukt hinzugegeben und der Ansatz für 10 min auf Eis inkubiert. Durch Hitzeschock bei $42^{\circ} \mathrm{C}, 90 \mathrm{sec}$ und Inkubation für 3 min auf Eis wurde das Plasmid in die Zellen aufgenommen. Dem Ansatz wurden $800 \mu 1$ LBMedium hinzugefügt und die Bakterien für 45 min bei $37^{\circ} \mathrm{C}$ unter leichtem Schütteln (Thermomixer compact) angezogen. $200 \mu \mathrm{l}$ der Bakteriensuspension wurden mittels steriler Glaskügelchen auf zuvor bei $37^{\circ} \mathrm{C}$ angewärmte LB-Agarplatten ausplattiert und ü.N. bei $37^{\circ} \mathrm{C}$ im Brutschrank (BM400) inkubiert.

\subsubsection{Elektrische Transformation kompetenter Bakterienzellen}

Zur Elektrotransformation wurde das Elektroporationsgerät „E. coli Pulser" verwendet. Vor der Pulsgabe wurden alle Schritte auf Eis durchgeführt. Ein Aliquot mit $40 \mu 1$ elektrokompetenten Bakterien in einem 1,5 ml Eppendorfgefäß wurde auf Eis aufgetaut und mit 1-2 $\mu 1$ Ligationsprodukt vermischt. Der Transformationsansatz wurde anschließend vollständig in eine Elektroporationsküvette (Eurogentec; $\mathrm{d}=0,1 \mathrm{~cm}$ ) überführt und luftblasenfrei an den Boden der Küvette geklopft. Die Elektroporation wurde mit einem Puls von 2,4 kV durchgeführt. Sofort nach der Pulsgabe wurden 0,5 $\mathrm{ml}$ LB-Medium in die Küvette pipettiert und gut mit der Bakteriensuspension vermischt. $200 \mu 1$ dieses Ansatzes wurden mittels steriler Glaskügelchen auf zuvor bei $37^{\circ} \mathrm{C}$ angewärmte LB-Agarplatten ausplattiert, die ein der Plasmidresistenz entsprechendes Selektivantibiotikum sowie, bei Verwendung des $p G E M$-T-Plasmids, je $60 \mu 1$ IPTG und X-Gal, welche eine spätere „Blau-Weiß-Selektion“ zur Kontrolle einer erfolgreichen Insertion ermöglichen, enthielten. Die mit Bakteriensuspension benetzten Kügelchen wurden außerdem zusätzlich auf eine zweite LB-Agarplatte mit gleichen Zusätzen wie oben gegeben, um einen weniger dichten Koloniebewuchs zu erzielen. Die Platten wurden ü.N. bei $37^{\circ} \mathrm{C}$ im Brutschrank (BM400) inkubiert.

IPTG (Isopropylthiogalactosid): $100 \mathrm{mM} \mathrm{IPTG} \mathrm{in} \mathrm{dH}_{2} \mathrm{O}$ 
X-Gal (5-Bromo-4-chloro-3-indolyl-ß-D-galactopyranosid): $\quad 20 \quad \mathrm{mg} / \mathrm{ml} \quad \mathrm{X}$-Gal in Dimethylformamid

\subsubsection{Isolierung von Plasmiden im analytischen Maßstab}

Für die Plasmidpräparation im analytischen Maßstab wurde das QIAprep ${ }^{\circledR}$ Miniprep Kit (Qiagen) verwendet. Dabei wurden $3 \mathrm{ml}$ einer Bakterien-Übernachtkultur in einem 1,5 ml Eppendorfgefäß durch zweimalige Zentrifugation bei $16000 \mathrm{x}$ g für $5 \mathrm{~min}$ (Eppendorf $5415 \mathrm{D}$ ) sedimentiert. Das Pellet wurde anschließend in $250 \mu 1$ Puffer P1 resuspendiert und die Zellen durch Zugabe von $250 \mu 1$ Puffer P2 und viermaligem Invertieren lysiert. Zum Abtrennen von Protein- und Zellwandbestandteilen wurden $350 \mu$ l Puffer N3 dazugegeben, der Ansatz gemischt und bei 16000 x g für 10 min zentrifugiert. Der so entstandene klare Überstand wurde durch Dekantieren auf eine QIAprep-Säule überführt und bei 16000 x g für 1 min zentrifugiert. Nach Waschen der Säule mit $750 \mu \mathrm{l}$ Puffer und Zentrifugation für 1 min bei $16000 \mathrm{x} g$ wurde dieselbige durch 1 minütiges Zentrifugieren bei 16000 x g getrocknet. Die Elution der PlasmidDNA erfolgte in ein 1,5 ml Eppendorfgefäß durch 1 minütiges Zentrifugieren mit $50 \mu 11 \mathrm{x}$ TEPuffer. Das Eluat wurde bei $-20^{\circ} \mathrm{C}$ gelagert.

\subsubsection{Isolierung von Plasmiden im präparativen Maßstab}

Für die Plasmidpräparation im präparativen Maßstab wurde das QIAGEN Plasmid Midi Kit (Qiagen) verwendet. Dazu wurden $50 \mathrm{ml}$ einer Bakterien-Übernachtkultur in einem $50 \mathrm{ml}$ Falconröhrchen durch Zentrifugieren für $15 \mathrm{~min}$ bei $6000 \mathrm{x} \mathrm{g}$ und $4^{\circ} \mathrm{C}$ (Heraeus Megafuge 1.0R) sedimentiert. Das entstandene Pellet wurde anschließend in $4 \mathrm{ml}$ Puffer P1 resuspendiert und die Zellsuspension in ein $12 \mathrm{ml}$ PPN-Röhrchen überführt. Durch Zugabe von $4 \mathrm{ml}$ Puffer P2, viermaligem Invertieren und fünfminütiger Inkubation bei RT wurden die Zellen lysiert. Nach Hinzufügen von $4 \mathrm{ml}$ kaltem Puffer P3 und viermaligem Invertieren fand eine Inkubation auf Eis für 10 min statt. Zum Abtrennen von Protein- und Zellwandbestandteilen erfolgte eine 30 minütige Zentrifugation des Röhrchens bei 20000 x g und $4^{\circ} \mathrm{C}$ (Sorvall RC-5B Plus). Währenddessen wurde eine QIAGEN-tip 100-Säule durch Beschicken mit 4 ml Puffer QBT äquilibriert. Zum Binden der Plasmid-DNA wurde die Säule mit dem durch Zentrifugation gewonnenen Überstand beschickt und anschließend mit jeweils $10 \mathrm{ml}$ Puffer QC gewaschen. Die Elution der Plasmid-DNA erfolgte in $12 \mathrm{ml}$ PPN-Röhrchen mittels $5 \mathrm{ml}$ Puffer QF. Durch Zugabe von 3,5 $\mathrm{ml}$ Isopropanol, Mischen und anschließender Zentrifugation für $30 \mathrm{~min}$ bei $15000 \times \mathrm{g}$ und $4^{\circ} \mathrm{C}$ wurde die DNA präzipitiert. Das entstandene Pellet wurde mit $2 \mathrm{ml} \mathrm{70 \%}$ Ethanol gewaschen und für $10 \mathrm{~min}$ bei $15000 \mathrm{x}$ g zentrifugiert. Nach Trocknung des Pellets wurde dieses in $50 \mu 11 \mathrm{x}$ TE-Puffer aufgenommen und gelöst. Die Lagerung erfolgte in 1,5 ml Eppendorfgefäßen bei $-20^{\circ} \mathrm{C}$ oder $4^{\circ} \mathrm{C}$. 


\subsubsection{Konzentrationsbestimmung von Nukleinsäuren}

Nukleinsäure-Konzentrationen wurden in einem Spektralphotometer (Ultrospec 2000) bei 260 $\mathrm{nm}$ gegen einen Leerwert bestimmt. Die Konzentration wurde aus der $\mathrm{OD}_{260 \mathrm{~nm}}$ wie folgt errechnet:

- $\mathrm{OD}_{260}=1$ entspricht $50 \mu \mathrm{g}$ dsDNA

- $\mathrm{OD}_{260}=1$ entspricht $40 \mu \mathrm{g}$ RNA

Um die Reinheit (Proteinfreiheit) einer Nukleinsäure-Präparation abzuschätzen, wurde außerdem die OD bei $280 \mathrm{~nm}$ gemessen. Der Quotient $\mathrm{OD}_{260 \mathrm{~nm}} / \mathrm{OD}_{280 \mathrm{~nm}}$ beträgt bei proteinfreier DNA bzw. RNA 1,8-2.

\subsubsection{PCR-vermittelte in vitro-Mutagenese}

Zur gezielten Veränderung von DNA-Sequenzen wurde das QuikChange ${ }^{\mathrm{TM}}$ Site-Directed Mutagenesis Kit (Stratagene) eingesetzt. Hierbei wurden in einer PCR-Amplifikation des gesamten Matrizenplasmids mit $P f u$-Polymerase zwei komplementäre Oligonukleotide, welche die gewünschte Mutation enthielten, direkt eingebaut und zu zwei zirkulären, nicht verknüpften DNA Strängen elongiert. Die methylierte Matrizen-DNA wurde anschließend mit dem methylierungsabhängigen Restriktionsenzym DpnI degradiert, während das mutierte, unmethylierte PCR-Syntheseprodukt erhalten blieb. Nach Transformation (s. 3.4.7) von XL1Blue Zellen wurden die Strangbrüche im Vektor durch bakterielle Reparaturenzyme repariert. Der Erfolg der Mutagenese wurde durch DNA-Sequenzierung überprüft.

\subsubsection{Nachweis der Integration klonierter DNA-Fragmente}

Die Integration klonierter DNA-Fragmente in einen Vektor wurde durch PCR auf FlüssigkulturAliquots oder Restriktionsanalyse überprüft.

\subsubsection{PCR auf Flüssigkultur-Aliquots (Colony-PCR)}

Es wurden einzelne Bakterien-Kolonien in jeweils $100 \mu 1$ Flüssigselektivmedium für 3-4 h im Schüttler (Innova 4230 ) bei $37^{\circ} \mathrm{C}$ angezogen. Ein Reaktionsansatz der Colony PCR folgte folgendem Schema:

- 2,5 $\mu$ l PCR-Puffer II (incl. 25 mM MgCl 2 ; Qbiogene)

- $1 \mu 1$ Bakterien-Kultur

- $0,5 \mu$ l Oligonukleotid (10 $\mu \mathrm{M}$; forward)

- 0,5 $\mu$ l Oligonukleotid (10 $\mu \mathrm{M}$; reverse)

- 0,2 $\mu 1$ dNTPs (25 mM; Biomol) 
- 0,5 $\mu 1$ Taq DNA-Polymerase (5 U/ $\mu 1$; Qbiogene)

- $\mathrm{dH}_{2} \mathrm{O}$ ad $25 \mu \mathrm{l}$

Folgendes PCR-Programm wurde verwendet (T3 Thermocycler):

- 2 min: $95^{\circ} \mathrm{C}$

- 45 min: $95^{\circ} \mathrm{C}$

- $45 \mathrm{sec}: 56^{\circ} \mathrm{C} \quad 30-35 \mathrm{x}$

- 1-3 min: $72^{\circ} \mathrm{C}$

- 10 min: $72^{\circ} \mathrm{C}$

Die Analyse der Reaktionsansätze erfolgte mittels Agarosegelelektrophorese.

dNTPs: dATP, dGTP, dCTP, dTTP; je 100 mM wurden zu gleichen Anteilen vermischt (Endkonzentration jeweils $25 \mathrm{mM}$ )

\subsubsection{Restriktionsanalyse}

Eine Überprüfung der Integration gewünschter DNA-Fragmente in den verwendeten Vektor konnte auch nach Plasmidpräparation mit Hilfe von Restriktionsenzymen erfolgen. Dazu wurde folgender Ansatz verwendet:

-100-200 ng Plasmid-DNA

- 1 l 10 x Restriktionspuffer (New England Biolabs GmbH; Fermentas GmbH)

- $1 \mu \mathrm{l}$ Restriktionsendonukleasen $(1: 1 ;$ je $50 \mathrm{U} / \mu 1$; New England Biolabs GmbH, Fermentas $\mathrm{GmbH})$

- $\mathrm{dH}_{2} \mathrm{O}$ ad $10 \mu 1$

Nach 1,5-2 h Inkubationszeit wurde der komplette Ansatz mittels Agarosegelelektrophorese aufgetrennt.

\subsubsection{DNA-Sequenzierung und Sequenzanalyse}

Die Sequenzierung von doppelsträngiger DNA erfolgte mit dem "Dye Terminator Cycle Sequencing Kit" (Applied Biosystems). Das angewendete Verfahren basiert auf der DidesoxyKettenabbruchmethode nach Sanger (Sanger et al., 1977). Im Ansatz sind Didesoxyanaloga der vier verschiedenen dNTPs (ddNTPs) enthalten, welche je nach Base mit unterschiedlichen Fluoreszenzfarbstoffen markiert sind und in die neusynthetisierten DNA-Stränge eingebaut werden. Aufgrund des Fehlens der 3'-Hydroxylgruppe bei der Didesoxyribose kommt es zu 
statistisch verteilten Kettenabbrüchen, wodurch ein Gemisch unterschiedlicher Kettenlängen erzeugt wird. Nach der Auftrennung dieses Gemisches über mit Polymer gefüllte Kapillaren (Abi Prism ${ }^{\circledR} 3100$ Genetic Analyzer) können die jeweils 3'-terminalen Nukleotide der unterschiedlich langen DNA-Moleküle mittels eines Lasers detektiert werden.

- 200 ng DNA-Matrize

- $1 \mu$ l Oligonukleotid $(10 \mu \mathrm{M})$

- $1 \mu 1$,Seq-Mix“

- $2 \mu 15 \mathrm{x}$,Seq-Puffer”

- $\mathrm{dH}_{2} \mathrm{O}$ ad $10 \mu \mathrm{l}$

Die PCR folgte folgendem Programm (UNO II Thermoblock, Biometra):

- 2 min: $96^{\circ} \mathrm{C}$

- 30 sec: $96^{\circ} \mathrm{C}$

- 20 sec: $50^{\circ} \mathrm{C} \quad 26 \mathrm{x}$

- 4 min: $60^{\circ} \mathrm{C}$

Zur Aufreinigung wurden $1 \mu \mathrm{l}$ EDTA (125 mM), $1 \mu 1 \mathrm{NaAc}(3 \mathrm{M})$ sowie $50 \mu 1$ 100\% Ethanol zugesetzt, der Ansatz $5 \mathrm{~min}$ bei RT inkubiert und anschließend $15 \mathrm{~min}$ bei $16000 \mathrm{x} \mathrm{g}$ (Eppendorf 5415 D) zentrifugiert. Die präzipitierte DNA wurde einmal mit $70 \mu 170 \%$ Ethanol gewaschen und 5 min bei $16000 \mathrm{x}$ g zentrifuguert. Nach vollständigem Trocknen des DNAPellets (Concentrator 5301) wurde dieses in $30 \mu 1 \mathrm{dH}_{2} \mathrm{O}$ aufgenommen und bei $-20^{\circ} \mathrm{C}$ gelagert. Alle weiteren Schritte (Auftrennung der Proben und Dokumentation) wurden im hauseigenen Sequenzierlabor durchgeführt.

Computergestützte Sequenzanalysen konnten mit Hilfe der Programme Lasergene, MacMolly ${ }^{\circledR}$ Tetra und des BLAST-Suchsystems für Datenbanken durchgeführt werden.

\subsubsection{Plasmidlinearisierung}

Zur Linearisierung von DNA-Plasmiden für eine anschließende in vitro RNA-Synthese wurde wie folgt vorgegangen:

- $10 \mu \mathrm{g}$ Plasmid

- 5 ㅅ 10 x Restriktionspuffer (New England Biolabs GmbH; Fermentas GmbH)

- $1 \mu 1$ Restriktionsendonuklease (50 U/ $\mu 1$; New England Biolabs GmbH, Fermentas GmbH)

- $\mathrm{dH}_{2} \mathrm{O}$ ad $50 \mu 1$ 
Das Reaktionsgemisch wurde ü.N. bei $37^{\circ} \mathrm{C}$ (BM400) inkubiert und ein $1 \mu$ l Aliquot durch Agarosegelelektrophorese aufgetrennt. Linearisierte DNA zeigt ein gegenüber zirkulärer DNA deutlich verändertes Laufverhalten im Agarosegel. Eine erfolgreiche Linearisierung ist deshalb durch den Vergleich beider Formen einfach festzustellen.

\subsubsection{Restriktionsspaltung von Vektor-DNA und DNA-Fragmenten}

Zur Vorbereitung auf eine Ligation von DNA-Fragmenten mit dem $p C S 2+-$ Vektor wurden selbige mit Hilfe von Restriktionsendonukleasen verdaut, um für die Ligation notwendige komplementäre 5'- und 3'-Enden zu erhalten.

$\bullet 0,5-5 \mu \mathrm{g}$ DNA

- 5 l 10 x Restriktionspuffer (New England Biolabs GmbH; Fermentas GmbH)

- $1 \mu 1$ Restriktionsendonukleasen $(1: 1$; je $50 \mathrm{U} / \mu \mathrm{l}$; New England Biolabs GmbH, Fermentas $\mathrm{GmbH})$

- $\mathrm{dH}_{2} \mathrm{O}$ ad $50 \mu 1$

Das Reaktionsgemisch wurde ü.N. bei $37^{\circ} \mathrm{C}$ (BM400) inkubiert und anschließend mittels präparativer Agarosegelelektrophorese (s. 3.4.15.2) aufgereinigt.

\subsubsection{Agarosegelelektrophorese}

Um DNA-Fragmente aufzutrennen, wurden diese in einer Agarosematrix einem horizontalen elektrischen Feld ausgesetzt. Je nach Größe der DNA-Fragmente wurden Gele aus 0,8-2,2\% (w/v) Agarose in TBE-Puffer verwendet, denen zum Nachweis der DNA-Banden 0,5 $\mu \mathrm{g} / \mathrm{ml}$ Ethidiumbromid zugegeben wurde. Vor dem Auftragen der DNA-Proben in die Geltaschen wurden diese mit 1 Vol. DNA-Probenpuffer versetzt. Die Elektrophoresen wurden bei $250 \mathrm{~mA}$ in einer horizontalen Elektrophoresekammer (hauseigene Werkstatt) in TBE-Laufpuffer durchgeführt.

Anschließend wurden die DNA-Banden mittels eines Videodokumentationssystems (Chemidoc) dokumentiert. Durch paralleles Auftrennen einer Molekulargewichtsstandardlösung konnte die Größe der DNA-Fragmente bestimmt werden.

2 x DNA-Probenpuffer: $10 \mathrm{mM}$ Tris- $\mathrm{HCl}(\mathrm{pH}$ 7.5); $1 \mathrm{mM}$ EDTA; 0,025\% Bromphenolblau; 0,025\% Xylencyanol; 30\% (v/v) Glycerin

DNA-Molekulargewichtsstandard One kb Ladder: 1 x DNA-Probenpuffer; 1/20 Vol. 10 x Boehringer Puffer H; 0,4 Vol. 1 x TE; 50 ng/ $\mu$ l One kb Ladder ( $1 \mu \mathrm{g} / \mu 1$, Invitrogen $)$ 


\subsubsection{Aufreinigung von DNA-Fragmenten}

\subsubsection{Aufreinigung von PCR-Produkten und linearisierten Plasmiden}

Die Aufreinigung von PCR-Produkten sowie von linearisierten Plasmiden erfolgte mit Hilfe des QIAquick $^{\circledR}$ PCR Purification Kit (Qiagen). Dazu wurden die Reaktionsansätze in einem 1,5 ml Eppendorfgefäß mit $\mathrm{dH}_{2} \mathrm{O}$ auf $100 \mu \mathrm{l}$ aufgefüllt und der gesamte Ansatz nach Zugabe von 500 $\mu 1$ Puffer-PB auf eine Säule mit DNA-bindender Silicagel-Membran gegeben. Nach einminütiger Zentrifugation bei 16000 x g (Eppendorf 5415 D) wurde die Säule durch Zugabe von $750 \mu$ l Puffer-PE und Zentrifugation für 1 min gewaschen. Eine Trocknung der Membran erfolgte durch erneutes, einminütiges Zentrifugieren der Säule bei 16000 x g. Anschließend wurde die gebundene DNA mit $20 \mu 1$ RNAse-freiem $\mathrm{H}_{2} \mathrm{O}$ (linearisierte Plasmide) oder $20 \mu 1$ $\mathrm{dH}_{2} \mathrm{O}$ und Zentrifugation für $1 \mathrm{~min}$ bei $16000 \mathrm{x} \mathrm{g}$ in ein 1,5 $\mathrm{ml}$ Eppendorfgefäß eluiert. Die aufgereinigten Proben wurden bei $-20^{\circ} \mathrm{C}$ gelagert.

\subsubsection{Isolierung von PCR-Produkten aus Agarosegelen}

Wurden durch PCR Produkte verschiedener Längen erhalten, so erfolgte die Isolation eines oder mehrerer Fragmente durch Gelextraktion mit Hilfe des QIAEX $^{\circledR}$ Gel Extraction Kit (Qiagen). Dazu wurden die betreffenden Banden nach Auftrennung des gesamten Reaktionsansatzes in einem 1-1,5\%igen Agarosegel über einem UV-Leuchttisch bei einer Wellenlänge von $366 \mathrm{~nm}$ ausgeschnitten und in 1,5 ml Eppendorfgefäßen aufgenommen. Nach Zugabe von 3 Vol. QX1Puffer $(100 \mathrm{mg}$ Gel $\approx 100 \mu \mathrm{l})$ wurden die Gelstücke durch zehnminütiges Inkubieren im Wasserbad bei $50^{\circ} \mathrm{C}$ unter gelegentlichem Vortexen vollständig gelöst. Nach Zugabe von 1 Gelvolumen Isopropanol wurde der gesamte Ansatz auf eine Säule mit DNA-bindender Silicagel-Membran gegeben und für $1 \mathrm{~min}$ bei $16000 \mathrm{x}$ g (Eppendorf $5415 \mathrm{D})$ zentrifugiert. Zum Waschen wurden $750 \mu$ Puffer-PE auf die Säule gegeben und diese für 1 min bei $16000 \mathrm{x}$ g zentrifugiert. Nach Trocknen der Säule durch erneutes einminütiges Zentrifugieren wurde die

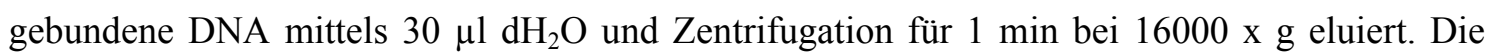
Lagerung des Eluats erfolgte bei $-20^{\circ} \mathrm{C}$.

\subsubsection{Ligation von DNA-Fragmenten}

Zur direkten Verknüpfung von mittels Taq-Polymerase erzeugten PCR-Produkten mit $p G E M-T$ Vektor-DNA bzw. von mittels Restriktionspaltung vorbereiteter DNA-Fragmente und $p C S 2+-$ Vektor-DNA wurde folgender Ligationsansatz verwendet:

- 50-100 ng DNA-Fragment

- $1 \mu 110$ x T4-Ligase-Puffer (Promega)

- $1 \mu 1$ pGEM-T-/pCS2+- Vektor-DNA (50-100 ng/ $\mu \mathrm{l})$ 
- $1 \mu 1$ T4-DNA-Ligase (3 U/ $\mu 1$, Promega)

- $\mathrm{dH}_{2} \mathrm{O}$ ad $10 \mu \mathrm{l}$

Die Ligation erfolgte ü.N. bei $4^{\circ} \mathrm{C}$.

\subsubsection{Durchmustern einer cDNA-Bank}

Zum Erhalt zusätzlicher Sequenzinformation in $5^{6}$-Richtung wurde eine fraktionierte $\lambda$-ZAP Express cDNA-Phagenbibliothek (Stratagene) aus Köpfen von Stadium 28-31 Xenopus laevis Embryonen mit Hilfe der PCR unter Verwendung cDNA-spezifischer Oligonukleotide durchmustert. Dabei wurde der gesuchte Phage, der die gewünschte cDNA enthielt, durch wiederholte Verdünnung und Amplifikation positiver Fraktionen angereichert und anschließend einer PCR mit Hilfe eines phagenspezifischen und eines cDNA-spezifischen Oligonukleotids unterzogen. Da der in dieser Phagenbank verwendete Vektor (ZAP Express ${ }^{\circledR}$ Vector) gerichtetes Klonieren von cDNA erlaubt, ist so die gezielte Amplifikation von 5'-cDNA-Fragmenten möglich.

\subsubsection{Identifikation positiver Phagenfraktionen}

Zum Test der einzelnen Phagenfraktionen auf Vorhandensein der gesuchten cDNA, wurden Aliquots der jeweiligen Überstände einer PCR mit für diese cDNA spezifischen Oligonukleotiden unterzogen:

- $2 \mu 1$ Phagenüberstand

- 2,5 $\mu 110$ x PCR-Puffer II (incl. $25 \mathrm{mM} \mathrm{MgCl}_{2}$, Roche)

- $0,5 \mu 1$ spezifisches Oligonukleotid $(10 \mu \mathrm{M}$; forward)

• $0,5 \mu 1$ spezifisches Oligonukleotid ( $10 \mu \mathrm{M}$; reverse)

• 0,2 $\mu 1$ dNTPs (25 mM, Biomol)

$\bullet 0,5 \mu 1$ Ampli ${ }^{\circledR}$ Taq DNA-Polymerase (5 U/ $\mu 1$, Roche)

- $\mathrm{dH}_{2} \mathrm{O}$ ad $25 \mu 1$

Folgendes PCR-Programm wurde verwendet (T3 Thermocycler):

- 2 min: $95^{\circ} \mathrm{C}$

- 1 min: $95^{\circ} \mathrm{C}$

- $45 \mathrm{sec}: 60^{\circ} \mathrm{C}$

- 1 min: $72^{\circ} \mathrm{C}$

- 15 min: $72^{\circ} \mathrm{C}$ 
Zur Analyse wurden $5 \mu 1$ des Reaktionsansatzes mittels Agarosegelelektrophorese aufgetrennt.

\subsubsection{Phagenplattierung}

Wurden durch PCR innerhalb der Phagenbank positive Fraktionen bestimmt, so wurden diese durch Ausplattieren auf 96-Loch-Mikrotiterplatten zunächst ausverdünnt und die „Subfraktionen“ anschließend angereichert. Dazu wurde zunächst ein Einzelkolonieausstrich des Bakterienstammes E. coli XL1-Blue MRF“ auf tetracyclinhaltigen LB-Agarplatten angefertigt. Eine Einzelkolonie wurde dann in $50 \mathrm{ml} \mathrm{LB}$-Flüssigmedium mit $10 \mathrm{mM} \mathrm{MgSO}_{4}$ und $0,2 \%$ Maltose bis zu einer $\mathrm{OD}_{600 \mathrm{~nm}}$ von $0,5-1,0$ herangezogen. Nach Zentrifugation für 10 min bei $500 \mathrm{x}$ g und $4^{\circ} \mathrm{C}$ (Sorvall RC-5B) wurden die Zellen in $10 \mathrm{mM} \mathrm{MgSO}_{4}$ zu einer $\mathrm{OD}_{600 \mathrm{~nm}}$ von 0,5 resuspendiert. Zum Adherieren der Phagen an die Wirtszellen wurden $200 \mu \mathrm{der}$ Bakteriensuspension zusammen mit 10 bzw. $2 \mu$ Phagenüberstand (zuzüglich $8 \mu$ l SM-Puffer, um gleiche Gesamtvolumina zu erhalten) aus den positiven Fraktionen in $12 \mathrm{ml}$ PPN-Röhrchen für 15 min bei $60 \mathrm{Upm}$ und $37^{\circ} \mathrm{C}$ geschwenkt (Innova 4230). Zum Ausplattieren wurden die Ansätze in je 6,4 ml NZY-Medium aufgenommen und in $100 \mu$ l Aliquots auf 8 x 8 Matrizen in 96-Loch Mikrotiterplatten verteilt. Die Platten wurden mit Klebefolie verschlossen und ü.N. bei $37^{\circ} \mathrm{C}$ im Schüttler (Innova 4230) inkubiert. Zum Test der so herangezogenen „Subfraktionen“ auf die gesuchte cDNA wurden die einzelnen Ansätze der Mikrotiterplatte zunächst zu acht Gruppen zusammengefaßt. Dabei wurden je $10 \mu 1$ der Vertiefungen der horizontalen Reihen A (1-8) bis H (1-8) verwendet. Aus den gebildeten Gruppen (A bis H) wurden dann $2 \mu 1$ der in 3.4.17.1 beschriebenen PCR unterzogen. Wurden positive Gruppen ermittelt, so wurden die zugehörigen acht Einzelfraktionen einzeln mittels PCR getestet. Positive Einzelfraktionen wurden erneut ausplattiert und die Prozedur wiederholt.

\subsubsection{Amplifikation spezifischer 5'-Fragmente}

Wurde der Phage, der die gewünschte cDNA enthielt, durch obige Verfahren angereichert, wurde mit der ihn enthaltenen Fraktion eine PCR mit vektorspezifischen, strangaufwärts der Klonierungsstelle liegenden Oligonukleotiden ( $C M V$-F) sowie dem bereits verwendeten rückwärtsgerichteten, cDNA spezifischen Oligonukleotid durchgeführt. Produkte, die möglicherweise zusätzliche 5'-Sequenzinformation enthielten, wurden aufgereinigt, in $p G E M-T$ ligiert und sequenziert. 


\subsection{Protein Methoden}

\subsubsection{In vitro Translation}

Für die in vitro Translation von Proteinen wurde das $\operatorname{TnT}^{\circledR}$-Coupled Reticulocyte Lysate System (Promega) verwendet, das eine Kopplung von Transkription und Translation und so die Proteinsynthese mit einem Expressionsvektor als Ausgangsmaterial ermöglicht.

- 6,25 $\mu 1 \mathrm{TnT}^{\circledR}$ Rabbit Reticulocyte Lysate

• $0,5 \mu 1 \mathrm{TnT}^{\circledR}$ Reaction Buffer

- $0,25 \mu 1 \mathrm{TnT}^{\circledR}$ SP6 RNA Polymerase

- 0,25 $\mu 1$ Amino Acid Mixture, Minus Methionine (1 mM)

- $0,5 \mu 1\left[{ }^{35} \mathrm{~S}\right]$ Methionine (> $1000 \mathrm{Ci} / \mathrm{mmol}$ at $10 \mathrm{mCi} / \mathrm{ml}$ )

- 0,25 $\mu 1$ RNasin $^{\circledR}$ Ribonuclease Inhibitor (40 U/ $\left.\mu \mathrm{l}\right)$

- $0,5 \mu 1$ DNA DNA-Matrize $(0,5 \mu \mathrm{g} / \mu \mathrm{l})$

- $1 \mu 1$ Morpholino-Antisense-Oligonukleotid (1 mM; optional)

- $\mathrm{dH}_{2} \mathrm{O}$ ad $12,5 \mu 1$

Der Reaktionsansatz wurde bei $30^{\circ} \mathrm{C}$ für 90 min inkubiert (Thermomixer compact) und anschließend durch SDS-PAGE (3.5.2.2) aufgetrennt. Zur Darstellung der radioaktiv markierten Translationsprodukte wurde das Gel anschließend für $1,5 \mathrm{~h}$ bei $70^{\circ} \mathrm{C}$ getrocknet (Model $583 \mathrm{Gel}$ Dryer) und mit Hilfe des Variable Mode Imager Typhoon 9400 analysiert.

\subsubsection{Nachweis von Fusionsproteinen in vivo}

Zum Nachweis der Translation von Fusionsproteinen in vivo wurden diese durch Immunpräzipitation (3.5.2.1) isoliert und mittels Western Blotting (3.5.2.3) detektiert.

\subsubsection{Immunpräzipitation}

Für die Immunpräzipitation von in vivo translatierten Fusionsproteinen wurden die entsprechenden synthetischen mRNAs in beide Zellen eines Zweizell-Stadiums injiziert und die Embryonen nach Erreichen des NF Stadiums 9 mit Hilfe einer $1 \mathrm{ml}$-Spritze mit G27-Kanüle in IP-Puffer auf Eis homogenisiert (240 $\mu 1$ IP-Puffer/12 Embryonen). Nach Zentrifugation für 15 min bei $16000 \mathrm{x} g$ und $4^{\circ} \mathrm{C}$ (Eppendorf $5415 \mathrm{D}$ ) wurde der Überstand abgenommen und mit IPPuffer auf $500 \mu 1$ aufgefüllt. Zum Binden an das Fusionsprotein wurde der jeweilige Antikörper hinzugegeben (anti-Flag, anti-c-myc; 1:500; Sigma-Aldrich Chemie GmbH) und der Ansatz $2 \mathrm{~h}$ bei $4^{\circ} \mathrm{C}$ auf einem Drehrad inkubiert. Zur Kopplung des Antikörpers an Protein-G-Sepharose wurden $20 \mu \mathrm{l}$ zuvor mit IP-Puffer gewaschener GammaBind ${ }^{\mathrm{TM}}$ Plus Sepharose ${ }^{\mathrm{TM}}$ (Amersham Pharmacia Biotech) zugegeben und der Ansatz erneut für $2 \mathrm{~h}$ bei $4^{\circ} \mathrm{C}$ auf einem Drehrad 
inkubiert. Die Probe wurde anschließend für $20 \mathrm{sec}$ bei $10000 \mathrm{x} \mathrm{g}$ und $4^{\circ} \mathrm{C}$ abzentrifugiert und der Überstand verworfen. Die Sepharose-Antikörper-Fusionsprotein-Komplexe wurden dreimal mit jeweils $1 \mathrm{ml}$ IP-Puffer gewaschen und abzentrifugiert. Die Lagerung erfolgte in $60 \mu 11 \mathrm{x}$ SDS-Probenpuffer bei $-20^{\circ} \mathrm{C}$. Zur Auftrennung mittels SDS-PAGE (3.5.2.2) wurden die Proben für 5 min bei $95^{\circ} \mathrm{C}$ denaturiert (GFL1002) und auf ein SDS-Polyacrylamid-Gel aufgetragen.

IP-Puffer: 40 mM Tris-HCL pH 7,8; $100 \mathrm{mM} \mathrm{NaCl;} \mathrm{0,5 \%} \mathrm{(v/v)} \mathrm{Nonidet} \mathrm{P40;} 1$ mM PMSF; eine Protease Inhibitor Cocktail Tablette (Roche); sterilfiltrieren

1 x SDS-Probenpuffer: $50 \mathrm{mM}$ Tris-HCL pH 6,8; $100 \mathrm{mM}$ Dithiothreitol; 2\% SDS; 0,1\% (w/v) Bromphenolblau; 10\% (v/v) Glycerol

\subsubsection{SDS-Polyacrylamid-Gelelektrophorese (SDS-PAGE)}

Proteine wurden gemäß ihres Molekulargewichts in SDS-Polyacrylamidgelen aufgetrennt. Zur Fokussierung der Proben wurde dem Trenngel ein Sammelgel vorgeschaltet. Ein Trenngel (10\% Acrylamid) setzte sich wie folgt zusammen:

- 10\% (v/v) 30\% Acrylamid Mix (Rotiphorese ${ }^{\circledR}$ Gel 30; Carl Roth GmbH + Co. KG)

- 375 mM Tris (pH 8,8)

$\bullet 0,1 \%(w / v)$ SDS

$\bullet 0,1 \%(\mathrm{w} / \mathrm{v})$ Ammoniumpersulfat

$\bullet 0,04 \%(\mathrm{v} / \mathrm{v})$ TEMED

Das Sammelgel (5\%) enthielt folgende Komponenten:

- 5\% (v/v) 30\% Acrylamid Mix (Rotiphorese ${ }^{\circledR}$ Gel 30; Carl Roth GmbH + Co. KG)

- 125 mM Tris (pH 6,8)

- $0,1 \%(w / v)$ SDS

- 0,1\% (w/v) Ammoniumpersulfat

- $0,1 \%(\mathrm{v} / \mathrm{v})$ TEMED

Zum Gießen eines Gels der Maße 110 x 140 x 0,5 mm wurden $20 \mathrm{ml}$ Trenngel-Lösung und $4 \mathrm{ml}$ Sammelgel-Lösung verwendet. In etwa $1 / 8$ des Gelvolumens wurde vom Sammelgel eingenommen. Die Auftrennung der jeweiligen Proteingemische erfolgte für ca. $3 \mathrm{~h}$ bei $35 \mathrm{~mA}$ in einer Gelkammer (Werkstatt des Instituts) in 1 x Elektrodenpuffer.

5 x Elektrodenpuffer: $125 \mathrm{mM}$ Tris; 1,25 M Glycin; 0,5\% SDS; pH 8,3 


\subsubsection{Western Blot}

Zum Elektrotransfer von durch SDS-PAGE aufgetrennten Proteingemischen auf Nitrocellulosemembranen und der nachfolgenden Detektion mit Hilfe spezifischer Antikörper wurde eine mit $\mathrm{dH}_{2} \mathrm{O}$ befeuchtete Nitrocellulosemembran $(0,45 \mu \mathrm{m}$, BA85; Schleicher \& Schuell) auf 3 Lagen mit Semi-Dry-Blot-Puffer befeuchtetem Filterpapier (Whatman) gelegt, darauf das Gel plaziert und mit 3 weiteren Lagen in Semi-Dry-Blot-Puffer getränktem Filterpapier luftblasenfrei bedeckt. Dieser „Sandwich“ wurde zwischen die angefeuchteten Flächenelektroden eines Elektroblotgeräts (Fastblot B 34) plaziert. Der Transfer erfolgte bei 0,8 $\mathrm{mA} / \mathrm{cm}^{2}$ Nitrocellulosemembran über einen Zeitraum von $1,5 \mathrm{~h}$. Nach kurzem Waschen in $1 \mathrm{x}$ PBST wurde die Membran zur Blockierung unspezifischer Antikörper-Bindungsstellen ü.N. in Blockierungspuffer bei $4^{\circ} \mathrm{C}$ auf einer Wippe inkubiert. Anschließend wurde die Membran in Plastikfolie eingeschweißt und mit $10 \mathrm{ml}$ in Blockierungspuffer verdünntem Erstantikörper (anti-Flag 1:10000; anti-c-myc 1:10000; Sigma-Aldrich Chemie $\mathrm{GmbH}$ ) für $2 \mathrm{~h}$ bei RT auf einer Wippe inkubiert. Nach dreimaligem Waschen in 1 x PBST für jeweils 10 min wurde die Membran erneut eingeschweißt und in Blockierungspuffer mit verdünntem Zweitantikörper (anti-rabbit/HRP 1:15.000; Santa Cruz Biotechnology; anti-mouse/HRP 1:15000; Amersham Pharmacia Biotech) für $2 \mathrm{~h}$ bei RT auf einer Wippe inkubiert. Überschüssiger Antikörper wurde durch dreimaliges Waschen in 1 x PBST für jeweils 10 min entfernt. Die Detektion der Peroxidase-Aktivität des Sekundärantikörpers erfolgte mit Hilfe des ECL+ plus Western Blotting Detection Systems (Amersham Pharmacia Biotech). Dazu wurden die DetektionsLösungen A und B in einem Verhältnis von 40:1 gemischt (100 $\mu 1$ Gesamtvolumen $/ \mathrm{cm}^{2}$ Membran), auf die Membran gegeben und für $5 \mathrm{~min}$ bei RT inkubiert. Zum Nachweis der Chemilumineszenz-Signale wurde die in Folie eingeschlagene Membran für $30 \mathrm{sec}$ bis $10 \mathrm{~min}$ in einer Filmkassette gegen Hyperfilm (Amersham Pharmacia Biotech) exponiert und der Film entwickelt (Röntgenfilmentwickler Optimax Typ TR).

1 x Semi-Dry-Blot-Puffer: $48 \mathrm{mM}$ Tris Base; 3 mM Glycin; 0,037\% (w/v) SDS; 20\% (v/v) Methanol; pH 9,2; Lagerung bei $4^{\circ} \mathrm{C}$

1 x PBST: 1 x PBS; 0,05\% Tween-20

Blockierungspuffer: $20 \mathrm{mM}$ Tris/ $\mathrm{HCl}(\mathrm{pH} 6,8) ; 150 \mathrm{mM} \mathrm{NaCl} ; 0,05 \%$ Tween-20; $5 \%$ Milchpulver 


\subsubsection{Nachweis der subzellulären Lokalisation von Fusionsproteinen}

Zum Nachweis der subzellulären Lokalisation von Fusionsproteinen wurden Immunfärbungen an ganzen Embryonen (3.5.3.1) oder Paraffinschnitten (3.5.3.2) durchgeführt.

\subsubsection{1 „Whole mount“" Immunfärbung}

Nach Mikroinjektion (3.2.1) der für das betreffende Fusionsprotein kodierenden mRNA in Zweizell-Stadien von Xenopus laevis wurden die Embryonen nach Erreichen des gewünschten Entwicklungsstadiums $1 \mathrm{~h}$ in MEMFA fixiert und zur Permeabilisierung der Zellen bei $-20^{\circ} \mathrm{C}$ ü.N. in Dents gelagert. Durch eine absteigende Methanolreihe (75\% Methanol/H2O, 50\% Methanol/H2O, 25\% Methanol/1 x PBS) und dreimaliges Waschen für jeweils 5 min in $1 \times$ PBS wurden die Embryonen rehydriert und unspezifische Antikörper-Bindungsstellen durch eine fünfstündige Inkubation in 20\% (v/v) Pferde-Serum/1 xPBS abgesättigt. Die Bindung des Primärantikörpers (anti-Flag 1:500; Sigma-Aldrich Chemie GmbH; anti-pH3 1:500; Santa Cruz Biotechnology) erfolgte in 20\% (v/v) Pferde-Serum/5\% (v/v) DMSO/1 x PBS für $5 \mathrm{~h}$ bei RT. Überschüssiger Antikörper wurde durch zweimaliges Waschen für $2 \mathrm{~h}$ bei RT in PBS-TB, zweistündiges Waschen bei RT in PBS-TBN, dreimaliges Waschen für 5 min bei RT in PBSTB und Waschen ü.N. bei $4^{\circ} \mathrm{C}$ in PBS-TB entfernt. Die Inkubation der Embryonen mit dem Sekundärantikörper (anti-rabbit/AP 1:1000; Sigma-Aldrich Chemie GmbH) erfolgte in 20\% (v/v) Pferde-Serum/5\% (v/v) DMSO/1 x PBS für $5 \mathrm{~h}$ bei RT. Überschüssiger Antikörper wurde durch Waschen mit PBS-TB (zweimal 30min), PBS-TBN (30min) und PBS-TB (ü.N., $4^{\circ} \mathrm{C}$ ) entfernt. Die Farbreaktion zur Darstellung vorhandener Alkalischer-Phosphatase-Aktivität wurde wie in 3.6.7.1 durchgeführt. Zur „Klärung“ wurden die Embryonen nach Beendigung der Farbreaktion in $100 \%$ Methanol dehydriert und in Benzylbenzoat/Benzylalkohol (Volumenverhältnis 2:1) aufgenommen.

1 x PBS-TB: 1 x PBS; 0,05\% (v/v) Tween-20; 0,2\% (w/v) Boehringer Mannheim Blocking Reagenz (Roche Diagnostics GmbH); pH 7,4

1 x PBS-TBN: 1 x PBS-TB; 0,3 M NaCl; pH 7,4

\subsubsection{Immunfärbung an Paraffinschnitten}

Von Embryonen, die das betreffende Fusionsprotein enthielten, wurden ParaffinMikrotomschnitte angefertigt und auf Objektträger aufgezogen. Diese wurden durch zweimaliges Waschen in Xylol für jeweils 10 min entwachst und anschließend durch eine absteigende Ethanolreihe (jeweils 2 min 100\% Ethanol, 80\% Ethanol, 50\% Ethanol) und dreimaliges Waschen in 1 x PBS rehydriert. Es folgte eine fünfminütige Inkubation in $0,25 \%$ (v/v) Triton-X-100/1 x PBS sowie, zum Blockieren unspezifischer Bindungen, eine 20 minütige 
Inkubation in Blockierungspuffer 1. Zum Binden des Primärantikörpers wurden die Objektträger ü.N. in Blockierungspuffer 1 inklusive des verdünnten Antikörpers (anti-Flag 1:200; Sigma-Aldrich Chemie GmbH; anti-c-myc 1:200; Sigma-Aldrich Chemie GmbH) überschichtet und bei RT inkubiert. Überschüssiger Antikörper wurde durch dreimaliges Waschen für jeweils $5 \mathrm{~min}$ in 1\% (v/v) Pferde-Serum/1 x PBS entfernt. Die Bindung des Sekundärantikörpers (anti-rabbit/Fitc 1:1000; Sigma-Aldrich Chemie GmbH; anti-mouse/Cy3 1:1000; Dianova $\mathrm{GmbH}$ ) erfolgte in Blockierungspuffer 1 für $1,5 \mathrm{~h}$ bei RT. Überschüssiger Antikörper wurde wiederum durch Waschen in 1\% (v/v) Pferde-Serum/1 x PBS entfernt und die Objektträger mit DAPI Einbettungsmedium (Vectashield; Linaris Biologische $\mathrm{GmbH}$, Wertheim) eingedeckelt.

Blockierungspuffer 1: 1 x PBS; 10\% (v/v) Pferde-Serum; 4\% (w/v) Boehringer Mannheim Blocking Reagenz (Roche Diagnostics GmbH); 0,25\% (v/v) Triton-X-100; pH 7,4

\subsubsection{Nachweis von proliferierenden oder apoptotischen Zellen}

\subsubsection{Nachweis von proliferierenden Zellen durch Detektion von phosphoryliertem}

\section{Histon 3 (pH3)}

Eine Methode zur Untersuchung von Zellproliferation beruht auf dem Vorkommen von phosphoryliertem Histon 3 während der späten G2-Phase bis zur Telophase im Zellzyklus (Hendzel et al., 1997; Paulson und Taylor, 1982). Unter Benutzung eines spezifischen Antikörpers gegen die phosphorylierte Form des Histon ( $p H 3)$ können proliferierende Zellen nachgewiesen werden (Saka und Smith, 2001). Zum Nachweis von phosphoryliertem Histon 3 wurde wie in 3.5.3.1 verfahren.

\subsubsection{Nachweis von proliferierenden Zellen durch Inkorporation von BrdU}

Eine weitere Möglichkeit des Nachweises proliferierender Zellen besteht in der Verwendung des Thymidin-Analogons 5-Bromo-2'-deoxy-Uridin (BrdU), welches in mitotischen Zellen im Zuge der DNA-Neusynthese eingebaut und anschließend mit Hilfe eines Antikörpers detektiert werden kann. Die Detektion erfolgte mit Hilfe des BrdU-Labeling and Detection Kits II (Roche Diagnostics GmbH) nach Hardcastle und Papalopulu, 2000.

Um Zellproliferation in Xenopus laevis Embryonen nachweisen zu können, wurden nach Erreichen des gewünschten Entwicklungsstadiums 0,5 (NF Stadium 32, Injektion in das anteriore Endoderm) bis $7 \mathrm{nl}$ (NF Stadium 18, Injektion in die sekundäre Leibeshöhle) BrdU injiziert, die Embryonen für 2,5 h kultiviert und für $1 \mathrm{~h}$ in MEMFA fixiert. Alle Embryonen wurden in $100 \%$ Ethanol überführt und bei $-20^{\circ} \mathrm{C}$ gelagert. Zur Detektion von BrdU wurden die Embryonen für jeweils $5 \mathrm{~min}$ in 100\%, 75\%, 50\% Ethanol und 25\% Ethanol/75\% 1 x PBS 
rehydriert. Es folgte ein fünfmaliges Waschen für jeweils 5 min in $1 \mathrm{x}$ PBS und eine Inkubation für $1 \mathrm{~h}$ in $2 \mathrm{~N} \mathrm{HCl}$. Die Embryonen wurden zweimal für 10 min in $1 \mathrm{x}$ PBS/0,3\% Triton-X-100 gewaschen und für $1 \mathrm{~h}$ in $1 \mathrm{x}$ PBS/3\% Pferdeserum inkubiert, um eine unspezifische Bindung des Primärantikörpers zu verhindern. Nach 30 min Äquilibrierung in Inkubationspuffer folgte die Inkubation in anti-BrdU (1:10 in Inkubationspuffer) für $3 \mathrm{~h}$ bei $37^{\circ} \mathrm{C}$. Anschließend wurde dreimal für 15 min und über Nacht in 1 x PBS gewaschen. Es folgte fünfmaliges Waschen für jeweils 5 min in $1 \times$ PBS/0,1\% Tween-20, $1 \mathrm{~h}$ Inkubation in $1 \times$ PBS/20\% Pferde-Serum und 5 $\mathrm{h}$ Inkubation in $1 \times \mathrm{PBS} / 20 \%$ Pferdeserum/anti-mouse Ig-AP (1:10). Danach wurde dreimal für 15 min und ü.N. in $1 \times$ PBS/0,1\% Tween-20 gewaschen. Am nächsten Tag wurde erneut zweimal für $5 \mathrm{~min}$ in $1 \mathrm{x} \mathrm{PBS} / 0,1 \%$ Tween-20 gewaschen und zweimal für $5 \mathrm{~min}$ in Substratpuffer äquilibriert. Die Färbung erfolgte für 30-60 $\min$ bei Raumtemperatur in Substratpuffer mit NBT $(4,3 \mu \mathrm{l} / \mathrm{ml})$ und X-Phosphat $(3,3 \mu 1 / \mathrm{ml})$. Eventuell entstandene Hintergrundfärbung wurde durch Waschen mit 100\% Methanol reduziert, die Embryonen anschließend in MEMFA fixiert und gelagert.

PBT: 1 x PBS; 2\% Boehringer Mannheim Blocking Reagenz; 0,1\% Triton-X-100; pH 7,4

Substratpuffer: $100 \mathrm{mM}$ Tris-HCl; $50 \mathrm{mM} \mathrm{MgCl}$; $100 \mathrm{mM} \mathrm{NaCl} ; 0,1 \%$ Tween-20; pH 9,5

\subsubsection{Nachweis von apoptotischen Zellen durch TUNEL-Analyse}

Während des programmierten Zelltodes (Apoptose) kommt es zur Fragmentierung von DNA, wodurch sogenannte ,nick-ends“, freie Enden von DNA-Abbruchfragmenten entstehen. In der TUNEL-Analyse

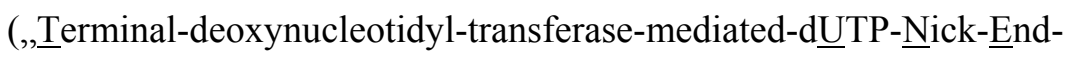
Labeling") wird an diese Enden durch die Aktivität einer Terminalen Deoxynucleotidyl Transferase (TdT) Digoxygenin-markiertes dUTP angehängt, welches durch spezifische Antikörper detektiert werden kann. Die TUNEL-Analyse in Xenopus laevis Embryonen erfolgte nach Hensey und Gautier, 1998. Dazu wurden die Embryonen für $1 \mathrm{~h}$ in MEMFA fixiert, in $100 \%$ Ethanol überführt und bei $-20^{\circ} \mathrm{C}$ gelagert. Zu Beginn der Analyse wurden die Embryonen für $5 \mathrm{~min}$ in $1 \mathrm{x}$ PBS, zweimal für $15 \mathrm{~min}$ in $1 \mathrm{x}$ PBS/0,2\% Tween-20 und zweimal für $15 \mathrm{~min}$ in $1 \mathrm{x}$ PBS gewaschen. Anschließend erfolgte eine Inkubation für $1 \mathrm{~h}$ in $1 \mathrm{x}$ TdT-Puffer (Invitrogen, in $1 \mathrm{x}$ PBS). Die Embryonen wurden in $1 \mathrm{x}$ PBS mit $1 \mathrm{x}$ TdT-Puffer, 0,5 $\mu \mathrm{M}$ Digoxygenin-dUTP und $150 \mathrm{U} / \mathrm{ml}$ TdT überführt und über Nacht bei Raumtemperatur horizontal geschüttelt. Am nächsten Tag wurde zweimal für $1 \mathrm{~h}$ in $1 \mathrm{x}$ PBS/1 mM EDTA bei $65^{\circ} \mathrm{C}$ und viermal für $1 \mathrm{~h}$ in $1 \mathrm{x}$ PBS bei Raumtemperatur inkubiert. Es folgten Inkubationen für 15 min in $1 \mathrm{x}$ PBT, für $1 \mathrm{~h}$ in $1 \mathrm{x} \mathrm{PBT} / 20 \%$ Pferdeserum und über Nacht in anti-DigoxygeninAP (1:2000) in $1 \times \mathrm{PBT} / 20 \%$ Pferdeserum bei $4^{\circ} \mathrm{C}$. Danach wurde sechsmal für $1 \mathrm{~h}$ und über Nacht in PBT gewaschen. Für die Farbreaktion wurden die Embryonen zweimal für 5 min in 
Substratpuffer inkubiert und bis zum Erreichen einer ausreichend starken Färbung in Substratpuffer mit NBT $(3,5 \mu \mathrm{l} / \mathrm{ml}$, Roche) und BCIP $(3,5 \mu \mathrm{l} / \mathrm{ml}$, Roche) gefärbt. Durch eine absteigende Methanolreihe konnte eine mögliche Hintergrundfärbung reduziert werden.

PBT: 1 x PBS; 2\% Boehringer Mannheim Blocking Reagenz; 0,1\% Triton-X-100

Substratpuffer: $100 \mathrm{mM}$ Tris- $\mathrm{HCl}(\mathrm{pH} 9,5) ; 50 \mathrm{mM} \mathrm{MgCl} \mathrm{m}_{2} ; 100 \mathrm{mM} \mathrm{NaCl} ; 0,1 \%$ Tween-20

\section{6 „Whole mount” in situ Hybridisierung}

Um die räumliche und zeitliche Expression von Genen zu analysieren, wurde die endogene mRNA von Xenopus laevis Embryonen in situ mit komplementären, Digoxigenin- oder Fluoreszein-markierten antisense-RNA Sonden (3.3.5) hybridisiert und in einer Färbereaktion detektiert. Zur Kontrolle der Spezifität wurde markierte sense-RNA eingesetzt.

\subsubsection{Rehydrieren der Embryonen}

Soweit nicht anders erwähnt, wurde bei jedem Schritt $5 \mathrm{ml}$ Lösung verwendet. Pro $5 \mathrm{ml}$ Schraubdeckelröhrchen (Schütt Labortechnik $\mathrm{GmbH}$ ) wurden nicht mehr als 30 Embryonen gleichzeitig behandelt.

\begin{tabular}{|c|c|c|c|c|}
\hline & Ethanol (\%) & Puffer (\%) & Dauer (min) & Anzahl \\
\hline 1. & Ethanol 100\% & & 5 & $1 \mathrm{x}-$ \\
\hline 2. & Ethanol 75\% & $\mathrm{dH}_{2} 025 \%$ & 5 & $1 \mathrm{x}-$ \\
\hline 3. & Ethanol 50\% & $\mathrm{dH}_{2} 050 \%$ & 5 & $1 \mathrm{x}-$ \\
\hline 4. & Ethanol 25\% & $\mathrm{PTw} 75 \%$ & 5 & $1 \mathrm{x}-$ \\
\hline 5. & & $\mathrm{PTw} 100 \%$ & 5 & $4 \mathrm{x}-$ \\
\hline
\end{tabular}

- = Wippe

\subsubsection{Proteinase-K Behandlung}

Um die Embryonen durchlässiger für die RNA-Hybridisierungssonden zu machen, wurden sie bis zu 30 min bei RT in PTw-Puffer inkubiert, dem 2,5 $\mu 1$ Proteinase-K Lösung (Merck, 20 $\mathrm{mg} / \mathrm{ml}$ ) zugesetzt worden waren (Endkonzentration $10 \mu \mathrm{g} / \mathrm{ml}$ ). Zeigten sich leichte Schäden an den Embryonen, wurde die Behandlung sofort abgebrochen. 


\subsubsection{Acetylierung und Refixierung}

Die Embryonen wurden in 0,1 M Triethanolamin ( $\mathrm{pH}$ 7,5) umgepuffert, durch zweimalige Zugabe von Acetanhydrid acetyliert und anschließend in PTw $+4 \%$ Formaldehyd (FA) refixiert.

\begin{tabular}{|c|c|c|c|c|}
\hline & Puffer & Zugabe von & Dauer (min) & Anzahl \\
\hline 1. & Triethanolamin & & 5 & $2 \mathrm{x}-$ \\
\hline 2. & Triethanolamin & $\begin{array}{c}12,5 \mu \mathrm{l} \\
\text { Acetanhydrid }\end{array}$ & 5 & $1 \mathrm{x} \sim$ \\
\hline 3. & $\begin{array}{c}12,5 \mu \mathrm{l} \\
\text { Acetanhydrid }\end{array}$ & 5 & $1 \mathrm{x} \sim$ \\
\hline 4. & PTw $100 \%$ & $5 \mathrm{x}-$ \\
\hline 5. & PTw $+4 \% \mathrm{FA}$ & & 5 & $1 \mathrm{x}-$ \\
\hline 6. & PTw $100 \%$ & & $5 \mathrm{x}-$ \\
\hline
\end{tabular}

$\sim=$ Drehrad

\subsubsection{Hybridisierung}

Der PTw-Puffer wurde bis auf ca. $1 \mathrm{ml}$ entfernt und $250 \mu \mathrm{l}$ Hybridisierungslösung hinzugegeben. Nach dem Absinken der Embryonen in die Hybridisierungslösung wurde das Puffergemisch durch $2 \mathrm{ml}$ Hybridisierungslösung ersetzt und die Röhrchen für $10 \mathrm{~min}$ bei leichtem Schwenken in der Dampfphase über einem Wasserbad $\left(68^{\circ} \mathrm{C}\right)$ inkubiert. Anschließend wurde die Hybridisierungslösung erneuert und die Embryonen für die Dauer von $6 \mathrm{~h}$ unter Schwenken in der Dampfphase prähybridisiert. Nach dem Abnehmen des Überstandes und Zugabe der RNA-Sonde (Endkonzentration je $1 \mu \mathrm{g} / \mathrm{ml}$ ) in $2 \mathrm{ml}$ Hybridisierungslösung erfolgte die Hybridisierung in der beschriebenen Dampfphase unter leichtem Schwenken über Nacht. Bei Doppelfärbungen wurden beide RNA-Sonden in der angegebenen Konzentration zugegeben.

\subsubsection{Waschen}

Um unspezifisch gebundene, einzelsträngig vorliegende Sonden-RNA zu entfernen, wurden die Embryonen unter stringenten Bedingungen gewaschen und mit $10 \mu \mathrm{g} / \mathrm{ml}$ RNase A und $10 \mathrm{U} / \mathrm{ml}$ RNase T1 verdaut. Die Sonden-RNA konnte bei $-20^{\circ} \mathrm{C}$ gelagert und mehrfach verwendet werden. 


\begin{tabular}{|c|c|c|c|c|}
\hline & Puffer & Dauer (min) & Temperatur $\left({ }^{\circ} \mathrm{C}\right)$ & Anzahl \\
\hline 1. & $\begin{array}{r}\text { Hybridisierungs- } \\
\text { Lösung }\end{array}$ & 10 & 60 & $1 \mathrm{x} \approx$ \\
\hline 2. & $2 \times \mathrm{SSC}$ & 20 & 60 & $3 \mathrm{x} \approx$ \\
\hline 3. & $\begin{array}{c}2 \times \mathrm{SSC} \text { mit } \\
\text { RNAsen }\end{array}$ & 30 & 37 & $2 \mathrm{x} \equiv$ \\
\hline 4. & $2 \times$ SSC & 10 & $\mathrm{RT}$ & $1 \mathrm{x}-$ \\
\hline 5. & $0,2 \times \mathrm{SSC}$ & 30 & 60 & $2 \mathrm{x} \approx$ \\
\hline
\end{tabular}

$\approx=$ Dampfphase über Wasserbad $\left(68^{\circ} \mathrm{C}\right)$

$\equiv=$ Brutschrank; gelegentlich von Hand schwenken

\subsubsection{Antikörper-Inkubation}

Die Hybride aus Digoxigenin- bzw. Fluoreszein-markierter Sonden-RNA und endogener mRNA konnten mit Hilfe eines Digoxigenin- bzw. Fluoreszein-spezifischen Antikörpers, an den alkalische Phosphatase gekoppelt war, nachgewiesen werden (anti-Digoxigenin/AP; antiFluoreszein/AP; Roche Diagnostics $\mathrm{GmbH}$, Mannheim). Zum Blockieren unspezifischer Bindungsstellen wurden die Embryonen vor Zugabe des Detektions-Antikörpers in 2\% Boehringer Mannheim Blocking Reagenz und 20\% hitzeinaktiviertem Pferdeserum (Biochrom $\mathrm{KG}$, Berlin) inkubiert.

\begin{tabular}{|c|c|c|c|c|}
\hline & Puffer & Dauer (min) & Temperatur $\left({ }^{\circ} \mathrm{C}\right)$ & Anzahl \\
\hline 1. & MAB & 15 & RT & $2 \mathrm{x}-$ \\
\hline 2. & $\mathrm{MAB}+2 \% \mathrm{BMB}$ & 30 & $\mathrm{RT}$ & $1 \mathrm{x}-$ \\
\hline 3. & $\begin{array}{c}\mathrm{MAB}+2 \% \mathrm{BMB} \\
+20 \% \text { Serum }\end{array}$ & 60 & $\mathrm{RT}$ & $1 \mathrm{x}-$ \\
\hline 4. & $\begin{array}{c}\mathrm{MAB}+2 \% \mathrm{BMB} \\
+20 \% \text { Serum } \\
+\mathrm{AK}(1: 5000)\end{array}$ & 240 & $\mathrm{RT}$ & $1 \mathrm{x}-$ \\
\hline
\end{tabular}




\begin{tabular}{|c|c|c|c|c|}
\hline 5. & MAB & 30 & RT & $2 \mathrm{x}-$ \\
\hline 6. & MAB & ü.N. & 4 & $1 \mathrm{x}-$ \\
\hline
\end{tabular}

\subsubsection{Farbentwicklung}

Je nach Art der gewünschten Färbung konnten die Embryonen in NBT/BCIP- oder FAST RED(Roche Diagnostics GmbH, Mannheim) Lösung inkubiert werden. Alkalische Phosphatase setzt die Substrate NBT/BCIP zu einem dunkelvioletten, FAST RED zu einem rötlichen Farbstoff um.

\subsubsection{NBT/BCIP-Färbung}

\begin{tabular}{|c|c|c|c|c|}
\hline & Puffer & Dauer (min) & Temperatur $\left({ }^{\circ} \mathrm{C}\right)$ & Anzahl \\
\hline 1. & MAB & 5 & RT & $2 \mathrm{x}-$ \\
\hline 2. & APB & 5 & 4 & $2 \mathrm{x}-$ \\
\hline 3. & APB + & 30 min -3 Tage & $4^{\circ} \mathrm{C}$ in Alufolie & $1 \mathrm{x}-$ \\
\hline
\end{tabular}

\subsubsection{FAST RED-Färbung}

\begin{tabular}{|c|c|c|c|c|}
\hline & Puffer & Dauer (min) & Temperatur $\left({ }^{\circ} \mathrm{C}\right)$ & Anzahl \\
\hline 1. & MAB & 60 & RT & $1 \mathrm{x}-$ \\
\hline 2. & $\mathrm{dH}_{2} \mathrm{O}$ & 2 & RT & $1 \mathrm{x}-$ \\
\hline 3 & $\begin{array}{c}0,1 \mathrm{M} \text { Tris-HCL } \\
\mathrm{pH} 8,2\end{array}$ & 15 & 4 & $2 x-$ \\
\hline
\end{tabular}




\begin{tabular}{|c|c|c|c|c|}
\hline 4. & $\begin{array}{c}\text { 1 Stück FAST } \\
\text { RED-Tabletten/ }\end{array}$ & 30 min-1 Tag & RT & $1 \mathrm{x}-$ \\
$2 \mathrm{ml} \mathrm{0,1} \mathrm{M} \mathrm{Tris-}$ & & & \\
\hline & HCL pH 8,2 & & & \\
\hline
\end{tabular}

\subsubsection{Abstoppen der Färbung und Auswertung}

Nach dem Erreichen der gewünschten Farbintensität wurde die Färbereaktion durch Inkubation in $100 \%$ Methanol gestoppt und eine eventuelle Hintergrundfärbung unter optischer Kontrolle reduziert. Anschließend wurden die Embryonen in einer absteigenden Methanolreihe rehydriert und in $1 \times$ MEMFA fixiert. In $1 \times$ MEMFA-Puffer konnten sie bei $4^{\circ} \mathrm{C}$ gelagert werden.

\begin{tabular}{|c|c|c|c|c|}
\hline & Lösung & Dauer (min) & Temperatur $\left({ }^{\circ} \mathrm{C}\right)$ & Anzahl \\
\hline 1. & Methanol $100 \%$ & $1-5$ & RT & $1 \mathrm{x}-$ \\
\hline 2. & Methanol $75 \%$ & 1 & RT & $1 \mathrm{x}-$ \\
\hline 3. & Methanol $50 \%$ & 1 & RT & $1 \mathrm{x}-$ \\
\hline 4. & Methanol $25 \%$ & 1 & RT & $1 \mathrm{x}-$ \\
\hline 5. & MEMFA & 15 & RT & $1 \mathrm{x}-$ \\
\hline 6. & MEMFA & ü.N. & RT & $1 \mathrm{x}-$ \\
\hline
\end{tabular}

Mit Hilfe eines Stereomikroskops (SZX12) mit Kameraaufsatz (Evolution ${ }^{\mathrm{TM} M P}$ Digital Camera) und eines Computers wurden die Ergebnisse dokumentiert. Eine nachträgliche Bearbeitung der Aufnahmen erfolgte mittels der Bildbearbeitungssoftware Photoshop 7.0 (Adobe Systems $\mathrm{GmbH})$.

\subsubsection{Doppelfärbungen}

Für Doppelfärbungen (NBT/BCIP + FAST RED) wurde zunächst die Digoxigenin-markierte RNA-Sonde der Färbung mittels anti-Digoxigenin-AP und FAST RED unterzogen. Nach Erreichen der gewünschten Intensität der Färbung wurde die Phosphatase-Aktivität des Antikörpers durch 15-30 minütige Inkubation in $1 \mathrm{x}$ MAB/100 mM EDTA bei $65^{\circ} \mathrm{C}$ im Wasserbad inaktiviert und das Protokoll ab 3.6.6 für den Fluoreszein-Antikörper und die Färbung mittels NBT/BCIP wiederholt. 
1 x PTw: 1 x PBS; 0,1\% (v/v) Tween-20; pH 7,4

Hybridisierungs-Lösung: $50 \%$ (v/v) Formamid (deionisiert); 5 x SSC; 1 mg/ml Torula-RNA; $10 \mu \mathrm{g} / \mathrm{ml}$ Heparin; 1 x Denhardt's; 0,1\% (v/v) Tween-20; 0,1\% (w/v) CHAPS; 10 mM EDTA; RNase freies $\mathrm{dH}_{2} \mathrm{O}$

RNasen: $20 \mu \mathrm{g} / \mathrm{ml}$ RNase A; $10 \mathrm{U} / \mathrm{ml}$ RNase T1

20 x SSC: $3 \mathrm{M} \mathrm{NaCl} ; 0,3 \mathrm{M}$ Na-Citrat; $\mathrm{pH}$ 7,2-7,4

5 x MAB: $500 \mathrm{mM}$ Maleinsäure; $750 \mathrm{mM} \mathrm{NaCl} ; \mathrm{pH}$ 7,5

10\% BMB: 1 x MAB wurde mit 10\% (w/v) BMB (Boehringer Mannheim Blocking Reagenz) zum Lösen erhitzt, autoklaviert und in Aliquots á $50 \mathrm{ml}$ eingefroren.

Alkaline Phosphatase Buffer (APB): $100 \mathrm{mM}$ Tris- $\mathrm{HCl}$ (pH 9,5); $50 \mathrm{mM} \mathrm{MgCl} 2 ; 100 \mathrm{mM}$ $\mathrm{NaCl} ; 0,1 \%(\mathrm{v} / \mathrm{v})$ Tween-20

Färbelösung NBT/BCIP: Pro $\mathrm{ml}$ APB wurden $3,5 \mu \mathrm{l}$ NBT $(100 \mathrm{mg} / \mathrm{ml}$ in $70 \%$ Dimethylformamid; Roche Diagnostics $\mathrm{GmbH})$ und $3,5 \mu \mathrm{l}$ BCIP $(50 \mathrm{mg} / \mathrm{ml}$ in $100 \%$ Dimethylformamid; Roche Diagnostics $\mathrm{GmbH}$ ) eingesetzt.

\subsection{Anfertigung von Gewebeschnitten}

\subsubsection{Vibratomschnitte}

Die Anfertigung von $30 \mu \mathrm{m}$ Gewebeschnitten erfolgte mit Hilfe eines Vibratoms (Leica VT1000S). Dazu wurden 1,5 $\mathrm{ml}$ Gelatine/Albumin-Einbettungsmedium in einem Wägeschälchen auf Eis mit $105 \mu 1$ 25\% Glutardialdehyd-Lösung (Sigma-Aldrich Chemie $\mathrm{GmbH}$ ) vermischt und luftblasenfrei in eine Kunststofform (Peel-A-Way ${ }^{\circledR}$, Polysciences Inc.) gegossen. Die ausgewählten Embryonen wurden für ca. $10 \mathrm{~min}$ in Einbettungsmedium äquilibriert und auf den in der Zwischenzeit verfestigten Sockel gebettet. Überschüssiges Medium wurde entfernt und der Embryo mit 1,5 ml Einbettungsmedium, vermischt mit $105 \mu 1$ $25 \%$ Glutardialdehyd-Lösung, überschichtet. War der so entstandene Block verfestigt, wurde er aus der Kunststofform herausgelöst und mit Hilfe einer Rasierklinge zurechtgeschnitten. Das Objekt wurde anschließend mit Sekundenkleber so auf einen Metallträger aufgeklebt, so dass der Embryo in der richtigen Orientierung ausgerichtet war. Der Träger wurde in das Vibratom 
eingespannt und es wurden submers in $\mathrm{dH}_{2} \mathrm{O} 30 \mu \mathrm{m}$ dicke Schnitte angefertigt, die mit Hilfe einer Kanüle auf mit Seife gespülte Objektträger überführt wurden. Nach kurzem Antrocknen wurden die Schnitte mit Moviol-Lösung eingebettet, mit einem Phasenkontrastmikroskop mit Nomarski-Optik (Axioskop) und Kameraaufsatz (DXC-950P Color Video Camera) ausgewertet, in einen Computer eingelesen und bearbeitet.

Gelatine/Albumin Einbettungsmedium: 1 x PBS; 4,88 mg/ml Gelatine; 0,3 g/ml Albumin; $0,2 \mathrm{mg} / \mathrm{ml}$ Sucrose. Die Gelatine wurde durch Erhitzen auf ca. $60^{\circ} \mathrm{C}$ gelöst, nach dem Abkühlen Albumin und Sucrose zugefügt. Die Lösung wurde aliquotiert und bei $-20^{\circ} \mathrm{C}$ gelagert.

Moviol-Lösung: 9,6 g Moviol in 19,35 ml 100\% Glycerin lösen, $1 \mathrm{~h}$ Rühren. Zugabe von $24 \mathrm{ml}$ $\mathrm{dH}_{2} \mathrm{O}, 2$ h Rühren. Zugabe von $48 \mathrm{ml} \mathrm{0,2} \mathrm{M}$ Tris- $\mathrm{HCl}(\mathrm{pH} 8.5), 10 \mathrm{~min}$ Erhitzen auf $50^{\circ} \mathrm{C}, 15$ min bei $5000 \mathrm{Upm}$ abzentrifugieren. Überstand aliquotiert bei $-20^{\circ} \mathrm{C}$ lagern.

\subsubsection{Kunststoffschnitte}

Zur Anfertigung von Kunststoffschnitten wurden die Embryos in ein Epoxidharz (Technovit 7100, Heraeus Kulzer GmbH \& Co. KG) eingebettet. Zunächst wurden die Embryos in einer aufsteigenden Ethanolreihe wie folgt dehydriert: je $5 \mathrm{~min}$ in $75 \% \mathrm{MEM} / 25 \%$ Ethanol, $50 \%$ $\mathrm{MEM} / 50 \%$ Ethanol und 25\% MEM/75\% Ethanol, zweimal in 100\% Ethanol (insgesamt $5 \mathrm{~min}$ ), einmal für $10 \mathrm{~min}$ in 100\% Ethanol. Die Präparate wurden mit dem Kunstharz infiltriert, indem sie zunächst für $5 \mathrm{~min}$, dann für $30 \mathrm{~min}$ in Präinfiltrationsmedium inkubiert wurden. Abschließend erfolgte eine Inkubation zweimal für $5 \mathrm{~min}$ und einmal für $15 \mathrm{~min}$ in Infiltrationsmedium. $1,5 \mathrm{ml}$ Einbettmedium wurden in Teflonformen vorgelegt und die äquilibrierten Embryonen auf diesem Sockel ausgerichtet. Die Embryonen wurden mit 1,5 ml Einbettmedium überschichtet und die Formen mit den Präparaten mit Parafilm luftdicht verschlossen. Die Blöcke wurden über Nacht bei $37^{\circ} \mathrm{C}$ ausgehärtet und anschließend aus den Formen gehebelt. Nach dem Trimmen mit einer Säge wurden die Präparate mit Sekundenkleber auf einen Plastik-Objektträger aufgeklebt und in ein Microtom (Leica RM2065) eingespannt. Es wurden Schnitte von $5 \mu \mathrm{m}$ Dicke angefertigt, die zur Glättung mit einer Pinzette auf einen mit $\mathrm{dH}_{2} \mathrm{O}$ beschichteten Objektträger aufgelegt wurden. Die Präparate wurden auf einer Heizplatte bei $40^{\circ} \mathrm{C}$ getrocknet. Die Einbettung erfolgte in ENTELLAN-Lösung (Merck). Die Dokumentation erfolgte wie unter 3.7.1 beschrieben.

Präinfiltrationsmedium: 50\% Technovit $7100 ; 50 \%$ Ethanol

Infiltrationsmedium: 100 mg Härter I in 10 ml Technovit 7100 lösen und sterilfiltrieren 
Einbettmedium: 1 ml Härter II in 15 ml Infiltrationsmedium

\subsubsection{Paraffinschnitte}

Die Dehydrierung der Embryonen erfolgte zweimal für 20 min in 100\% Ethanol und einmal für 20 min in $100 \%$ Xylol. Das Paraffin (PolyFin, Polysciences Inc.) wurde bei $60^{\circ} \mathrm{C}$ verflüssigt und die Embryonen in einem Heizblock zweimal für $1 \mathrm{~h}$ und anschließend über Nacht mit Flüssig-Paraffin infiltriert. Zur Einbettung wurde etwas Flüssig-Paraffin in einer Kunststofform (Peel-A-Way ${ }^{\circledR}$, Polyscience Inc.) vorgelegt, die sich auf einer eiskalten Metallplatte befand. Unmittelbar danach wurde der äquilibrierte Embryo hinzugegeben und mit Hilfe einer auf $60^{\circ} \mathrm{C}$ vorgewärmten Glasnadel, an deren Ende eine Haarschlaufe befestigt war, zügig ausgerichtet und kurz gewartet, bis der Boden des Paraffins durch die Kühlung von unten auszuhärten begann. Der Block wurde bei Raumtemperatur ausgehärtet und bei $4^{\circ} \mathrm{C}$ gelagert. Zum Schneiden wurde der Paraffinblock mit einer Rasierklinge getrimmt, durch kurzes Anschmelzen der Unterseite auf einen hölzernen Objekthalter aufgeklebt und in ein Mikrotom (Leica RM2065) eingespannt. Die Schnittserien von $5 \mu \mathrm{m}$ Dicke wurden mit Hilfe von Pinzetten auf beschichtete Objektträger (SuperFrost Plus, Menzel GmbH \& Co KG) übertragen, die mit 75\% Ethanol benetzt worden waren, und auf einer Heizplatte bei $40^{\circ} \mathrm{C}$ getrocknet. Die Paraffinschnitte wurden in Immunfärbungen (s. 3.5.3.2) eingesetzt. 



\section{Experimente und Ergebnisse}

\subsection{Die Klonierung des Eyes absent Homologs 3 aus Xenopus laevis (Xeya3)}

Bis heute sind in Vertebraten vier Homologe des Drosophila eyes absent (eya) Gens bekannt. Untersuchungen an einer Eyal ${ }^{-/}$-Mutante der Maus (Xu et al., 1999) sowie das Auftreten des Branchio-Oto- bzw. des Branchio-Oto-Renalen-Syndroms bei Menschen mit Mutationen im EYA1-Locus (Abdelhak et al., 1997) weisen diesem Mitglied der Eya-Familie essentielle Funktionen während der Entwicklung der betroffenen Organe wie z.B. Ohr und Niere zu. Bezüglich einer Beteiligung von Mitgliedern der Eya-Familie im Rahmen der Embryonalentwicklung des Vertebratenauges ist wenig bekannt, jedoch scheint ein Zusammenhang zwischen EYAl-Mutationen und dem Auftreten von angeborenen Katarakten zu bestehen (Azuma et al., 2000).

In Xenopus laevis wurden bisher zwei eyes absent Homologe, Xeyal $\alpha / \beta$ (David et al., 2001) und Xeya2 (Kriebel, 2001 (Diplomarbeit)), isoliert. Diese werden insbesondere innerhalb cranialer Plakoden stark exprimiert, im Bereich der Augenanlagen sind jedoch zu keinem Zeitpunkt der Embryonalentwicklung Transkripte nachweisbar.

Zur Klonierung weiterer eyes absent homologer cDNAs aus Xenopus laevis wurde mit Hilfe der cDNA-Sequenz des humanen eyes absent Homologs 3 (EYA3) ein Abgleich mit einer XenopusEST Datenbank durchgeführt (Xenopus EST Blast Server; http://www.sanger.ac.uk/cgibin/blast/submitblast/x tropicalis). Der Sequenzabgleich eines so erhaltenen EST-Klons (Acc.No.: AW643370) mit einer Proteinsequenzdatenbank (blastx, http://www.ncbi.nlm.nih.gov/BLAST/, Altschul et al., 1997 ) zeigte das Vorhandensein der putativen Xeya3-Translations-Initiationsstelle innerhalb der EST-Sequenz. Zum Erhalt der vollständigen Sequenz einer Xeya3-cDNA wurde eine RACE-PCR in 3'-Richtung durchgeführt (Oligonukleotid: Xeya3-3'-Race), die den vollständigen Leserahmen lieferte (s. Abb. 4.1). Durch einen Vergleich der daraus abgeleiteten, putativen Aminosäuresequenz mit bekannten Vertebraten Eya-Homologen (blastx; MegAlign, Lasergene) konnte die Zugehörigkeit der erhaltenen cDNA zur Eya3-Subklasse eindeutig bestimmt werden (s. auch Abb. 4.2, 4.3). Die proteinkodierende Region der Xeya3-cDNA wurde mittels RT-PCR aus Xenopus laevis NFStadium 36 total RNA-Präparationen amplifiziert (Oligonukleotide: Xeya3-cds-F2, Xeya3-cds$\mathrm{R})$ und in den Vektor $p G E M-T$ kloniert. Anschließend wurde der offene Leserahmen (ORF) der Xeya3-cDNA zu Überexpressionszwecken in den Vektor $p C S 2+$ subkloniert (s. 2.8.2; Oligonukleotide: Xeya3-F-Cla1, Xeya3-R-Xho1). Zur Herstellung c-myc-(MEQKLISEEDLNE) bzw. Flag-(PDYKDDDDK) Epitop tragender Xeya3-Fusionsproteine wurde der ORF der Xeya3-cDNA in $p C S 2+M T$ bzw. $p C S 2+$, nach Hinzufügen des Flag-Epitops über das rückwärtsgerichtete Oligonukleotid mittels PCR, subkloniert (s. 2.8.2; Oligonukleotide: Xeya3F-Stu1, Xeya3-R-Xho1; Xeya3-F-Cla1, Xeya3-Flag-R-Xho1). 
AS: $\quad \begin{array}{lllllllllllllllllll} & M & E & N & G & Q & D & L & A & E & Q & P & V & K & K & P & K & M & Q\end{array}$ N: ATG GAG AAC GGA CAG GAT TTA GCA GAG CAG CCG GTA AAG AAA CCC AAA ATG CAG
Pos.:
18
27
36

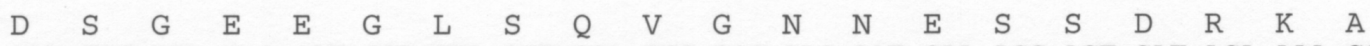

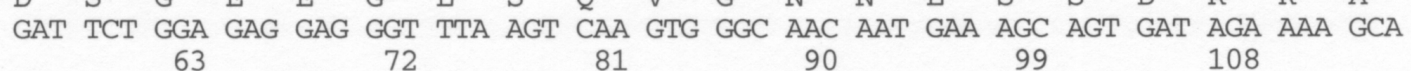

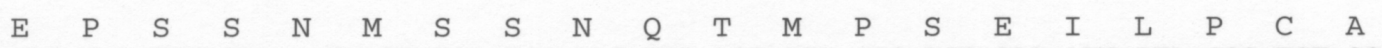
GAG CCA TCT TCA AAT ATG TCA TCA AAC CAA ACT ATG CCC AGT GAA ATT CTA CCC TGT GCC $\begin{array}{llllll}123 & 132 & 141 & 150 & 159 & 168\end{array}$

$\begin{array}{lllllllllllllllllllll}D & Y & I & L & R & A & N & D & Y & A & S & Q & I & Y & P & A & K & S & Y & T\end{array}$ GAT TAC ATT CTA CGT GCA AAT GAC TAT GCT TCA CAG ATC TAT CCT GCA AAA TCA TAT ACC 183

$192 \quad 201$ 210 219 228

$\begin{array}{lllllllllllllllllllll}\mathrm{H} & \mathrm{I} & \mathrm{L} & \mathrm{S} & \mathrm{V} & \mathrm{P} & \mathrm{V} & \mathrm{A} & \mathrm{E} & \mathrm{T} & \mathrm{V} & \mathrm{A} & \mathrm{T} & \mathrm{Y} & \mathrm{T} & \mathrm{G} & \mathrm{Q} & \mathrm{T} & \mathrm{Q} & \mathrm{Y}\end{array}$ CAC ATC CTC TCG GTA CCA GTA GCA GAA ACT GTG GCA ACA TAT ACT GGG CAA ACA CAG TAT $\begin{array}{llllll}243 & 252 & 261 & 270 & 279 & 288\end{array}$

$\begin{array}{lllllllllllllllllllll}Q & T & L & Q & P & S & Q & P & Y & T & V & Y & P & K & A & S & P & T & Y & G\end{array}$

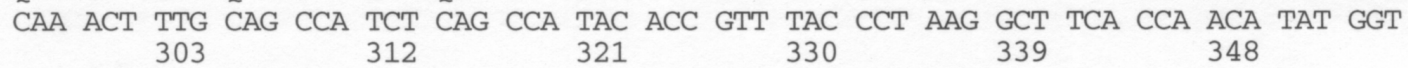

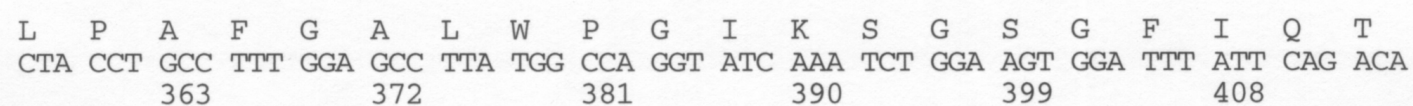
$\begin{array}{llllllllllllllllllll}P & \text { S } & \text { S } & \text { P } & \text { V } & \text { V } & \text { L } & \text { T } & \text { S } & \text { S } & \text { G } & \text { V } & \text { T } & \text { S } & \text { S } & \text { Q } & \text { V } & \text { Q } & \text { S } & \text { C } \\ \text { CCA } & \text { TCT } & \text { TCA } & \text { CCT } & \text { GTT } & \text { GTG } & \text { CTA } & \text { ACA } & \text { TCA } & \text { TCA } & \text { GGA } & \text { GTT } & \text { ACC } & \text { AGC } & \text { AGC } & \text { CAG } & \text { GTC } & \text { CAG } & \text { TCC } & \text { TGT } \\ & & 423 & & & 432 & & & 441 & & & 450 & & 459 & & 468 & \end{array}$ $\begin{array}{llllllllllllllllllll}V & S & T & H & I & L & C & K & \text { L } & \text { H } & \text { L } & \text { H } & \text { N } & \text { A } & \text { S } & \text { A } & \text { I } & \text { S } & \text { S } & \text { P }\end{array}$

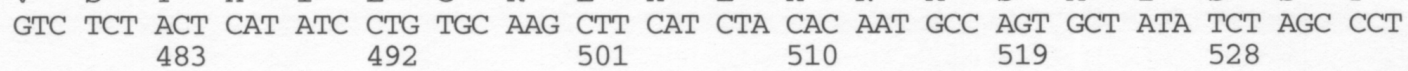
$\begin{array}{llllllllllllllllllll}T & \text { T } & \text { I } & \text { A } & \text { N } & \text { I } & \text { S } & \text { I } & \text { P } & \text { T } & \text { V } & \text { T } & \text { S } & \text { I } & \text { S } & \text { N } & \text { Q } & \text { E } & \text { Y } & \text { P } \\ \text { ACA } & \text { ACC } & \text { ATT } & \text { GCA } & \text { AAT } & \text { ATT } & \text { TCA } & \text { ATC } & \text { CCA } & \text { ACA } & \text { GTT } & \text { ACC } & \text { AGC } & \text { ATC } & \text { TCA } & \text { AAC } & \text { CAG } & \text { GAG } & \text { TAC } & \text { CCA } \\ & & 543 & & & 552 & & & 561 & & & 570 & & & 579 & & 588 & \end{array}$ $\begin{array}{lllllllllllllllllllll}T & Y & T & I & L & G & Q & N & Q & Y & P & Q & C & Y & P & N & Q & G & F & P\end{array}$

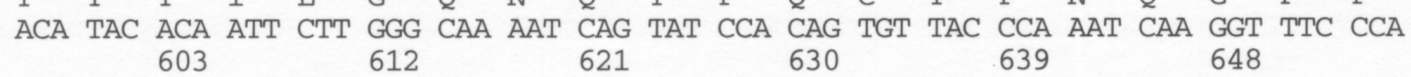
$\begin{array}{lllllllllllllllllllll}P & S & A & S & S & S & N & A & E & A & N & S & V & P & Q & S & F & A & V & D\end{array}$

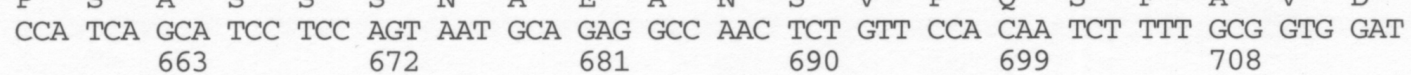
$\begin{array}{lllllllllllllllllllllllllllllllllll}K & A & E & N & T & V & P & T & Q & A & S & Q & Q & P & L & T & D & N & A & R\end{array}$ AAA GCA GAA AAC ACA GTA CCA ACA CAG GCA TCT CAG CAG CCA CTA ACT GAC AAT GCA AGA $\begin{array}{llllllllllllllllllll}A & M & G & S & K & E & T & E & E & Q & N & K & K & T & A & P & V & K & N & R\end{array}$ $\begin{array}{cccccc}\text { GCA ATG GGC AGC AAG GAG ACT GAA GAG CAA AAT AAG AAA ACT GCG CCT GTA AAG AAC AGA } \\ 783 & 792 & 801 & 810 & 819 & 828\end{array}$ $\begin{array}{llllllllllllllllllll}\text { G } & K & \text { S } & \text { K } & \text { K } & \text { A } & \text { D } & \text { A } & \text { S } & \text { S } & \text { P } & \text { Q } & \text { H } & \text { S } & \text { D } & \text { L } & \text { E } & \text { R } & \text { V } & \text { F } \\ \text { GGG } & \text { AAG } & \text { AGT } & \text { AAG } & \text { AAA } & \text { GCA } & \text { GAT } & \text { GCC } & \text { TCC } & \text { TCG } & \text { CCA } & \text { CAA } & \text { CAC } & \text { AGT } & \text { GAT } & \text { CTT } & \text { GAG } & \text { CGT } & \text { GTG } & \text { TTT }\end{array}$ 843 852 861 870 


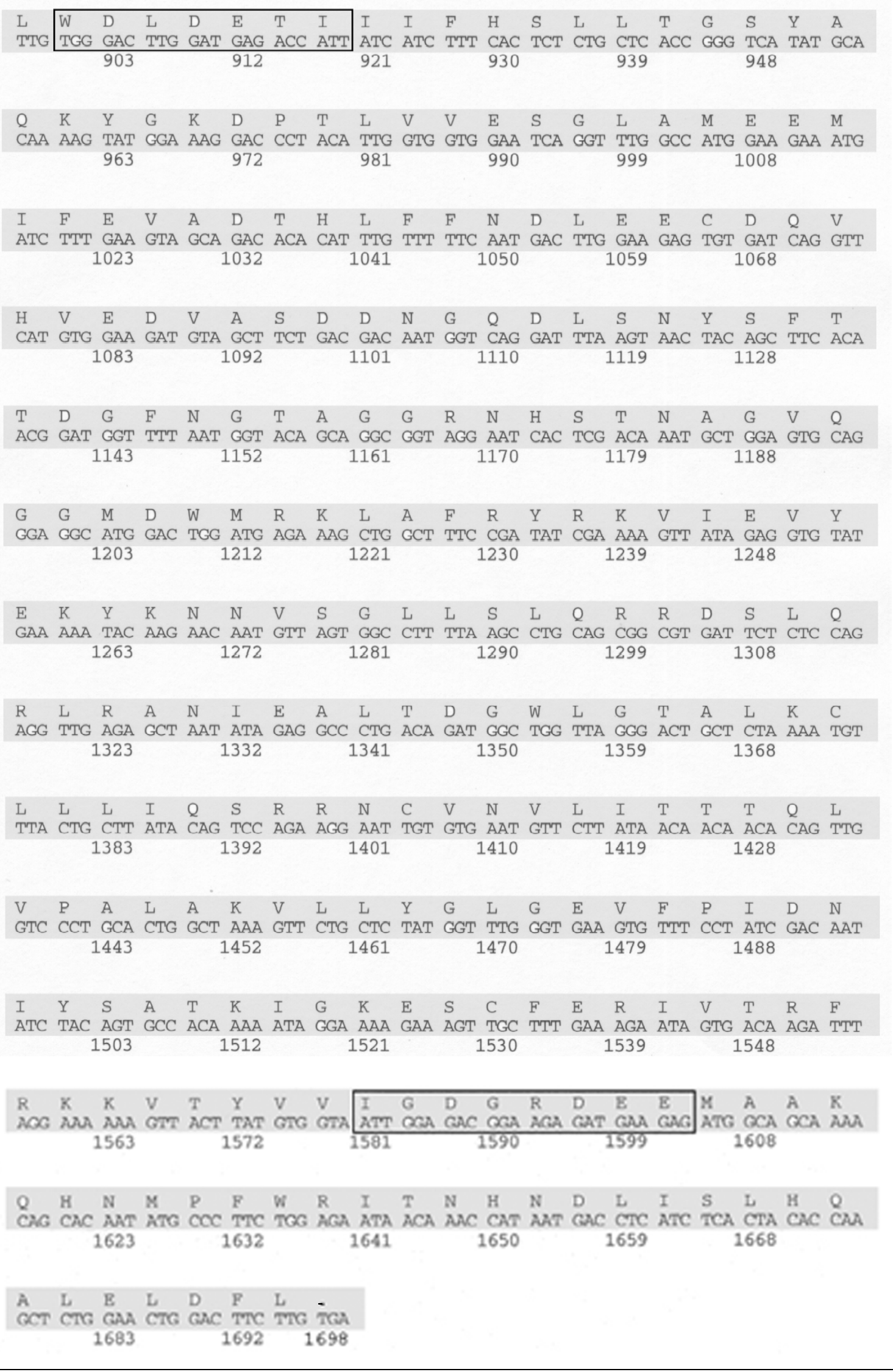

Abb. 4.1: Nukleotid- und Aminosäuresequenz des offenen Leserahmens von Xeya3. Die aus der Nukleotidsequenz (N) der Xeya3-cDNA abgeleitete Aminosäuresequenz (AS) ist jeweils oberhalb dieser dargestellt. Die Zahlen geben die Position (Pos.) des jeweils letzten Nukleotids des betreffenden Tripletts 
an, das Stopkodon ist durch einen Strich markiert. Die C-terminale Eya-Domäne ist grau hinterlegt, die beiden konservierten Motive der Phosphatase-Aktivität sind eingerahmt.

\subsection{Das Xenopus Eya-Homolog Xeya3 ist in eine C-terminale „PST“- und eine N-terminale}

\section{Eya-Domäne gegliedert}

Die Nukleotidsequenz des offenen Leserahmens des Xeya3-Gens kodiert für ein Protein einer Länge von 565 Aminosäuren mit einem rechnerischen Molekulargewicht von 62226,89 Dalton. Wie alle Mitglieder der Eya-Familie lässt sich auch Xeya3 in eine N-terminale Prolin-, Serinund Threonin reiche „PST“- (Aminosäurepositionen 1 bis 294) sowie eine C-terminal gelegene Eya-Domäne (Aminosäurepositionen 295 bis 565) untergliedern (Abb. 4.1, 4.2).

A

B
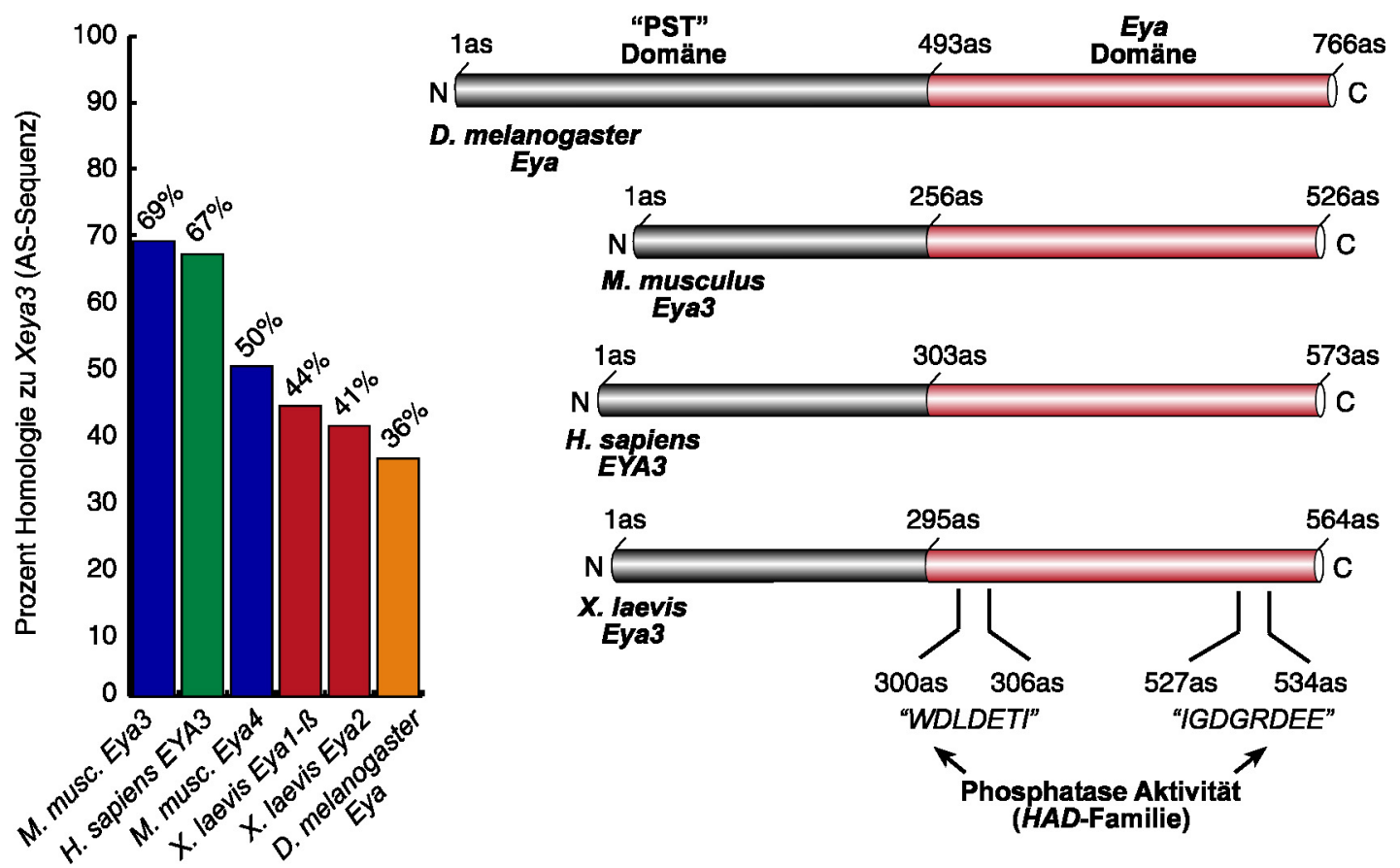

Abb. 4.2: Хeya3 als Mitglied der Eya3-Subklasse innerhalb der Eyes absent-Familie von Proteinen. (A) Höchste Sequenzverwandtschaft von Xeya3 zu Eya3-Homologen aus Maus und Mensch. Gegenüber anderen Homologen der Eyes absent Proteinfamilie besteht geringere Sequenzhomologie (Angabe in Prozent identische Aminosäuren (AS)). (B) Übersicht über Mitglieder der Eya3-Subfamilie von Proteinen sowie Eyes absent aus Drosophila melanogaster. Charakteristisch für alle Eya-Proteine ist ein variabler N-terminaler Bereich, der reich an den hydrophilen Aminosäuren Prolin, Serin und Threonin ist („PST“Domäne), sowie die hochkonservierte Eya-Domäne am C-Terminus des Proteins. Letztere beinhaltet zwei Motive des aktiven Zentrums einer Phosphohydrolase, die Eyes absent Proteinen eine Phosphatase- 
Aktivität verleihen. Abkürzungen: M. musc., Mus musculus; N, N-Teminus; C, C-Terminus; as, Aminosäureposition.

Erstere ist durch das vermehrte Vorkommen der hydrophilen Aminosäuren Prolin, Serin und Threonin (P: 9,2\%; S: 14,3\%; T: 8,2\%; $\Sigma=32 \%$ ) gekennzeichnet und ist als Bereich transaktivierender Aktivität beschrieben worden (Silver et al., 2003). Die Einteilung der Vertebraten Eya-Familie in die vier Subklassen Eyal bis Eya4 beruht zum größten Teil auf Sequenzverwandschaften/-Homologien innerhalb der „PST“-Domäne. Die C-terminale EyaDomäne findet sich mit einem hohen Grad an Konservierung der Aminosäuresequenz in allen Mitgliedern der Eya-Famile (Duncan et al., 1997). So sind etwa die Primärstrukturen der EyaDomänen des Vertebraten Xeya3 und des Drosophila Eya zu 60\% identisch, bei nur 36\% Homologie über die gesamte Aminosäuresequenz (Abb. 4.2, 4.4).

\subsection{Xeya3 besitzt eine Phosphatase-Aktivität im Bereich der Eya-Domäne}

Kürzlich wurde für das humane Eyes absent 3 eine Serin-/Thyrosin-Phosphatase-Aktivität im Bereich der Eya-Domäne beschrieben (Li et al., 2003). Eine Datenbanksuche unter Verwendung der Xeya3-Aminosäuresequenz (http://myhits.isb-sib.ch/cgi-bin/motif_scan (Falquet et al., 2002)) ergab ebenfalls eine signifikante Homologie zur Familie der Haloacid Dehalogenaseähnlichen Hydrolasen innerhalb der Eya-Domäne (Position 295-550). Diese Familie umfasst neben L-2-Haloacid Dehalogenasen und Epoxid Hydrolasen eine große Gruppe von Phosphatasen (Hisano et al., 1996). Wie für EYA3 beschrieben finden sich innerhalb der EyaDomäne von Xeya3, murinem Eya3 sowie Drosophila melanogaster Eya zwei konservierte Motive, die das Protein als Phosphatase kennzeichnen (Position 300-306, 527-534; Abb. 4.2, 4.3, 4.4). Dabei besitzt das am N-Terminus der Eya-Domäne gelegene Motiv mit der Consensus-Sequenz $\Psi$ DXDXT $\Psi$ katalytische Aktivität, das C-terminal gelegene Motiv mit der Consensus-Sequenz $\Psi \mathrm{GDGXX}(\mathrm{D} / \mathrm{E}) \mathrm{X}$ ist für die Bindung von $\mathrm{Mg}^{2+}$-Ionen im Zuge einer Dephosphorylierungs-Reaktion verantwortlich (Wang et al., 2002).

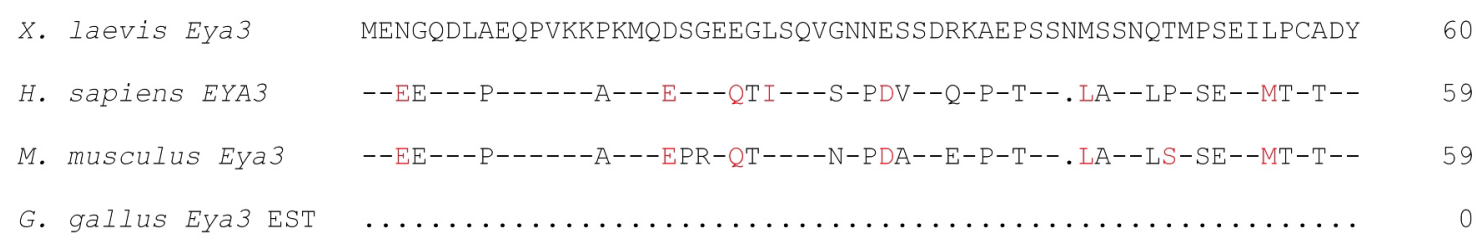



X. Iaevis Eya3
H. sapiens EYA3
M. musculus Eyaz
G. gallus Eya3 EST
X. Iaevis Eya3
H. sapiens EYA3
M. musculus Eya3
G. gallus Eya3 EST

ILRAN-DYASQIYPAKSYTHILSVPVAETVATYTGQTQYQTLQPSQPYTVYPKASPTYGL

$-\mathrm{P}-\mathrm{S} S \mathrm{SN}--\mathrm{T}--\mathrm{M}-\mathrm{S}--\mathrm{P}-\mathrm{A}-------\mathrm{S}--. \mathrm{A}-\mathrm{P}---------\mathrm{QT}---\mathrm{A}---\mathrm{Q}-\mathrm{TQ}----$

$-\mathrm{P}-\mathrm{SSN}--\mathrm{T}--\mathrm{M}-\mathrm{S}--\mathrm{P}-\mathrm{A}-------\mathrm{S}--\ldots--\mathrm{P}---------\mathrm{Q}----\mathrm{A}---\mathrm{Q}-\mathrm{T} \mathrm{Q}----$

PAFGALWPGIKSGSGFIQTPSSP. . VVLTSSGVTSSQVQSCVSTHILCKLHLHNASAISS

-P-------M-PE--L-----PSQHS---CTTGLTTSQP-PAHYSYPIQASST---L--T

. ASST---L-PT
119

PTTIANISIPTVTSISNQEYPTYTILGQNQY PQCYPNQGFPPS . ASSSNAEANSVPQS . F

X. Iaevis Eya3

AVDKAENTVPTQASQQPLT.DN

.ARAMGSKETEEQNKKTAPVKNRGKSKKADASS

288

QSE-PSVMA-AP-A-RLSSG-PSTSPSLSQTTP--D-DD-SR-NMTS-----.R----T-

249

0

G. gallus Eyaz EsT
X. Iaevis Eya3
H. sapiens EYA3
M. musculus Eya3
G. gallus Eyaz EST

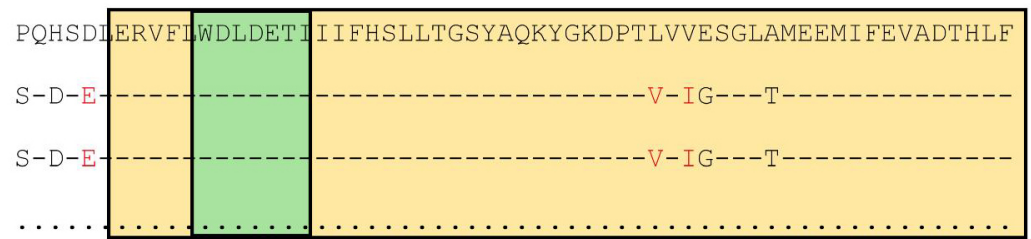

\begin{abstract}
X. Iaevis Eya3
H. sapiens EYA3

M. musculus Eya3

G. gallus Eya3 EST
\end{abstract}
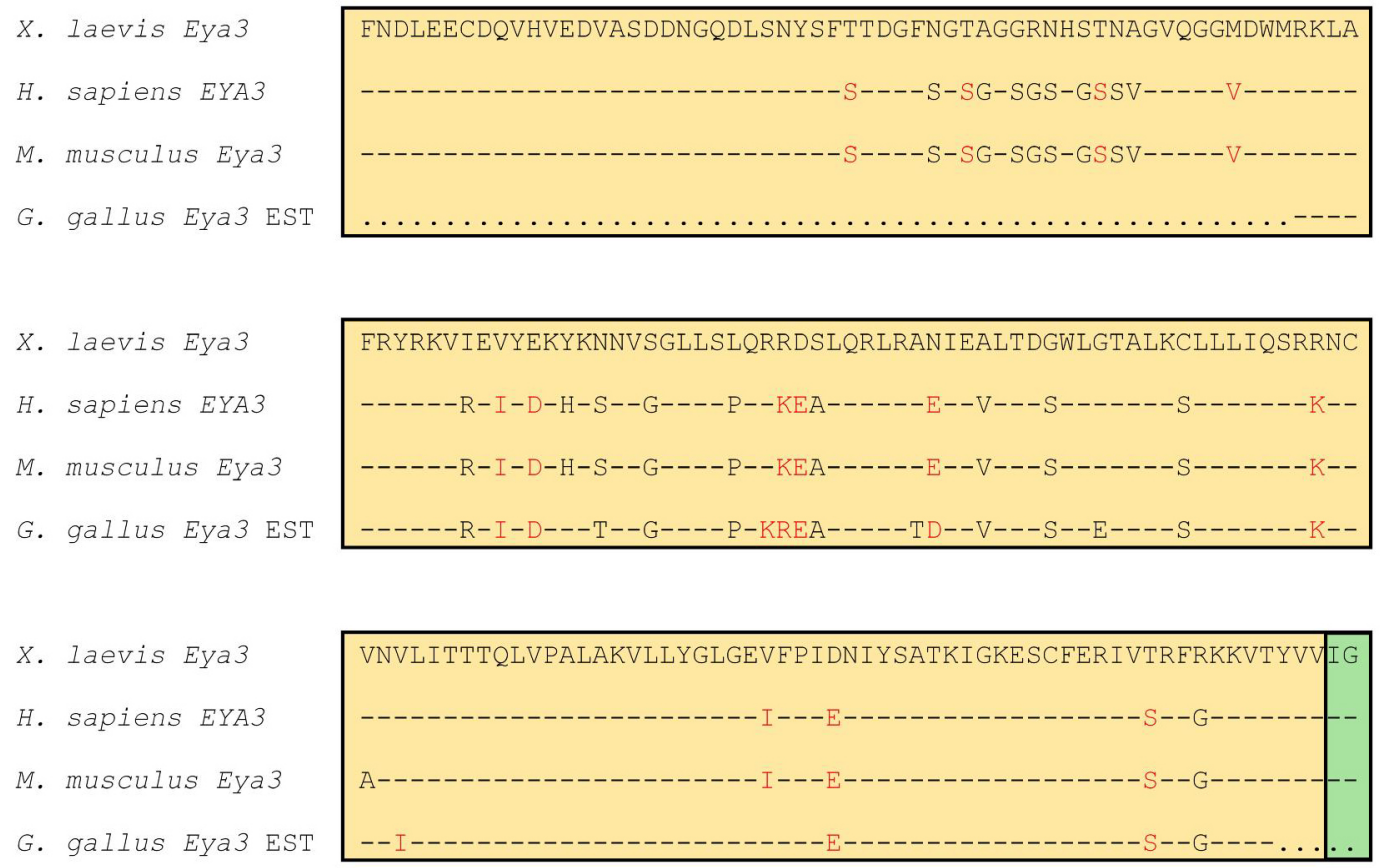
Abb. 4.3: Vergleich der Aminosäuresequenzen von Xeya3 und Eya3-Proteinen anderer

Vertebraten. Rechts sind die Positionen der Aminosäuren am Ende der jeweiligen Zeile angegeben. Identische Aminosäuren sind durch horizontale Striche, fehlende Aminosäuren durch Punkte, die Terminations-Kodons durch Sternchen markiert. Konservierte Aminosäure-Austausche sind rot hinterlegt. Als konservierte Aminosäure-Austausche gelten: A/G, V/I/L/M, F/Y, D/E/N/Q, S/T, K/R (George et al., 1990). Die zwischen den Spezies stark konservierte Eya-Domäne ist eingerahmt, der Bereich der Hydrolase gelb hinterlegt. Die für eine Phosphatase-Aktivität essentiellen Motive (Katalyse, Consensus-Sequenz: $\quad \Psi D X D X T \Psi ; \quad \mathrm{Mg}^{2+}$-Bindung, Consensus-Sequenz: $\quad$ GGDGX(D/E)X; $\Psi=$ Hydrophobe AS) sind grün eingefärbt.

\footnotetext{
X. Laevis Eya3 M...ENG........QLAEQPVKKPKMQDSGEEGLSQVGNNESSDRKAEPSSNMSSN

D. melanogaster eya MVTL-PYNYAAPRCGLIDKMI-PK--R--TDHTDTHERNRLC-LSQQQQQQQ-QQQQTHQ
} 
X. Iaevis Eya3 $\ldots \ldots \ldots$.....ARAMGSKETEEQ.......NKKTAPVKNRGKSK.......KADA 286

D. melanogaster eya GPLGNVSAAAA-A-LN-SGGSSVGTAGSGGVATS--T-TGKT-RARGRRHQRPSPTRST- 480

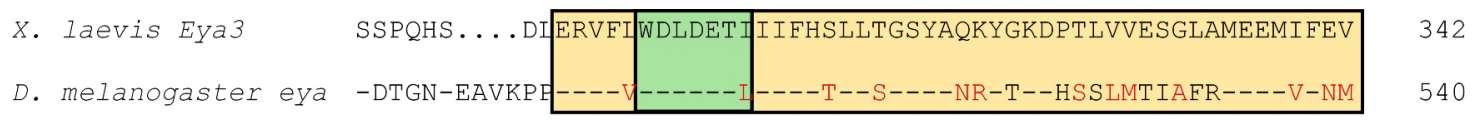

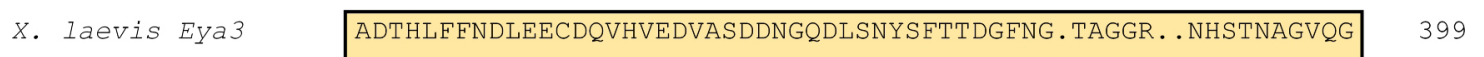

D. melanogaster eya ----F---EI-------ID--S---------A-N-A----HTN-PP-APP-LCLPT--R-

$\begin{array}{ll}\text { X. Iaevis Eya3 } & \text { GMDWMRKLAFRYRKVIEVYEKYKNNVSGLLSLQRRDSLQRLRANIEALTDGWLGTALKCL } \\ \text { D. melanogaster eya } & \\ & \end{array}$

$\begin{array}{lll}\text { X. Iaevis Eya3 } & \text { LLIQSRRNCVNVLITTTQLVPALAKVLLYGLGEVFPIDNIYSATKIGKESCFERIVTRFR } \\ \text { D. melanogaster eya } & \\ \text { SM-SQ-E------V-S---A--------F---GI-N-E-----H---H-T-Y-------G }\end{array}$

X. Iaevis Eya3

D. melanogaster eya

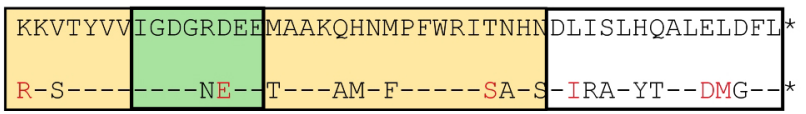

Abb. 4.4: Vergleich der Aminosäuresequenzen von Xeya3 und Eyes absent aus Drosophila melanogaster (Legende siehe Abb. 4.3).

\subsection{Xeya3 wird in anterioren neuralen Strukturen exprimiert}

Zur Darstellung der räumlichen wie zeitlichen Expression von Xeya3 wurden ,whole mount“ in situ Hybridisierungen (,WMISH“) an Xenopus laevis Embryonen verschiedener Entwicklungsstadien durchgeführt.

Xeya 3 ist bereits während der Eireifung als maternale Komponente detektierbar, wobei sich die Transkripte mit zunehmendem Reifestadium der Oozyten im animalen Pol anreichern (Abb. 4.5A, B). Diese Verteilung bleibt auch nach der Fertilisation bis in Blastula-Stadien bestehen (Abb. 4.5C). Nach Abschluss der Gastrulation und dem Beginn der Neurulation ist Xeya3Expression innerhalb der offenen Neuralplatte im Bereich prospektiver Hirnregionen sowie, weiter anterior, im Bereich des Augenfeldes sichtbar. Die Mittellinie der Neurula bleibt dabei frei von Xeya3-Transkripten (Abb. 4.5D). Gegen Ende der Neurulation in NF Stadium 20 sind die Xeya3-Expressionsdomänen innerhalb der optischen Vesikel sowie Mittel- und Hinterhirnregionen klar erkennbar. Zusätzlich finden sich zu diesem Zeitpunkt Transkripte in Zellen der ektodermalen Linsenplakode und im Areal von prämigratorischen Neuralleistenzellen (Abb. 4.5E). Im Zuge der Elongation des Embryos und fortschreitender Organentwicklung zeigen vor allem die evaginierten optischen Vesikel, die otischen Vesikel des 
sich entwickelnden auditorischen Systems, die mittlerweile nach ventral ausgewanderten Neuralleistenzellen sowie Bereiche von Vorder-, Mittel- und Hinterhirn Expression von Xeya 3 (Abb. 4.5F, F'). Der Transversalschnitt durch einen NF Stadium 27 Embryo zeigt, dass bezüglich der Genexpression innerhalb des Diencephalons nahezu ausschließlich dorsale Abschnitte betroffen sind. Zellen des sich formenden optischen Bechers transkribieren nach wie vor Xeya3 (Abb. 4.5G, G'). Im frühen Kaulquappenstadium zeigen vor allem die weiter nach ventral ausgewanderten Derivate der Neuralleistenzellen und, innerhalb der reifenden Linse, primäre Linsenfasern Xeya3-Expression. Die in früheren Entwicklungsstadien deutliche Genexpression innerhalb der prospektiven Hirnregionen ist erkennbar zurückgegangen und besteht nur noch in wenigen Bereichen. Vollständig frei von Xeya3-Transkripten ist mit Erreichen dieses Entwicklungsstadiums die neurale Retina (Abb. 4.5H, H').
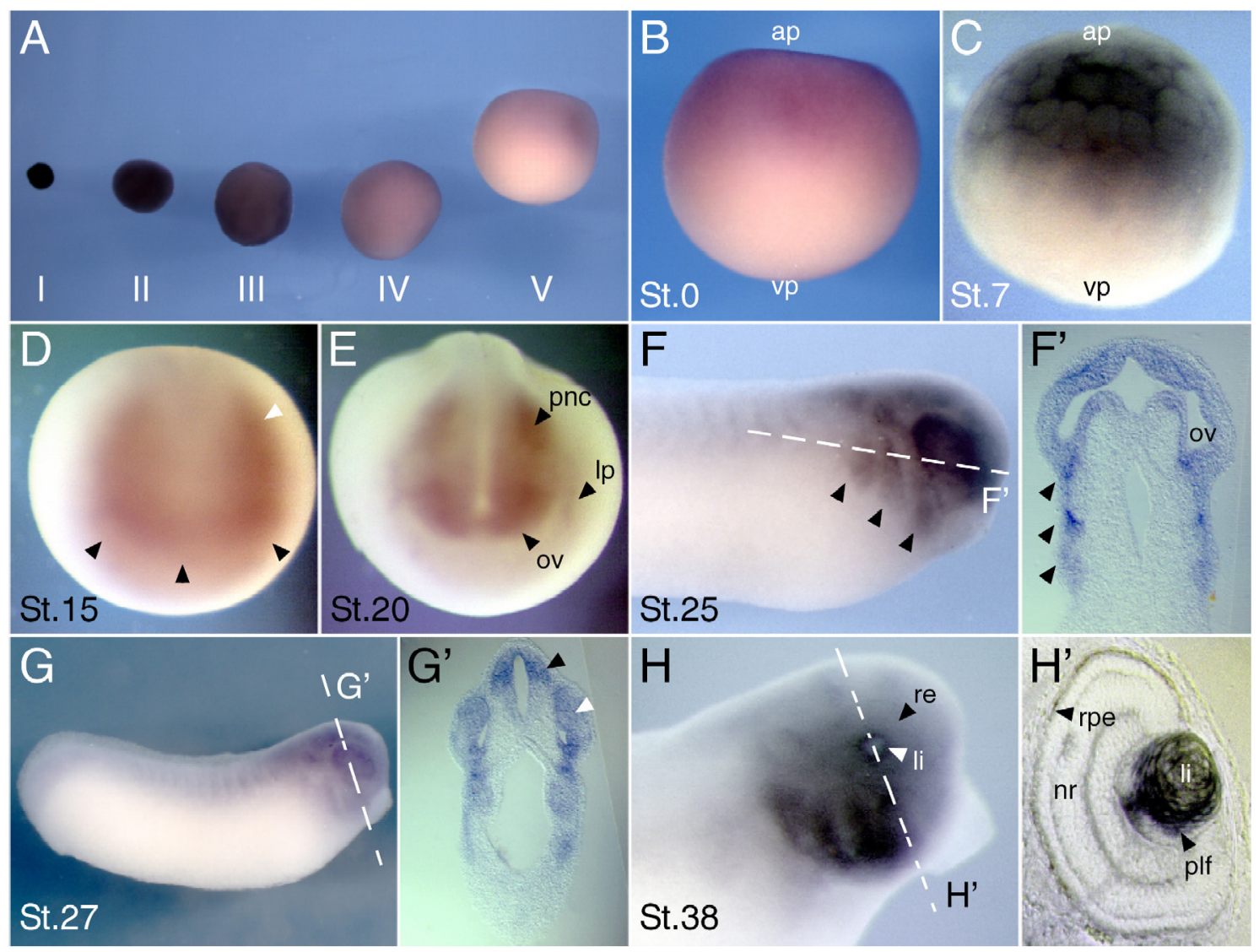

Abb. 4.5: Räumliche und zeitliche Expression von Xeya3 während der Embryonalentwicklung von Xenopus laevis. (A) Oozytenstadien I-V. (B) Reife Oozyte; ap, animaler Pol; vp, vegetaler Pol. (C) NF Stadium 7 Blastula. (D) NF Stadium 15 Neurula, frontale Ansicht; weißer Pfeil, prospektive Hirnregionen; schwarze Pfeile, vorderer Rand der Neuralplatte/Augenfeld. (E) NF Stadium 20 Neurula; lp, Linsenplakode; ov, optischer Vesikel; pnc, prämigratorische Neuralleistenzellen. (F) NF Stadium 25 Embryo, laterale Ansicht; schwarze Pfeile, migratorische Neuralleistenzellen. (F') Horizontalschnitt 
durch den Kopfbereich des Embryos aus (F) in Höhe der optischen Vesikel. (G) NF Stadium 25 Embryo, laterale Ansicht. (G') Transversalschnitt durch den Embryo aus (G) im Bereich der optischen Becher und des Diencephalons; schwarzer Pfeil, dorsales Diencephalon; weißer Pfeil, optischer Becher. (H) NF Stadium 38 Embryo (Kopfbereich, laterale Ansicht); li, Linse; re, Retina. (H') Transversalschnitt durch ein Auge des Embryos aus $(\mathrm{H})$; nr, neurale Retina; plf, primäre Linsenfasern; rpe, Retinales Pigmentepithel.

Der Vergleich der durch „WMISH“ gewonnenen Daten mit den Ergebnissen einer RT-PCR auf total RNA-Präparationen aus Xenopus laevis Embryonen verschiedener Entwicklungsstadien (Abb. 4.6A) bestätigt das Vorhandensein maternaler Transkripte von Xeya3 in NF Stadien vor Beginn der zygotischen Genexpression, der „Mid Blastula Transition“ in NF Stadium 8/9. Des Weiteren können auch durch RT-PCR Xeya3 Transkripte bis in Kaulquappenstadien nachgewiesen werden, wobei die Gesamtmenge an mRNA im Verlauf der frühen Embryonalentwicklung relativ konstant bleibt.

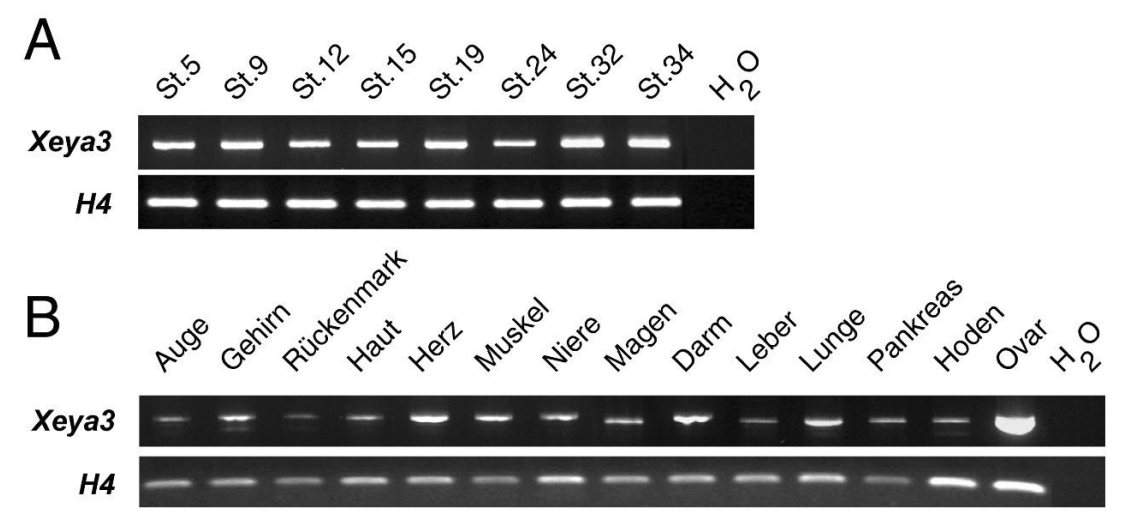

Abb. 4.6: ExpressionsNiveau von Xeya3 in Embryonalstadien und adulten Geweben von Xenopus laevis. (A) RT-PCR auf total RNA verschiedener $X$. laevis Embryonalstadien. (B) RT-PCR auf total RNA adulter Gewebe von X. laevis. Zur Kontrolle der eingesetzten Menge an RNA-Matrize wurde im Zuge der RT-PCR zusätzlich Histon 4 (H4) amplifiziert. Verwendete Oligonukleotide: Xeya3-RT-F, Xeya3-RT-R1; H4-F, H4-R.

Mit Xeya3 als maternaler Komponente zeigt sich bezüglich der Genexpression in adulten Geweben besonders innerhalb der Ovarien als Ort der Eireifung ein hohes Expressions-Niveau (Abb. 4.6B). Daneben findet in allen hier getesteten Geweben und Organen Transkription des Xeya3-Gens statt. Eine erhöhte Rate kann jedoch innerhalb des Gehirns, des Herz- und Skelettmuskels sowie des Darms und der Lunge beobachtet werden. Damit besteht ein Unterschied zum Expressionsmuster während der Embryogenese (Abb. 4.5), wo z.B. endodermale Bereiche frei von Xeya3-Expression sind. 


\subsection{Das Xeya3-Protein ist ausschließlich nukleär lokalisiert}

Zur Darstellung der subzellulären Lokalisation des Xeya3-Proteins wurden Xeya3-FlagFusionsproteine verwendet (Abb. 4.7C), welche nach Injektion der entsprechenden mRNA in eine Blastomere von Xenopus laevis Zweizell-Stadien durch „whole mount“ Immunfärbung (Abb. 4.7A, A') bzw. durch Immunfärbung an Paraffinschnitten mit Hilfe eines Flag-Epitopspezifischen Antikörpers (Abb. 4.7B, B', B', B',') nachgewiesen werden konnten.

Dabei zeigt sich, dass Xeya 3 ausschließlich nukleär lokalisiert ist. Phänotypische Effekte wie etwa eine Vergrößerung von Bereichen des zentralen Nervensystems, die durch die Überexpression des Proteins während der frühen Embryogenese hervorgerufen werden (s. Kapitel 4.9), treten zudem exakt in jenen Bereichen auf, in denen das Fusionsprotein detektiert werden kann.
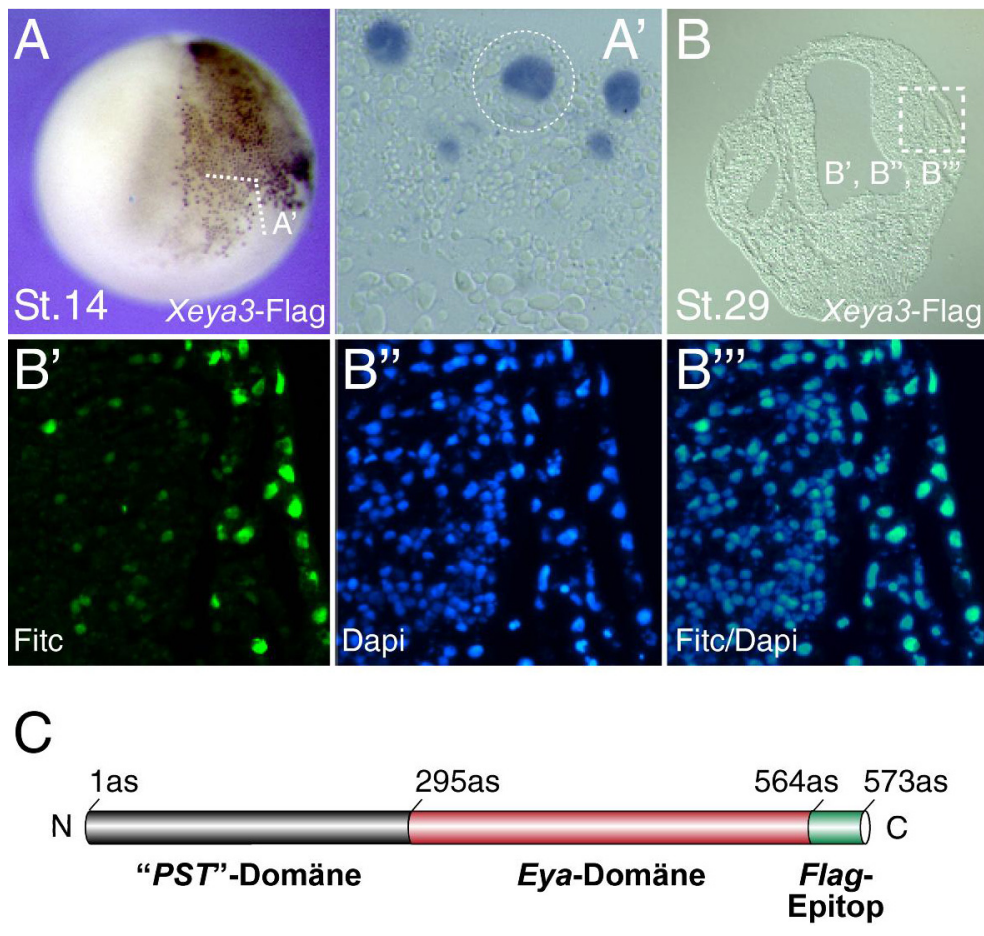
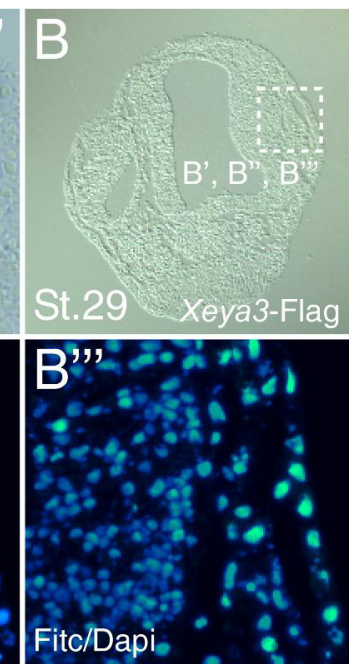

Abb. 4.7: Subzelluläre Lokalisation von Xeya3. (A) „Whole mount“ Immunfärbung an NF Stadium 14 AlbinoEmbryonen nach Mikroinjektion von 400pg Xeya3-Flag-mRNA in eine Blastomere eines Xenopus laevis Zweizell-Stadiums, frontale Ansicht.

Transversalschnitt durch den in (A) gekennzeichneten Bereich. Nur Nuklei zeigen DetektionsSignale. Der vollständige Durchmesser einer Zelle ist eingekreist.

Transversalschnitt durch einen NF Stadium 29 Embryo nach Mikroinjektion von 800pg Xeya3-FlagmRNA in eine Blastomere eines Xenopus laevis Zweizell-Stadiums. (B', B", B'”) Jeweils identischer Ausschnitt des Transversalschnittes aus (B). Nukleär lokalisiertes Protein ist innerhalb vergrößerter Vorderhirnregionen sichtbar. (C) Übersicht über das verwendete Xeya3-Flag-Fusionsprotein. Das FlagEpitop liegt C-terminal des Xeya3-ORF.

Die Lokalisation des Proteins im Zellkern ist unabhängig von in diesem Zusammenhang untersuchten Bereichen oder Geweben des Embryos, was eine Translokation des Proteins in den Nukleus unabhängig von regional vorhandenen Faktoren nahelegt. 


\subsection{Ein Xeya3-Funktionsverlust verursacht massiven Verlust anterioren neuralen Gewebes}

Eine Möglichkeit der Analyse von Protein-Funktionen in vivo bietet die Durchführung von Funktionsverluststudien. Neben dominant-negativen Formen des zu untersuchenden Faktors hat sich in Xenopus die Anwendung von Morpholino-Antisense-Oligonukleotiden (Morpholinos) als besonders effizient herausgestellt. Dabei handelt es sich um kurze OligonukleotidAnalogons, die sich durch ihre Morpholino-Gruppen von herkömmlichen Nukleotidketten unterscheiden. Als zum Bereich der Translationsinitiationsstelle komplementäre Sequenz bilden sie zusammen mit der jeweiligen mRNA ein doppelsträngiges Hybrid aus. Eine Translation der mRNA an den Ribosomen wird so sterisch blockiert, es findet keine Proteinsynthese statt.

Die Verringerung der endogenen Xeya3-Proteinkonzentration durch Injektion geringer Mengen an Xeya3-Morpholino (0,3-0,4pmol) in eine Blastomere eines Zweizell-Stadiums von Xenopus laevis führt von einer deutlichen Verkleinerung des Auges zu in schweren Fällen massivem Verlust anterioren neuralen Gewebes (Abb. 4.8A-C'). So zeigt etwa die betroffene Seite des sich entwickelnden Diencephalons einen stark hypoplastischen Phänotyp, Augenstrukturen sind bis auf Rudimente eines Retinalen Pigmentepithels nicht mehr ausgebildet (Abb. 4.8C, C'). Die nicht injizierte Seite (Kontrollseite) des Embryos entwickelt sich hingegen normal. Die beobachteten Effekte nach Injektion des Morpholinos beschränken sich dabei ausschließlich auf anteriore neurale Derivate, nach caudal bis in Bereiche des Rhombencephalons. Andere Bereiche des Embryos zeigen keinerlei phänotypische Veränderungen. Ein Vergleich der betroffenen Gewebe mit dem Expressionsmuster von Xeya3 (s. Abb. 4.5) macht deutlich, dass es sich hierbei ohne Ausnahme um solche Regionen handelt, die aus Bereichen endogener Xeya3-Expression, wie etwa aus Zellen der anterioren Neuralplatte mitsamt der Anlage der Augen, hervorgehen.

Zum weiteren Nachweis der Xeya3-Spezifität des eingesetzten Morpholinos wurde dieser in einem in vitro Translationssystem $\left(\mathrm{TnT}^{\circledR}\right.$-Coupled Reticulocyte Lysate System) getestet (Abb. 4.8D). Wie erwartet kommt es bei Einsatz des Morpholinos zu einer vollständigen Inhibition der Xeya3-Proteinsynthese. Eine an der jeweils dritten Basen-Position der MorpholinoBindungssequenz mutierte Xeya3-mRNA (Xeya3-wob, „wobbled“) wird hingegen auch in Anwesenheit des Xeya3-Morpholinos translatiert. Die hierbei etwas geringere Ausbeute an Protein lässt sich durch eine nach wie vor schwache Bindung des Morpholinos an seine nunmehr unvollständige, komplementäre Sequenz erklären.

Mit Hilfe des Xeya3-wob-Konstruktes wurden zusätzlich Rescue-Experimente mit dem Ziel durchgeführt, die durch die Injektion von Xeya3-Morpholino inhibierte Proteinsynthese endogener Xeya3-mRNA zu ersetzen und so die Ausprägung von Funktionsverlust-Phänotypen zu verhindern. Zu diesem Zweck wurden verschiedene Kombinationen von Xeya3-Morpholino und Xeya3-wob-mRNA in eine Blastomere eines Zweizell-Stadiums ko-injiziert und die 

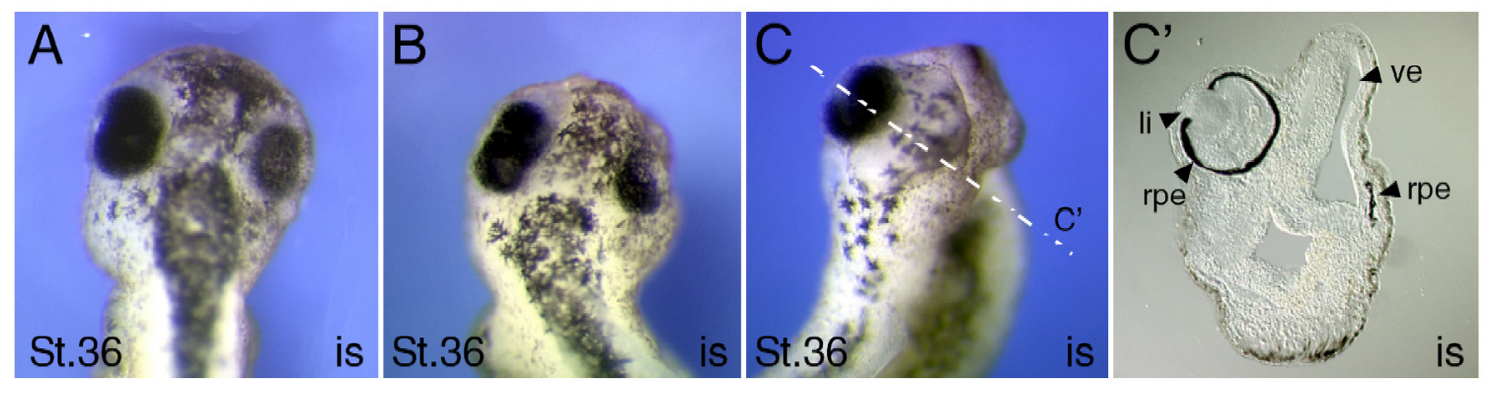

D

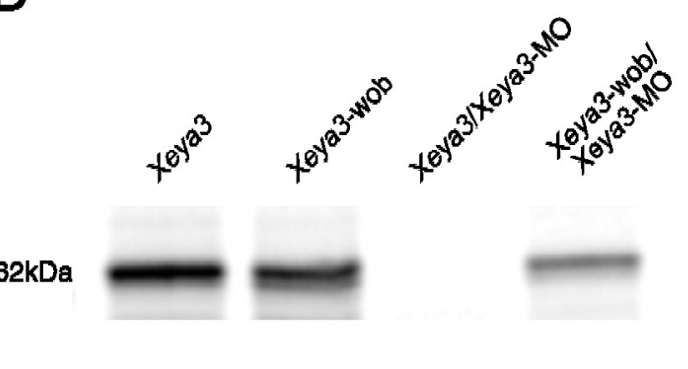

Xeya3: ATGGAGAACGGACAGGATTTAGCA

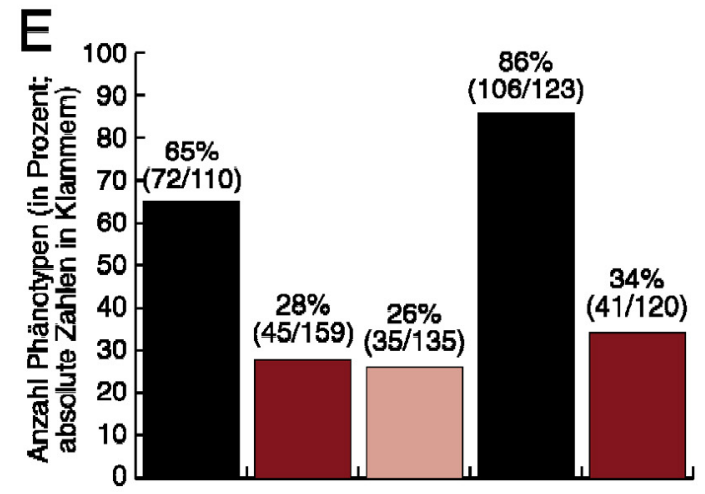
$\mathrm{M} \mathrm{E} \mathrm{N} \in \mathrm{G} \quad \mathrm{Q} \quad \mathrm{D} \quad \mathrm{L} A$ Xeya3-wob: ATGGAÄAATGGGCAÄGACTT $\stackrel{*}{*} \stackrel{*}{*}$

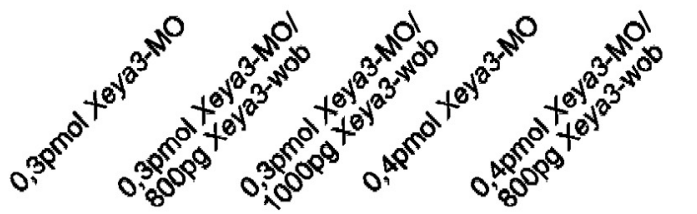

Abb. 4.8: Reduktion neuralen Gewebes durch Funktionsverlust von Xeya3. (A-C) NF Stadium 36 Xenopus laevis Embryonen nach Mikroinjektion von 0,4pmol Xeya3-Morpholino-AntisenseOligonukleotid (MO) in eine Blastomere eines Zweizell-Stadiums, dorsale Ansicht des Kopfbereiches. Die injizierte Seite (is) des Embryos befindet sich jeweils rechts. Die erhaltenen Phänotypen reichen von Reduktion (A, B) bis nahezu vollständiger Abwesenheit neuraler Strukturen wie Auge und Gehirn (C). (C') Transversalschnitt durch den in (C) gekennzeichneten Bereich, injizierte Seite rechts. Die rechte Hälfte des Diencephalons ist stark hypoplastisch, bis auf rudimentäre Reste von Retinalem Pigmentepithel sind keine Augenstrukturen ausgebildet; li, Linse; rpe, Retinales Pigmentepithel; ve, Ventrikel des Diencephalons. (D) Test auf Spezifität des eingesetzten MO. Xeya3-MO blockiert spezifisch die Translation von Xeya3-mRNA im in vitro System (TnT ${ }^{\circledR}$-Coupled Reticulocyte Lysate System), eine im Bereich der MO-Bindungssequenz mutierte Xeya3-mRNA (Xeya3-wob, Basenaustausche sind durch Sternchen markiert) wird auch in Gegenwart des MO translatiert. (E) Rescue-Experiment unter Verwendung von Xeya3-wob. Durch Ko-Injektion von Xeya3-MO und Xeya3wob-mRNA kann der Prozentsatz an Embryonen mit neuraler Hypoplasie erheblich gesenkt werden.

Ausprägung des Funktionsverlust-Phänotyps quantitativ beobachtet (Abb. 4.8E). Es zeigt sich, dass die Anzahl an Embryonen mit neuraler Hypoplasie bei Einsatz der Xeya3-wob-RNA um mehr als $50 \%$ gesenkt werden kann. Dies unterstreicht die Spezifität des eingesetzten 
Morpholinos für endogene Xeya3-mRNA, deren Funktion durch Xeya3-wob-mRNA ersetzt werden kann.

\subsection{Ein Xeya3-Funktionsverlust führt anterior zur Suppression neuraler Markergene}

Zur weiteren Charakterisierung der in Kapitel 4.6 beschriebenen Effekte auf molekularer Ebene sowie zur Klärung der Frage, zu welchem Zeitpunkt der Embryonalentwicklung die beschriebenen Phänotypen angelegt werden, wurden Xenopus laevis Albino-Embryonen nach Injektion von 0,4pmol Xeya3-Morpholino in eine Blastomere eines Zweizell-Stadiums einer „WMISH“ in Neurula- bzw. frühen Kaulquappenstadien unterzogen. Dabei wurden antisenseRNA Sonden von Genen verwendet, deren Expressionsmuster Bereiche und Gewebe endogener Xeya3-Expression und deren Derivate, wie etwa das Areal der anterioren Neuraplatte, Linsengewebe und Hirnbereiche, kennzeichnen (Abb. 4.9).

Bezüglich früher Neurula-Stadien lässt sich eine starke Reduktion der Expression aller getesteten Gene im Bereich endogener Xeya3 Expression beobachten (Abb. 4.9A-D). So fällt im Fall von Xotx2 die Repression der Expression innerhalb prospektiver Hirnregionen auf der injizierten Seite des Embryos auf, wobei die Expressionsdomäne im Bereich der Zementdrüsenanlage anterioventral der Neuralplatte von dieser Reduktion nicht betroffen ist (76\%, $\mathrm{n}=25$; Abb. 4.9A). Dabei ist zu beachten, dass letzteres Areal zu keinem Zeitpunkt der Embryonalentwicklung Teil der Expressionsdomäne von Xeya3 ist. Wie für Xotx2 kann auch bezüglich des panneural exprimierten Gens Xsox3 eine starke Herabregulation innerhalb der vorderen Neuralplatte beobachtet werden $(80 \%, n=30)$. Daneben fällt zusätzlich auf, dass Zellen des plakodalen Linsenektoderms, einer weiteren Expressionsdomäne von Xsox3, keine Xsox3Expression mehr zeigen (Abb. 4.9B). Der Trend der negativen Regulation anteriorer Expressionsdomänen neuraler Markergene setzt sich auch bei Betrachtung der im Bereich des Augenfeldes (im Areal der anterioren Neuralplatte) exprimierten Gene Xpax6 (64\%, $\mathrm{n}=25)$ und Xrxl $(40 \%, \mathrm{n}=30)$ fort. Im Fall von Xpax6 tritt zusätzlich eine deutlich schwächere Transkription innerhalb zukünftiger Hinterhirnbereiche auf (Abb. 4.9C, D).

Durch einen Funktionsverlust von Xeya3 kommt es zu massivem Verlust anterioren neuralen Gewebes wie Hirn und Retina (s. Kapitel 4.6). Xeya3 wird zusätzlich von Zellen des plakodalen Linsenektoderms transkribiert (s. Abb. 4.5E). Zum Test auf Verbleib von Linsengewebe nach Funktionsverlust von Xeya3 durch Morpholino-Injektion wurden frühe Kaulquappenstadien einer „WMISH“ mit Xpitx3-antisense-RNA-Sonden unterzogen (Abb. 4.9E, E’). Diese Embryonen zeigen eine deutliche Reduktion, in schweren Fällen den vollständigen Verlust von Xpitx3-Expression (69\%, $\mathrm{n}=26)$. Mit Blick auf den bezüglich des Linsenektoderms beschriebenen Effekt für Xsox3 legt dies nahe, dass die Entwicklung prospektiven Linsengewebes schon früh gestört ist, eine Reifung der Linsenplakode nicht mehr stattfindet. 
Die bei Xeya3-Funktionsverlust auftretende Hypoplasie anterioren neuralen Gewebes (s. Abb. 4.8C') stellt die Frage nach dem Charakter verbleibender Zellen des betroffenen Gewebes. Eine „WMISH“ an fühen Kaulquappenstadien unter Verwendung des neuralen DifferenzierungsMarkergens N-Tubulin (Abb. 4.9F, F', F'") zeigt, dass in milderen Phänotypen etwa rudimentär verbleibendes Gehirn- oder Retina-Gewebe nach wie vor ausdifferenzierte Neuronen, positiv für die Expression von N-Tubulin, beinhaltet (Abb. 4.9F"; 20/28). Im Zusammenhang mit der beobachteten Reduktion neuraler Expressionsdomänen in Neurula-Stadien ist dies ein möglicher Hinweis auf eine verringerte Anzahl an neuralen Vorläuferzellen, die im Verlauf der Entwicklung diese Organe ausbilden.
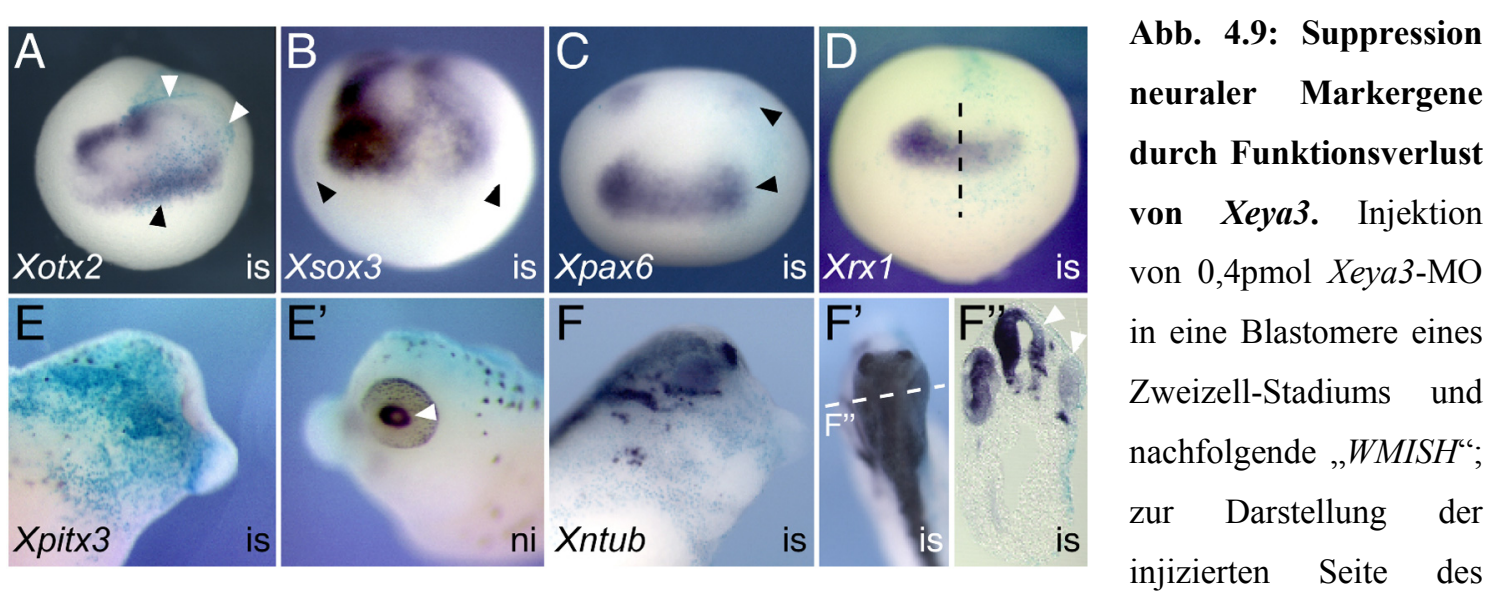

Embryos wurde synthetische mRNA für $\beta$-Galaktosidase ko-injiziert und $\beta$-Galaktosidase vor der „WMISH“ durch eine Färbereaktion nachgewiesen; A-D, NF Stadium 13/14, frontale Ansicht; E-F”, NF Stadium 36. (A) Suppression der Xotx2-Expression im Bereich prospektiver Hirnregionen (weiße Pfeile), die Expressionsdomäne innerhalb der Zementdrüsenanlage (schwarzer Pfeil) ist nicht betroffen (is, injizierte Seite). (B) Suppression der Xsox3-Expression im Bereich der anterioren Neuralplatte sowie der Linsenplakode (schwarze Pfeile). (C) Suppression der Xpax6-Expression im Augenfeld und in prospektiven Hinterhirnregionen (schwarze Pfeile). (D) Suppression des retinalen Markergens Xrxl innerhalb des Augenfeldes (gestrichelte Linie, Mittellinie des Embryos). (E, E') Abwesenheit des Linsenmarkergens Xpitx3 auf der injizierten Seite des Embryos (schwarzer Pfeil in E'; ni, nicht injizierte Seite; laterale Ansicht). (F, F', F') Starke Reduktion des neuralen Differenzierungsmarkergens $N$ Tubulin im Bereich neuraler Hypoplasie (weiße Pfeile in F'; F, laterale Ansicht; F', dorsale Ansicht; F', Transversalschnitt durch den in (F') gekennzeichneten Bereich).

\subsection{Ein Xeya3-Funktionsverlust führt zur Apoptose von neuralen Vorläuferzellen}

Als Ursache für die beobachtete neurale Hypoplasie (Abb. 4.8) sowie die Reduktion anteriorer neuraler Markergene (Abb. 4.9) kommen prinzipiell drei Möglichkeiten in Betracht. Denkbar ist zum Einen eine Transdetermination neuraler Vorläuferzellen unter dem Einfluss eines 
Funktionsverlustes von Xeya3. Da es in letzterem Fall jedoch zu einem massiven Verlust an Gewebe kommt und keine Vergrößerung von Derivaten der beiden anderen Keimblätter beobachtet werden kann, ist dies eher unwahrscheinlich. Weiter könnte eine verminderte Proliferationsrate der einzelnen neuralen Vorläuferzellen $\mathrm{zu}$ den beschriebenen Phänotypen führen. Die in Neurula-Stadien erhaltenen Hybridisierungsmuster der verwendeten molekularen Marker, wie etwa die ,ausgedünnte“ anteriore Expressionsdomäne von Xsox3, sind so allerdings nicht zu erklären. Die verminderte Ausbildung neuraler Strukturen wie Gehirn oder Auge kann drittens Folge einer erhöhten Apoptose-Rate neuraler Vorläuferzellen sein. Tatsächlich lässt sich in mit Xeya3-Morpholino injizierten Embryonen auf der Seite der Injektion eine vermehrte Anzahl apoptotischer Zellen der anterioren Neuralplatte detektieren (Abb. 4.10A, A', A'; 66\%, $\mathrm{n}=29$ ). Der Transversalschnitt (Abb. 4.10A") zeigt, dass es sich dabei ausschließlich um Zellen innerhalb der sensorischen Schicht des Neuroektoderms handelt. Als Folge der verringerten Anzahl neuraler Progenitorzellen kommt es während der weiteren Entwicklung zu einer absolut verringerten Zellproliferation als sekundärem Effekt (Abb. 4.10B-C; 44\%, n=25).
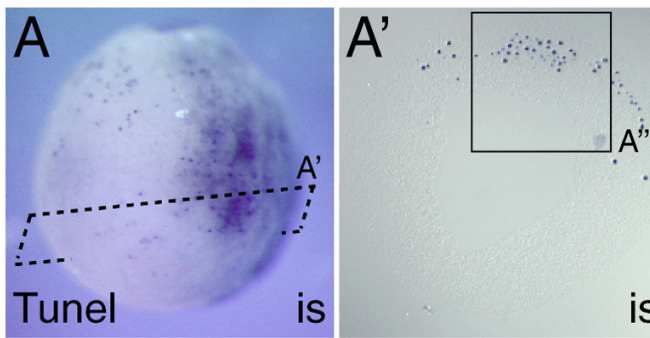

is
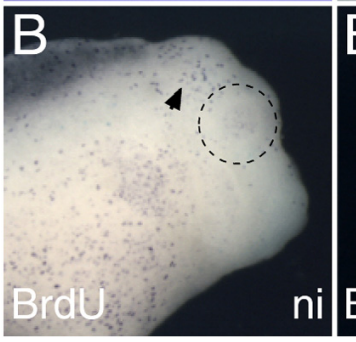
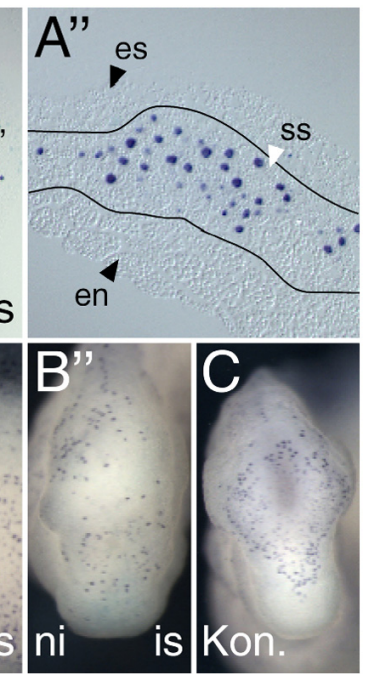

Abb. 4.10: Apoptose neuraler Vorläuferzellen nach Funktionsverlust von Xeya3. (A) TUNEL-Färbung in NF Stadium 13 nach Injektion von $0,8 \mathrm{pmol}$ Xeya3Morpholino in eine Blastomere eines ZweizellStadiums, frontale Ansicht, injizierte Seite (is) rechts. Es sind vermehrt apoptotische Zellen im Bereich der anterioren Neuralplatte detektierbar. (A', A') $5 \mu \mathrm{m}$ Transversalschnitt durch den in (A) gekennzeichneten Bereich. Apoptotische Zellen finden sich ausschließlich innerhalb der sensorischen Schicht des Neuroektoderms, welche neurale Vorläuferzellen beinhaltet; en, Endoderm; es, epitheliale Schicht des Neuroektoderms; ss, sensorische Schicht des Neuroektoderms. (B, B', B') BrdU-Färbung in NF Stadium 32 nach Injektion von 0,4pmol Xeya3-Morpholino in eine Blastomere eines Zweizell-Stadiums, laterale und frontale Ansicht. Aufgrund der verringerten Anzahl an Vorläuferzellen kommt es während der Organogenese anteriorer neuraler Gewebe in späteren Entwicklungsstadien zu absolut verringerter Zellproliferation (prospektive Hirnregionen sind durch schwarze Pfeile markiert, das Auge der nicht injizierten Seite (ni) ist eingekreist). (C) Kontrollembryo, frontale Ansicht. 


\subsection{Eine Xeya3-Überexpression führt zu Neoplasie anterioren neuralen Gewebes}

Zur Untersuchung möglicher entwicklungsrelevanter Funktionen des Xeya3-Proteins wurde dieses weiter durch Mikroinjektion von synthetischer Xeya3-mRNA in Xenopus laevis Embryonen überexprimiert und entstehende Phänotypen dokumentiert. Zum Nachweis einer erfolgreichen Translation der injizierten mRNA wurde zunächst für ein c-myc-Xeya3-

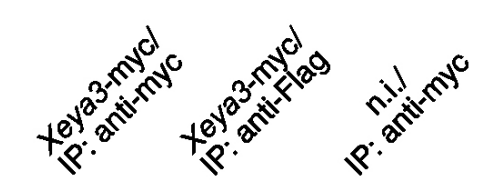
Fusionsprotein kodierende mRNA (2ng) injiziert, das gebildete Protein mittels Immunpräzipitation isoliert und durch WesternBlot detektiert (Abb. 4.11).

Die Mikroinjektion geringer Mengen (250pg; Injektion in eine dorsale Blastomere eines Vierzell-Stadiums) an synthetischer Blot: anti-myc Xeya3-mRNA führt außer zu einer geringen Vergrößerung des Auges auf der Seite der Injektion $(24 \%, n=51)$ zu keinen

Abb. 4.11: Translation von auffälligen phänotypischen Veränderungen in frühen Xeya3-myc in vivo. Kaulquappenstadien (Abb. 4.12A, A'). Bei Erhöhung der Menge an injizierter RNA (800pg; Injektion in eine dorsale Blastomere eines Vierzell- Stadiums) tritt die Vergrößerung des Auges deutlicher hervor und es kommt zusätzlich zu einer leichten Expansion neuralen Gewebes im Bereich des sich entwickelnden Gehirns sowie in einigen Fällen zu tumorösen Auswüchsen im Bereich von Derivaten der cranialen Neuralleiste (57\%, n=47; Abb. 4.12B, B', B' '). Eine weitere Steigerung der Xeya3-Proteinkonzentration (1000pg, Injektion in eine dorsale Blastomere eines 16-ZellStadiums) resultiert in einer schweren Neoplasie des Gehirns und des Auges $(100 \%, n=25)$, welches im Zuge der Neoplasie ein Kolobom, einen Defekt bezüglich des ventralen Schlusses des optischen Bechers und Nervs, ausbildet. Strukturen des Rumpfes zeigen keine Reaktion auf die Xeya3-Überexpression (Abb. 4.12C, D, D', E, E'). Der Transversalschnitt durch das betroffene Auge lässt eine abnormale Einfaltung der neuralen Retina von proximal her erkennen (Abb. 4.12D'). Dies ist möglicherweise eine Folge des Größenzuwachses des Auges innerhalb eines durch umgebendes Gewebe, wie auch des dorsal stark vergrößerten Diencephalons, begrenzten Raumes. Neben einem enormen Gewebezuwachs zeigt der Transversalschnitt in Höhe der otischen Vesikel die Bildung eines zusätzlichen, sekundären Hirn-Ventrikels innerhalb der betroffenen Gehirnhälfte (Abb. 4.12E, E'). Zellen der ventrikulären Zone des heranwachsenden Gehirns tragen durch Proliferation zur Genese neuer Neurone bei. So ist hier die Bildung eines weiteren Zentrums der Proliferation neuraler Vorläuferzellen denkbar. Das Rückenmark entwickelt sich bei Xeya3-Überexpression normal (Abb. F, F').

Der Vergleich der durch Xeya3-Überexpression induzierten Phänotypen mit dem Expressionsmuster von Xeya3 (Abb. 4.5) macht deutlich, dass es sich bei den hier betroffenen Geweben nur um solche handelt, die auch im Verlauf der Embryonalentwicklung durch eine endogene Expression von Xeya 3 gekennzeichnet sind. Ist dies bezüglich der beschriebenen 
räumlichen Auswirkungen eines Funktionsverlustes von Xeya3 (s. 4.6) zu erwarten, so muss

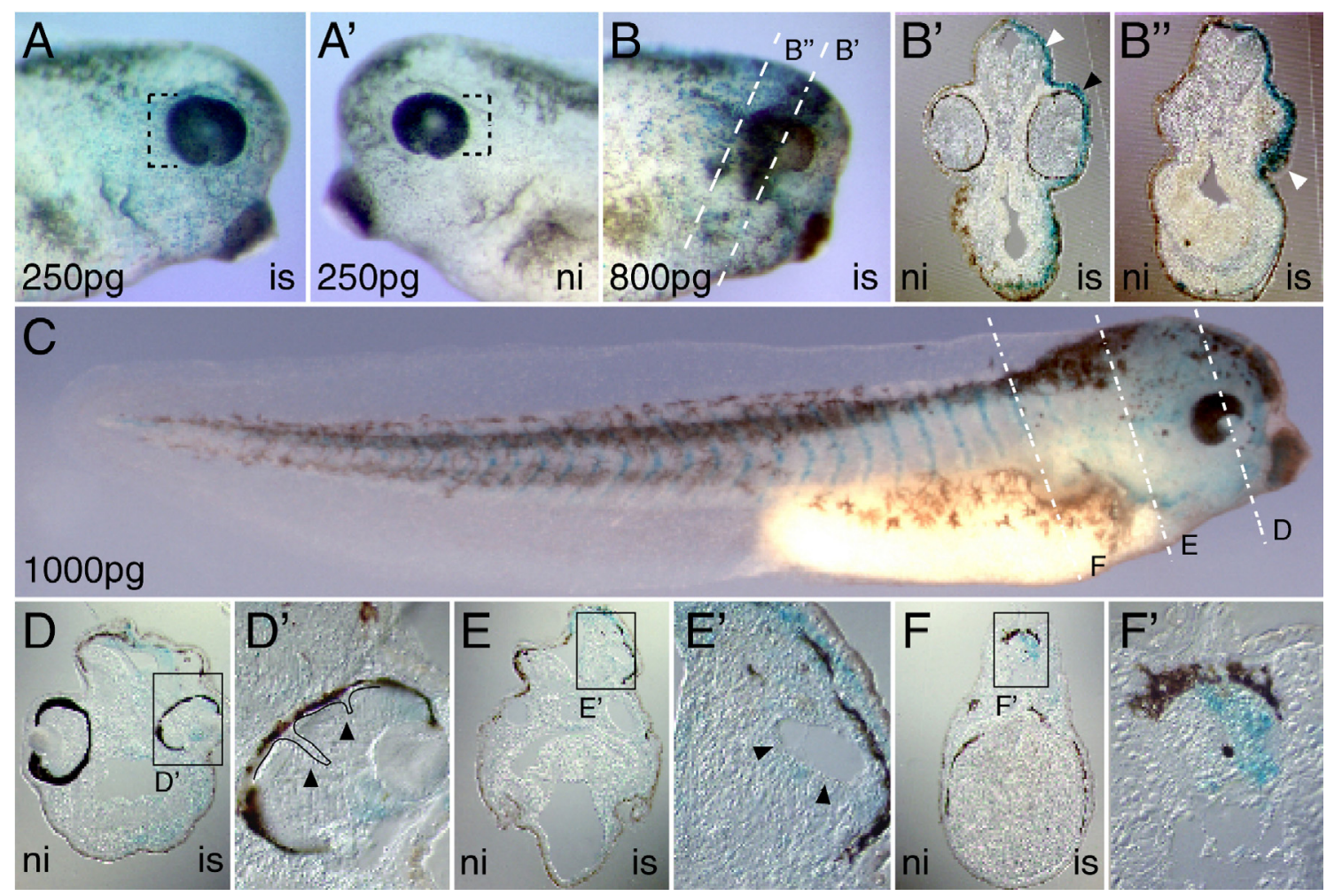

Abb. 4.12: Neoplasie anterioren neuralen Gewebes als Folge einer Überexpression von Xeya3. (A, A') NF Stadium 38 Xenopus laevis Embryo nach Mikroinjektion von 250pg Xeya3-mRNA in eine dorsale Blastomere eines Vierzell-Stadiums, laterale Ansicht. Es kommt zu einer leichten Vergrößerung des Auges auf der injizierten Seite; is, injizierte Seite; ni, nicht injizierte Seite. (B, B', B'’) NF Stadium 38 Xenopus laevis Embryo nach Mikroinjektion von 800pg Xeya3-mRNA in eine dorsale Blastomere eines Vierzell-Stadiums, laterale Ansicht und Transversalschnitte. Durch Erhöhung der injizierten mRNAMenge kommt es zu einer weiteren Vergrößerung retinaler Strukturen und zur Vergrößerung der betroffenen Hirnhälfte (B', schwarzer bzw. weißer Pfeil) sowie vereinzelt zu tumorähnlichen Auswüchsen im Bereich von Derivaten der cranialen Neuralleiste (B', weißer Pfeil). (C-F') NF Stadium 40 Xenopus laevis Embryo nach Mikroinjektion von 1000pg Xeya3-mRNA in eine dorsale Blastomere eines 16-Zell-Stadiums, laterale Ansicht und Transversalschnitte. Die so erhaltenen phänotypischen Veränderungen beschränken sich auf anteriore neurale Gewebe, die Entwicklung von Rumpfstrukturen ist nicht betroffen. (C-E') Unter dem Einfluss hoher Konzentrationen an Xeya3-Protein zeigt sich ein Defekt bezüglich des ventralen Schlusses des optischen Bechers (Kolobom), eine atypische Faltung der neuralen Retina (D', schwarze Pfeile; der Verlauf der Einfaltung im Bereich des Transversalschnittes ist durch eine schwarze Linie verdeutlicht) sowie eine starke Neoplasie von Hirngewebe (E, E'). Dabei kommt es morphologisch zur Bildung sekundärer Ventrikel (schwarze Pfeile). (F, F') Neurales Gewebe des Rückenmarks caudal des Hinterhirns zeigt keinerlei Veränderung. 
dies im Kontext der Überexpression bedeuten, dass exogen zugeführtes Xeya3-Protein nur bei Vorhandensein bestimmter, innerhalb seiner Expressionsdomäne vorliegender Faktoren agieren kann.

\subsection{Eine Xeya3-Überexpression verursacht eine Expansion der vorderen Neuralplatte}

Die temporäre wie räumliche Anlage der in Kapitel 4.9 beschriebenen Phänotypen nach Überexpression des Xeya3-Proteins wurde mit Hilfe von „WMISH“ an Xenopus laevis Embryonalstadien nach Mikroinjektion von Xeya3-mRNA weitergehend untersucht. Bezüglich früher Neurula-Stadien zeigt sich dabei, dass es zu einer Expansion von Zellschicksalen der
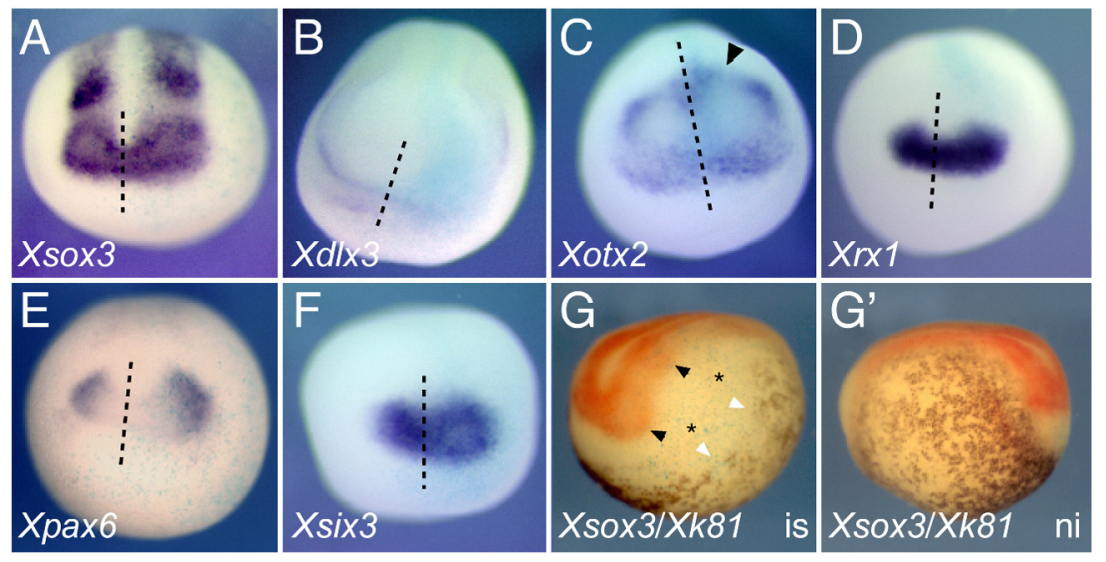

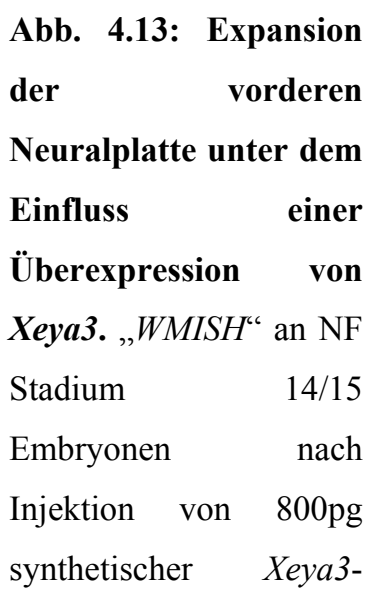

mRNA in eine Blastomere eines Zweizell-Stadiums; zur Darstellung der injizierten Seite des Embryos wurde synthetische mRNA für $\beta$-Galaktosidase ko-injiziert und $\beta$-Galaktosidase vor der „WMISH“ durch eine Färbereaktion nachgewiesen. A-F, frontale Ansicht, injizierte Seite rechts, die Mittellinie des Embryos ist durch eine gestrichelte Linie kenntlich gemacht. (A) Expansion der anterioren Expressionsdomäne des panneuralen Markergens Xsox3 nach lateral auf der injizierten Seite. (B) Verschiebung nach anteriolateral und leichte Reduktion des Expressionsbereiches von $X d l x 3$. (C) Vergrößerung des durch Xotx2 gekennzeichneten Bereiches innerhalb der Neuralplatte. Die posteriore Expressionsdomäne ist leicht nach caudal verschoben (schwarzer Pfeil). (D, E, F) Vergrößerung der Expressionsdomänen der Augenanlage von Xrxl, Храx6 und Xsix3 nach (anterio-)lateral. (G, G') Doppelfärbung von $X s o x 3$ sowie dem nicht-neuralen epidermalen Markergen $X k 81$; is, injizierte Seite; ni, nicht injizierte Seite. Neben einer Xsox3-Expansion (schwarze Pfeile) kommt es zu starker Repression von $X k 81$ (weiße Pfeile) und einer Ausdehnung der sowohl für Xsox3-als auch Xk81-Expression negativen Region (Sternchen).

anterioren Neuralplatte kommt (Abb. 4.13). So ergibt sich für das innerhalb des Bereiches der offenen Neuralplatte exprimierte panneurale Markergen Xsox3 eine Vergrößerung nach lateral $(50 \%, \mathrm{n}=20$; Abb. 4.13A). Mit dieser Beobachtung korrespondiert eine Verschiebung der Expressionsdomäne von $X d l x 3$, das von Zellen der Grenze von neuralem zu nicht-neuralem 
Ektoderm exprimiert wird, in Richtung anteriolateral. Neben dieser räumlichen Auswirkung der Xeya3-Überexpression ist zusätzlich eine leichte Repression der Xdlx3-Expression anterior zu beobachten (53\%, $\mathrm{n}=30 ; \quad$ Abb. 4.13B). Die Xotx2-Expression spart in diesem Entwicklungsstadium das durch retinale Markergene wie Xrxl definierte Augenfeld aus. Im Zusammenhang mit einer nach lateral expandierten Expressionsdomäne von Xrxl (50\%, n=30) ist auch die Expression von Xotx2 in diese Richtung verschoben (40\%, n=30; Abb. 4.13C, D). Weitere gut charakterisierte retinale Markergene wie Xpax6 $(80 \%, \mathrm{n}=15)$ und Xsix3 $(34 \%$, $\mathrm{n}=29$ ) folgen unter dem Einfluss einer Überexpression von Xeya 3 in ihrem Expressionsmuster dem Trend zur Expansion im Zusammenhang mit einer Vergrößerung vorderer Bereiche der Neuralplatte (Abb. 4.13E, F). Eine Doppelhybridisierung mit RNA-Sonden für Xsox3 sowie für das nicht-neurale, epidermale Markergen $X k 81$ (epidermales Keratin) zeigt neben der bereits beschriebenen Expansion anteriorer Expressionsbereiche von Xsox3 eine starke Repression der Xk81-Expression. Dadurch entsteht ein Bereich, der sowohl für eine Expression von Xsox3 als auch $X k 81$ negativ ist $(84 \%, \mathrm{n}=25$; Abb. 4.13G, G'). Die Identität dieses Gewebeabschnittes kann nicht eindeutiger geklärt werden. Eine Repression der Xk81-Expression tritt indes auch auf, wenn exogenes Protein durch Mikroinjektion in ventrale Bereiche des Embryos eingeführt wird. Da es nach Xeya3-Überexpression in ventralen Bereichen späterer Entwicklungsstadien zu keinen offensichtlichen morphologischen Veränderungen kommt, handelt es sich hierbei um einen transienten Effekt im Zuge der Überexpression von Xeya3.

\subsection{Zellen einer durch Xeya3-Überexpression vergrößerten Retina durchlaufen den Differenzierungsprozess}

Eine weitere „WMISH“-Analyse in späteren Entwicklungsstadien zeigt in Übereinstimmung mit den in Kapitel 4.9 beschriebenen Beobachtungen eine Expansion retinal exprimierter Gene wie Xrx1 (80\%, n=15), Xsix3 (87\%, $\mathrm{n}=15)$ und Xoptx2 (53\%, n=15) im Zuge einer durch Xeya3Überexpression induzierten moderaten retinalen Neoplasie (Abb. 4.14A-C'). Dabei kommt es im Schnitt zu um ca. 30\% vergrößertes retinales Gewebe (gestrichelte Linien in Abb. 4.14A', B', C'). In einigen Fällen, wie hier durch die Detektion endogener Xoptx2-mRNA gezeigt, nimmt das Gewebe des ansonsten konkav geformten optischen Bechers aufgrund des Größenzuwachses der prospektiven Retina eine konvexe Form an (Abb. 4.14C').

Betrachtet man die Morphologie des in Abb. 4.12D' gezeigten Auges (insbesondere die auftretenden Einfaltungen der neuralen Retina), so stellt sich die Frage nach der unter diesen Bedingungen vorliegenden Schichtung retinaler Zelltypen. Zur Klärung wurden „WMISH“ an Xeya3-injizierten Embryonen im NF Stadium 40 unter Verwendung von RNA-Sonden des photorezeptorspezifisch exprimierten Gens Xrhodopsin durchgeführt. In diesem Entwicklungsstadium hat die Genese der verschiedenen differenzierten retinalen Zelltypen bereits begonnen. In schweren Phänotypen zeigt sich dabei eine atypische Verteilung 
Xrhodopsin positiver Zellen, welche in normal entwickelten Retinae ausschließlich proximal, in nächster Nähe des Retinalen Pigmentepithels zu finden sind (Abb. 4.14D, D', D'). Diese Beobachtung kann zum Teil durch eine abnormale Faltung des optischen Bechers sowohl entlang einer proximodistalen als auch anterioposterioren Achse erklärt werden, welche dazu führt, dass als Photorezeptoren determinierte Vorläuferzellen in für sie untypischen Bereichen der neuralen Retina zu liegen kommen. In weniger starken Phänotypen, in denen keine atypische Faltung der Retina beobachtet wird, ist die Schicht der Photorezeptoren normal lokalisiert. Als Folge der retinalen Neoplasie ist sie allerdings wie auch restliches retinales Gewebe erheblich vergrößert (Abb. 4.14E-E"').
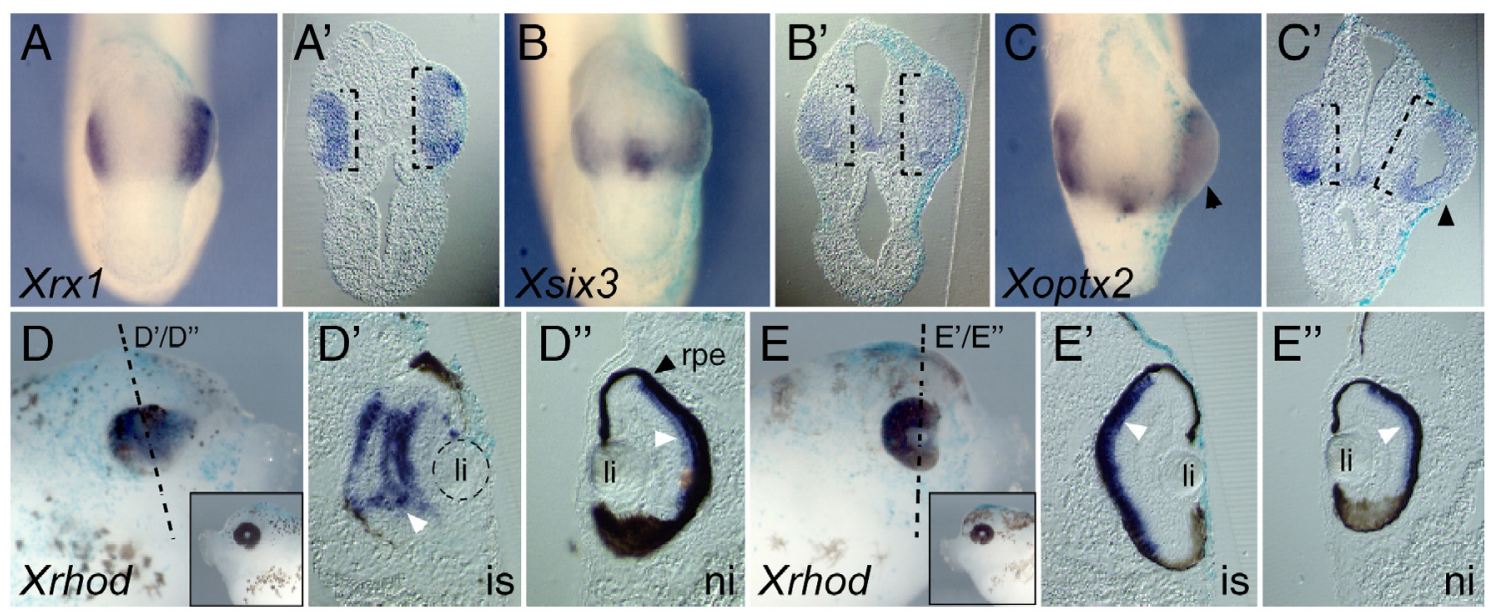

Abb. 4.14: Retinaler Größenzuwachs und atypisches retinales Differenzierungsmuster nach Überexpression von Xeya3. „WMISH“ an NF Stadium 31 (A-C'; frontale Ansicht und Transversalschnitte) bzw. NF Stadium 40 Embryonen (D-E'; laterale Ansicht und Transversalschnitte) nach Injektion von 800pg synthetischer Xeya3-mRNA sowie 100pg synthetischer mRNA für $\beta$ Galaktosidase in eine Blastomere eines Zweizell-Stadiums und anschließender Färbung gegen $\beta$ Galaktosidase. (A-C') Die induzierte Vergrößerung von Augenstrukturen führt zu einer Expansion der Expression retinaler Markergene wie Xrx1 (A, A'), Xsix3 (B, B') und Xoptx2 (C, C'). In einigen Fällen kommt es durch die bestehende retinale Neoplasie zu Defekten in der Ausbildung eines optischen Bechers (schwarze Pfeile in C, C'). (D, D', D') Schwere Phänotypen zeigen ein atypisches Differenzierungsmuster bezüglich des photorezeptorspezifisch exprimierten Gens Xrhodopsin (weiße Pfeile; is, injizierte Seite; li, Linse; ni, nicht injizierte Seite; rpe, Retinales Pigmentepithel; die nicht injizierte Seite des Embryos ist verkleinert in D dargestellt). (E, E', E') Leichterer Phänotyp mit deutlichem Größenzuwachs an retinalem Gewebe. Die korrekte räumliche Organisation von Zellen mit Xrhodopsin-Expression (weiße Pfeile) bleibt jedoch erhalten (die nicht injizierte Seite des Embryos ist verkleinert in E dargestellt). 


\subsection{Die Überexpression von Xeya3 bewirkt eine Expansion dorsaler Hirnbereiche sowie} die Ausweitung von Zentren der Neurogenese

In Kapitel 4.9 ist neben einer retinalen Neoplasie auch eine massive Vergrößerung von Hirngewebe nach Überexpression von Xeya3 beschrieben. Damit einher geht das sporadische Auftreten von sekundären Ventrikeln innerhalb vergrößerter Hirnregionen (Abb. 4.12E, E'). Die Analyse von Markergenen des zentralen Nervensystems durch „WMISH“ in Kombination mit der Anfertigung von Gewebeschnitten unterstreicht diese Beobachtung (Abb. 4.15). Zellen des expandierten Gewebes exprimieren sowohl Markergene der neuralen Zelldifferenzierung wie $N$ Tubulin (100\%, n=15; Abb. 4.15A-A"') und proneurale Gene wie XmyT1 (74\%, n=19; Abb. 4.15B, B'), als auch Faktoren, die im Zusammenhang mit der Genese von Neuronen im Bereich der ventrikulären Zone stehen, beispielsweise Xpax3 (47\%, n=17; Abb. 4.15C-D'). Wichtig dabei ist, dass sich die Größenzunahme vorwiegend auf dorsale Bereiche des Gehirns beschränkt (s. Abb. 4.15A"). Dies zeigt zum einen die deutliche Expansion der Expressionsdomäne des dorsal exprimierten Gens Xpax3 (Abb. 4.15C') als auch die Tatsache, dass es bezüglich der Expression des ventral exprimierten Xshh (sonic hedgehog) bei erheblicher Ausdehnung neuralen Gewebes zu praktisch keiner Veränderung seines Expressionsmusters in proximodistaler oder ventrodorsaler Orientierung kommt (Abb. 4.15E).

Zusätzlich ist innerhalb des Metencephalons die Bildung eines weiteren, bezüglich der Expression von $N$-Tubulin negativen Bereiches distal der $N$-Tubulin-Expressionsdomäne zu beobachten (Abb. 4.15A'"'). Innerhalb dieses Areals kann eine zweite, distal lokalisierte Domäne erhöhter Expression von XmyT1 detektiert werden (Abb. 4.15B'). So sind differenzierte Neurone, gekennzeichnet durch eine Expression von $\mathrm{N}$-Tubulin, proximal wie distal von Zellen umgeben, die den neuralen Determinierungsmarker XmyT1 exprimieren. Für den dorsalen Hirnmarker Xpax3 kann im Transversalschnitt nicht nur eine zusammenhängende Expansion der Expressionsdomäne nach distal sondern auch das Auftreten von vom ursprünglichen Expressionsbereich abgetrennten Zellgruppen beobachtet werden, in denen die Bildung eines sekundären Ventrikels stattfinden kann (Abb. C', C', D'). Berücksichtigt man die normalerweise vorwiegend ventrikulär lokalisierte Xpax3-Expression sowie die für $\mathrm{N}$ Tubulin und XmyT1 beschriebenen Phänomene, legt dies nahe, dass es unter dem Einfluss einer Xeya3-Überexpression zur Bildung weiterer Zentren der Neurogenese innerhalb vergrößerter Gehirnbereiche kommt. In extremen Fällen sind diese durch die Ausbildung sekundärer GehirnVentrikel gekennzeichnet.

Da es bezüglich der untersuchten Markergene wie Xpax3 und Xshh zu keiner Ausdehnung der Expressionsbereiche in dorsoventraler bzw. ventrodorsaler Orientierung kommt, sind Auswirkungen des Xeya3-Funktionsgewinns auf die dorsoventrale Musterbildung innerhalb des sich entwickelnden zentralen Nervensystems eher auszuschließen (Abb. C'-E). 


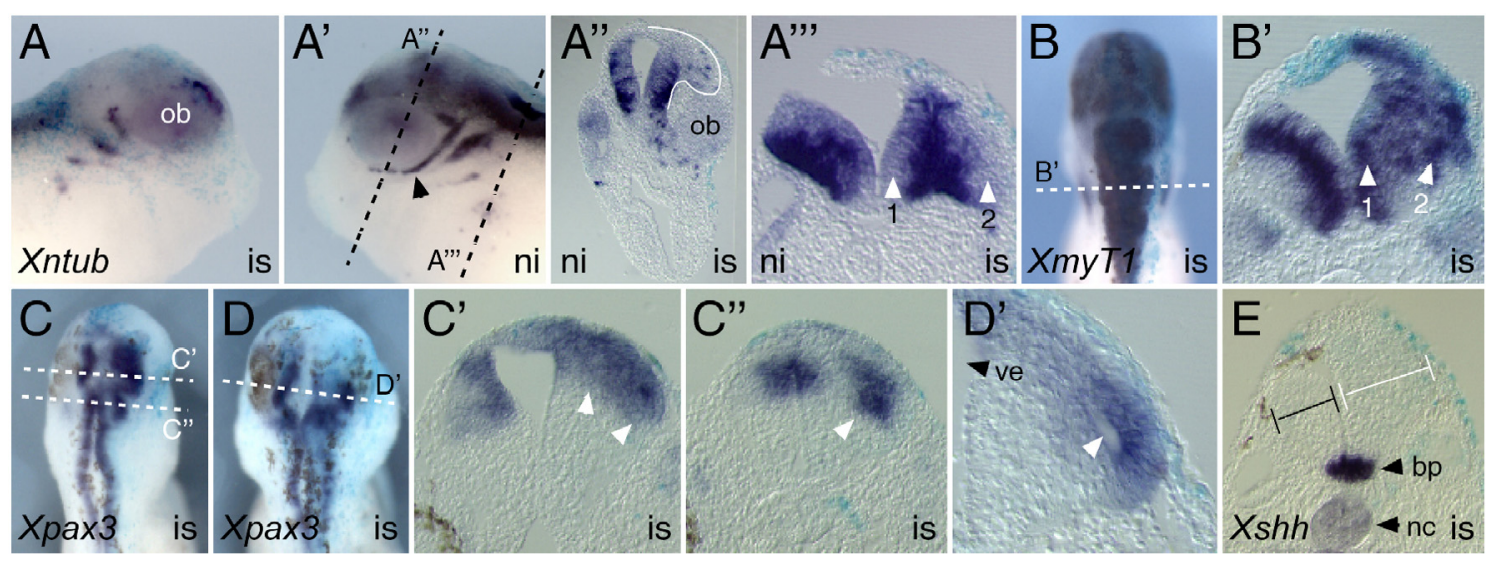

Abb. 4.15: Veränderung des Expressionsmusters von Markergenen des zentralen Nervensystems nach einer Überexpression von Xeya3. „WMISH“ an NF Stadium 30 (A-B'; laterale, dorsale Ansicht und Transversalschnitte) bzw. NF Stadium 35 Embryonen (C-E; dorsale Ansicht und Transversalschnitte) nach Injektion von 800pg synthetischer Xeya3-mRNA und 100pg synthetischer mRNA für $\beta$ Galaktosidase in eine Blastomere eines Zweizell-Stadiums und anschließender Färbung gegen $\beta$ Galaktosidase. (A-A',') Expression des neuralen Differenzierungsmarkers N-Tubulin. (A, A'; laterale Ansicht) Es kommt zu einer starken Reduktion cranialer Nerven wie dem trigeminalen Nerv (schwarzer Pfeil in A'); is, injizierte Seite; ni, nicht injizierte Seite; ob, optischer Becher. (A') Im Zuge der Expansion dorsalen Diencephalon-Gewebes (weiße Markierung in A') exprimieren vereinzelte Zellen $N$ Tubulin. (A',') In Höhe des Metencephalons entsteht durch Xeya3-Überexpression ein weiterer, bezüglich einer Expression von $N$-Tubulin negativer Bereich distal der $N$-Tubulin-Expressionsdomäne (,2“, weiße Pfeile). (B, B'; dorsale Ansicht und Transversalschnitt) Expansion der Expression von XmyT1, einem in determinierten neuralen Vorläuferzellen exprimierten Gen, in vergrößerte Metencephalonbereiche. Es besteht eine zweite Domäne erhöhter Expression in distalen Bereichen (,2“, weiße Pfeile in B'). (C-D’) Ausdehnung der Expression (C') und Bildung sekundärer, abgetrennter Expressionsdomänen (C', D') des dorsal und ventrikulär innerhalb des zentralen Nervensystems exprimierten Gens Xpax3 (weiße Pfeile). Vereinzelt auftretende sekundäre Ventrikel sind von Zellen mit Xpax3-Expression umgeben (weißer Pfeil in c'; ve, primärer Ventrikel). (E) Die ventral im Bereich der Bodenplatte (bp) lokalisierte Expressionsdomäne von Sonic hedgehog $(X s h h)$ zeigt keine Veränderung in ventrodorsaler Orientierung nach durch Überexpression von Xeya3 verursachter Vergrösserung des Hinterhirns (weißer und schwarzer Balken; nc, Notochord).

Bei Überexpression von Xeya 3 kommt es außerdem zur Reduktion cranialer Nerven als Derivate anteriorer ektodermaler Plakoden. Dies zeigt sich durch eine Repression der Expression von $N$-Tubulin (Abb. 4.15A, A') beispielsweise im Bereich des trigeminalen Nervs. In Kapitel 4.10 ist eine Reduktion des plakodalen Markergens Xdlx3 in Neurula-Stadien nach Xeya3-Überexpression beschrieben worden (Abb. 4.13B). Damit ist die Entwicklung cranialer Nerven wie des trigeminalen Nervs unter einer Xeya3-Überexpression schon zu diesem 
Zeitpunkt der Entwicklung gestört, so dass sich in frühen Schwanzknospen-Stadien der beschriebene Effekt zeigt.

\subsection{Eine Xeya3-Überexpression stimuliert die Zellproliferation innerhalb neuralen}

\section{Gewebes}

Durch Überexpression von Xeya 3 in Xenopus laevis kommt es zu massiven Vergrößerungen neuraler Derivate wie Gehirn und Retina. Da dies bis auf den beschriebenen Verlust von Strukturen wie cranialen Nerven, die sich aus plakodalem Ektoderm ableiten, ohne die Reduktion nicht neuralen Gewebes geschieht, ist eine Beteiligung von Zellproliferationseffekten naheliegend.

Tatsächlich kommt es nach Injektion synthetischer Xeya3-mRNA zu einer erheblichen Zunahme der Proliferationsrate von Zellen innerhalb des Bereiches der Neuralplatte in NF Stadium 14 Embryonen (53\%, n=30; Abbildung 4.16B). Zur detaillierteren Analyse dieser Beobachtung wurden am Beispiel zweier Embryonen des beschriebenen Phänotyps nach „Clearing“ derselben in Benzylbenzoat/Benzylalkohol (2:1) jeweils für $p H 3$ positive Zellen ausgezählt. Dabei wurden Bereiche gleicher Pixelanzahl sowohl auf der injizierten als auch auf der nicht injizierten Seite ausgewählt (Abb. 4.16A). Hierbei ergibt sich nahezu eine Verdoppelung der Zahl an mitotisch aktiven Zellen bei Vergleich der injizierten- zur nicht injizierten Seite des Embryos (95 zu 55, n=2).

In vorangegangenen Abschnitten wurde die Expansion dorsaler Hirnbereiche, die Bildung sekundärer Hirnventrikel sowie die ektopische Expression von Markergenen der ventrikulären Zone, wie etwa Xpax3, beschrieben. Durch Detektion des Mitosemarkers $p H 3$ in NF Stadium 28 Embryonen finden sich nach einer Überexpression von Xeya3 zusätzlich zum Areal der ventrikulären Zone aktiv proliferierende Zellen auch in distalen Hirnbereichen (Abb. 4.16C). Mit der ventrikulären Zone als Ort der Proliferation von neuralen Vorläuferzellen und der Genese neuraler Zelltypen unterstützt diese Beobachtung die zuvor gemachte Vermutung nach Bildung zusätzlicher Zentren der Neurogenese innerhalb anteriorer Abschnitte des zentralen Nervensystems (s. auch Kapitel 4.9, 4.12).

Die Wirkung von Xeya3 als Mitogen zeigt sich auch im „5-Bromo-2'-deoxy-Uridin (BrdU)“Assay, der die Beobachtung von Zellproliferation innerhalb eines Zeitfensters erlaubt. So ergeben sich eindeutige und vielzahlige Signale innerhalb expandierter Hirnregionen sowie im Bereich eines entstandenen sekundären Hirn-Ventrikels (Abb. 4.16D, D'). Wie mittels „TUNEL“-Assay gezeigt, kommt es als Reaktion der Zellen auf die durch Xeya3Überexpression induzierte Hyperproliferation innerhalb betroffenen Gewebes vermehrt zum programmierten Zelltod, der Apoptose (Abb. 4.16E, E'). Die Ausführung des apoptotischen Programmes dient u.a. der Elimination von Zellen, in denen durch endogene Kontrollmechanismen ein fehlerhaftes Fortschreiten des Zellzyklus angezeigt ist. Übermäßige 
Zellproliferation kann so kontrolliert und verhindert werden. Der beobachtete Anstieg der Apoptoserate nach Überexpression von Xeya3 kann somit als Folge der induzierten Hyperproliferation angesehen werden und stellt eine endogene Reaktion auf die Steigerung der Proliferationsrate dar.
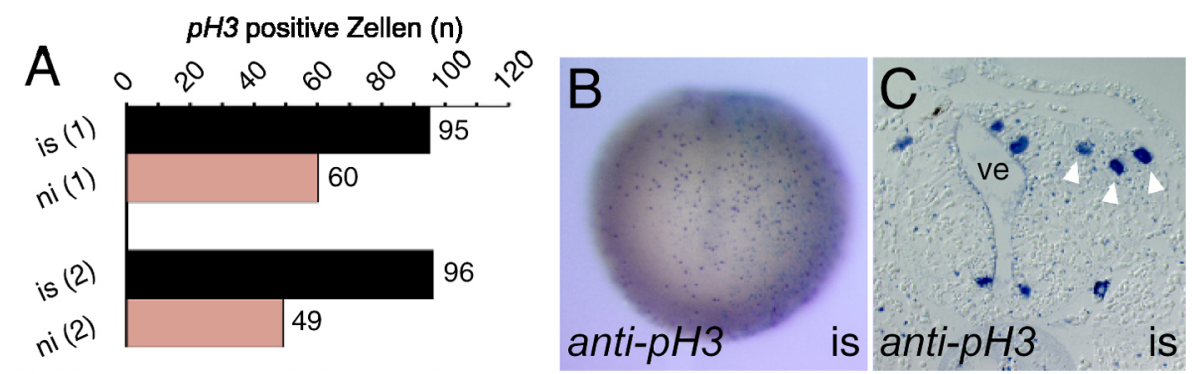

Abb. 4.16:
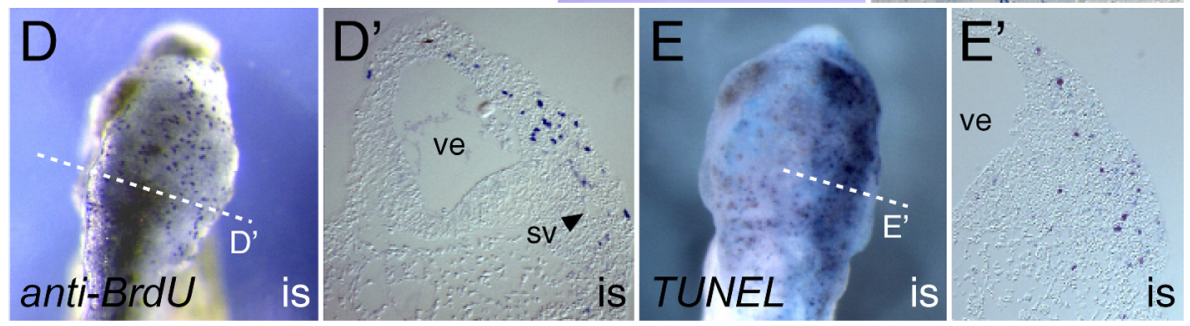

Stimulation der Zellproliferation durch Xeya3Überexpression. Detektion von phosphoryliertem Histon 3, „BrdU“bzw. „TUNEL“Assay nach Injektion von synthetischer Xeya3-mRNA und 100pg synthetischer mRNA für $\beta$-Galaktosidase in eine Blastomere eines Zweizell-Stadiums und anschließender Färbung gegen $\beta$-Galaktosidase. (A-C) Detektion von phosphoryliertem Histon 3. (A, B) Durch Überexpression von Xeya3 kommt es zu einem erheblichen Anstieg der Zellproliferationsrate in Bereichen der Neuralplatte auf der injizierten Seite des Embryos; (1), Embryo 1; (2), Embryo 2; is, injizierte Seite; ni, nicht injizierte Seite. (B) NF Stadium 14, frontale Ansicht. (C) Transversalschnitt im Bereich des Hinterhirns eines NF Stadium 28 Embryos. Es finden sich mitotische Zellen besonders in dorsodistalen Bereichen des reifenden Gehirns (weiße Pfeile; ve, Ventrikel). (D, D') Dorsale Ansicht eines NF Stadium 32 Embryos und Transversalschnitt in Höhe des Hinterhirns. Proliferierende Zellen innerhalb neoplastischer Hirnbereiche werden ebenso mittels „BrdU“Assay detektiert (sv, sekundärer Ventrikel). (E, E') Dorsale Ansicht eines NF Stadium 32 Embryos und Transversalschnitt in Höhe des Metencephalons. Als Reaktion auf hyperproliferierendes Gewebe kommt es zur Induktion von Apoptose.

Eine Behandlung von mit synthetischer Xeya3-mRNA injizierten Embyronen mit den Mitoseinhibitoren Hydroxyurea und Aphidicolin („HUA“) in Gastrulastadien führt des Weiteren zu weitaus geringeren Effekten bezüglich einer Expansion des panneuralen Markergens Xsox3 (Abb. 4.17), wie es für einen durch vermehrte Zellproliferation ausgelösten Phänotyp zu erwarten ist. $\mathrm{Zu}$ beobachten ist jedoch nach wie vor eine Reduktion plakodaler Expression (Abb. 4.17A; s. auch Abb. 4.13B (Xdlx3)), welche somit das Ergebnis einer aktiven Repression seitens des Xeya3-Proteins darstellt. 


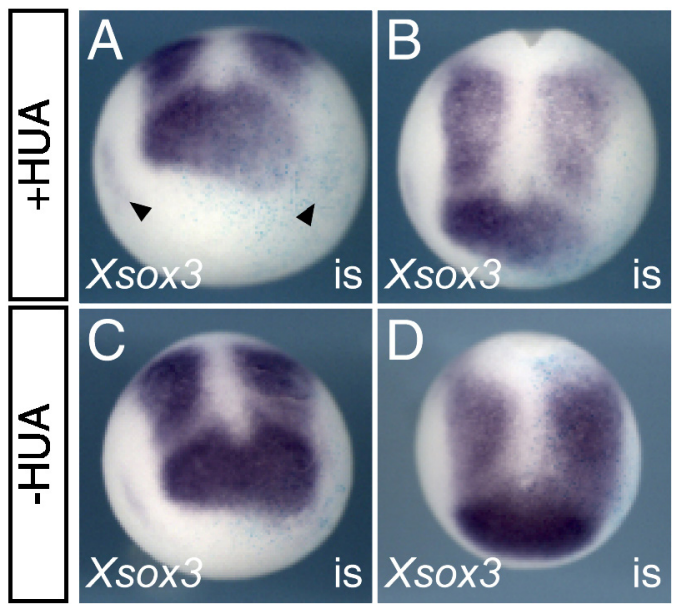

Abb. 4.17: Repression der durch Хeya3Überexpression induzierten Phänotypen durch „HUA“-Behandlung. „WMISH“ an NF Stadium 14 Embryonen nach Injektion von 800pg synthetischer Xeya3-mRNA und 100pg synthetischer mRNA für $\beta$ Galaktosidase in eine Blastomere eines ZweizellStadiums, „HUA“-Behandlung in NF Stadium 9,5 und anschließender Färbung gegen $\beta$-Galaktosidase; (A, C) frontale Ansicht; (B, D), anteriodorsale Ansicht. Durch „HUA“-Behandlung kommt es zur Repression der Expansion der Xsox3-Expressionsdomäne nach anterior wie lateral. Die Reduktion plakodaler Expression bleibt jedoch erhalten (schwarze Pfeile in (A); is, injizierte Seite).

\subsection{Ein Verlust der Phosphatase-Aktivität von Xeya3 führt zu einer gesteigerten Aktivität} des Xeya3-Proteins

In Zellkulturexperimenten konnte gezeigt werden, dass die intrinsische Phosphatase-Aktivität des Eya3-Proteins der Maus unerlässlich für dessen korrekte Funktion innerhalb eines multimeren Komplexes von Transkriptionsfaktoren ist (Li et al., 2003). Zur Untersuchung einer möglichen Funktion der Phosphatase-Aktivität des Eya3-Proteins aus Xenopus laevis in vivo wurden im Bereich des katalytischen Motivs der Phosphohydrolase-Domäne Punktmutationen eingeführt, welche zu einem Verlust der Phosphatase-Aktivität führen (Li et al., 2003; Abb. 4.18A). Die korrespondierenden synthetischen mRNAs für Xeya3-mut1, Xeya3-mut2 und Xeya3-mut3 wurden im Vergleich mit synthetischer mRNA für Xeya3 durch Mikroinjektion in Xenopus laevis Embryonen auf ihre Phänotyp-induzierende Wirkung hin getestet (Abb. 4.18BD'). Dabei zeigt sich, dass ein Verlust der Xeya3-Phosphatase-Aktivität zu einer quantitativen (Abb. 4.18B) wie auch qualitativen (Abb. 4.18C-D') Steigerung der Phänotyp-auslösenden Aktivität des Xeya3-Proteins führt. So ist die Anzahl an Embryonen, welche einen für Xeya3 typischen Phänotyp (Vergrößerung des Auges, leicht ausgeprägtes Kolobom, Neoplasie in Bereichen des Gehirns; s. auch Kapitel 4.9) ausprägen, nach Injektion der für Phosphatasedefiziente Proteine kodierenden, synthetischen mRNAs im Durchschnitt um den Faktor vier erhöht. Die qualitative Steigerung der Phänotyp-induzierenden Aktivität äußert sich am Beispiel von 400pg injizierter synthetischer mRNA in einer massiven Neoplasie und daraus folgender Einfaltung der neuralen Retina, was weiter zur Bildung multipler Linsen führt (Abb. 4.18C, C'). Bei diesen Mengen an injizierter synthetischer mRNA kommt es im Falle von Wildtyp-Xeya3 zu allenfalls leicht vergrößerten Augenstrukturen, derart schwere Fehlbildungen, wie für Xeya3mut1 beschrieben, konnten zu keinem Zeitpunkt beobachtet werden (Abb. 4.18D, D').

Dies zeigt, dass die intrinsische Phosphatase-Aktivität des Xeya3-Proteins im Zusammenhang mit einer Induktion der beschriebenen Funktionsgewinn-Phänotypen erlässlich ist und es im 
Gegenteil zu einer Verstärkung der durch Funktionen des Proteins ausgelösten neoplastischen phänotypischen Äußerungen kommt.

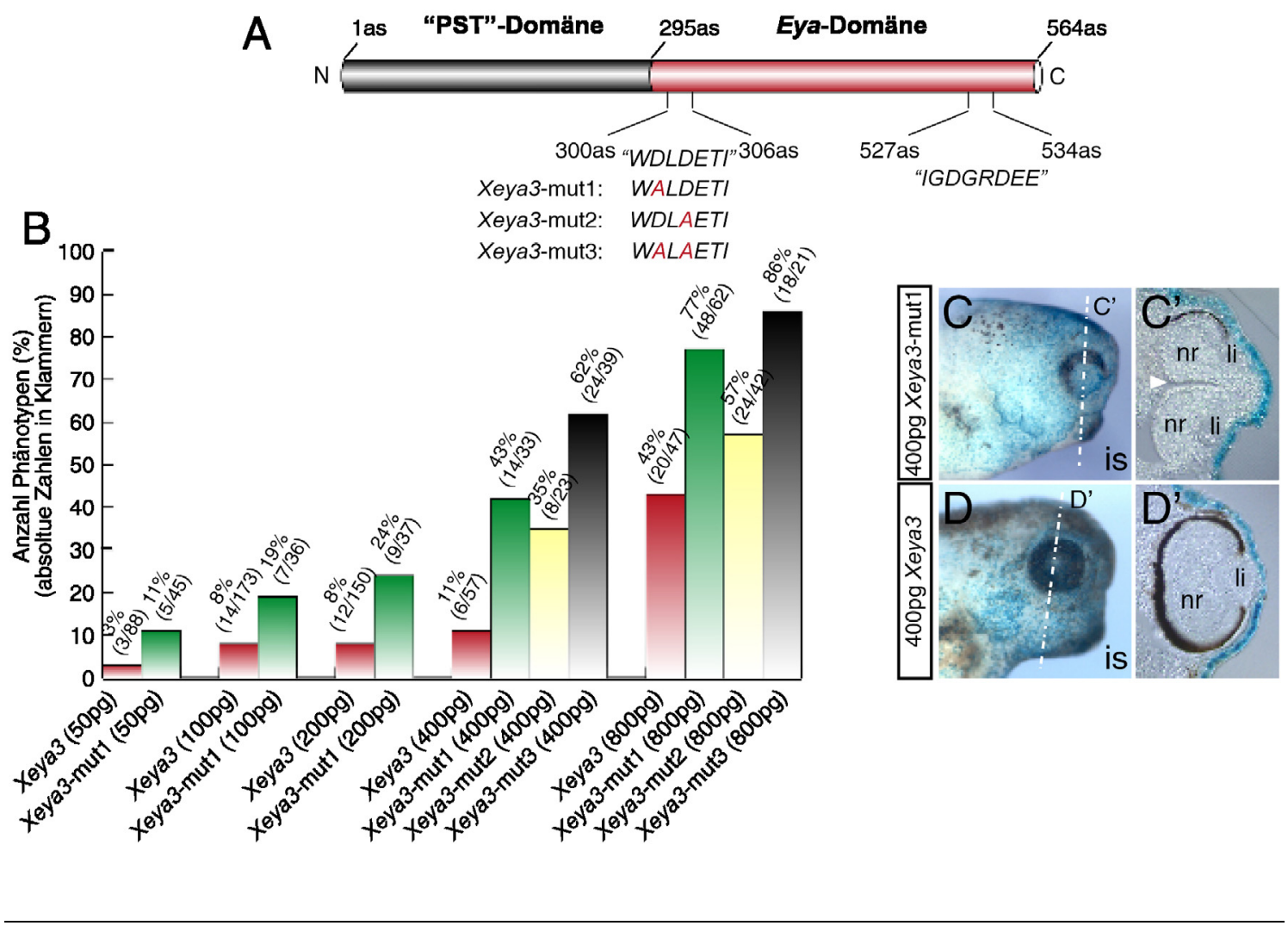

Abb. 4.18: Aktivitätssteigerung von Xeya3 nach Inaktivierung seiner Phosphatase-Aktivität. (A) Übersicht über die eingeführten Missense-Mutationen im Bereich des katalytischen Motivs der Phosphatase-Domäne von Xeya3 (as, Aminosäureposition; C, C-Terminus; N, N-Terminus). (B) Die Mikroinjektion synthetischer mRNA der Xeya3-Phosphatase-Mutanten (Xeya3-mut1-3) in eine Blastomere eines Zweizell-Stadiums führt im Vergleich mit synthetischer Xeya3-mRNA zu einer deutlichen Erhöhung der Anzahl an Embryonen mit Phänotypen, wie sie für einen Funktionsgewinn von Xeya 3 beschrieben worden sind. (C-D'; laterale Ansicht und Transversalschnitte im Bereich des Auges) NF Stadium 38 nach Mikroinjektion von 400pg synthetischer mRNA für Xeya3-mut1 bzw. Xeya3 in eine Blastomere eines Zweizell-Stadiums. Es wird zusätzlich eine Steigerung der Xeya3-Aktivität in qualitativer Hinsicht beobachtet. Bezüglich Xeya3-mut1 zeigt sich eine massive Einfaltung der neuralen Retina (nr; weißer Pfeil in C') und die Bildung zweier Linsen (li). 


\subsection{Die Klonierung des Dachshund Homologs 1 aus Xenopus laevis (Xdach1)}

Zum Transkriptionsfaktor Dachshund aus Drosophila melanogaster sind in Vertebraten drei Homologe, Dachshund1, Dachshund2 und DachshundB bekannt (Davis et al., 1999; Davis et al., 2001b; Hammond et al., 2002). Untersuchungen zur Muskelentwicklung in Hühnerembryonen haben eine Beteiligung von Dachsund2 als Teil eines multimeren Transkriptionsfaktor-Komplexes, weiter bestehend aus Mitgliedern der Eyes absent- und SixProteinfamilie, gezeigt (Heanue et al., 1999). Bezüglich einer Funktion eines DachshundProteins im Zusammenhang mit der Entwicklung des Wirbeltierauges ist bislang nichts bekannt. Zwar existiert eine Dachshund1 $1^{-/}$-Maus, Nachkommen sterben jedoch kurz nach der Geburt ohne offensichtliche Entwicklungsdefekte zu zeigen (Davis et al., 2001a).

Zur Klonierung einer Dachshund1 homologen cDNA aus Xenopus laevis wurde zunächst ein 414bp großes Fragment durch RT-PCR aus NF Stadium 28 total RNA-Präparationen mittels aus Sequenzinformation anderer Vertebraten Homologe abgeleiteter degenerierter Primer amplifiziert (Oligonukleotide: Xdsh-deg-F2, Xdsh-deg-R1). Eine anschließende 3'-RACE-PCR lieferte den vollständigen Leserahmen in 3'-Richtung. Durch 5'-RACE-PCR konnte, bei Sequenzvergleich mit anderen Dachshund-Homologen, nur eine partielle Sequenz erhalten werden (Oligonukleotide: Xdach-part-3'Race, Xdach-part-5'-Race). Zur Gewinnung der vollständigen Sequenzinformation in 5'-Richtung wurde eine fraktionierte Phagen-cDNA-Bank, welche das Transkriptom aus NF Stadium 29-31 Xenopus laevis Köpfen repräsentierte, durch PCR unter Verwendung Dachshund-spezifischer Oligonukleotide durchmustert (Oligonukleotide: Xdach-F.b., Xdach-R). Positive Fraktionen wurden als Matrize in einer nachfolgenden PCR mit Phagenvektor-spezifischen sowie Dachshund-spezifischen Oligonukleotiden eingesetzt (Oligonukleotide: $C M V$-F, Xdach-R), welche zusätzliche 5'Sequenzinformation lieferte. Der vollständige Leserahmen in 5'-Orientierung wurde durch eine weitere 5'-RACE-PCR erhalten (Oligonukleotid: Xdach-141). Nach Amplifikation des ORF (2088bp) einer Xdach-cDNA durch PCR mit einer vorher positiv identifizierten Fraktion der Phagen-cDNA-Bank als Matrize wurde dieser in $p G E M-T$ kloniert (Oligonukleotide: Xdachcds-F, Xdach-R2) und anschließend in den Expressionsvektor $p C S 2+$ subkloniert (Xdach1-FCla1, Xdach1.2-R-Xho1). Der Sequenzabgleich mit Dachshund-Homologen anderer Vertebraten zeigte die Zugehörigkeit der erhaltenen cDNA zur Dachshundl-Subklasse (,blastx“, http://www.ncbi.nlm.nih.gov/BLAST/, Altschul et al., 1997; MegAlign, Lasergene). Eine weitere Xdach-cDNA (Xdach-B, 2250bp) wurde durch Dr. E. Amaya (Cambridge, U.K.) zur Verfügung gestellt. Zur Herstellung c-myc-(MEQKLISEEDLNE) bzw. Flag(PDYKDDDDK) Epitop tragender $X d a c h$-Fusionsproteine wurde die proteinkodierende Region der jeweiligen $X d a c h$-cDNA in $p C S 2+M T$ bzw. $p C S 2+$, nach Hinzufügen des Flag-Epitops über das rückwärtsgerichtete Oligonukleotid mittels PCR, subkloniert (s. 2.8.2; Oligonukleotide: Xdach-F-Stu1, Xdach1.2-R-Xho1; Xdach-F-Cla1, Xdach-Flag-R-Xho1). 


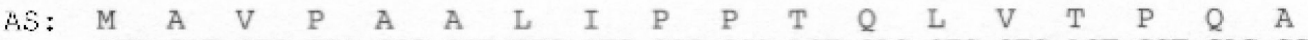

N: ATG GCT GTG CCA GCC GCT TTG ATC CCC CCG ACT CAG CTG GTG ACT CCT CAG GCA

$\begin{array}{lllllll}\text { Pos.: } & 9 & 18 & 27 & 36 & 45\end{array}$

$\begin{array}{llllllllllllllllllll}A & I & S & S & S & A & S & S & S & S & S & S & S & A & N & S & T & S & S & A\end{array}$ GCG ATC TCT TCC TCT GCG TCT TCC TCG TCC TCC TCC TCT GCC AAC TCG ACT TCT TCG GCC 63

72

81

99

108

$\begin{array}{lllllllllllllllllllll}N & N & S & P & S & P & S & V & A & P & S & S & S & G & Q & S & \text { L } & Y & R & P\end{array}$ AAT AAT TCT CCT TCG CCT TCA GTC GCC CCT TCC TCG TCC GGG CAG AGT TTG TAC CGA CCA 123 132

141

150

159

168

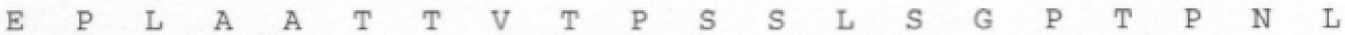
GAG CCG CTC GCT GCC ACC ACA GTT ACT CCC AGC AGC CTC AGC GGC CCG ACT CCC AAC CTC 183

192

201

210

219

228

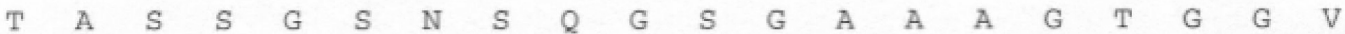
ACG GCC AGC AGC GGC AGC AAC AGC CAA GGG TCC GGG GCA GCG GCG GGG ACT GGG GGA GTT 243

252

261

270

279 288

$\begin{array}{llllllllllllllllllll}G & G & G & G & G & G & S & N & G & I & L & S & N & C & N & S & P & S & T & T\end{array}$ GGA GGA GGA GGA GGA GGC AGC AAT GGG ATC CTG AGC AAC TGC AAC AGC CCC AGC ACC ACC $\begin{array}{llllll}303 & 312 & 321 & 330 & 339 & 348\end{array}$

$\begin{array}{llllllllllllllllllll}\mathbb{N} & S & S & N & S & S & H & H & N & N & \mathbb{N} & \mathbb{N} & \text { L } & \text { I } & \text { I } & \text { P } & G & S & \text { T } & S\end{array}$ AAT AGC AGC AAC AGC AGC CAC CAT AAT AAT AAT AAC CTT ATT ATC CCA GGC AGC ACC TCA

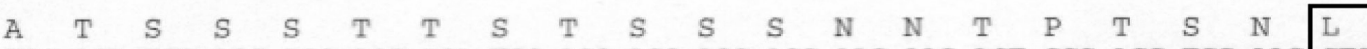
GCC ACA TCC AGC AGC ACC ACA TCC ACC AGC AGC AGC AAC AAC ACT CCC ACC TCC AAC CTG $\begin{array}{llllll}423 & 432 & 441 & 450 & 459 & 468\end{array}$ \begin{tabular}{|llllllllllllllllllll|}
\hline $\mathrm{P}$ & $\mathrm{G}$ & $\mathrm{K}$ & $\mathrm{P}$ & $\mathrm{V}$ & $\mathrm{Y}$ & $\mathrm{S}$ & $\mathrm{T}$ & $\mathrm{P}$ & $\mathrm{S}$ & $\mathrm{P}$ & $\mathrm{V}$ & $\mathrm{E}$ & $\mathrm{N}$ & $\mathrm{I}$ & $\mathrm{P}$ & $\mathrm{Q}$ & $\mathrm{N}$ & $\mathrm{N}$ & $\mathrm{E}$ \\
$\mathrm{CCCC}$ & GGG & AAG & CCC & GTC & TAC & TCC & ACT & CCGG & TCC & CCC & GTG & GAG & AAC & ATC & CCC & CAG & AAC & AAT & GAG \\
\hline
\end{tabular}

\begin{tabular}{|llllllllllllllllllll|}
\hline C & R & M & V & E & L & R & G & A & K & V & A & S & F & T & V & E & T & C & E \\
TGC & AGG & ATG & GTG & GAAG & CTA & AGA & GGG & GCC & AAG & GTG & GCT & TCA & TTC & ACG & GTA & GAG & ACC & TGC & GAG \\
\hline
\end{tabular}

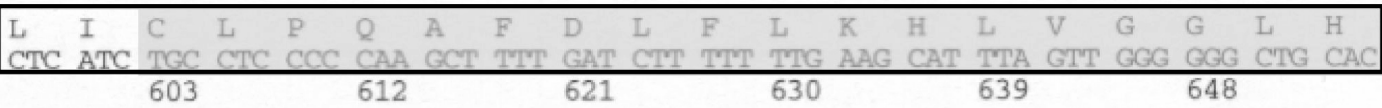

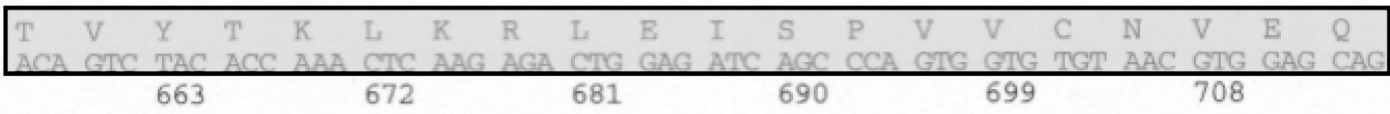

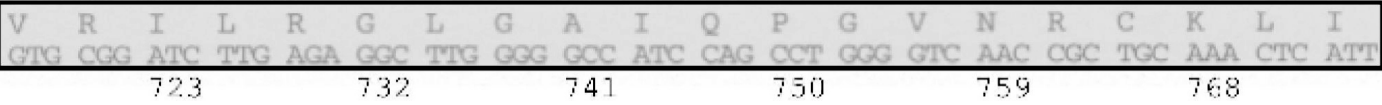

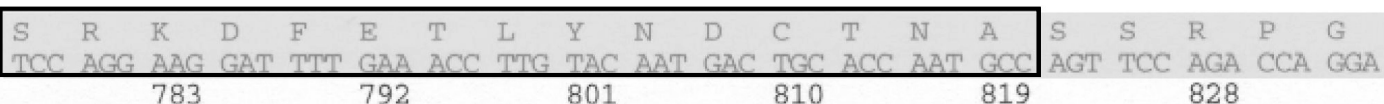

$\begin{array}{llllllllllllllllllll}R & P & P & K & R & T & Q & S & V & T & S & S & \text { D } & \text { N } & \text { P } & \text { H } & \text { I } & \text { M } & \text { P } & \text { H } \\ \text { AGA } & \text { CCC } & \text { CCT } & \text { AAA } & \text { AGA } & \text { ACG } & \text { CAG } & \text { AGT } & \text { GTT } & \text { ACC } & \text { TCA } & \text { TCA } & \text { GAC } & \text { AAT } & \text { CCA } & \text { CAT } & \text { ATC } & \text { ATG } & \text { CCA } & \text { CAT } \\ & & 843 & & & 852\end{array}$

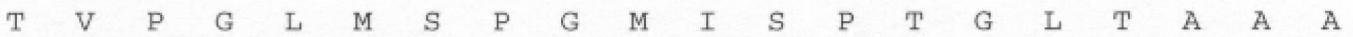
ACG GTT CCT GGT CTC ATG TCT CCT GGG ATG ATC TCT CCA ACA GGT TTG ACT GCA GCA GCC 903

912

921

930

939 


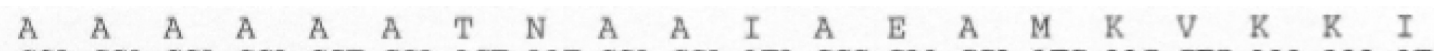
GCA GCA GCA GCA GCT GCA ACT AAT GCA GCA ATA GCG GAA GCA ATG AAG GTG AAA AAA ATC $\begin{array}{llllll}963 & 972 & 981 & 990 & 999 & 1008\end{array}$

$\begin{array}{llllllllllllllllllll}K & \text { L } & \text { E } & \text { A } & \text { M } & \text { T } & \text { N } & \text { Y } & \text { H } & \text { G } & \text { S } & \text { N } & \text { N } & \text { Q } & \text { H } & \text { G } & \text { A } & \text { D } & \text { S } & \text { D }\end{array}$ AAG TTG GAA GCT ATG ACC AAC TAT CAT GGC AGC AAT AAC CAG CAT GGA GCT GAT TCT GAC

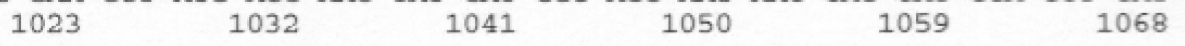

$\mathrm{N} G \quad \mathrm{D} \quad \mathrm{F} \quad \mathrm{S} \quad \mathrm{S} \quad \mathrm{S} \quad \mathrm{V} \quad \mathrm{G} \quad \mathrm{IN} \mathrm{S}$

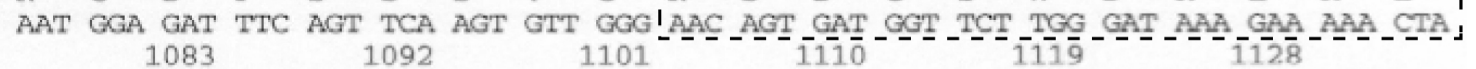

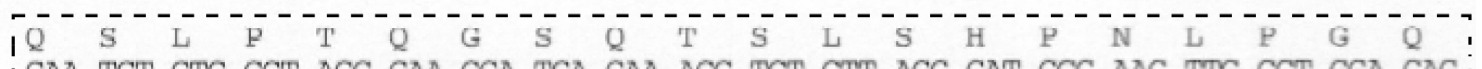
ICAA TCT CTC CCT ACC CAA CGA TCA CAA ACC TCT CTT AGC CAT CCC MAC TTC CCT CGA CAC i

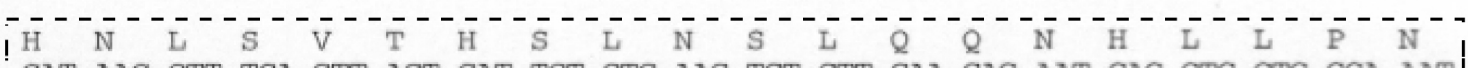
I CAT AAC CTT TCA GTT ACT CAT TCT CTC AAC TCT CTT CAA CAG AAT CAC CTC CTG CCA AAT

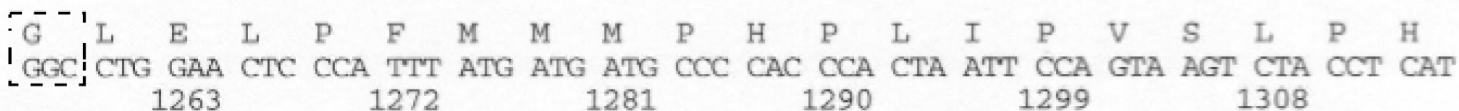

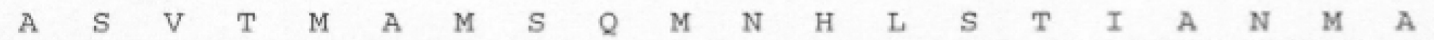
GCA TCT GTT ACC ATG GCG ATG AGC CAG ATG AAC CAT CTC AGT ACC ATT GCA AAC ATG GCA

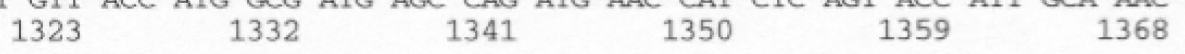

$\begin{array}{llllllllllllllllllll}A & A & A & Q & V & Q & S & T & P & S & R & M & E & T & S & V & I & R & E & R\end{array}$ GCA GCA GCA CAA GTA CAA AGC ACT CCC TCC AGA ATG GAA ACA TCA GTA ATT AAG GAA CGT $\begin{array}{llllll}1383 & 1392 & 1401 & 1410 & 1419 & 1428\end{array}$


GTT CCA GAC AGT CCC TCC CCT GCT CCA TCT CTA GAA GAT GGT CGA AGG CCG GTC AGT CAT $\begin{array}{lrrrrr}1443 & 1452 & 1461 & 1470 & 1479 & 1488\end{array}$

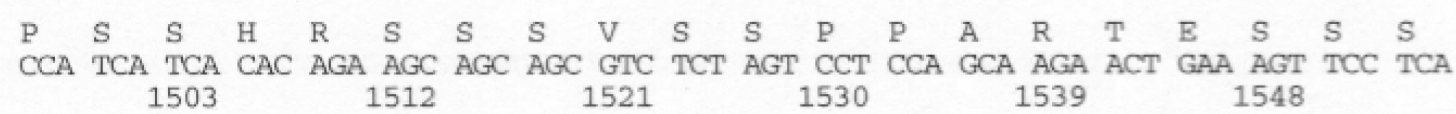
$\begin{array}{llllllllllllllllllll}\mathrm{D} & \mathrm{R} & \mathrm{I} & \mathrm{P} & \mathrm{V} & \mathrm{H} & \mathrm{Q} & \mathrm{N} & \mathrm{G} & \mathrm{I} & \mathrm{S} & \mathrm{I} & \mathrm{N} & \mathrm{Q} & \mathrm{M} & \mathrm{L} & \mathrm{M} & \mathrm{G} & \text { L } & S \\ \text { GAC } & \text { AGA } & \text { ATT } & \text { CCT } & \text { GTC } & \text { CAT } & \text { CAA } & \text { AAT } & \text { GGC } & \text { ATT } & \text { TCA } & \text { ATT } & \text { AAT } & \text { CAA ATG } & \text { TTA } & \text { ATG GGT } & \text { CTG } & \text { TCA }\end{array}$ $\begin{array}{llllll}1563 & 1572 & 1581 & 1590 & 1599 & 1608\end{array}$

$\begin{array}{llllllllllllllllllll}\mathrm{P} & \mathrm{N} & \mathrm{I} & \mathrm{I} & \mathrm{P} & \mathrm{G} & \mathrm{P} & \mathrm{K} & \mathrm{E} & \mathrm{G} & \mathrm{D} & \mathrm{L} & \mathrm{A} & \mathrm{G} & \mathrm{H} & \mathrm{E} & \mathrm{V} & \mathrm{G} & \mathrm{H} & \mathrm{E}\end{array}$ CCT AAC ATC ATA CCT GGA CCA AAA GAA GGT GAT CTT GCT GGT CAT GAA GTG GGA CAT GAG $\begin{array}{llllll}1623 & 1632 & 1641 & 1650 & 1659 & 1668\end{array}$

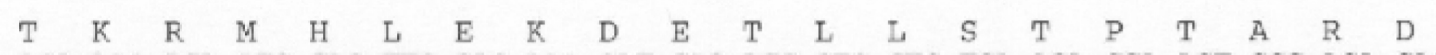

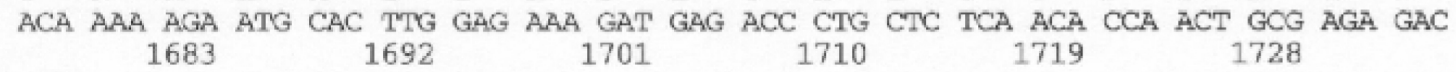

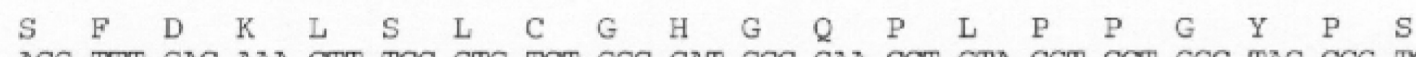

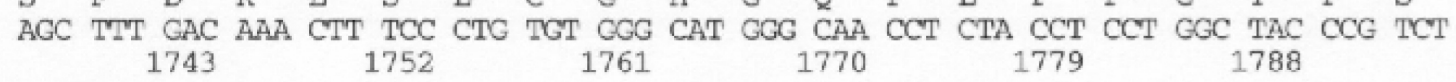

$\begin{array}{llllllllllllllllllll}\text { P } & \text { F } & \text { L } & \text { F } & \text { P } & \text { D } & \text { G } & \text { L } & \text { S } & \text { S } & \text { I } & \text { E } & \text { T } & \text { L } & \text { L } & \text { T } & \text { N } & \text { I } & \text { Q } & \text { G } \\ \text { CCT } & \text { TTT } & \text { CTA } & \text { TTT } & \text { CCT } & \text { GAT } & \text { GCA } & \text { TTG } & \text { TCT } & \text { TCC } & \text { ATA } & \text { GAG } & \text { ACA } & \text { CTT TTA } & \text { ACT } & \text { AAC ATC } & \text { CAG } & \text { GGC }\end{array}$ $\begin{array}{llllll}1803 & 1812 & 1821 & 1830 & 1839 & 1848\end{array}$ 


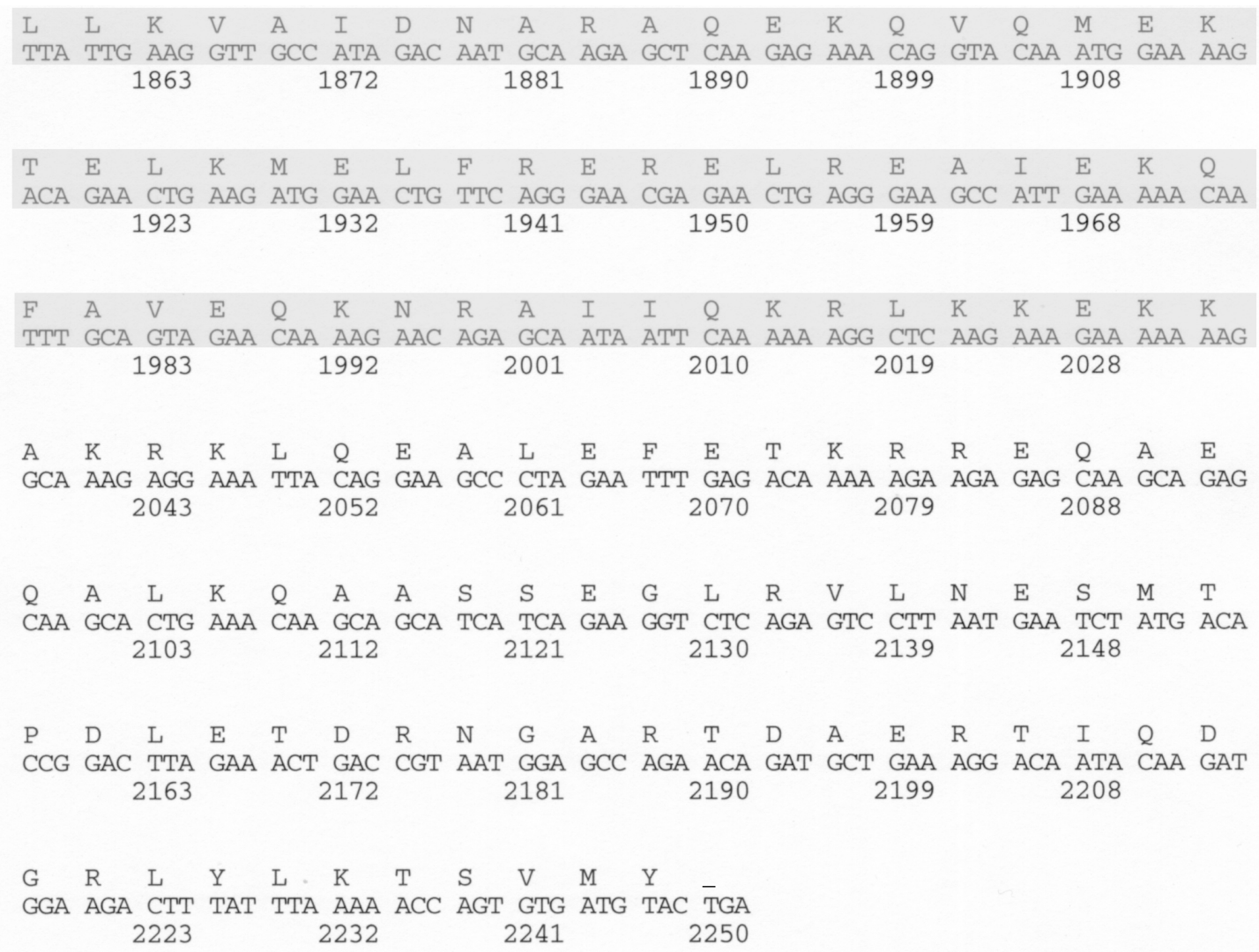

Abb. 4.19: Nukleotid- und Aminosäuresequenz des offenen Leserahmens von Xdach1-B. Die aus der Nukleotidsequenz (N) der Xdach1-B-cDNA abgeleitete Aminosäuresequenz (AS) ist jeweils oberhalb dieser dargestellt. Die Zahlen geben die Position (Pos.) des jeweils letzten Nukleotids des betreffenden Tripletts an, das Stopkodon ist durch einen Strich markiert. Die N-terminale Dachshund-Domäne1 (DD1) sowie die C-terminale Dachshund-Domäne2 (DD2) sind grau hinterlegt. Der zu den Proto-Onkogenen Ski und Sno homologe Bereich ist eingerahmt. Der im Vergleich mit Xdach1-A zusätzlich vorhandene Sequenzabschnitt ist durch gestrichelte Linien kenntlich gemacht.

\subsection{Xdach1-A und Xdach1-B besitzen zwei konservierte Dachshund-Domänen und zeigen} Sequenzverwandtschaft zu den Proto-Onkogenen Ski und Sno

Die Nukleotidsequenzen der Dachshund homologen cDNAs aus Xenopus laevis Xdach1-A (2088bp) und Xdach1-B (2250bp) kodieren für Proteine einer Länge von 695 bzw. 749 Aminosäuren mit einem rechnerischen Molekulargewicht von 73718,2 bzw. 79519,41 Dalton. Wie auch andere Dachshund-Proteine besitzen Xdach1-A und Xdach1-B zwei innerhalb der Proteinfamilie konservierte Domänen (Abb. 4.20B), die Dachshund-Domäne1 am N-Terminus sowie die Dachshund-Domäne2 im Bereich des C-Terminus der Polypeptidkette (Tavsanli et al., 2004). Der Größenunterschied zwischen Xdach1-A und Xdach1-B begründet sich im Wesentlichen auf einen zusätzlichen Sequenzabschnitt im Fall von Xdach1-B im Bereich zwischen den beiden Dachshund-Domänen (Aminosäure-Positionen 368-419; Abb. 4.19, 4.21). 
Eine Suche nach konservierten Motiven innerhalb der Primärstruktur von Xdach1-A und Xdach1-B sowie anderer Vertebraten Homologe von Dachshund ergibt zudem eine Sequenzverwandschaft mit den Proto-Onkogenen Ski und Sno (PROSITE, MotifScan; http://myhits.isb-sib.ch/cgi-bin/motif_scan). Der damit in Zusammenhang stehende konservierte Sequenzabschnitt überlappt dabei partiell mit der Dachshund Domäne1 (Abb. 4.19, 4.20).

A

B
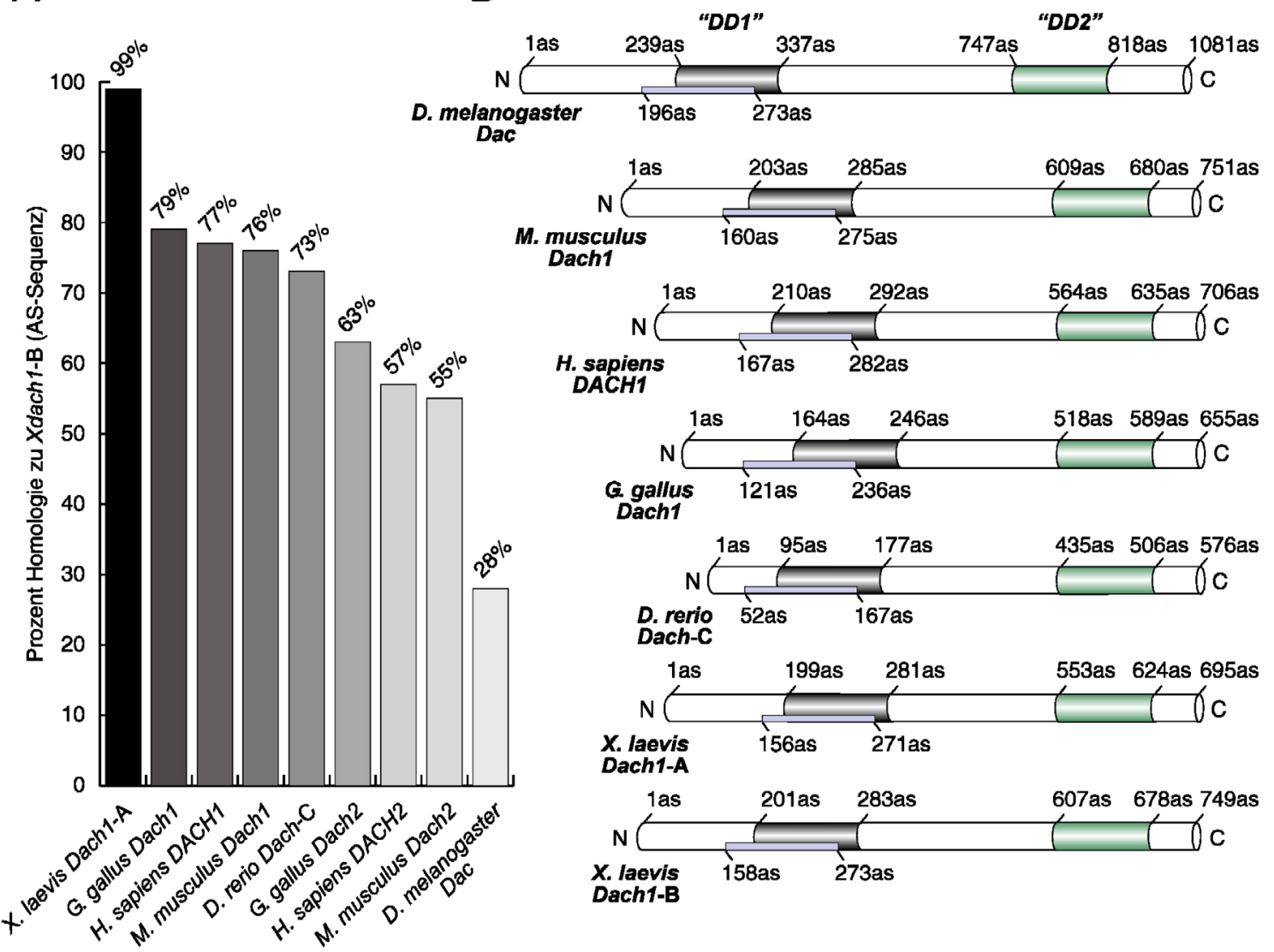

DACH1
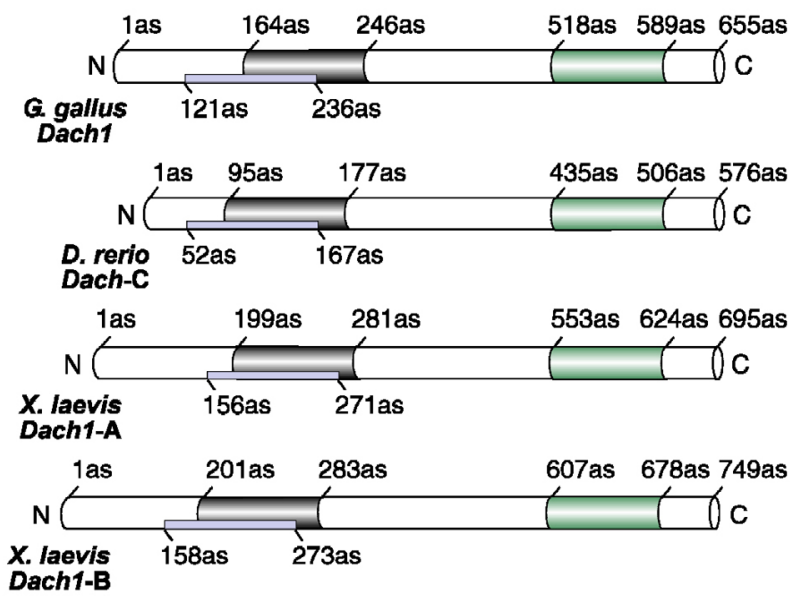

Abb. 4.20: Xdach1-A/-B als Mitglied der Dach1-Subklasse innerhalb der Dachshund-Familie von Proteinen. (A) Höchste Sequenzverwandtschaft von Xdach1-B zu Xdach1-A, Dachshund1 aus Huhn, Mensch und Maus sowie zu DachshundC aus Zebrafisch. Gegenüber anderen Homologen der Dachshund Proteinfamilie besteht geringere Sequenzhomologie (Angabe in Prozent identische Aminosäuren (AS)). (B) Übersicht über Mitglieder der Dachshund1-Subfamilie von Proteinen sowie Dachshund aus Drosophila melanogaster. Der Bereich der Dachshund Domäne 1 (DD1) ist jeweils grau, der der Dachshund Domäne 2 (DD2) grün hinterlegt. Der Sequenzabschnitt mit Homologie zu den ProtoOnkogenen Ski und Sno ist durch einen hellblauen Balken angezeigt. Abkürzungen: N, N-Teminus; C, CTerminus; as, Aminoäureposition. 

X. laevis Dach1-B
$X$. laevis Dach1-A
H. sapiens DACH1
M. musculus Dach1
G. gallus Dach1
D. rerio Dach-C

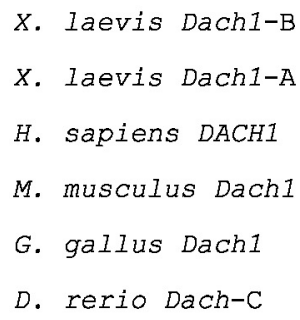

X. Iaevis Dach1-B

$X$. Iaevis Dach1-A

H. sapiens DACHI

M. musculus DachI

G. gallus Dach1

D. rerio Dach-C

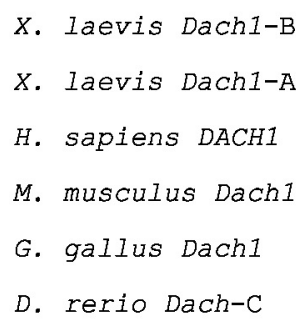

X. Iaevis Dach1-B

$X$. Iaevis Dach1-A

H. sapiens $D A C H 1$

M. musculus DachI

G. gallus Dach1

D. rerio Dach-C

X. Laevis Dach1-B

$X$. laevis Dach1-A

II. sapiens DACHI

M. musculus Dach1

G. gallus Dachl

D. rerio $\mathrm{DaCh}-\mathrm{C}$
MAVPAALIPPTQLVTPQAAISSSASSSSSSSANSTSSANNSPSPSVA..PSSSGQSLYRPE 59

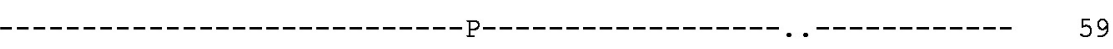

------------P--PP--T-----G. TTT-----TS--A--IG.P-A---PT-F--- 58

------------P--PP--T-----G. .TTT-----TS--A--IG.P-A---PT-E--- 58

AP--P--PPV-T--ACTTT.TTT-SAA-TS--A-AI-PP-PA--TN-F--- 60

- ......... АНАРPM-I--VVN . .... STP-TL------- ... PA-P--F-T- 38

PLAATTVTPSSLSGPTPNLTASSGSNSQGSGAAAGTGGVGGGGGGSNGILSNCNSPSTTNS 120

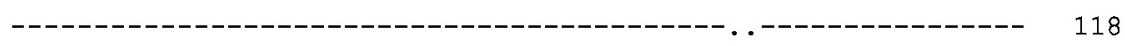

-I-SAAAAAATVT . . . . . STGG-GGGG---GGG-SS-N-----.GG-GG----PNLAAA- 112

-I-SSASSSAAAT. . . . . VT.P.GGGGG--GGG-S--N--- . . . . GG----PSLAAG- 107

-I--PAAAAATVT. . . . STATTTTTG---GGG-S--G--S..........PSLGSGT 103

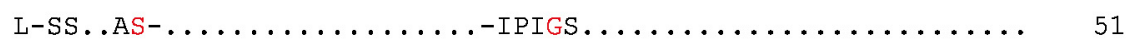

SNS. ................ LHHNNNNLIIPGSTSATSSSTTSTSSSNNTPTSN.... 161

159

NG-GGGGGGISAGGGVASSTPINAST--S-SS---SS-S---SSSSS-SSS. . CGP--- 170

-G. . . . GGVSAGGGGASSTPITAST--SSSS---SS-S---SSSSS-SSSSSSCGP---- 163

GG................. TSGTSTPNAGAAG. $\ldots \ldots \ldots \ldots \ldots-124$

55

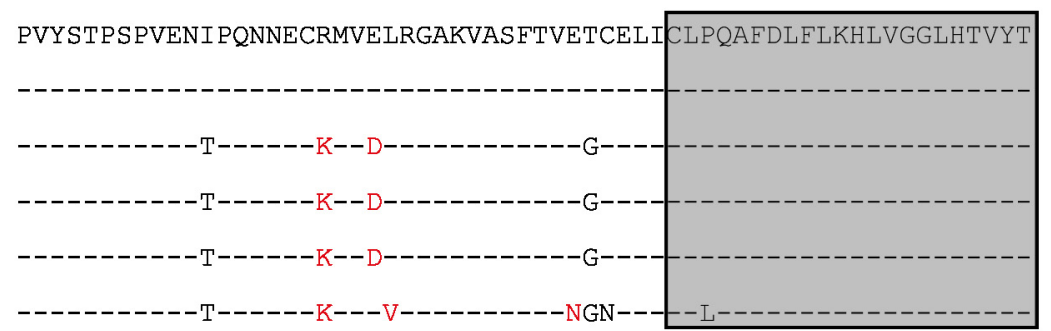

222

220

231

224

185

116

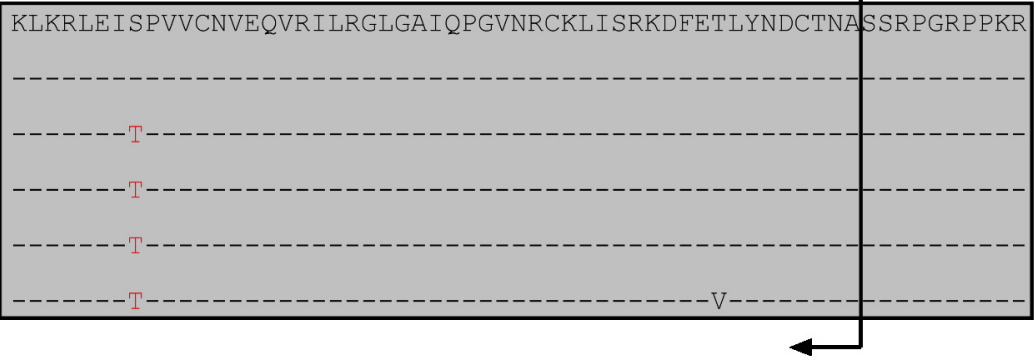

283

281

292

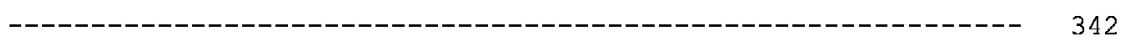

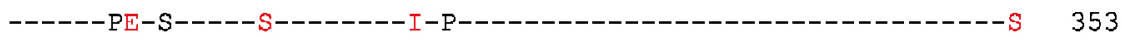

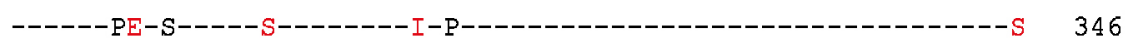

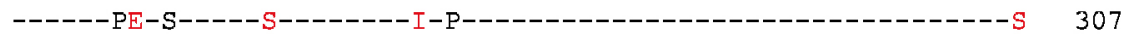

------P-S--VL--S-S----S-LM-H---- . . . . . . AT. . L-----.------V-N 227 

X. Laevis Dach1-B
$X$. Laevis Dach1-A
H. sapiens DACH1
M. musculus Dach1
G. gallus Dach1
D. rerio Dach-C

NYHGSNNQHGADSDNGDFSSSVGNSDGSWDKEKLQSLPTQGSQT SLSHPNL PGQHNLSVTH

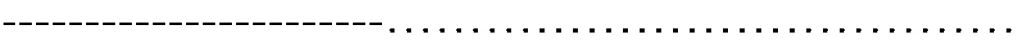

$---\mathrm{A}---------\mathrm{E}---\mathrm{MN}----\ldots \ldots \ldots \ldots \ldots \ldots \ldots \ldots \ldots \ldots$

---A---------E---MN----S-G------T-H-P-S----APVA-ARM-AAFS-P-S-

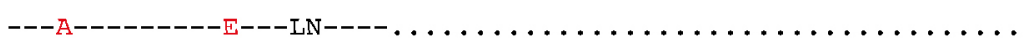

$\mathrm{S}---\mathrm{N}----\mathrm{S}---\mathrm{E}---\mathrm{IT}--\mathrm{M}-$.

SLNSLQQNHLLPNGLELPFMMMPHPLI PVSLPHASVTMAMSQMNHLSTIANMAAAAQVQST

........ . . .

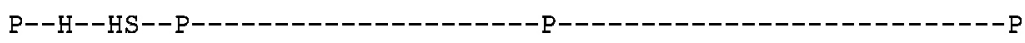

.............

$-\mathrm{P}-$

$-\mathrm{N}-$

S-

$--\mathrm{V}$

PSRMETSVIKERVPDSPSPAPSLEDGRRPVSHPSSHRSSSVSSPPARTESSSDRI PVHQNG

X. Laevis Dach1-B

$X$. Laevis DachI-A

H. Sapiens DACH1

M. musculus Dach1

G. gallus Dach1

D. rerio Dach-C
X. Iaevis Dach1-B
$X$. laevis Dach1-A
H. sapiens DACH1
M. musculus Dach1
G. gallus DachI
D. rerio Dach-C

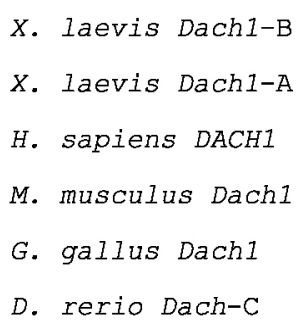

X. laevis Dach1-B

$X$. laevis Dach1-A

H. sapiens DACH1

M. musculus Dach1

G. gallus Dach1

D. rerio Dach-C

ISINQMLMGLSPNIIPGPKEGDLAGHEVGHETKRMHLEKDETLLSTPTARDSFDKLSLCGH
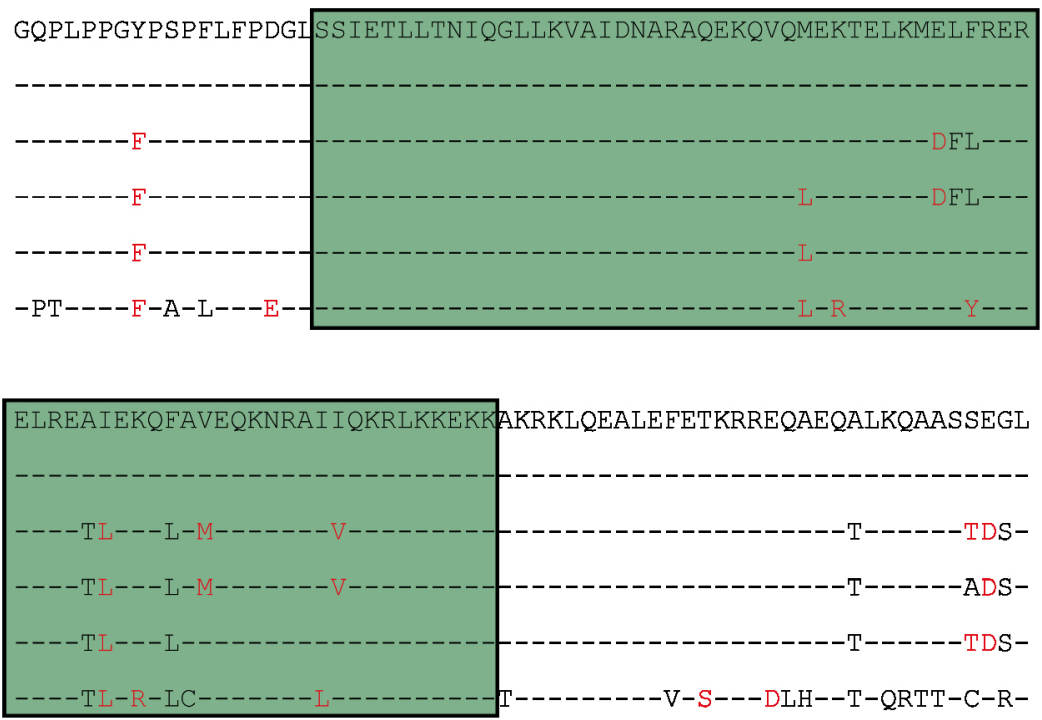


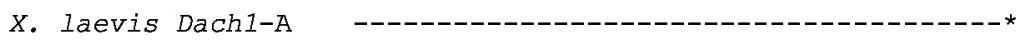

H. sapiens DACHI

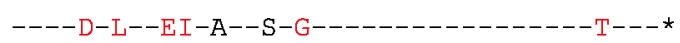

M. musculus Dach1

$----D-L--E I-A--S-G-A---------------T---*$

G. gallus Dachl

----D-L--EI-A--S-G---------GS. . . DAYA. . *

D. rerio Dach-C

$\mathrm{PIH}-\mathrm{D}-\mathrm{QQ}-\mathrm{E}---\mathrm{ILITSK}--\mathrm{T}-\mathrm{G}-------\mathrm{F}--\mathrm{STM}--$ *

\section{Abb. 4.21: Vergleich der Aminosäuresequenzen von Xdach1-B und Xdach1-A mit denen von}

Dach1-Proteinen anderer Vertebraten. Rechts sind die Positionen der Aminosäuren am Ende der jeweiligen Zeile angegeben. Identische Aminosäuren sind durch horizontale Striche, fehlende Aminosäuren durch Punkte, die Terminations-Kodons durch Sternchen markiert. Konservierte Aminosäure-Austausche sind rot hinterlegt. Als konservierte Aminosäure-Austausche gelten: A/G, V/I/L/M, F/Y, D/E/N/Q, S/T, K/R (George et al., 1990). Die Dachshund-Domäne 1 ist grau, die Dachshund-Domäne 2 grün hinterlegt. Der Sequenzabschnitt mit Homologie zu den Proto-Onkogenen Ski und Sno ist durch Pfeile markiert.

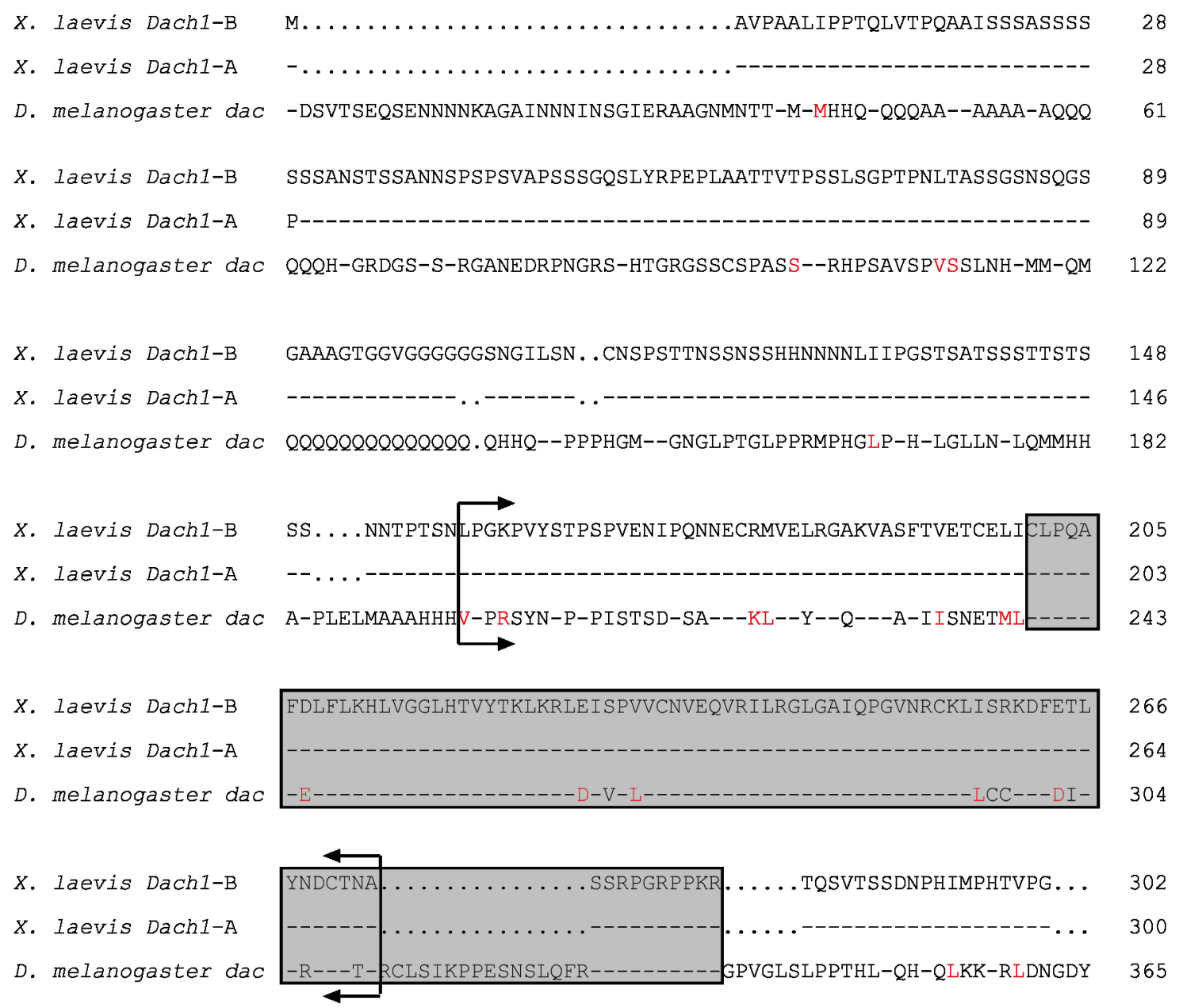


x. laevis Dach1-B $\ldots \ldots \ldots \ldots \ldots \ldots \ldots \ldots \ldots \ldots \ldots \ldots \ldots \ldots$ LMSPGMiSPTGLTA.....

$X$. laevis Dach1-A

D. melanogaster daC AYENGHISDMKSPLLANGYNPPPINHMAFMQMNAHHPGAAA------P.-H--H-RPESQM

X. Iaevis Dach1-B . AAAAAAAATNAAIAEAMKVKKIKLEAMTNYHGSNNQHG. . . ADSDNGDFSSSVGNSDGS

X. laevis Dach1-A

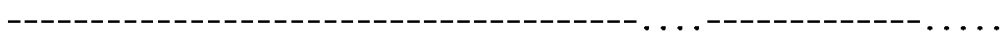

D. melanogaster dac

LK---QN-GMS--NMD-LARSG-WENCRAA-EDIVKHLERLREERT-ERQQAMG--G. . AV

X. laevis Dach1-B WDKEKLQSLPTQGSQTSLSHPNLPGQHNLSVTHSLNSLQQNHLLPNGLELPFMMMPHPLIP

X. laevis Dach1-A $\ldots \ldots \ldots \ldots \ldots \ldots \ldots \ldots \ldots \ldots \ldots \ldots \ldots \ldots \ldots \ldots \ldots$

D. melanogaster dac

V-RVGNVMVAEHKPRDLS-RNCS-TRQSPVLNL-KSGGNTD-GGS-CDAGSERSDC-SVAG

X. laevis Dach1-B

. . GYPSPFLFPDG . .... SSIETLLTNIQGLLKVAIDNARAQEKQVQMEKTELKMELFRE

X. laevis Dach1-A

D. melanogaster dac

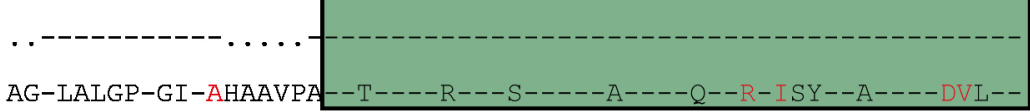

$X$. laevis Dach1-A

D. melanogaster dac

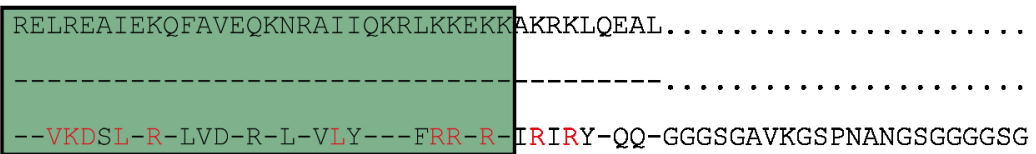

X. Laevis Dach1-B

D. melanogaster dac

D. melanogaster daC SCDVTAGHSAGSVSGSISAGLNCPDSPTHFK--PSSDHEGSVERQPRSSAASLAAHDEDNT

D. melanogaster daC KRCGSRDRDERPPSGSAASVAAEGSLAAAAA-AA-AAA--A-N-KGPWSYPGIDLMATGAF 


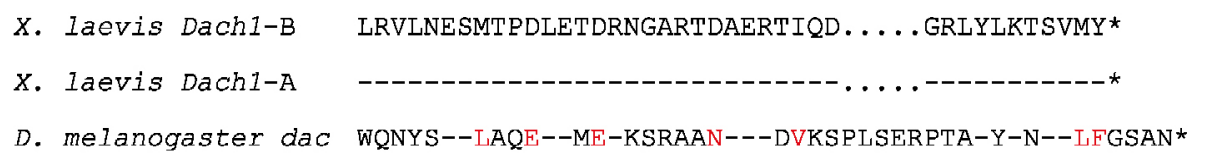

Abb. 4.22: Vergleich der Aminosäuresequenzen von Xdach1-B und Xdach1-A mit der des Dachshund (dac) Proteins aus Drosophila melanogaster. Rechts sind die Positionen der Aminosäuren am Ende der jeweiligen Zeile angegeben. Identische Aminosäuren sind durch horizontale Striche, fehlende Aminosäuren durch Punkte, die Terminations-Kodons durch Sternchen markiert. Konservierte Aminosäure-Austausche sind rot hinterlegt. Als konservierte Aminosäure-Austausche gelten: A/G, V/I/L/M, F/Y, D/E/N/Q, S/T, K/R (George et al., 1990). Die Dachshund-Domäne 1 ist grau, die Dachshund-Domäne 2 grün hinterlegt. Der Sequenzabschnitt mit Homologie zu den Proto-Onkogenen Ski und Sno ist durch Pfeile markiert.

\subsection{Xdach1 wird in neuralen und mesodermalen Geweben exprimiert}

Zur Darstellung der räumlichen wie zeitlichen Expression von $X d a c h 1$ wurden „WMISH“ an Xenopus laevis Embryonen verschiedener Entwicklungsstadien durchgeführt. Dabei wurde eine antisense RNA-Sonde verwendet, die zu Xdach1-A und Xdach1-B komplementär ist (Basenpositionen 1266-2205, s. Abb. 4.19, 4.21).

Eine erste Expression von Xdach1 lässt sich nach Abschluss der Neurulation in NF Stadium 21 in Bereichen des prospektiven Hinterhirns sowie innerhalb der frühen optischen Vesikel erkennen (Abb. 4.23A). In NF Stadium 25 Embryonen ist die Transkriptionsrate von Xdach1 innerhalb dieser Areale stark angestiegen. Zusätzlich finden sich jetzt auch Transkripte in der Anlage des trigeminalen Nervs. Der Transversalschnitt in Höhe der optischen Vesikel und des zukünftigen Hinterhins zeigt, dass sich die Expression von Xdachl auf distale Bereiche der Augenvesikel sowie dorsale Abschnitte des Metencephalons beschränkt (Abb. 4.23B, B'). Die Xdach1-Expression innerhalb präsumtiver distaler Retina und dorsaler Hirnbereiche bleibt nach Bildung des optischen Bechers und Invagination von Linsenktoderm bestehen und wird mit dem Erreichen von NF Stadium 32 durch eine zusätzliche Expression innerhalb ventrolateraler Hirnbereiche, innerhalb des prospektiven Nierenkanals sowie hypaxialer Muskelvorläuferzellen ergänzt (Abb. 4.23C, D, D'). Dieses Xdach1-Expressionsmuster wird auch in frühen Kaulquappenstadien beobachtet, wobei jetzt Zellen weiterer cranialer Plakoden wie der mittleren Seitenlinienplakode und epibranchialer Plakoden Xdach1 transkribieren (Abb. 4.23E). Der Transversalschnitt durch das Auge eines NF Stadium 38 Embryos zeigt eine im Bereich der sich formenden, distal gelegenen Ganglionzellschicht sowie Teilen des Retinalen Pigmentepithels verbleibende Expression von Xdach1. Im Hinterhirn findet vor allem in dorsalen Abschnitten, daneben aber auch innerhalb der ventrikulären Zone und in ventral 
gelegenen Arealen, ausgenommen der Bodenplatte, Xdach1-Transkription statt (Abb. 4.23E', E').

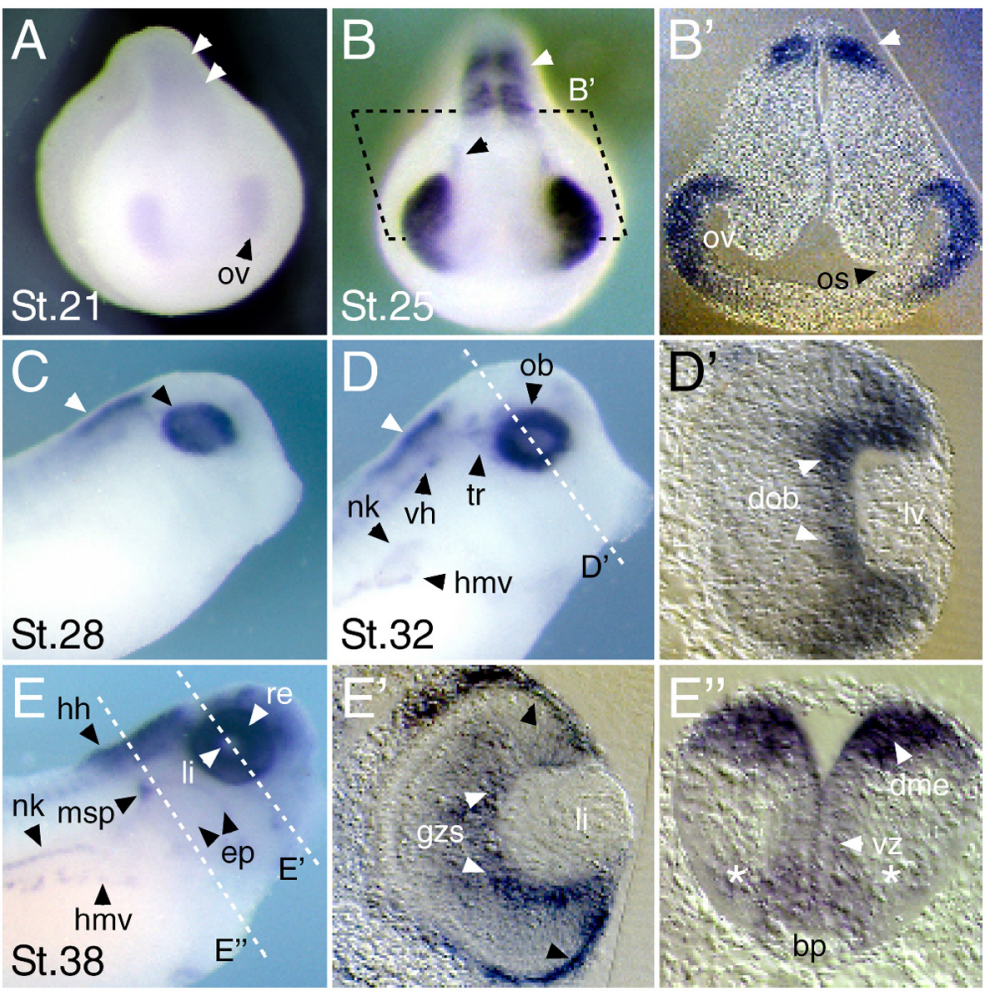

Abb. 4.23: Räumliche und zeitliche Expression von Xdach1 während der Embryonalentwicklung von Xenopus laevis. (A) NF Stadium 21, frontale Ansicht; weiße Pfeile, prospektive Hinterhirnregionen; ov, optischer Vesikel. (B) NF Stadium 25, frontale Ansicht; weißer Pfeil, prospektive Hinterhirnregionen; schwarzer Pfeil, Anlage des trigeminalen Nervs. (B') Transversalschnitt in Höhe der optischen Vesikel und des Hinterhirns; weißer Pfeil, prospektives dorsales

Hinterhirn; os, optischer Stiel. (C) NF Stadium 28, laterale Ansicht, anterior rechts; weißer Pfeil, dorsales Hinterhirn; schwarzer Pfeil, optischer Becher. (D) NF Stadium 32, laterale Ansicht, anterior rechts; weißer Pfeil, dorsales Hinterhirn; hmv, hypaxiale Muskelvorläuferzellen; nk, prospektiver Nierenkanal; ob, optischer Becher; tr, trigeminaler Nerv; vh, ventrales Hinterhirn. (D') Transversalschnitt durch einen NF Stadium 32 optischen Becher; dob, distaler optischer Becher; 1v, Linsenvesikel. (E) NF Stadium 38, laterale Ansicht, anterior rechts; ep, epibranchiale Plakoden; hh, Hinterhirn; li, Linse; msp, mittlere Seitenlinienplakode; re, Retina. (E’) Transversalschnitt durch ein NF Stadium 38 Auge; gzs, Ganglionzellschicht; schwarze Pfeile, Retinales Pigmentepithel. (E') Transversalschnitt durch ein NF Stadium 38 Metencephalon; Sternchen, ventrolaterale Bereiche des Metencephalons; bp, Bodenplatte; dme, dorsales Metencephalon; vz, ventrikuläre Zone.

Im Zuge der Analyse des Expressions-Niveaus von Xdach1 in einer RT-PCR auf Präparationen von total RNA aus Xenopus laevis Embryonen verschiedener Entwicklungsstadien sowie adulten Geweben konnten aufgrund der hohen Sequenzhomologie zwischen den Xdach1Formen, Xdach1-A und Xdach1-B, beide gleichzeitig mit Hilfe eines einzigen Oligonukleotidpaares amplifiziert werden (Abb. 4.24; Oligonukleotide: Xdach-Splice-F, XdachSplice-R). 


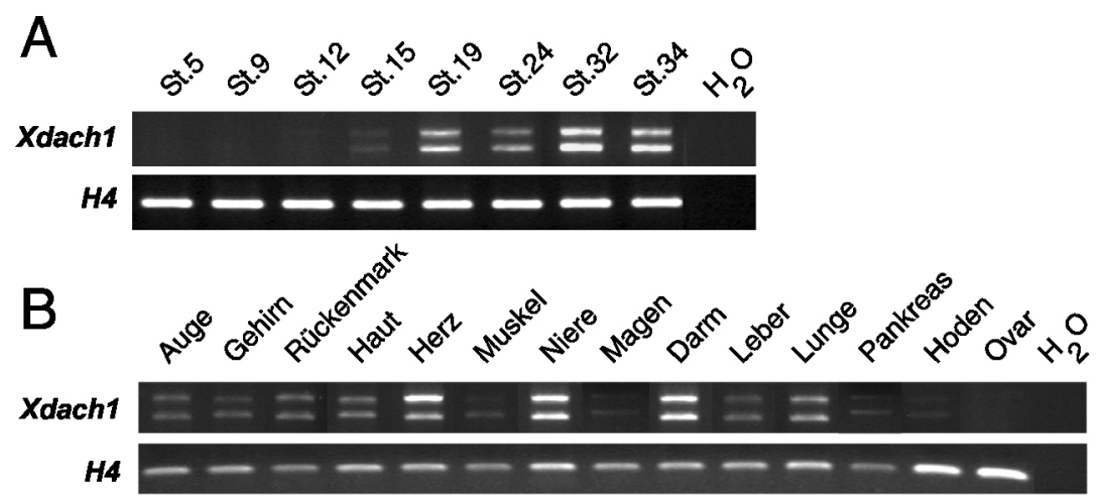

Abb. 4.24: ExpressionsNiveau von Xdach1-A und Xdach1-B in Embryonalstadien und adulten Geweben von Xenopus laevis. (A) RTPCR auf total RNA verschiedener $X$. laevis Embryonalstadien.

RT-PCR auf total RNA adulter Gewebe von X. laevis. Zur Kontrolle der eingesetzten Menge an RNAMatrize wurde im Zuge der RT-PCR zusätzlich Histon 4 (H4) amplifiziert. Verwendete Oligonukleotide: Xdach-Splice-F, Xdach-Splice-R; H4-F, H4-R.

Beide Formen zeige keine Unterschiede hinsichtlich ihres Transkriptionsbeginns im Verlauf der Embryogenese sowie ihrer Expression in Geweben adulter Frösche. So können durch RT-PCR bereits in NF Stadium 15 Neurulae erste Transkripte beider Formen detektiert werden, zum Ende der Neurulation in NF Stadium 19 hat die Expression erheblich zugenommen und bleibt in allen weiter getesteten Entwicklungsstadien auf vergleichbar hohem Niveau. Damit kann ein im Vergleich mit der „WMISH“-Analyse früherer Startpunkt der Xdach1-Transkription ermittelt werden (Abb. 4.24A; s. auch Abb. 4.23).

Bezüglich der Expression in adulten Geweben fallen vor allem die Ergebnisse für total RNA aus dem Herz, der Niere, dem Darm und, mit im Vergleich dazu etwas niedrigerem Expressionsniveau, der Lunge auf. Besonders geringe bis hin zu nicht detektierbare Mengen an Xdach1-mRNA finden sich in Zellen des Skelettmuskels, des Magens, des Pankreas sowie im Hoden und Ovar. Organe neuraler Herkunft wie Auge, Gehirn und Rückenmark zeigen eine vergleichbar starke Transkription beider Xdach1-Formen (Abb. 4.24B).

Somit ergeben sich bei Vergleich mit den durch „WMISH“ gewonnenen Expressionsdaten im Zusammenhang mit der Embryonalentwicklung zumindest bezüglich des Darmes und der Lunge als endodermalen Derivaten klare Unterschiede zwischen der Larvalentwicklung und den Verhältnissen im adulten Tier. Die bereits während der Embryonalentwicklung begonnene Xdach1-Expression innerhalb des Pronephros besteht hingegen im weiteren Verlauf des Lebenszyklus innerhalb der Niere. Ähnliches, wenn auch in abgeschwächter Form, gilt auch für die untersuchten neuroektodermalen Derivate wie Auge, Gehirn und Rückenmark.

\subsection{Das Xdach1-B-Protein ist im Zellkern lokalisiert}

Wie bereits in Kapitel 4.5 bezüglich des Xeya3-Proteins beschrieben, wurden zur Darstellung der subzellulären Lokalisation des Xdach1-B-Proteins Fusionsproteine durch Mikroinjektion in Xenopus laevis Embryonen exprimiert und durch Immunfärbungen an ganzen Embryonen (Abb. 
4.25A, A') bzw. an Paraffinschnitten (Abb. 4.25B-B',') nachgewiesen. Dabei kamen sowohl Flag-Epitop- (am C-Terminus, s. Abb 4.7C) wie auch c-myc-Epitop tragende Proteine zum Einsatz (4.25C).

Xdach1-B-Protein findet sich ausschließlich innerhalb des Zellkerns (Abb. 4.24A-B'"'). Die auf Bereiche zusätzlichen neuralen Gewebes beschränkte Expression des Xdachl-B-c-myc Proteins (Abb. 4.14B-B"') unterstreicht zudem die Spezifität der durch eine Überexpression des Xdach1-B-Proteins erzeugten Phänotypen (s. Kapitel 4.22). Wie im Falle von Xeya3 kommt es auch bezüglich der Xdach1-B-Fusionsproteine zu einer vom betrachteten Gewebe unabhängigen Translokation in den Nukleus. Der Kerntransport nach erfolgter Proteinsynthese sollte somit ebenfalls unabhängig von Gewebe-spezifischen Importfaktoren sein.


Abb. 4.25: Subzelluläre Lokalisation von Xdach1-B. (A) „Whole mount" Immunfärbung an NF Stadium 14 Albino-Embryonen nach Mikroinjektion von $150 \mathrm{pg}$ $X d a c h 1-\mathrm{B}-c-m y c-\mathrm{mRNA}$ in eine Blastomere eines Xenopus laevis Zweizell-Stadiums, frontale Ansicht.

Transversalschnitt durch den in (A) gekennzeichneten Bereich. Nur Nuklei zeigen DetektionsSignale. Der vollständige Durchmesser einer Zelle ist eingekreist.

Transversalschnitt durch einen NF Stadium 29 Embryo nach Mikroinjektion von 150pg Xdachl-B-c-mycmRNA in eine Blastomere eines Zweizell-Stadiums. (B', B", B"') Jeweils identischer Ausschnitt des Transversalschnittes aus (B). Nukleär lokalisiertes Protein (weiße Pfeile) ist innerhalb zusätzlichen Hirngewebes sichtbar. (C) Übersicht über das verwendete Xdach1-B-c-myc-Fusionsprotein. Die sechs $c$ myc-Epitope befinden sich am N-Terminus des Xdach1-B-ORF.

\subsection{Ein Xdach1-Funktionsverlust führt zu Defekten in der embryonalen Augenentwicklung}

Zur Analyse möglicher Xdach1-Funktionen im Verlauf der Embryogenese von Xenopus laevis wurden Funktionsverluststudien durch Mikroinjektion von Morpholino-Antisense- 
Oligonukleotiden durchgeführt. Die Erkennungssequenz des Morpholinos findet sich aufgrund der hohen Sequenzhomologie zwischen beiden Xdach1-Formen sowohl innerhalb der 5'untranslatierten-Region (5'-UTR) von Xdach1-A als auch Xdach1-B.
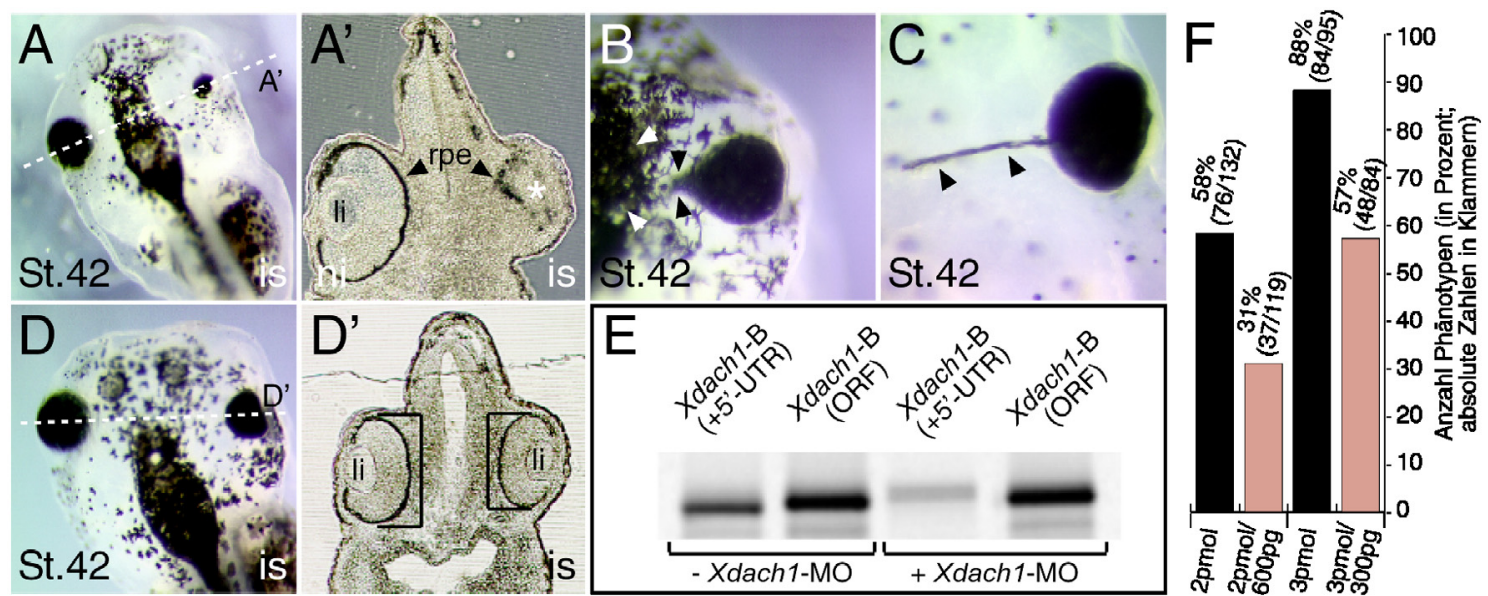

Abb. 4.26: Defekte der Augenentwicklung nach Funktionsverlust von Xdach1. (A-D') NF Stadium 42 Xenopus laevis Embryonen nach Mikroinjektion von 3pmol Xdach1-Morpholino-AntisenseOligonukleotid (MO) in eine Blastomere eines Zweizellstadiums, dorsale Ansicht des Kopfbereiches, Vergrößerungen dorsaler Ansichten und Transversalschnitte. (A) Starke Verkleinerung des Auges mit einhergehender Reduktion Retinalen Pigmentepithels auf der injizierten Seite (is). (A') Es verbleiben Gewebe-Ausstülpungen mit Rudimenten von Retinalem Pigmentepithel (rpe) an Stelle des Auges (weißes Sternchen). Eine Linse wird nicht ausgebildet (li, Linse; ni, nicht injizierte Seite). (B) Expansion Retinalen Pigmentepithels (schwarze Pfeile) in Richtung des Diencephalons (weiße Pfeile). (C) Pigmentierung des optischen Nervs (schwarze Pfeile). (D, D') Verkleinerung des Auges als Folge der Reduktion retinalen Gewebes in weniger schweren Phänotypen (schwarze Klammern). Die ausgebildete Linse erscheint normal. (E) Xdach1-MO blockiert spezifisch die Translation von Xdach1-B (+5'UTR)mRNA im in vitro Translationssystem. Synthetische Xdach1-B (ORF)-mRNA wird auch in Gegenwart des Morpholinos translatiert. (F) Rescue-Experiment unter Verwendung von Xdach1-B (ORF). Durch Ko-Injektion von Xdach1-MO und Xdach1-B (ORF)-mRNA kann der Prozentsatz an Embryonen mit den beschriebenen Phänotypen signifikant gesenkt werden.

Im Zuge eines Xdach1-Funktionsverlustes durch Mikroinjektion des Xdach1-Morpholinos in eine Blastomere eines Zweizell-Stadiums von Xenopus laevis kommt es zu einer deutlichen Verkleinerung von Retina-Gewebe bis hin zum nahezu vollständigen Verlust von Augenstrukturen inklusive der Linse. Dies zeigt sich äußerlich vor allem durch eine Reduktion von Zellen des Retinalen Pigmentepithels (Abb. 4.26A, A', D, D’). Dass dies nicht, wie etwa im Falle eines Funktionsverlustes von Xeya3 (s. Kapitel 4.6), die Folge eines massiven absoluten 
Verlustes von Gewebe ist, zeigt ein Transversalschnitt in Höhe der Augen eines betroffenen Embryos (Abb. 4.26A'). So besteht an Stelle des Auges eine Gewebe-Ausstülpung, in der sich Rudimente eines Pigmentepithels erkennen lassen. Ein weiterer Aspekt im Zusammenhang mit einem Xdachl-Funktionsverlust ist die Ausdehnung Retinalen Pigmentepithels (und möglicherweise darunter gelegenem neuralem Gewebe der Retina) bis in Bereiche des Diencephalons (Abb. 4.26B) bzw. die Pigmentierung des optischen Nervs (Abb. 4.26C).

Neben den beschriebenen Defekten der Augenentwicklung in Xdachl-Morpholino-injizierten Embryonen fällt eine Veränderung der Zellmorphologie innerhalb der betroffenen Hälfte des Mittel- und Hinterhirns auf, welche normalerweise eine grobe Einteilung in proximale und distale Bereiche erlaubt. Dies ist nach einem Xdach1-Funktionsverlust nicht mehr möglich.

Die Spezifität des eingesetzten Morpholinos wurde im in vitro Translationssystem $\left(\operatorname{TnT}^{\circledR}{ }^{\circledR}\right.$ Coupled Reticulocyte Lysate System) sowie im Zuge eines Rescue-Experiments überprüft. Da die Erkennungssequenz des Morpholinos im Bereich der 5'-UTR von Xdach1 liegt, wird die Translation einer synthetischen mRNA, die lediglich den offenen Leserahmen (ORF) von Xdach1-B enthält, nicht inhibiert. Die Proteinsynthese mit einer Xdach1-B-mRNA voller Länge als Matrize wird hingegen deutlich unterdrückt (Abb. 4.26E). Des Weiteren kann durch KoInjektion des Morpholinos sowie synthetischer Xdach1-B-mRNA in Rescue-Experimenten die Ausbildung der beschriebenen Phänotypen zum Teil qualitativ wie quantitativ verhindert werden (Abb. 4.26F).

\subsection{Ein Funktionsverlust von Xdach1 hat Defekte der Musterbildung während der Augenentwicklung zur Folge}

Mit Hilfe der „WMISH“ wurden die in Kapitel 4.19 beschriebenen Defekte der Augenentwicklung nach Funktonsverlust von Xdachl weiter untersucht. Dabei können, in Übereinstimmung mit dem zeitlichen Expressionsmuster von Xdach1, in frühen Neurulae der NF Stadien 13-15 keine Veränderungen hinsichtlich des Expressionsverhaltens der untersuchten Markergene des retinalen Primordiums wie Xpax6 und Xrxl beobachtet werden (Daten nicht gezeigt). Erst zum Ende der Neurulation ab NF Stadium 18 zeigt sich eine Reaktion auf die Abwesenheit bzw. die ungenügende Konzentration einer oder beider Xdach1-Proteine (Abb. 4.27A-C). Bezüglich Xpax6 kommt es dabei zu unterschiedlichen Veränderungen innerhalb der anterior gelegenen und der Expressionsdomäne im Bereich der Rhombomere drei und vier des prospektiven Hinterhirns $(100 \%, \mathrm{n}=26$; Abb. 4.27A). So erscheint erstere als wenig strukturierter Bereich im Vergleich mit der Kontroll-Seite des Embryos, wobei es nicht zu quantitativen Effekten kommt. Im Areal des zukünftigen Hinterhirns zeigt sich hingegen eine starke Repression der Xpax6-Expression. Ebenso lässt sich im Fall von Xrxl weniger eine Herabregulation der Expression als vielmehr eine verminderte Expansion von Xrxl exprimierenden Zellen nach lateral im Zuge der Separation des Augenfeldes beobachten $(100 \%$, 
$\mathrm{n}=15$; Abb. 4.27B). Im Gegensatz zu den für Xpax6 und Xrxl beschriebenen Effekten innerhalb der Augenanlagen führt ein Xdachl-Funktionsverlust zu einer erheblichen Reduktion der Expression von Xoptx2 (Xsixø). Eventuell restliche, Xoptx2 exprimierende Zellen verbleiben analog zu den für Xrxl beschriebenen Beobachtungen in proximalen Bereichen, in nächster Nähe der Mittellinie (94\%, n=17; Abb. 4.27C).

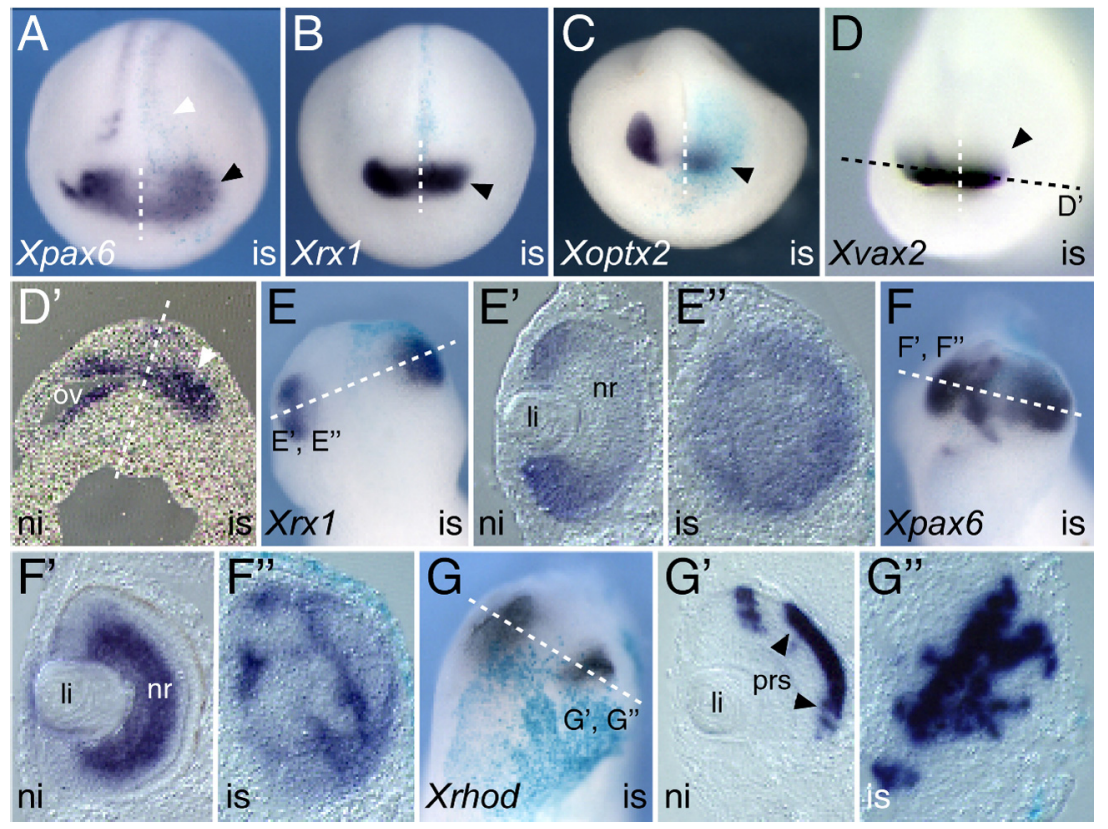

Abb. 4.27: Fehlerhafte
Musterbildung im Zuge der Augenentwicklung nach Funktionsverlust von Xdach1. Injektion von 3pmol Xdachl-MO in eine Blastomere eines Zweizell-Stadiums und nachfolgende „WMISH“; zur Darstellung der injizierten Seite des Embryos wurde synthetische mRNA für $\beta$-Galaktosidase ko-

injiziert und $\beta$-Galaktosidase vor der „WMISH“ durch eine Farbreaktion nachgewiesen; A-C, NF Stadium 18/19, frontale Ansicht; D-D', NF Stadium 25, frontale Ansicht und Horizontalschnitt; E-G', NF Stadium 36, dorsale Ansicht und Transversalschnitte. (A) Desorganisation der anterioren (schwarzer Pfeil) und Repression der Hinterhirn-Expressionsdomäne (weißer Pfeil) von Xpax6 nach Xdach1Morpholino Mikroinjektion (gestrichelte Linie, Mittellinie des Embryos; is, injizierte Seite). (B) Verminderte Expansion des retinalen Markergens Xrxl nach lateral (schwarzer Pfeil). (C) Deutliche Repression der Xoptx2-Transkription (schwarzer Pfeil). (D) Verminderte Expansion des im optischen Stiel exprimierten Xvax2 nach distal (schwarzer Pfeil). (D') Im Horizontalschnitt wird der fehlende optische Vesikel (weißer Pfeil) auf der injizierten Seite des Embryos sichtbar (ni, nicht injizierte Seite; ov, optischer Vesikel). (E, E', E'") Desorganisation der Xrxl-Expression im frühen Kaulquappenstadium. Ein optischer Becher sowie eine Linse werden nicht ausgebildet (E'), eine spezifische Lokalisation von Xrxl transkribierenden Zellen (s. E') ist nicht erkennbar (li, Linse; nr, neurale Retina des optischen Bechers). (F, F', F') Desorganisation der Xpax6-Expression im frühen Kaulquappenstadium. (G, G', G’) Zellen des betroffenen Gewebes exprimieren den Differenzierungsmarker Xrhodopsin (G"), nehmen jedoch nicht die typische räumliche Organisation an (s. G').

Ähnliches zeigt sich auch in NF Stadium 25 bei Betrachtung der Expression von Xvax2, einem im ventralen Diencephalon, dem optischen Stiel sowie dem ventralen optischen Vesikel 
exprimierten Gen (80\%, n=15; Abb. 4.27D). Im Horizontalschnitt wird deutlich, dass es zu keiner Ausbildung eines optischen Vesikels auf der Seite der Injektion des Morpholinos gekommen ist und lediglich ein Bereich an Xvax2 exprimierenden Zellen verbleibt (Abb. 4.27D').

Für späte Entwicklungsstadien wurde in Kapitel 4.19 bezüglich schwerer Phänotypen der Verbleib einer Gewebe-Ausstülpung anstelle des Auges sowie ein Fehlen von Linsenstrukturen beschrieben. Die „WMISH“-Analyse in frühen Kaulquappenstadien zeigt, dass es innerhalb dieses Gewebes nach wie vor zur Expression retinaler Markergene wie Xrx1 und Xpax6 kommt (57\%, n=30; 44\%, n=25; Abb. 4.27E-F'). Eine klare räumliche Organisation von Xrxl- bzw. Xpax6 exprimierenden Zellen (Abb. 4.27E', F') ist allerdings nicht zu erkennen, eine in diesem Entwicklungsstadium beginnende, an Hand der Zellmorphologie erkennbare Schichtung der Retina hat nicht stattgefunden (Abb. 4.27E', F'), eine dorsoventrale als auch proximodistale Achse innerhalb der Retina besteht nicht. Das es innerhalb dieses desorganisierten Gewebes trotzdem zu Zelldifferenzierunsprozessen kommt, zeigt das Vorhandensein von Photorezeptorzellen, gekennzeichnet durch die Expression von Xrhodopsin $(100 \%, \mathrm{n}=45$; Abb. 4.27G-G'”).

\subsection{Ein Xdach1-Funktionsverlust verhindert Neurogenese in Bereichen des zentralen Nervensystems}

Neben Defekten der Musterbildung während der Augenentwicklung sind bei Xdach1Funktionsverlust Anomalien der Zellmorphologie in Bereichen des Mittel- und Hinterhirns beschrieben worden, die möglicherweise Ausdruck einer gestörten Neurogenese sind (s. Kapitel 4.19). Eine „WMISH“-Analyse unter Verwendung von Markergenen für differenzierte Neurone (N-Tubulin) sowie Zellen innerhalb von Bereichen der dorsalen ventrikulären Zone des Gehirns (Xpax3, Храх6) unterstreicht die weiter oben gemachten Beobachtungen. So kommt es zu einem
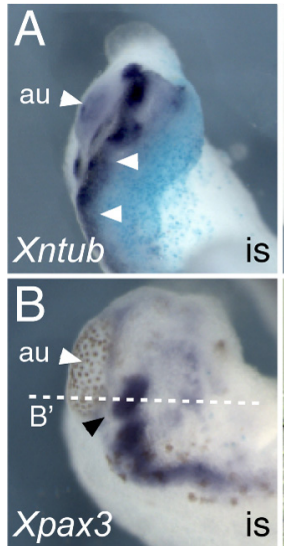
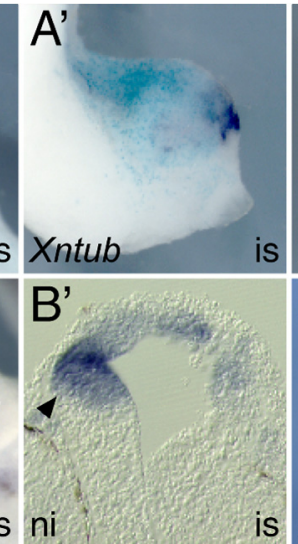
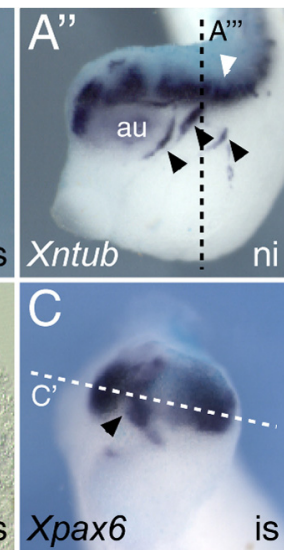
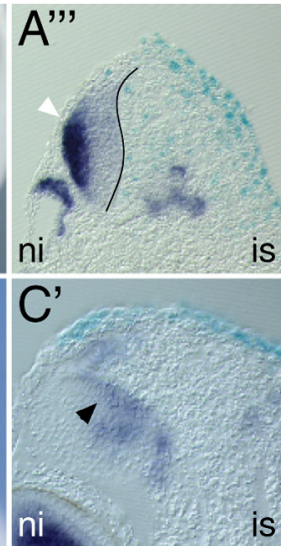

Abb. 4.28: Gestörte Neurogenese nach Funktionsverlust von Xdach1. Injektion von 3 pmol Xdach1-MO in eine Blastomere eines Zweizell-Stadiums und nachfolgende ,WMISH“; zur Darstellung der injizierten Seite des

Embryos wurde synthetische mRNA für $\beta$-Galaktosidase ko-injiziert und $\beta$-Galaktosidase vor der „WMISH“ durch eine Farbreaktion nachgewiesen. (A-A"') Verlust der Expression des neuralen 
Differenzierungsmarkers $N$-Tubulin auf der durch Xdach1-Funktionsverlust betroffenen Seite des Embryos. Neben Hirnstrukturen (weiße Pfeile) sind auch craniale Nerven (schwarze Pfeile) betroffen (A, dorsale Ansicht; A', A", laterale Ansicht; A",, Transversalschnitt; die Grenze zwischen den Gehirnhälften ist durch eine schwarze Linie markiert; au, Auge; is, injizierte Seite; ni, nicht injizierte Seite). (B, B') Verlust der Xpax3-Expression (schwarze Pfeile) auf der injizierten Seite (B, dorsale Ansicht; B', Transversalschnitt). (C, C') Verlust der Xpax6-Expressionsdomäne innerhalb des Diencephalons (schwarze Pfeile; C, dorsale Ansicht; C', Transversalschnitt).

nahezu vollständigen Verlust der Expression der angesprochenen Gene im Bereich der betroffenen Gehirnhälfte (Abb. 4.28), im Fall von N-Tubulin ist zusätzlich ein Verlust der Expression in cranialen Nerven, wie etwa dem trigeminalen Nerv, zu beobachten (Abb. 4.28A, A', A"). Unter einem Funktionsverlust von Xdach1 ist somit die Ausbildung oder auch Erhaltung verschiedener Zelltidentitäten innerhalb des Gehirns, im Gegensatz zu den Verhältnissen während der Retinogenese, gestört. Eine proximodistale bzw. auch dorsoventrale Musterbildung ist nicht zu erkennen.

\subsection{Eine Überexpression von Xdach1-B führt zur Vergrößerung von Derivaten neuralen} Ektoderms

Zur Überexpression des Xdach1-B-Proteins wurde synthetische Xdach1-B-mRNA in Xenopus laevis Embryonen verschiedener Entwicklungsstadien mikroinjiziert. Der Nachweis einer erfolgreichen Xdachl-B-mRNA Translation in vivo erfolgte durch Injektion einer c-mycXdach1-B-mRNA, die anschließende Immunpräzipitation des korrespondierenden Proteins und dessen Detektion mittels Western Blot (Abb. 4.29). Überexpressionsstudien mit dem verkürzten Dachshund-Homolog Xdach1-A wurden in der vorliegenden

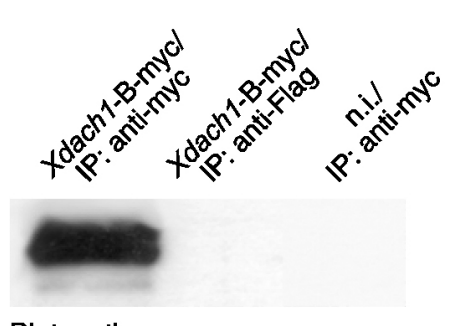

Blot: anti-myc

Abb. 4.29: Translation von

Xdach1-B-myc in vivo. Arbeit nicht durchgeführt.

Bezüglich Kopfstrukturen kommt es unter einer Xdachl-BÜberexpression zu einer deutlichen Ausdehnung von Gewebe im Bereich des Gehirns auf der injizierten Seite sowie zur Bildung eines massiven Koloboms (50pg: 24\%, $\mathrm{n}=75$; 300pg: 89\%, $\mathrm{n}=123$; Injektion in eine Blastomere eines Zweizell-Stadiums; 150pg: $100 \%, \mathrm{n}=20$; Injektion in eine dorsale Blastomere eines 16-Zell-Stadiums; Abb. 4.30A-A,",'). Dabei ist in anterior gelegenen Arealen eine Trennung zwischen retinalem Gewebe und putativem Hirngewebe nur schwer möglich (Abb. 4.30A', A'), weiter posterior erscheint der gebildete optische Becher aufgrund des Defektes bezüglich seines ventralen Schlusses in seiner Lage verändert (Abb. 4.30A'”, A','). In beiden Fällen ist Retinales Pigmentepithel sichtbar, Linsenstrukturen als Derivate plakodalen Ektoderms sind jedoch nicht ausgebildet 
(bestätigt mittels „WMISH“ durch eine vollständige Abwesenheit des Linsenmarkergens Xpitx3, nicht gezeigt). Vereinzelt kommt es darüberhinaus zur Entstehung von z.T. stark pigmentierten Gewebeauswüchsen an Orten hoher Xdach1-B-Konzentration (Abb. 4.30B). Eine Abhängigkeit der Bildung dieser Strukturen von bestimmten Regionen des Embryos ist dabei nicht zu erkennen.

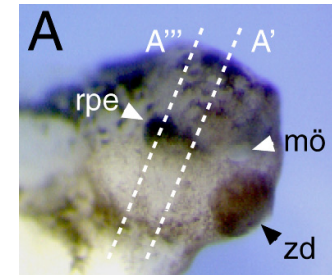

St.38

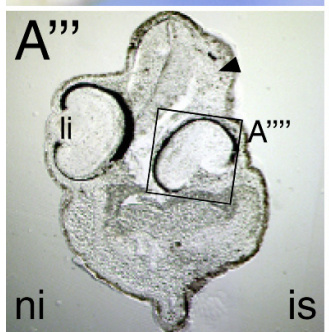

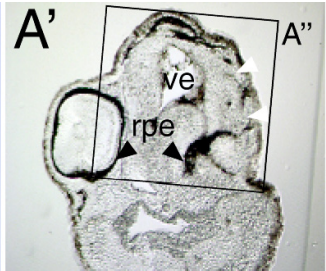

is ni

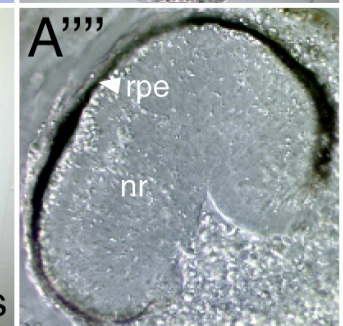

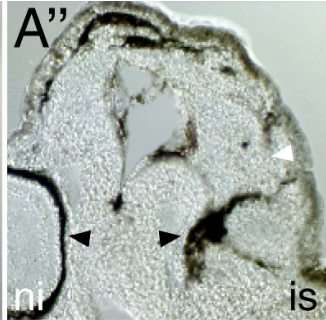

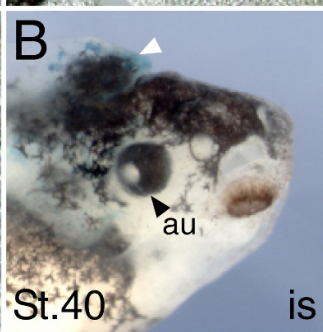

Abb. 4.30: Ausdehnung von Hirngewebe nach Überexpression von Xdach1-B. (A-A,",) NF Stadium 38 Xenopus laevis Embryo nach Mikroinjektion von $300 \mathrm{pg}$ synthetischer Xdach1-B-mRNA in eine Blastomere eines Zweizell-Stadiums, laterale Ansicht und Transversalschnitte. (A, A', A') Es kommt zu einer starken Ausdehnung von Gehirngewebe nach distal (weiße Pfeile in A', A') und Defekten der Augenmorphologie; mö, Mundöffnung; rpe, Retinales Pigmentepithel; ve, Hirnventrikel; zd, Zementdrüse. (A, A",, A,",') Als Folge des Größenzuwachses von Hirngewebe (schwarzer Pfeil in A"') wird eine Dislokation des optischen Bechers beobachtet. Eine Linse wird nicht ausgebildet (li, Linse; nr, neurale Retina). (B) NF Stadium 40 Xenopus laevis Embryo nach Mikroinjektion von 150pg synthetischer Xdach1-B-mRNA in eine dorsale Blastomere eines 16-Zell-Stadiums, laterale Ansicht. Es bilden sich pigmentierte Auswüchse (weißer Pfeil) an Orten hoher Xdach1-B-Konzentration (Färbung für $\beta$-Galaktosidase; au, Auge).

\subsection{Die Überexpression von Xdach1-B hat einen stark neuralisierenden Effekt}

Die in Kapitel 4.22 beschriebenen Phänotypen werden schon früh in der Embryonalentwicklung durch einen stark neuralisierenden Effekt von Xdach1-B nach Überexpression angelegt. So kommt es in Neurula-Stadien zur starken Expansion der Expressionsdomäne des panneuralen Markergens Xsox3 nach lateral (Abb. 4.31A, B). Gleichzeitig kann eine starke Repression der Expression des epidermalen Markergens $X k 81$ im Areal der injizierten mRNA beobachtet werden (Abb. 4.31C). Eine Doppelhybridisierung mit RNA-Sonden für Xsox3 und Xk81 zeigt ein komplementäres Hybridisierungsmuster bezüglich beider Transkripte (Abb. 4.31D, D'; vergl. auch Abb. 4.13G, G'). Zellen, nach Überexpression von Xdach1-B negativ für Xk81, transkribieren nun also das von frühen, neuralen Vorläufern exprimierte $X s o x 3$. Einen weiteren Hinweis auf eine Transdetermination nicht-neuralen Gewebes als Ursache des neuralisierenden 
Effektes der Xdach1-B-Überexpression gibt das Ausbleiben von Proliferationseffekten auf Seite der Injektion (Abb. 4.31E). So ergibt sich nach Detektion des Proliferationsmarkers $p H 3$ weder eine signifikante $\mathrm{Zu}$ - noch Abnahme der Anzahl an proliferierenden Zellen bei Vergleich injizierter zu nicht injizierter Seite des Embryos (93\% der Embyronen ohne Differenzen zwischen injizierter Seite/nicht injizierter Seite, $n=30$ ). Des Weiteren bleiben die bezüglich Xsox 3 und Xk81 weiter oben beschriebenen Effekte nach Xdach1-B-Überexpression auch nach Behandlung der Embryonen mit Hydroxyurea/Aphidicolin („HUA“, s. auch Kapitel 4.13) bestehen (nicht gezeigt). Die Zunahme von Gewebe neuralen Schicksals geht somit auf Kosten nicht-neuralen Gewebes und ist nicht die Folge erhöhter Proliferationsraten neuraler Vorläuferzellen.
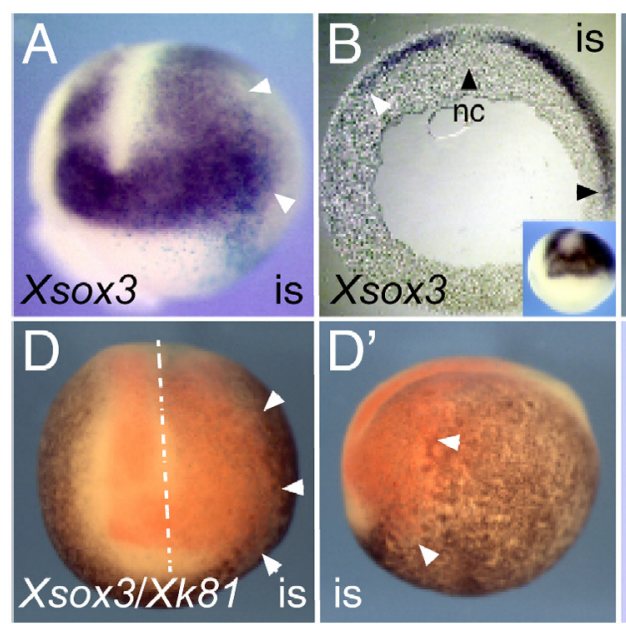
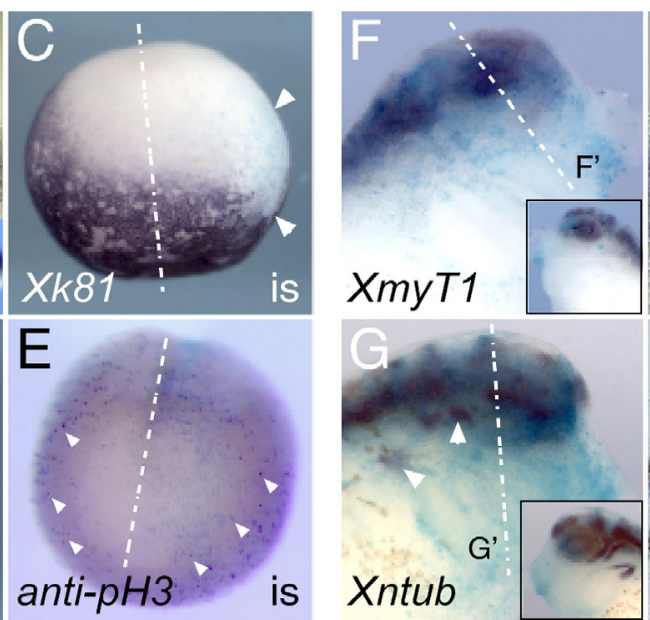

Abb. 4.31: Transdeterminierung nicht-neuralen in neurales Gewebes nach Überexpression von

Xdach1-B. Injektion von 150pg synthetischer Xdach1-B-mRNA in eine Blastomere eines ZweizellStadiums und nachfolgende „WMISH“ bzw. Detektion von phosphoryliertem Histon 3 (pH3); zur Darstellung der injizierten Seite des Embryos wurde synthetische mRNA für $\beta$-Galaktosidase ko-injiziert und $\beta$-Galaktosidase durch eine Farbreaktion nachgewiesen. (A, B) Expansion der Expressionsdomäne des panneuralen Markergens Xsox3 in NF Stadium 14 Neurulae (frontale Ansicht und Transversalschnitt; is, injizierte Seite; nc, Notochord). (C) Repression des epidermalen Markergens $X k 81$ (epidermales Keratin) im NF Stadium 14 nach Mikroinjektion von Xdach1-B-mRNA (frontale Ansicht; gestrichelte Linie, Mittellinie des Embryos). (D, D') Doppelfärbung von Xsox3 und Xk81 in NF Stadium 15. Es zeigt sich ein komplementäres Expressionsmuster bezüglich der beiden Gene (frontale und laterale Ansicht; gestrichelte Linie, Mittellinie des Embryos). (E) Detektion von phosphoryliertem Histon 3 in NF Stadium 14 nach Überexpression von Xdachl-B. Es kommt zu keiner Veränderung der Proliferationsrate (frontale Ansicht; gestrichelte Linie, Mittellinie des Embryos; einige $p H 3$-positive Zellen sind durch weiße Pfeile gekennzeichnet). (F, F') Laterale Ansicht und Transversalschnitt eines NF Stadium 34 Embryos. Zellen des vergrößerten Hirngewebes exprimieren XmyT1 (schwarze Pfeile in F'; die nicht injizierte Seite ist 
verkleinert in F dargestellt). (G, G') Laterale Ansicht und Transversalschnitt eines NF Stadium 34 Embryos. Zellen des vergrößerten Hirngewebes exprimieren den Differenzierungsmarker N-Tubulin (schwarze Pfeile in G'). Neurale Derivate cranialer Plakoden sind stark reduziert (weiße Pfeile in G; re, Retina; die nicht injizierte Seite ist verkleinert in G dargestellt).

Die Expression von neuralen Markergenen wie XmyT1 (Abb. 4.31F, F') und dem Differenzierungsmarker N-Tubulin (Abb. 4.31 G, G') innerhalb des in Kapitel 4.22 beschriebenen vergrößerten Areals im Bereich des Gehirns zeigt, dass es zur Bildung zusätzlichen neuralen Gewebes kommt, welches zudem Differenzierungsprozesse durchläuft. Im Fall von N-Tubulin ist außerdem eine starke Repression der Expression in Derivaten cranialen plakodalen Ektoderms, wie etwa dem trigeminalen Nerv, zu beobachten (Abb. 4.30G). Haben diese Strukturen auch nach Durchlaufen ihres Differenzierungsprozesses neuralen Charakter, so fallen doch ihre nicht-neuralen, ektodermalen Vorläufer, wie im übrigen auch Zellen plakodalen Linsenektoderms (s. Kapitel 4.22, Xpitx3), der induzierten Neuralisierung zum Opfer.

\subsection{Xdach1-B inhibiert den Xbmp4-Signaltransduktionsweg}

In Kapitel 4.22 und 4.23 ist eine Neuralisierung durch Xdachl-B-Überexpression als Folge der Transdeterminierung nicht-neuraler Areale beschrieben worden. Ein akzeptiertes Modell beschreibt die Entstehung neuralen Gewebes als Resultat der Inhibition von Signaltransduktionskaskaden, welche durch sezernierte Moleküle der $T G F-\beta$-Familie aktiviert werden (Munoz-Sanjuan und Brivanlou, 2002; Weinstein und Hemmati-Brivanlou, 1999). Ein Beispiel für einen solchen Antagonisten ist der sezernierte Faktor Chordin, der direkt Bmp4, ein Mitglied der $T G F-\beta$-Proteinfamilie, bindet und so eine Interaktion mit seinem Zellmembranrezeptor verhindert (Piccolo et al., 1996). Xdach1 besitzt einen zu den Protoonkogenen Ski und Sno homologen Bereich (s. Abb. 4.19, 4.20, 4.21). Es konnte gezeigt werden, dass $S k i$ und Sno als negative Regulatoren der $T G F-\beta$-vermittelten Signaltransduktion wirken (Luo, 2004).

Zum Test einer in diesem Zusammenhang möglichen antagonistischen Funktion des Xdach1-BProteins, wurden verschiedene Kombinationen des Xdach1-B- sowie des Xbmp4-Proteins in animalen Gewebeexplantaten überexprimiert und deren Transkriptom mit Hilfe einer semiquantitativen RT-PCR auf das Vorkommen von mRNA spezifischer Zielgene hin untersucht (Abb. 4.32A). Dabei ergibt sich, analog zu den durch „WMISH“ erhaltenen Daten, eine deutliche Aktivierung der Xsox3-Transkription nach Injektion von 200pg an Xdach1-BmRNA, was die Neuralisierung der Gewebeexplantate zeigt. Ebenso lässt sich die Transkription von Xmsx1, einem Zielgen der Xbmp4-Signaltransduktionskaskade, durch Überexpression von Xbmp4 (1000pg) hochregulieren. Dieser Effekt kann durch gleichzeitige Injektion von Xdach1- 
B-mRNA deutlich abgeschwächt werden und es kommt im Gegensatz dazu zu einem Anstieg der Xsox3-Transkription (1000pg Xbmp4/200pg Xdach1-B). Daraus folgt eine gegenüber der Xbmp4-Funktion antagonistische Wirkung des Xdach1-B-Proteins, die als Erklärung für die beobachteten transdeterminierenden und neuralisierenden Effekte herangezogen werden kann.

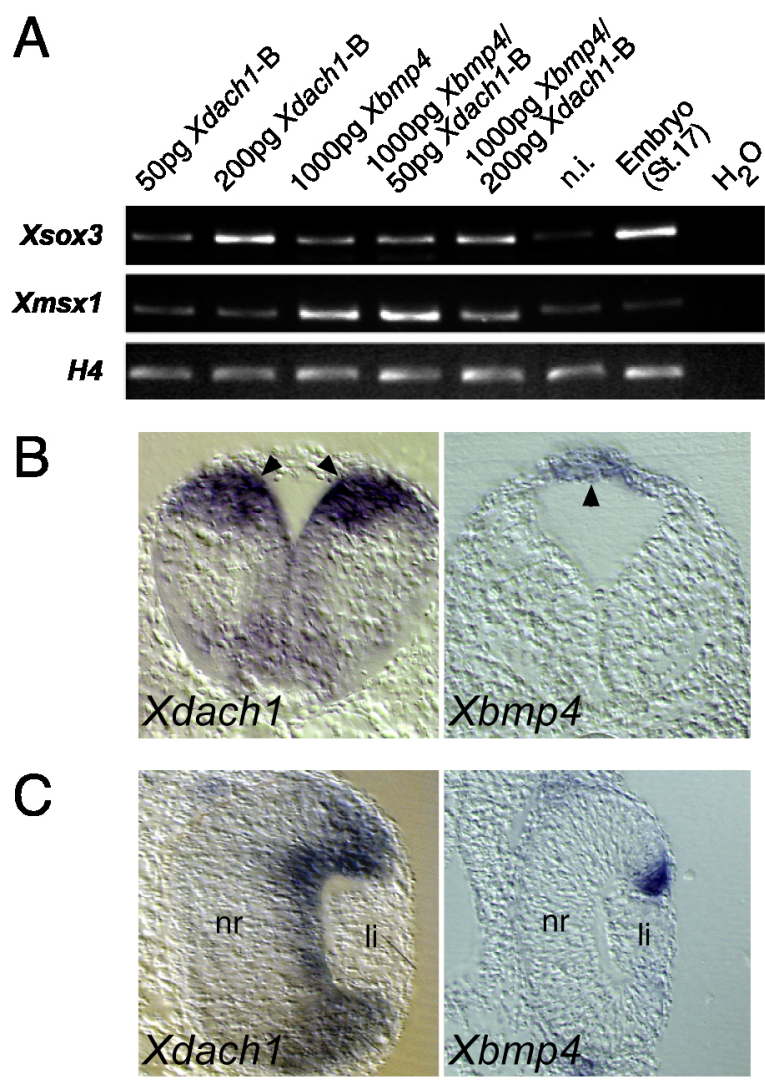

Abb. 4.32: Xdach1-B als Inhibitor der Xbmp4-Signaltransduktion. (A) RT-PCR auf total RNA aus animalen Gewebeexplantaten im korrespondierenden NF Stadium 17 aus Xenopus laevis. Die injizierten mRNAs sind oberhalb, die im Zuge der RT-PCR definierten Zielgene links angegeben (n.i., nicht injizierte Gewebeexplantate; Embryo (St.17), Kontrollembryo NF Stadium 17; H4, Histon 4). Durch Injektion von 200pg an Xdach1-BmRNA kommt es zur Neuralisierung der Gewebeexplantate, erkennbar anhand der deutlichen Hochregulation der Xsox3Transkription. Die Aktivierung der Xbmp4Signaltransduktionskaskade durch Injektion von Xbmp4 führt zur Transkription des Zielgens Xmsx1 (1000pg Xbmp4). Eine Ko-Injektion von Xdach1-B-mRNA führt zur Repression der

Xmsx1-Transkription und gleichzeitig zur Aktivierung der Transkription des neuralen Markergens Xsox3 (1000pg Xbmp4/200pg Xdach1-B). (B) Transversalschnitte im Bereich des Hinterhirns von NF Stadium 38 Embryonen. Es ergibt sich ein komplementäres Expressionsmuster von Xdach1 und Xbmp4. (C) Transversalschnitte des Auges von NF Stadium 32 Embryonen. Die Expression von Xdach1 grenzt im dorsalen optischen Becher unmittelbar an die Expressionsdomäne von Xbmp4.

Ein möglicher in vivo Zusammenhang zwischen Funktionen des Xdach1-B- und des Xbmp4Proteins ergibt sich bei Betrachtung der korrespondierenden Expressionsmuster im Bereich des Hinterhirns in NF Stadium 38 und des optischen Bechers in NF Stadium 32 Xenopus laevis Embryonen (Abb. 4.32B, C). So wird Xbmp 4 im Hinterhirn und Rückenmark ausschließlich von äußerst dorsal gelegenen Zellen der Dachplatte exprimiert, ein morphogenetischer Gradient des Xbmp4-Proteins sollte in dorsoventraler Orientierung bestehen. Die direkt in Richtung ventral angrenzende Expressionsdomäne von Xdach1 könnte dabei die Wirkungen der verschiedenen Konzentrationen an Xbmp4-Protein modifizieren und somit Bmp-abhängige Musterbildungsprozesse in dorsoventraler Orientierung unterstützen. Ähnliches ist im Fall des 
optischen Bechers bezüglich einer Musterbildung der Retina in dorsoventraler als auch proximodistaler Orientierung denkbar, da die Expressionsdomänen beider Gene auch hier direkt aneinander grenzen (Abb. 4.32C; li, Linse; nr, neurale Retina).

\subsection{Eine Ko-Injektion von Xdach1-B und Msix6 führt zu positiven synergistischen Effekten bezüglich retinalen Wachstums}

Der Komplexaugenentwicklung in Drosophila melanogaster liegt ein genetisches Netzwerk zugrunde, das auf z.T. direkten Interaktionen der beteiligten Faktoren (ey, so, eya, dac) beruht (Tavsanli et al., 2004). In der Maus ist ein funktioneller Zusammenhang zwischen Six6, einem Homolog des sine oculis Gens aus Drosophila melanogaster, und Dachshund1 bezüglich der Entwicklung retinaler Strukturen beschrieben worden, wo sie als direkte Interaktionspartner zusammen mit anderen Faktoren einen Repressorkomplex ausbilden und Zellproliferation stimulieren (Li et al., 2002).

A

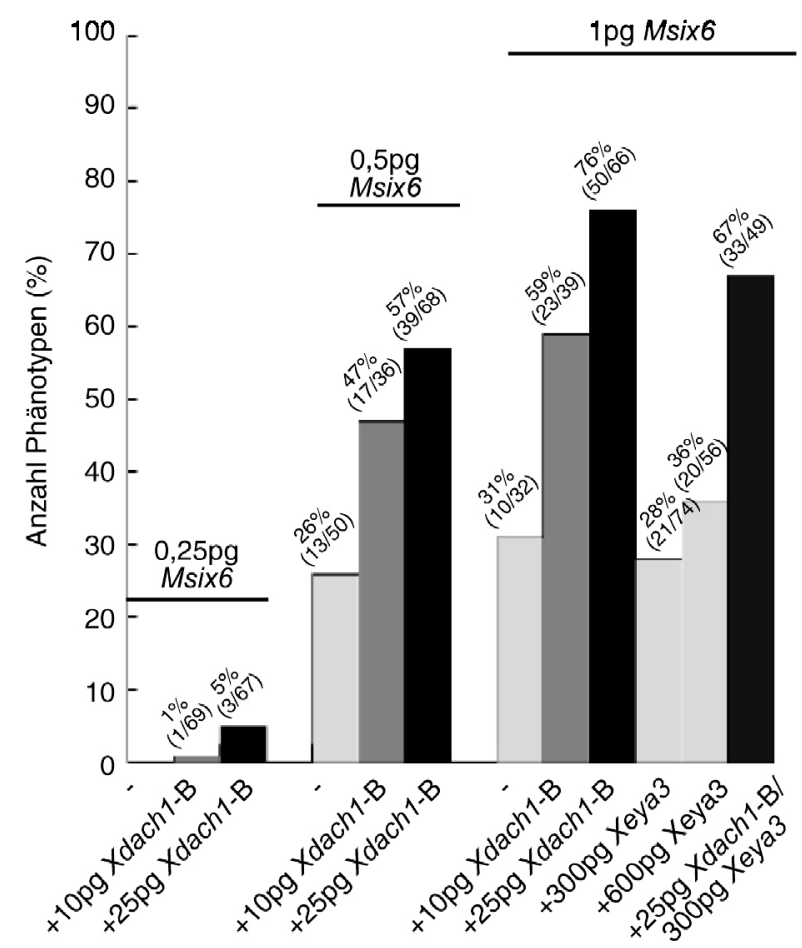

B
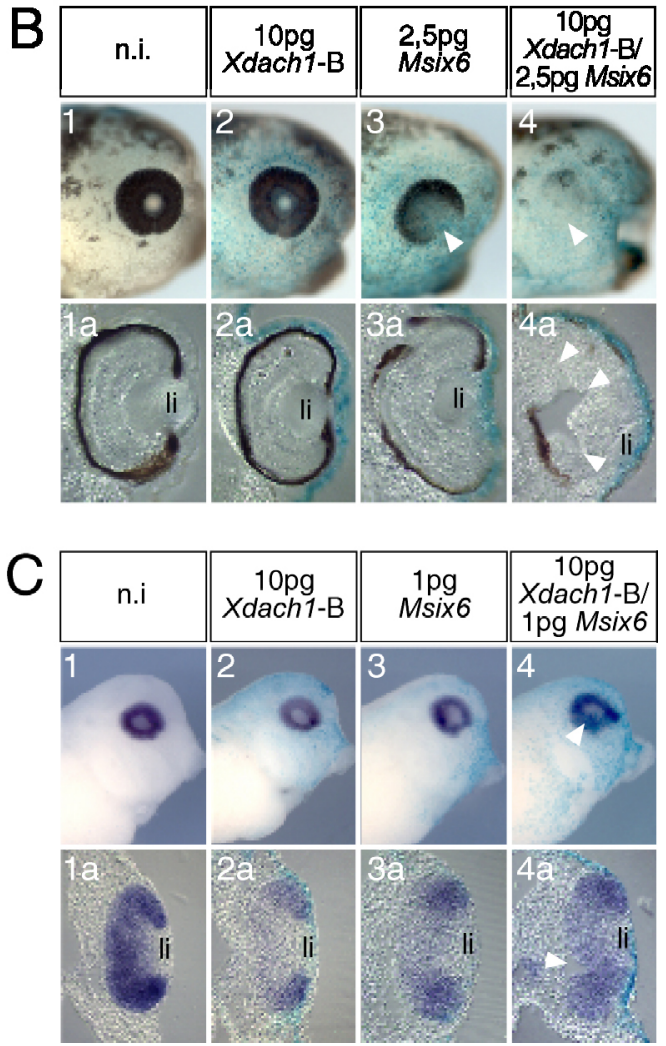

Abb. 4.33: Synergismus zwischen Xdach1-B und Msix6. (A) Ko-Injektionsexperiment unter Verwendung synthetischer mRNA kodierend für Maus Six6 (Msix6) und Xenopus laevis Xdach1-B und Eya3. Durch Ko-Injektion geringer Mengen von Msix6- und Xdach1-B-mRNA in eine Blastomere eines Zweizell-Stadiums kann die Anzahl an Embryonen mit phänotypischen Veränderungen im Bereich des Auges deutlich gesteigert werden. Eine Ko-Injektion von Xeya3-mRNA kann die durch eine Msix6- 
Überexpression hervorgerufenen Phänotypen nicht quantitativ verstärken. (B) Qualitative Veränderung der erhaltenen Phänotypen bei Ko-Injektion von Msix6 und Xdachl-B im Vergleich zur Msix6Überexpression. Anstatt der Ausbildung eines Koloboms (weißer Pfeil in 3) und einem leichten Größenzuwachs der Retina (3, 3a) kommt es in NF Stadium 36 zu massiver retinaler Neoplasie inklusive mehrfacher Einfaltungen (weiße Pfeile in 4a) innerhalb des neu gebildeten Retinagewebes (4, 4a). Die alleinige Injektion geringer Mengen an Xdach1-B-mRNA hat keinen Effekt (2, 2a; li, Linse; n.i., nicht injizierter Embryo). (C) Nachweis des retinalen Markergens Xrxl in NF Stadium 32 durch „WMISH“ (laterale Ansicht des Kopfbereiches und Transversalschnitte durch das Auge auf der injizierten Seite, gekennzeichnet durch die Färbung gegen $\beta$-Galaktosidase). Die Hybridisierung bestätigt die unter (B) gemachten Beobachtungen eines massiven Zuwachses an retinalem Gewebe mit als Folge davon auftretenden Einfaltungen bei Ko-Injektion von Msix6- und Xdach1-B-mRNA (weiße Pfeile in 4, 4a).

Zum Test auf mögliche funktionelle Wechselwirkungen zwischen Xdach1-B, Xeya3 sowie dem Six6-Protein der Maus wurden diese durch Ko-Injektion in Zweizell-Stadien von Xenopus laevis auf die Ausprägung möglicher synergistischer Effekte hin untersucht. Dabei wurden mRNA Mengen verwendet, welche alleine quantitativ wie qualitativ keine oder nur geringe Auswirkung auf die Ausbildung der entsprechenden Phänotypen haben. In Übereinstimmung mit den aus der Maus bekannten Daten zeigt sich dabei ein starker Synergismus zwischen Msix6 und Xdach1-B, der bei Einsatz von 25pg Xdach1-B-mRNA durchschnittlich zu einer Erhöhung der Anzahl an betroffenen Embryonen um den Faktor 2,4 führt (Abb. 4.33A). Neben diesen quantitativen Beobachtungen fällt bei Ko-Injektion von Msix6 und Xdach1-B zudem die Ausbildung deutlich stärkerer retinaler Phänotypen auf, was sich in einer massiven Neoplasie der betroffenen Retina (Abb. 4.33B4, 4a) im Vergleich zu einer moderaten Vergrößerung inklusive der Ausbildung eines Koloboms nach Mikroinjektion von Msix6-mRNA (Abb. 4.33B3, 3a) äußert. Eine „WMISH“-Analyse unter Verwendung des retinalen Markergens Xrx 1 bestätigt die beobachteten Effekte, als dass sich eine Vergrößerung seiner Expressionsdomäne (Abb. 4.33C3, 3a) bis hin zu wachstumsbedingten Einfaltungen (Abb. 4.33C4, 4a) zeigt.

Im Gegensatz dazu hat eine Ko-Injektion von Msix6 und Xeya3 weder qantitative noch qualitative Auswirkungen bezüglich der Ausprägung retinaler Phänotypen (Abb. 4.33A). Eine Ko-Injektion von Xdach1-B und Xeya3 zeigt ebenfalls keine Effekte (nicht gezeigt). Der starke, quantitative synergistische Effekt bei Ko-Injektion von Msix6, Xdach1-B und Xeya3 erklärt sich durch die bereits weiter oben beschriebenen Auswirkungen einer gemeinsamen Überexpression von Msix6 und Xdach1-B. Der Versuch, die beschriebenen Effekte durch Ko-Injektion eines anderen Mitgliedes der Six-Familie von Proteinen, Msix3, zu erhalten, schlägt fehl (nicht gezeigt), was auf eine Spezifität der Xdach1-B/Msix6-Wechselwirkung schließen lässt. 



\section{Diskussion}

\subsection{Xeya3 als Mitglied der Eyes absent-Familie von Proteinen}

Das mit dieser Arbeit vorgestellte Eyes absent Homolog 3 aus Xenopus laevis ist Teil der in Vertebraten mittlerweile vier Mitglieder umfassenden Eya-Familie von Proteinen (Abdelhak et al., 1997; Borsani et al., 1999; Zimmerman et al., 1997). In Xenopus laevis sind bislang lediglich zwei Eya-Homologe, Xeyal (David et al., 2001) und Xeya2 (Kriebel, Diplomarbeit 2001), bekannt. Beide werden im Mesoderm hypaxialer Muskelvorläuferzellen und, im Fall von Xeya2, in der Pronephros-Anlage exprimiert. Abgesehen von neuralen Derivaten plakodalen Ektoderms zeigt sich jedoch, im Gegensatz zu murinen Eyal und Eya2 Homologen (Xu et al., 1997), zu keinem Zeitpunkt der Entwicklung Expression innerhalb neuroektodermalen Gewebes wie etwa Gehirn oder Retina. Durch seine Expression in undifferenziertem neuralen Gewebe wie der Neuralplatte inklusive des Augenfeldes ist Xeya3 diesbezüglich zur Zeit das einzige Xenopus laevis Eya-Homolog und unterscheidet sich somit klar von den beiden anderen Homologen. Dabei zeigen sich beim Vergleich des Xeya3-Expressionsmusters mit dem von murinem Eya3, stärker als für die Homologe 1 und 2, deutliche Ähnlichkeiten (s. Abb. 5.1; Xu et al., 1997).

Das Auftreten von kongenitalen Katarakten ist beim Menschen mit Mutationen innerhalb des EYA1-Gens in Verbindung gebracht worden. Neben der branchiootischen- (BO) bzw. branchiootorenalen Dysplasie (BOR) und einem postnatal progressiven Gehörverlust (DFNA10), deren Auftreten mit einer Haploinsuffizienz von EYAl sowie EYA4 korrelieren (Abdelhak et al., 1997; Vincent et al., 1997; Zhang et al., 2004), ist dies ein weiterer Entwicklungsdefekt bezüglich einer ursächlichen Beteiligung der Eya-Familie (Azuma et al., 2000). Weder das Xenopus Eyal- (David et al., 2001) noch das Eya2-Homolog (Kriebel, Diplomarbeit 2001) werden im Verlauf der Embryonalentwicklung von Zellen des Linsenektoderms oder innerhalb der aus der Neuralleiste abgeleiteten embryonalen Branchialbögen transkribiert. Für Xeya3 konnte in der vorliegenden Arbeit eine Expression innerhalb der Linsenplakode zum Ende der Neurulation, innerhalb primärer Linsenfasern nach Invagination des Linsenvesikels und im Bereich der Branchialbögen gezeigt werden (s. Kapitel 4.4). Des Weiteren zeigen beide Strukturen, Linse wie Kiemenbögen, phänotypische Veränderungen als Folge einer Verminderung bzw. Erhöhung der Xeya3-Proteinkonzentration während der Embryonalentwicklung (s. Kapitel 4.6, 4.9). Besteht auch eine, auf Sequenzhomologien zwischen den verschiedenen Vertebraten-Eya-Homologen beruhende Einteilung in die vier Subklassen, so ist es doch im Verlauf der Evolution zu einer Veränderung der Spezifitäten auf Ebene der transkriptionellen Regulation der Eya-Mitglieder wie auch hinsichtlich ihrer Funktionen während der Entwicklung gekommen. Die weiter oben 
beschriebenen humanen Entwicklungsdefekte erscheinen so als eine Kombination der aus Xenopus laevis bekannten Charakteristika der verschiedenen Eya-Homologe.

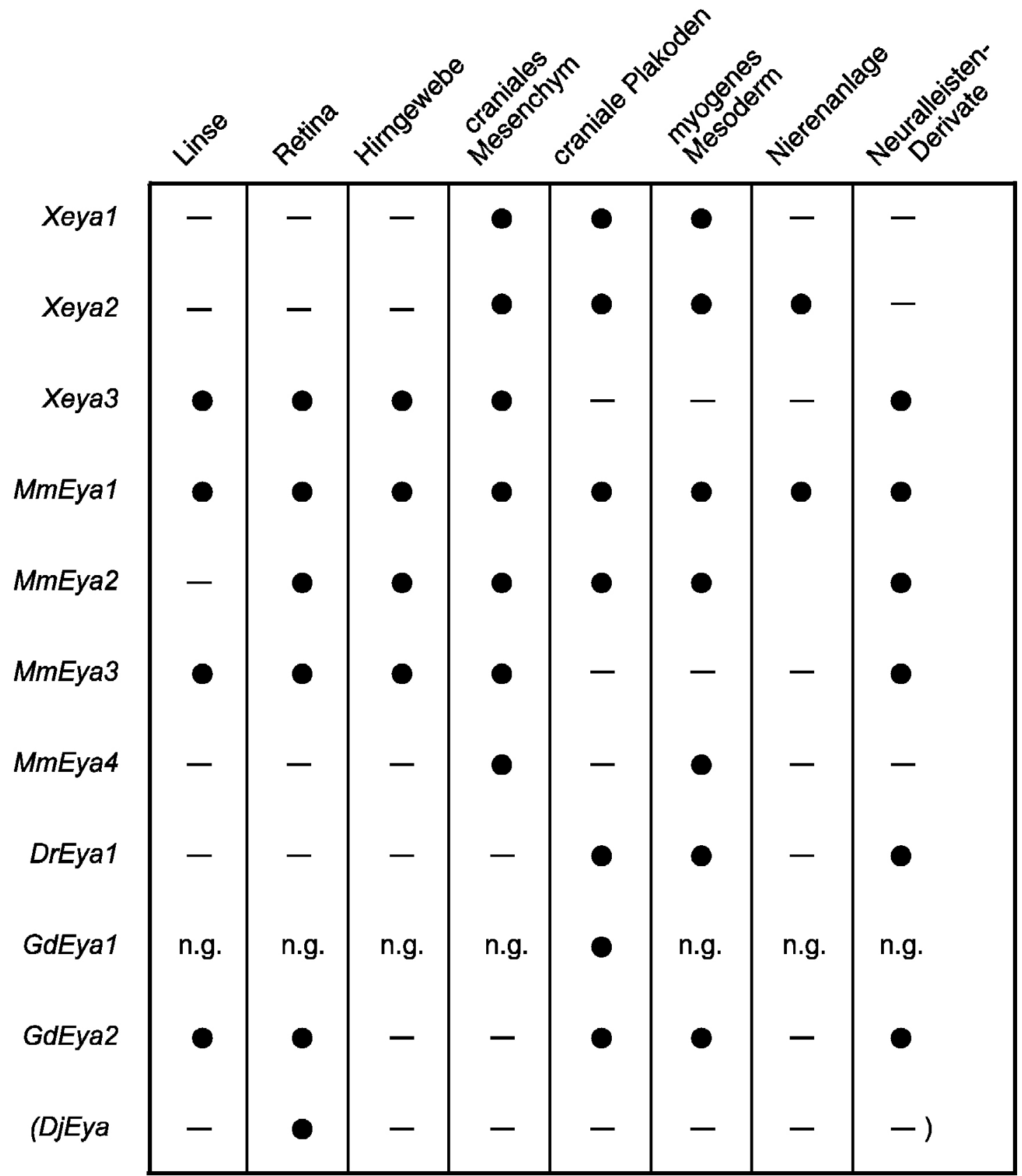

Abb. 5.1: Räumliches Expressionsmuster von Eyes absent Homologen außerhalb Drosophila melanogaster. Abkürzungen: Dj, Dugesia japonica (als Invertebrat in Klammern; „Retina“ bezieht sich in diesem Fall auf die ausgebildeten Becherocellen); Dr, Danio rerio; Gd, Gallus domesticus; Mm, Mus musculus; n.g., nicht getestet; $X$, Xenopus laevis. 


\subsection{Xeya3 als trophischer Faktor der Spezifikation und Determination anterioren neuralen}

\section{Gewebes}

Transkripte des maternal exprimierten Gens Xeya3 finden sich vor Beginn der Gastrulation in der gesamten animalen Hemisphäre der Xenopus laevis Blastula. Zum Zeitpunkt früher Neurula-Stadien kommt es zur Eingrenzung der Xeya3-Expression auf vordere Abschnitte der entstandenen Neuralplatte (s. Kapitel 4.4). Dieses Areal beinhaltet Zellen des prospektiven Gehirns wie auch der Augenanlagen. Möglicherweise wird die Xeya3-Transkription dabei negativ von caudalisierend wirkenden Morphogenen (z.B. Retinsäure, Fgf, Wnt) reguliert, welche innerhalb dorsalen Mesoderms in einem Gradienten mit posterior - anteriorer Orientierung vorliegen und im Zusammenhang mit anterioposterioren Musterbildungsprozessen stehen (Papalopulu et al., 1991; Sive et al., 1990).

Die durch Funktionsverlust- bzw. Funktionsgewinnstudien bezüglich Xeya3 erhaltenen Daten unterstreichen seine essentielle Funktion während der Spezifikation und weiteren Entwicklung anterioren neuralen Gewebes. Dabei ist die Induktion des apoptotischen Programmes und die daraus folgende Reduktion der betroffenen Gewebe/Organe im Zuge eines Funktionsverlustes (s. Kapitel 4.6, 4.7, 4.8) auch für Eya-Homologe anderer Spezies beschrieben worden. So kommt es vergleichbar in Eyal'/Eyal-Mäusen zum Zelltod von Zellen der auditorischen sowie der renalen Anlage, beides Gewebe mit endogener Expression von Eyal. In heterozygoten Fällen zeigen sich mildere Effekte, die den Phänotypen in Patienten mit dem BOR-Syndrom entsprechen (Xu et al., 1999). Ebenso verhindern Mutationen im eya-Locus von Drosophila melanogaster die Differenzierung von Zellen zu funktionellen Einheiten, den Ommatidien, im Verlauf der Entwicklung des Komplexauges. Analog zu den in Vertebraten beschriebenen Verhältnissen kommt es vielmehr zum vermehrten Zelltod von Vorläuferzellen anterior der Morphogenetischen Furche. In diesem Zusammenhang wurde eine Eya-Funktion hinsichtlich der Kontrolle der Anzahl an Progenitor- und, daraus abgeleitet, differenzierenden Zellen vorgeschlagen (Bonini et al., 1993). Damit im Einklang steht der in Xenopus laevis beobachtete positive Proliferationseffekt bei Überexpression des Xeya3-Proteins, der zu einer deutlichen Vergrößerung neuraler Gewebe wie Gehirn und Auge als Folge einer erhöhten Anzahl neuraler Vorläuferzellen führt (s. Kapitel 4.9, 4.11, 4.12, 4.13). Die Ausprägung der beschriebenen Funktionsverlust- und Funktionsgewinn-Phänotypen ist, wie durch die Analyse molekularer Marker gezeigt, schon früh in der Embryonalentwicklung angelegt (s. Kapitel 4.7, 4.10). Damit besitzt Хeya3 eine Funktion in anterioren neuralen Vorläuferzellen schon zu Beginn der primären Neurogenese noch vor bekannten Faktoren mit Expression innerhalb der anterioren Neuralplatte wie beispielsweise Xotx2 (Pannese et al., 1995). Eine Notwendigkeit der Xeya3Expression in Zellen der animalen Hemisphäre in Blastula-Stadien kann des Weiteren nicht ausgeschlossen werden, da es schon bei nur geringfügiger Erhöhung der Menge an injiziertem Morpholino zu einem starken Anstieg der Letalitätsrate der Embryonen kommt. 
Mit beginnender Differenzierung geht die Xeya3-Expression innerhalb anterioren neuralen Gewebes stark zurück. So lassen sich in Kaulquappenstadien innerhalb von Zellen der neuralen Retina wie auch innerhalb von Hirnregionen, bis auf wenige Ausnahmen, keine Xeya3Transkripte mehr nachweisen (s. Kapitel 4.4). Eine Funktion von Xeya3 im Zusammenhang mit der primären Spezifikation und Determination neuraler Progenitorzellen steht damit im Einklang.

Eine Überexpression des Xeya3-Proteins führt lediglich in Bereichen endogener Xeya3Expression zu phänotypischen Veränderungen, die in „WMISH“ eingesetzten Markergene wurden nicht ektopisch, d.h. räumlich getrennt von ihrer im Wildtyp vorzufindenden Expressionsdomäne, exprimiert (s. Kapitel 4.10, 4.11, 4.12). Dies legt nahe, dass das Protein nur in Anwesenheit spezifischer Faktoren funktionell aktiv sein kann, die selbst, alleine oder in Kombination, innerhalb der endogenen Xeya3-Expressionsdomäne vorzufinden sind. Oder bzw. und durch Mikroinjektion synthetischer mRNA exogen zugeführtes Xeya3-Protein wird, ähnlich wie schon weiter oben vorgeschlagen, durch morphogenetische Gradienten oder komplementär zu Xeya 3 exprimierte Faktoren in seiner Funktion blockiert.

Neben starker Hypoplasie neuralen Gewebes fällt im Zusammenhang mit einem Xeya3Funktionsverlust ebenso das Fehlen von Linsenstrukturen auf. Eine Expression von Xeya3 innerhalb plakodalen Linsenektoderms kann zum Ende der Neurulation beobachtet werden (s. Kapitel 4.4), einem Zeitpunkt, der die beginnende Spezifizierung des Linsenektoderms durch Wechselwirkungen mit dem darunterliegenden neuralen Gewebe der optischen Vesikel markiert (Henry und Grainger, 1990). Der beobachtete Defekt der Linsenbildung ist so möglicherweise sowohl eine primäre (wegen des Fehlens von Xeya3 innerhalb des heranreifenden Linsenvesikels) als auch eine sekundäre Folge des Xeya3-Funktionsverlustes (aufgrund des Zelltodes neuraler Vorläufer des optischen Vesikels und der damit ausbleibenden Interaktion zwischen neuralem und nicht-neuralem Gewebe), der hier neurales wie auch nicht-neurales Ektoderm betrifft.

\subsection{Das Xeya3-Protein besitzt möglicherweise zusätzlich eine transdeterminierende Funktion}

In Zuge der Xeya3-Überexpression konnte eine Repression der Expression von Markergenen plakodalen $(X d l x 3, X s o x 3)$ sowie epidermalen Ektoderms $(X k 81)$ lateral der offenen Neuralplatte beobachtet werden (s. Kapitel 4.10). Die Identität der betroffenen Zellen konnte nicht abschliessend geklärt werden. Denkbar ist jedoch die Bildung zusätzlichen cranialen Neuralleistengewebes, das während der späteren Entwicklung an der Bildung der Branchialbögen beteiligt ist, da es zu Defekten in der Ausbildung cranialer Nerven (s. Kapitel 4.12) sowie, in einigen Fällen, zur Bildung aktiv proliferierender tumoröser Auswüchse im Bereich der Branchialbögen kommt (s. Kapitel 4.9). Eine transdeterminierende Funktion ist 
auch für Eyes absent aus Drosophila melanogaster beschrieben worden, das bei ektopischer Überexpression innerhalb der Antennen-Imaginalscheibe die Bildung ektopischen Augengewebes verursacht (Bonini et al., 1997; Chen et al., 1997).

Als eine Folge der Xeya3-Überexpression konnte eine Repression der Xk81-Expression auch in ventralen Regionen des Xenopus laevis Embryos beobachtet werden, die jedoch zu keinen offensichtlichen morphologischen Veränderungen in späteren Entwicklungsstadien führte. Dies legt die Vermutung nahe, dass transdeterminierende Effekte des Xeya3-Proteins, analog zu den weiter oben beschriebenen Beobachtungen mit Ursache in einer Steigerung der Zellproliferationsrate, abhängig von räumlich und eventuell auch zeitlich begrenzt vorliegenden Kofaktoren sind.

\subsection{Die Phosphatase-Aktivität des Xeya3-Proteins hat möglicherweise autoregulatorische Funktion}

Für humanes EYA3 sowie für Eyes absent aus Drosophila melanogaster ist eine PhosphataseAktivität im Bereich der konservierten, C-terminalen Eya-Domäne beschrieben worden (Li et al., 2003; Tootle et al., 2003). Auch im Xenopus laevis Homolog Xeya3 findet sich ein Sequenzabschnitt, der das Protein als Mitglied der Haloacid Dehalogenase-ähnlichen Phosphohydrolasen kennzeichnet (s. Kapitel 4.3).

In Zellkulturexperimenten mit murinen Eya3-Mutanten bezüglich des katalytischen Motivs der Phosphatase-Domäne wurde gezeigt, dass die Phosphatase-Aktivität des Proteins für eine Änderung der regulatorischen Funktion eines Transkriptionsfaktor-Komplexes, bestehend aus Sixl und Dach1, von einer Repression zu einer Aktivierung der Transkription von Zielgenen unerlässlich ist ( $\mathrm{Li}$ et al., 2003). Gleichfalls führte die Expression von Phosphatase-Mutanten von Eya in eya--Tieren von Drosophila melanogaster zu einer, im Vergleich zum WildtypProtein, stark verminderten Aktivität bezüglich der Ausbildung von Ommatidien. Das Potential der Ausbildung ektopischen Augengewebes bei Überexpression mutierten Proteins war ebenfalls erheblich gesenkt. Die Aktivität des Eya-Proteins als Ko-Aktivator im Zusamenspiel mit Sine oculis wurde durch die Mutationen innerhalb der Phosphatase-Domäne jedoch nicht verringert (Tootle et al., 2003). In der vorliegenden Arbeit konnte gezeigt werden, dass ein Verlust der Phosphatase-Aktivität des Xeya3-Proteins zu keiner Verringerung der weiter oben beschriebenen Effekte eines Xeya3-Funktionsgewinns führt. Im Gegenteil konnte eine sowohl quantitative als auch qualitative Aktivitätssteigerung bei Mikroinjektion der entsprechenden synthetischen mRNAs beobachtet werden (s. Kapitel 4.14). Dies steht im Gegensatz zu den zuvor beschriebenen Ergebnissen aus anderen Spezies.

Durch Deletion der Eya-Domäne konnte die innerhalb der „PST“-Domäne lokalisierte transaktivierende Aktivität des Eya-Proteins aus Drosophila melanogaster im Zellkultursystem erheblich gesteigert werden. Des Weiteren zeigt sich ein ebenfalls positiver Effekt bei 
Aktivierung der RAS/MAPK-Signaltransduktion mittels konstitutiv aktivem $\operatorname{Ras}^{V 12}$, was zur Phosphorylierung des Proteins über $M A P K$-Phosphorylierungsstellen im Bereich der „PST“Domäne führt (Hsiao et al., 2001). Durch Verwendung der Deletions-Konstrukte bezüglich der Eya-Domäne konnte letzterer Effekt zusätzlich gesteigert werden (Silver et al., 2003). In Anbetracht der Tatsache, dass Phosphohydrolase- und Eya-Domäne nahezu vollständig überlappen, weist dies stark auf eine mögliche autoregulatorische Funktion der PhosphataseAktivität bezüglich des Phosphorylierungsstatus und somit der potentiellen Aktivität des EyaProteins hin. Analog dazu könnte es bei Verlust dieser intrinsischen Kontrollinstanz im Fall der Phosphatase-Mutanten von Xeya3 zu einer länger anhaltenden Hyperphosphorylierung des Proteins kommen, die Ursache für die im Zusammenhang mit Funktionsgewinnstudien gemachten Beobachtungen der quantitativen wie qualitativen Aktivitätssteigerung ist. Dafür nötige potentielle Phosphorylierungsstellen finden sich nach Analyse der Xeya3-Primärstruktur (Serine der Positionen 20, 34, 193, 292; http://www.cbs.dtu.dk/services/NetPhos/ (Blom et al., 1999); http://myhits.isb-sib.ch/cgi-bin/motif_scan (Falquet et al., 2002)). Da es zwischen EyaProteinen in Drosophila melanogaster zu einer über die „PST“-Domäne vermittelten Homodimerisierung kommt (Silver et al., 2003) und in vivo Experimente zeigen konnten, dass Eya selbst ein Substrat der Phosphatase-Aktivität innerhalb der Eya-Domäne sein kann (Tootle et al., 2003), ist zusätzlich die gegenseitige Kontrolle einer über den Phosphorylierungsgrad gesteuerten, transaktivierenden Aktivität denkbar. Die bei Überexpession der mutierten Formen beobachtete Aktivitätssteigerung des Xeya3-Proteins (s. Kapitel 4.14) ist so möglicherweise auch das Ergebnis eines dominant negativen Effektes, der durch Dimerisierungen zwischen endogenem Wildtyp-Protein und mutiertem, exogen zugeführtem Protein entsteht. Durch ausbleibende oder verringerte Dephosphorylierung des Xeya3-Proteins vom Wildtyp durch die Phosphatase-defiziente Form ist so eventuell auch ersteres in seiner Aktivität gesteigert und trägt zur verstärkten Ausbildung der für einen Xeya3-Funktionsgewinn beschriebenen Phänotypen bei.

\subsection{Die Zellkernlokalisation des Xeya3-Proteins}

Bezüglich Хeya3 wurde eine Lokalisation ausschließlich innerhalb des Zellkerns beobachtet. Dabei zeigten sich bei Überexpression des Proteins weder im zeitlichen Verlauf für unterschiedliche Entwicklungsstadien noch hinsichtlich der räumlichen Verteilung innerhalb des Embryos Unterschiede.

Im Zusammenhang mit möglichen Protein - Protein Wechselswirkungen zwischen Mitgliedern der Eya- und Six-Proteinfamilie in Vertebraten wurde am Beispiel der Maus eine KernTranslokation der Eya-Proteine 1-3 durch die Six-Proteine 2, 4 und 5 beschrieben. Allein in Zellen transfiziertes Eya-Protein zeigte hingegen eine im wesentlichen zytoplasmatische 


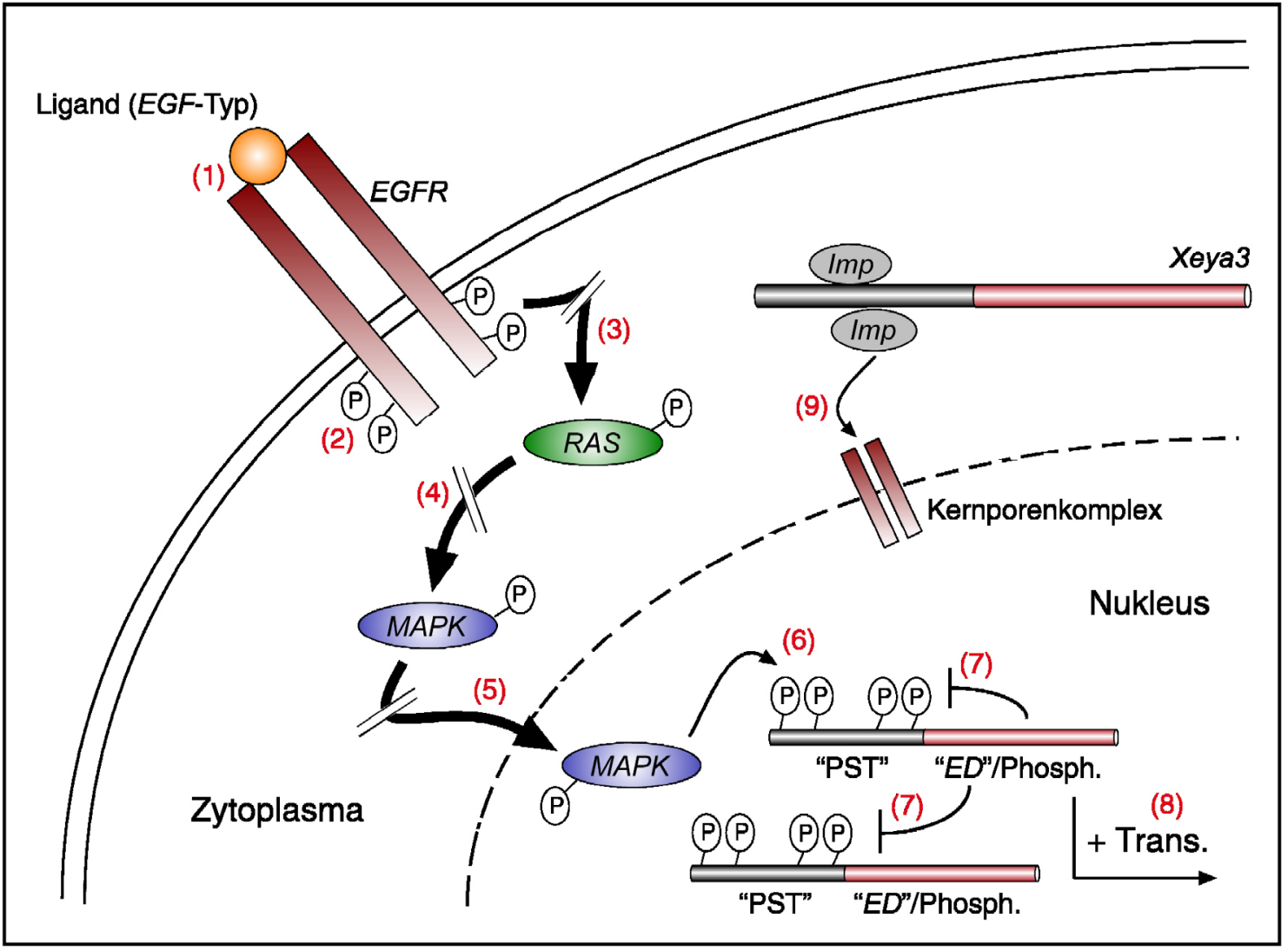

Abb. 5.2: Rezeptor-Tyrosin-Kinase (RTK)-vermittelte, RAS/MAPK-abhängige Signaltransduktion und transaktivierende Funktion von Xeya3. Durch Bindung des Liganden vom EGF (Epidermal Growth Factor)-Typ (1) kommt es zur Dimerisierung und Autophosphorylierung (P) des zytoplasmamembranständigen Rezeptors (2). Die Initialisierung der Signaltransduktionskaskade führt zur Phosphorylierung des G-Proteins $R A S$ (3) und in der Folge zur Phosphorylierung der zytoplasmatisch lokalisierten MAPK (Mitogen Activated Protein Kinase) (4). Phosphorylierte MAPK tritt in den Zellkern ein (5). Über Phosphorylierungsstellen im Bereich der „PST“-Domäne erfolgt eine $M A P K$-abhängige Phosphorylierung des Xeya3-Proteins (6). Durch die intrinsische Phosphatase-Aktivität innerhalb der „Eya“-Domäne $(E D)$ kommt es zur Feinjustierung des Aktivitätsgrades bzw. zum Aktivitätsverlust des Transkriptionsfaktors bei ausbleibender RTK-Signaltransduktion aufgrund einer Dephosphorylierung. Dabei sind sowohl Autodephosphorylierung als auch die Dephosphorylierung durch andere Xeya3Moleküle denkbar (7). Die Aktivierung des Xeya3-Transkriptionsfaktors hat positven Einfluss auf die Transkription (Trans.) von Zielgenen, welche die Proliferation neuraler Vorläuferzellen steuern (8). In Phosphatase-Mutanten des Xeya3-Proteins fehlt eine intrinsische, negative Kontrollinstanz, was zur Aktivität auch nach Ausbleiben eines RTK-vermittelten Signals führt und sich in einer generellen Aktivitätssteigerung des Proteins bei Überexpression äußert. Die Translokation von Xeya 3 in den Zellkern ist über ubiquitär vorhandene Importfaktoren (Imp) denkbar (9).

Verteilung (Ohto et al., 1999). Schon ein zeitlicher wie auch räumlicher Vergleich der Expressionsdomänen von in Xenopus laevis bekannten Six-Proteinen mit der des Xeya3-Proteins 
schließt die Six-Proteinfamilie als hauptsächliche Faktoren des nukleären Transports des Xeya3Proteins aus. So ist bis zum heutigen Zeitpunkt kein so-Homolog in Xenopus laevis mit einem Expressionsmuster vergleichbar dem zu Beginn der Neurulation bestehenden Xeya3Expressionsmuster bekannt. Es kommt zwar zu Überschneidungen wie etwa im Bereich der Augenanlagen im Fall von Xsix3, Xsix6 und Xeya3, Xeya3-Expressionsbereiche wie z.B. präsumtives Hinterhirn zeigen jedoch zu keinem Zeitpunkt der frühen Embryonalentwicklung Expression von Genen der Six-Familie (Ghanbari et al., 2001). Für die beiden anderen Mitglieder der Eya-Familie aus Xenopus laevis sind die in der Maus beschriebenen, den Kerntransport betreffenden Six-Eya-Interaktionen eher denkbar, treten hier doch weitaus stärkere Überschneidungen der Expressionsdomänen wie etwa im Bereich von cranialen Plakoden und mesodermalem Gewebe wie der Nierenanlage und Muskelvorläuferzellen auf (David et al., 2001; Ghanbari et al., 2001; Heanue et al., 1999). Bezüglich Xeya3 ist somit ein Kerntransport über ubiquitär vorhandene Importfaktoren/-Rezeptoren naheliegend, der abhängig von nukleären Lokalisationssignalen innerhalb der Primärstruktur des Xeya3-Proteins ist. Bislang konnten hier jedoch noch keine diesbezüglich konservierten Motive identifiziert werden. Ein Modell der Xeya3 Integration in Aspekte von Signaltransduktion, Autoregulation sowie Zellkerntransport ist in Abb. 5.2 dargestellt.

\subsection{Xdach1 als Mitglied der Dachshund-Familie von Proteinen}

In dieser Arbeit ist die Klonierung, Expressionsanalyse und funktionelle Charakterisierung einer Dachshund homologen cDNA aus Xenopus laevis (Xdach1) beschrieben worden. Dabei wurden zwei Formen, Xdach1-A und Xdach1-B, isoliert, die sich hinsichtlich der Primärstruktur des jeweils enkodierten Proteins vorwiegend durch zusätzliche Sequenzinformation im Fall von Xdach1-B unterscheiden (s. Kapitel 4.15, 4.16). Für beide Formen zeigt sich beim Vergleich mit den in Vertebraten vorhandenen Familienmitgliedern Dachshund1 (Dach1), Dachshund2 (Dach2) und Dachshund B (DachB, aus Zebrafisch) eine deutliche Sequenzverwandschaft mit Dach1. Die Analyse der Expression der beiden Formen mittels RT-PCR auf total RNAPräparationen aus Xenopus laevis Embryonalstadien sowie adulten Geweben zeigte ebenfalls keine Unterschiede hinsichtlich der temporären und räumlichen Verteilung der beiden Xdach1Formen. Im Menschen finden sind ähnlich den Verhältnissen in Xenopus laevis durch ihrer Länge unterscheidbare Formen von $D A C H 1$. Zwei davon stellen exakt das Vorhandensein bzw. den Verlust des für Xdach1 angesprochenen Sequenzabschnittes dar (Acc.-No.: Q9UI36, NP542937) und sind mit hoher Wahrscheinlichkeit das Ergebnis alternativen Splicings. Dies ist auch für die Xenopus laevis Homologe Xdach1-A und Xdach1-B anzunehmen und scheint somit einen evolutionär konservierten Prozess darzustellen. 


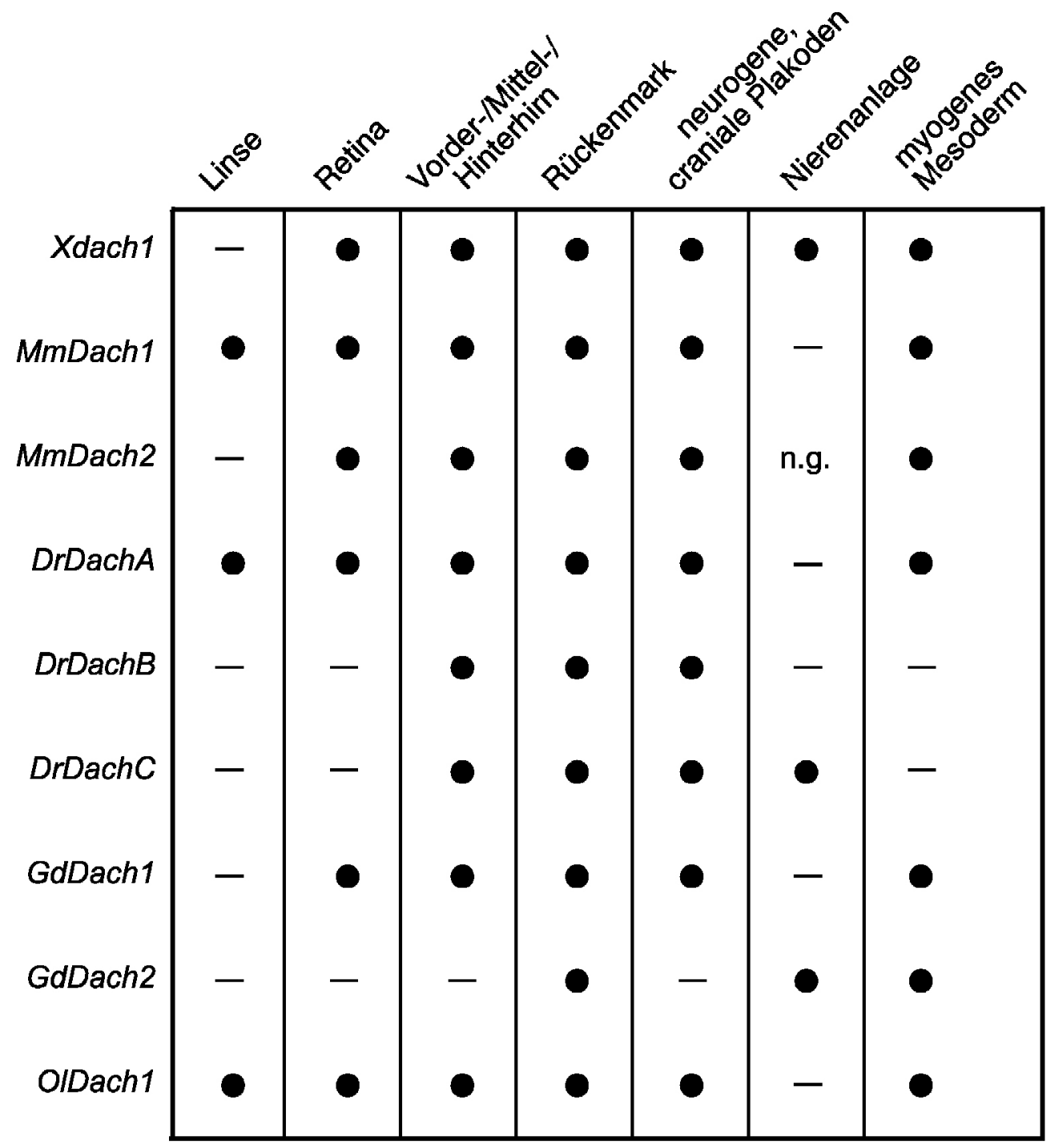

Abb. 5.3: Räumliches Expressionsmuster von Dachshund Homologen außerhalb Drosophila melanogaster. Abkürzungen: Dr, Danio rerio; Gd, Gallus domesticus; Mm, Mus musculus; n.g., nicht getestet; Ol, Oryzas latipes; X, Xenopus laevis.

Neben der betrachteten Sequenzhomologie zwischen Xdachl und insbesondere den Dachshundl Homologen aus anderen Vertebraten zeigen sich auch bei Betrachtung der jeweiligen embryonalen räumlichen wie zeitlichen Expressionsmuster deutliche Ähnlichkeiten (s. Kapitel 4.17; Abb. 5.3). So ergibt sich analog zu den in Xenopus laevis gemachten Beobachtungen ein Start der Transkription von Dachshund homologen mRNAs erst zu Beginn der Organentwicklung und beschränkt sich dabei auf Gewebe ektodermaler wie mesodermaler Herkunft (Davis et al., 1999; Hammond et al., 2002; Heanue et al., 2002; Heanue et al., 1999; Loosli et al., 2002). Dabei stimmen die Expressionsmuster z.T. auch im Detail überein. So beschränkt sich eine etwaige Dach-Expression innerhalb des zentralen Nervensystems stets auf 
dorsale Abschnitte, wobei in einigen Fällen auch die für Xdach1 beschriebene, schwächer ausgeprägte Expression in Nähe der Bodenplatte des Hinterhirns bzw. des Rückenmarks rekapituliert wird (Davis et al., 1999). Im Fall des DachshundA-Homologs des Zebrafisches kommt es in fortgeschrittenen Entwicklungsstadien, wie für Xdach1 aus Xenopus laevis beschrieben, $\mathrm{zu}$ einer Konzentration retinaler Genexpression im Bereich der Ganglionzellschicht (Hammond et al., 2002). Weitere, evolutionär konservierte Expressionsdomänen sind der trigeminale Nerv, der sich dorsocaudal des Auges als Teil neurogener, cranialer Plakoden entwickelt, sowie mesodermale Muskelvorläuferzellen. Im Gegensatz dazu lässt sich in Xenopus laevis zu keinem Zeitpunkt der Embyronalentwicklung Xdachl-Expression innerhalb von Linsengewebe nachweisen, wie es für Homologe der Maus (Davis et al., 1999), des Zebra- (Hammond et al., 2002) sowie des Kugelfisches (Loosli et al., 2002) beschrieben wurde. Möglicherweise ist es, wie schon weiter oben im Zusammenhang mit Homologen von Eyes absent beschrieben, zu Veränderungen bezüglich der transkriptionellen Regulation von Mitgliedern der Dachshund-Familie gekommen. Das Vorkommen von mindestens zwei Dachshund-Homologen im Menschen (Davis et al., 2001b; Kozmik et al., 1999), in der Maus (Davis et al., 1999; Davis et al., 2001b), im Zebrafisch (Hammond et al., 2002) und im Huhn (Heanue et al., 2002; Heanue et al., 1999) lassen auch in Xenopus laevis die Existenz eines weiteren Dachshund-Homologs vermuten.

Die in adulten Geweben/Organen von Xenopus laevis beobachtete Verteilung der Genexpression von Xdach1 mit prominenter Expression innerhalb des Herzens, der Niere, des Darms und der Lunge ergibt sich interessanterweise auch bezüglich humaner bzw. muriner adulter Gewebe mit entsprechender Herkunft (Kozmik et al., 1999). Dies zeigt, dass eine evolutionäre Konservierung der Regulation und einer damit einhergehenden möglichen Funktion von Dachshund-Homologen nicht nur auf die Embryogenese beschränkt sind, sondern sich auch auf den Rest des Lebenszyklus ausdehnen.

\subsection{Xdach1 in Morphogenese und Musterbildung des Amphibienauges}

Durch weitergehende Analyse mit Hilfe von Funktionsverluststudien konnten dem Xdach1Protein aus Xenopus laevis essentielle Funktionen bezüglich der Morphogenese und Musterbildung innerhalb des sich entwickelnden Auges zugewiesen werden. So verhindert die Mikroinjektion von Xdachl-spezifischen Morpholino-Oligonukleotiden die korrekte Evagination des optischen Vesikels am Ende der Neurulation was in der weiteren Entwicklung morphologisch durch das Fehlen eines optischen Bechers sowie eines davon proximal gelegenen optischen Stiels führt (s. Kapitel 4.19, 4.20). Zu beachten ist dabei, dass es dennoch zu Differenzierungsprozessen, gezeigt anhand des Photorezeptor-spezifisch exprimierten Gens Xrhodopsin, kommt. Wie auch die Expressionsmuster von anderen in der neuralen Retina exprimierten Genen zeigen, fehlt es der betroffenen Retina jedoch an einer klaren Schichtung, 
wie sie für retinales Gewebe typisch ist. $\mathrm{Ob}$ es dennoch zur Genese aller retinalen Zelltypen kommt, kann nicht abschließend beantwortet werden.

In einigen Fällen eines Funktionsverlustes von Xdachl wurde außerdem das Fehlen einer Linse beobachtet, was mit einer extrem proximalen Lokalisation des präsumtiven Retina-Gewebes einherging. Da es während der Embryonalentwicklung von Xenopus laevis zu keinem Zeitpunkt zur Expression von Xdachl in Bereichen prospektiven oder reifenden Linsengewebes kommt, stellt diese Beobachtung sehr wahrscheinlich einen sekundären Effekt des Funktionverlustes dar, der die Notwendigkeit einer direkten Interaktion zwischen Retina- und Linsengewebe unterstreicht (Henry und Grainger, 1990). Fehlende Induktionsvorgänge des Linsengewebes als Ursache für die fehlerhafte Musterbildung innerhalb des betroffenen retinalen Primordiums können indes ebensowenig ausgeschlossen werden.

Außer Xoptx2, dessen zeitlicher Expressionsbeginn mit dem des Xdach1-Gens vergleichbar ist (Ghanbari et al., 2001; Zuber et al., 1999), zeigen die in späten Neurula-Stadien untersuchten molekularen Marker des anterioren Neuroektoderms keinen quantitativen Rückgang ihrer Expression. Vielmehr deuten die beobachteten Expressionsmuster bereits auf die in späteren Entwicklungsstadien erkennbaren phänotypischen Veränderungen wie die fehlerhafte Evaginaton und Musterbildung innerhalb des optischen Vesikels hin (s. Kapitel 4.20). Dies schließt aber aus, dass die Expression der betroffenen Gene in späteren Stadien der Augenentwicklung von Xdach1 abhängig ist bzw. durch Xdach1 stabilisiert wird. Studien in der Maus konnten zeigen, dass dies im Fall von Pax6 auch in umgekehrter Hinsicht gilt, da es im genetischen Hintergrund der Pax6-Nullmutante ,small eyes“ (sey) nach wie vor zur Expression von Dach1 im Bereich der verkleinerten optischen Vesikel kommt (Heanue et al., 2002). Zwischen Xdach1 und Xoptx2 als Mitglied der Six-Familie von Proteinen besteht hingegen ein engerer Zusammenhang, auf den weiter unten detailliert eingegangen werden soll.

Nullmutanten des Dachshund Gens (dac) von Drosophila melanogaster zeigen neben einer Verkürzung der Extremitäten einen Verlust von Ommatidien, den funktionellen Einheiten des Komplexauges von Insekten. Grund dafür ist eine unterbleibende Ausbildung der Morphogenetischen Furche am posterioren Rand der Augen-Imaginalscheibe des Puppenstadiums (Mardon et al., 1994). Die in Xenopus laevis beschriebene, zu Beginn der Bildung des optischen Vesikels angelegte fehlerhafte Morphogenese und Musterbildung des Auges nach Xdach1-Funktionsverlust stellt ein vergleichbares Ereignis dar, wenn auch zwischen der Augenentwicklung der Insekten und Wirbeltiere erhebliche morphologische Unterschiede bestehen. Kommt es in Dac-Mutanten von Drosophila melanogaster zu vereinzelter Bildung von Ommatidien, so sind diese durch eine fehlerhafte Anordnung bzw. Anzahl der verschiedenen ommatidialen Zelltypen gekennzeichnet (Mardon et al., 1994). Auch in Embryonen von Xenopus laevis wurde eine Differenzierung retinaler Zelltypen vor dem Hintergrund eines Xdach1-Funktionsverlustes beobachtet aber ihre Anordnung folgt, scheinbar 
analog zu den in Drosophila melanogster beobachteten Verhältnissen, keinem erkennbaren Muster (s. Kapitel 4.20).

In der Maus wurde durch Erzeugung von Dach1-Nullmutanten (Dach $1^{-/}$) versucht, das entsprechende Protein funktionell zu charakterisieren (Davis et al., 2001a). Defekte innerhalb von Organen mit embryonaler Dach1-Expression sowie Ursachen für die durch Atemnot und Zyanose ausgelöste postnatale Lethalität der neugeborenen Tiere konnten allerdings trotz einer Vielzahl von Analysen nicht gefunden werden. Es besteht jedoch die Möglichkeit, dass es sich dabei um Auswirkungen handelt, die mit Dach1-Funktionen im adulten Tier verknüpft sind. So könnte der Verlust der in der adulten Lunge bestehenden Expression von Dachl eine Ursache für die beobachtete Atemnot und die sehr wahrscheinlich daraus resultierende Zyanose darstellen. Auch in Xenopus laevis und im Menschen exprimieren Zellen der adulten Lunge Dach1, eine in diesem Zusammenhang über Speziesgrenzen hinweg konservierte Funktion des Proteins ist deshalb denkbar.

\subsection{Xdach1 in Entwicklung und Differenzierung von Hirngewebe}

In schweren phänotypischen Äußerungen nach Xdachl-Funktionsverlust kommt es morphologisch zu einer nahezu vollständigen Verschmelzung von präsumtivem Hirn- und Retinagewebe. Die Analyse der Expression von Markergenen zeigt jedoch Unterschiede in der Reaktion der beiden neuralen Gewebe auf einen Verlust des Xdach1-Proteins. Transkribieren Zellen der betroffenen Retina nach wie vor eine Vielzahl an auch in unbehandeltem Gewebe exprimierten Faktoren, so kommt es im Bereich der untersuchten Hirngewebe zum Verlust aller getesteten Markergene (s. Kapitel 4.20, 4.21). Im Fall von Xpax6 findet diese Repression schon zum Ende der Neurulation, dem Startpunkt der Xdach1-Transkription, in Bereichen des zukünftigen Rhombencephalons statt. Dies deutet im Gegensatz zu den Verhältnissen während der Augenentwicklung auf eine Abhängigkeit der Xpax6-Transkription von Xdach1 im Zusammenhang mit der Entwicklung von Gehirnstrukturen hin. Neben dem Verlust der Expression der untersuchten Gene konnte eine deutliche Veränderung der Morphologie der Zellen der betroffenen Hirnhälfte beobachtet werden. Zusammen mit den beobachteten Defekten hinsichtlich der Genexpression legt dies eine ausbleibende Neurogenese innerhalb des zentralen Nervensystems nahe.

Auch innerhalb von Strukturen des Gehirns von Drosophila melanogaster, dem sogenannten Pilzkörper, zeigen sich bei Verlust des Dac-Proteins Veränderungen, die im Zusammenhang mit Differenzierungsdefekten neuraler Zellen stehen und bereits während Puppenstadien angelegt werden (Martini et al., 2000). Wie schon bezüglich der Augenentwicklung ergeben sich somit Analogien zwischen Insekt und Wirbeltier, die eine Konservierung des Dachshund-Proteins nicht nur auf Ebene seiner Primärstruktur sondern auch hinsichtlich funktioneller Aspekte zeigen. 


\subsection{Die Zellkernlokalisation des Xdach1-Proteins}

Durch Verwendung Epitop-tragender Versionen konnte eine ausschließliche Lokalisation des Xdach1-B-Proteins im Zellkern festgestellt werden. Auch Dac aus Drosophila melanogaster ist ohne Ausnahme im Nukleus lokalisiert (Mardon et al., 1994; Tavsanli et al., 2004). Dabei wurden bei Analyse der Primärstruktur des Drosophila-Proteins zwei Motive gefunden, die eine selbstständige Translokation über rezeptorvermittelten Kerntransport ermöglichen könnten. Ein bipartites Kern-Lokalisatons-Signal (NLS) findet sich am Ende der DD2 und zeigt einen erkennbaren Grad an Konservierung zwischen verschiedenen Spezies. Eine weitergehende Analyse dieses Motivs lies jedoch erkennen, dass es weder ausreichend noch notwendig für eine Lokalisation des Dac-Proteins ist (Tavsanli et al., 2004). Vielmehr scheint insbesondere der $D D 1$, innerhalb der kein entsprechendes Motiv gefunden werden konnte, eine besondere Funktion bezüglich der subzellulären Lokalisation des Proteins zuzukommen. Bei Deletion dieser Domäne kommt es zu einer verstärkten Lokalisation von Dac im Zytoplasma (Tavsanli et al., 2004). Die Suche nach NLS innerhalb von Xdach1-B ergibt ein mögliches bipartites NLS Cterminal der DD2 (Pos. 680 - 697), das zwischen Vertebraten hoch konserviert ist, in Drosophila melanogaster jedoch nicht existiert (http://myhits.isb-sib.ch/cgi-bin/motif_scan; Falquet et al., 2002). Da für Dac bzw. Dach1 Wechselwirkungen mit anderen nukleären Proteinen wie Eyes absent (Chen et al., 1997) und einer Reihe von Ko-Repressoren beschrieben worden sind (Li et al., 2002), ist eine Kernlokalisation des Dachshund-Proteins auch durch eine Bindung an kernlokalisierte Interaktionspartner denkbar.

\subsection{Der Synergismus zwischen Xdach1-B und Msix6}

Durch Ko-Injektion geringer Mengen synthetischer mRNA von Xdach1-B bzw. Msix6, die alleine injiziert keine oder nur geringe phänotypische Äußerungen zur Folge haben, konnte in Xenopus laevis eine synergistische Wirkungsweise der daraus translatierten Proteine beobachtet werden (s. Kapitel 4.25). So zeigte sich in quantitativer Hinsicht bei alleiniger Injektion kleiner Mengen von Msix6-mRNA eine geringe Penetranz der für eine Six6-Überexpression bekannten phänotypischen Äusserungen wie u.a. retinale Neoplasie durch Hyperproliferation von Vorläuferzellen (Bernier et al., 2000; Zuber et al., 1999). Die gleichzeitige Mikroinjektion von kleinen Mengen an Xdach1-B-mRNA, welche in dieser Grössenordnung alleine keine Entwicklungsdefekte auslösen, führte zum deutlichen Anstieg der Anzahl an Embryonen mit vergrößertem retinalen Gewebe. Ein Synergismus der beiden Proteine zeigte sich auch auf qualitativer Ebene, wobei es beginnend mit einer einfachen Vergrößerung des betroffenen Auges zu massivem Gewebezuwachs und in der Folge abnormen Einfaltungen der Retina kam. Dass es sich dabei um spezifische Effekte bezüglich einer Wechselwirkung zwischen Xdach1-B und Msix6 handelt, wurde durch die Ko-Injektion von synthetischer mRNA für Msix3 oder Xeya3 gezeigt, was in beiden Fällen keine synergistischen Auswirkungen zur Folge hatte. 
In der Maus sind hinsichtlich kooperativer Effekte zwischen Six6 und Dach1 analoge Beobachtungen gemacht worden. Es konnte die Bildung eines transkriptionellen Repressorkomplexes mit durch Six6 bereitgestellter DNA-Bindung und durch Dach1 vermittelter Rekrutierung von nukleären Ko-Repressoren nachgewiesen werden, der zur negativen Regulation von Inhibitoren des Zell-Zyklus führt (Li et al., 2002). Somit ist eine gewebespezifische Steuerung der Proliferation von Vorläuferzellen möglich, in diesem Fall innerhalb der Augen- und Hypophysenanlage. Bezüglich der Augenentwicklung kommt es in Six $6^{-1-}$-Mäusen zum verfrühten Austritt von Vorläuferzellen der präsumtiven Ganglionzellschicht aus dem Zellzyklus, was einem Stop der Zellproliferation entspricht (Li et al., 2002). Nimmt man ähnliche Verhältnisse auch für die Embryonalentwicklung von Xenopus laevis an, so ist neben den weiter oben beschriebenen synergistischen Effekten der Ko-Injektion zu beachten, dass für Xdach1 aus Xenopus laevis sowie für DachA aus Danio rerio eine im Bereich der präsumtiven Ganglionzellschicht angereicherte Genexpression beschrieben worden ist (Hammond et al., 2002). Die unter einem Funktionsverlust von Xdach1 innerhalb betroffenen retinalen Gewebes nahezu ubiquitär verbreitete Genexpression von z.B. Xrxl, das ansonsten vorwiegend in distalen Bereichen der Retina exprimiert wird (s. Kapitel 4.20), ist ein weiterer Hinweis auf einen negativen Effekt des Xdachl-Funktionsverlustes hinsichtlich der Entwicklung der Ganglionzellschicht der Retina. In letzterem Zusammenhang ist eine Notwendigkeit der Xdach1-Funktion innerhalb eines auch in Xenopus laevis möglicherweise vorhandenen Six6/Xdachl-Komplexes denkbar, zumal es im Verlauf der Retinogenese zu Überschneidungen der Expressionsdomänen von Xdach1 und Xsix6 kommt.

Im Zuge des Xdach1-Funktionsverlustes ist im Gegensatz zu anderen, durch „WMISH“ analysierten Genen mit Funktion in der frühen Augenentwicklung eine deutliche Repression der Xsix6 (Xoptx2) Expression beobachtet worden. Zeitlich gesehen beginnt die Transkription von Xsix6 kurz vor der erstmalig zum Ende der Neurulation nachgewiesenen Xdach1-Expression. So stellt sich Six6 nicht nur als möglicher Interaktionspartner von Xdach1 im Zuge der Steuerung der Proliferation u.a. retinalen Vorläufergewebes dar, sondern ist daneben auch hinsichtlich der Stabilisierung seiner Transkription von Xdach1 abhängig.

Ein Vergleich der oben gemachten Beobachtungen mit den bis heute bekannten Daten aus Drosophila melanogaster läßt insofern Differenzen erkennen, als dass eine direkte Interaktion zwischen Dachshund (Dac) und Sine oculis (so), dem Six-Homolog, in der Fliege bislang nicht beschrieben worden ist. Vielmehr bestehen physikalische Interaktionen zwischen So und Eya (Pignoni et al., 1997) bzw. Eya und Dac (Chen et al., 1997), so dass es zu einem möglichen trimeren Transkriptionsfaktor-Komplex So - Eya - Dac kommen kann, wie er auch im Zusammenhang mit der Muskelentwicklung im Hühnerembryo beschrieben worden ist (Heanue et al., 1999). Die Interaktion mit Mitgliedern der Eya-Familie von Proteinen bedarf dabei der 
konservierten DD2 (Heanue et al., 1999). Für die bislang nur in Vertebraten beschriebene Komplexbildung zwischen Dach1 und Six6 ist dagegen die DD1 unerlässlich (Li et al., 2002).

\subsection{Xdach1 als Inhibitor der Xbmp4 induzierten Signaltransduktion}

Nach Überexpression des Xdach1-B-Proteins in Xenopus laevis Embryonen wurde eine starke Neuralisierung nicht-neuralen Gewebes beobachtet. In der weiteren Entwicklung führte dies zu einer massiven Vergrößerung von Hirnstrukturen sowie dem Verlust ektodermaler Derivate wie Linse und cranialen Nerven, die sich aus nicht-neuralen, ektodermalen Plakoden ableiten (s. Kapitel 4.22, 4.23). In Experimenten mit animalen Gewebeexplantaten wurde gezeigt, dass dies Folge einer Inhibition der Xbmp4 induzierten Signaltransduktion ist, die an Prozessen der epidermalen Induktion und neuralen Inhibition beteiligt ist (s. Kapitel 4.24; Harland, 2000; Suzuki et al., 1997).

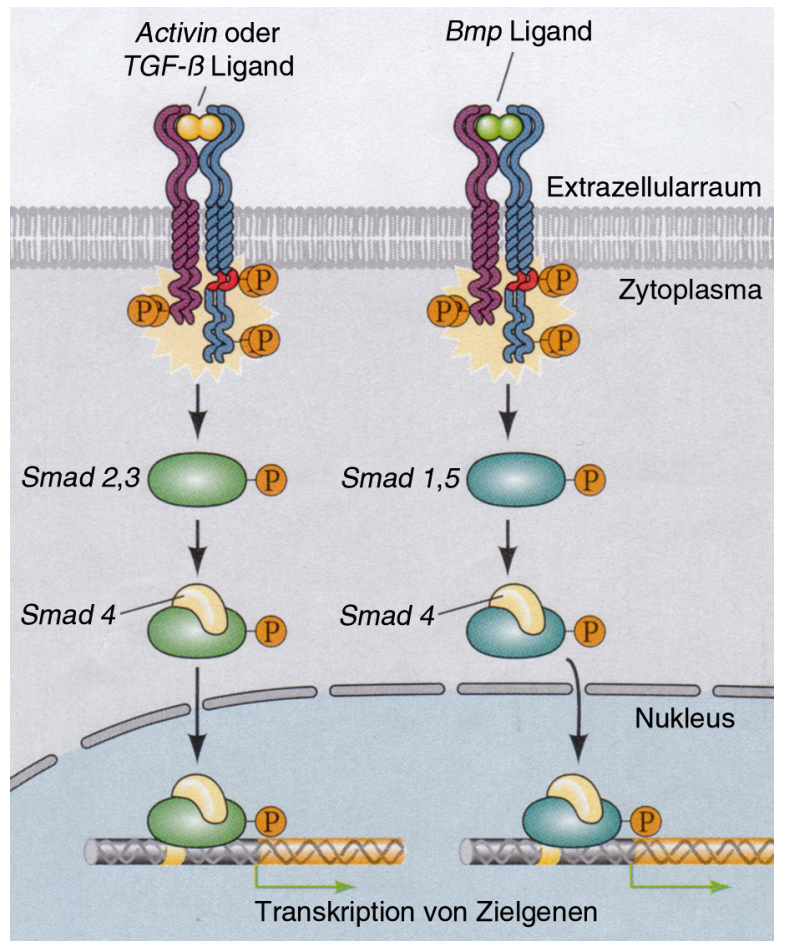

\begin{abstract}
Abb. 5.4: TGF- $\beta$ Signaltransduktion. Die Bindung des Activin-, $T G F-\beta$ - oder Bmp Liganden an den Rezeptor vom Typ II (violett) löst die Dimerisierung mit dem Rezeptor vom Typ I (blau), dessen Phosphorylierung und somit Aktivierung aus. Der Typ I Rezeptor phosphoryliert die zytoplasmatisch lokalisierten Smad-Proteine. Rezeptoren, die Activin oder $T G F-\beta$ Moleküle binden, phosphorylieren die Smads 2 und 3, Rezeptoren, die Bmp Moleküle binden, phosphorylieren die Smads 1 und 5. Die phosphorylierten Smad-Proteine binden Smad4 und bilden einen TranskriptionsfaktorKomplex, der in den Nukleus eintritt und die Transkription der jeweiligen Zielgene steuert. Nach Gilbert, 2000.
\end{abstract}

Im Bereich der $D D 1$ des Xdach1-Proteins besteht Sequenzhomologie zu den Proto-Onkogenen Ski und Sno, die beide als Inhibitoren von Signaltransduktionskaskaden charakterisiert worden sind, die durch Mitglieder der $T G F-\beta$-Familie von Signalmolekülen induziert werden (Amaravadi et al., 1997; Luo, 2004). Bei Überexpression von Xski, dem Ski-Homolog aus Xenopus laevis, in animalen Gewebeexplantaten kommt es analog zu den Beobachtungen für Xdach1-B zur Neuralisierung des Gewebes und andererseits zur Repression von Markergenen epidermaler Differenzierungsprozesse (Wang et al., 2000). Als Ursache wurden eine direkte 
Interaktion des Ski-Proteins mit Mitgliedern der Smad-Familie von Transkriptionsfaktoren, die Teil des $T G F-\beta$-Signaltransduktionsapparates sind (s. Abb. 5.4), und die Rekrutierung von KoRepressoren wie $\mathrm{N}-\mathrm{CoR}$ zum so gebildeten nukleären Komplex ermittelt (Luo et al., 1999; Wang et al., 2000). Neben Smad1 und Smad5, die im Zuge einer Bmp induzierten Signaltransduktionskaskade phosphoryliert und somit aktiviert werden, werden auch Smad2 sowie Smad3, Teil einer Activin oder TGF- $\beta$ induzierten Signaltransduktion, und das sogenannte Ko-Smad, Smad4, durch Ski gebunden und die Aktivierung von Zielgenen durch die Bildung eines Repressorkomplexes unter Ausschluss von Ko-Aktivatoren wie $p 300$ verhindert (Akiyoshi et al., 1999; Sun et al., 1999).

Tatsächlich konnte auch für Dachl eine inhibitorische Funktion der $T G F-\beta$ induzierten Signaltransduktionskaskade nachgewiesen werden (Wu et al., 2003). Durch eine Expression von Dachl kam es, vergleichbar mit den hier in animalen Gewebeexplantaten von Xenopus laevis gemachten Beobachtungen, zur Repression einer $T G F-\beta$-vermittelten Aktivierung von geeigneten Reporterkonstrukten. Dabei ist der Bereich des Proteins mit Homologie zu den Proto-Onkogenen Ski und Sno, die DD1, essentiell. Ein ebenso negativer regulatorischer Effekt des Dach1-Proteins ergibt sich bei Aktivierung von TGF- $\beta$ Reporterkonstrukten durch Mitglieder der Smad-Proteinfamilie (Smad2, Smad3, Smad4). Wiederum ist die DD1 in diesem Zusammenhang unerlässlich. In Übereinstimmung damit konnte weiter gezeigt werden, dass es, analog zu den bezüglich $S k i$ erhaltenen Ergebnissen, zur direkten Interaktion von Dachl mit Smad-Proteinen sowie einer Dachl-vermittelten Rekrutierung von Ko-Repressoren wie $\mathrm{N}$-CoR über die $D D 1$ und $\operatorname{Sin} 3 A$ über die $D D 2$ zum neu gebildeten Komplex kommt. Dies hat die Repression von Zielgenen der $T G F-\beta$-Signaltransduktionskaskade anstelle einer Aktivierung zur Folge. Dabei werden sowohl hinsichtlich des eingesetzten Morphogens spezifische Smads (Smad2 und Smad 3 sind Teil der durch $T G F-\beta$ und Activin induzierten Signaltransduktion) als auch das Ko-Smad, Smad4, durch Dach1 gebunden. Smad4 ist für die Ausbildung des beschriebenen Repressorkomplexes unerlässlich, da die Repression der Reportergen-Aktivität in Abwesenheit von Smad4 fehlschlägt (Wu et al., 2003).

Auch das im Zuge einer Bmp-vermittelten Signaltransduktion phosphorylierte Smadl wird von Dach1 gebunden und so Teil eines multimeren Repressorkomplexes aus u.a. Smad4 und dem Ko-Repressor $\operatorname{Sin} 3 A$. Verantwortlich dafür, wie auch für die Bindung von $\operatorname{Smad} 4$ und $\operatorname{Sin} 3 A$, ist die DD2 von Dach1 (Wu et al., 2003), die auch mit Protein-Wechselwirkungen zwischen Dachshund- und Eyes absent-Proteinen in Verbindung gebracht worden ist (Chen et al., 1997; Heanue et al., 1999). Wie schon weiter oben als Ursache des zwischen Msix6 und Xdach1 beobachteten Synergismus beschrieben, ergibt sich für das Dachshund-Protein somit auch im Zusammenhang mit der $T G F-\beta$-Signaltransduktion eine Repressor-Funktion. Diese ist in der Rekrutierung von Ko-Repressormolekülen und der Bildung von multimeren Kernkomplexen begründet, die die Transkription von Zielgenen, hier des Xbmp4-Zielgens Xmsxl, verhindern. 
Neben der durch Überexpression des Xdach1-Proteins hervorgerufenen Neuralisierung des Xenopus laevis Embryos als Folge der Inhibition der durch Xbmp4 induzierten Signaltransduktion führt ein Funktionsverlust durch Morpholino-Injektion u.a. zu Defekten in der Musterbildung und Organogenese des Auges (s. Kapitel 4.20). Die dabei gemachten Beobachtungen sind denen einer gezielten Überexpression des Morphogens Xbmp4 in Zellen des Augenprimordiums ähnlich (Sasagawa et al., 2002). Xbmp4 wird innerhalb der Retina spezifisch von Zellen des distal gelegenen, dorsalen Augenbecherrands exprimiert, Xdach1 kann innerhalb des distalen optischen Vesikels und später im Bereich der Ganglionzellschicht der neuralen Retina detektiert werden (s. Kapitel 4.17, 4.24).

Ein Verlust der Funktion des Xdach1-Proteins resultiert in einem Verlust proximalen retinalen Gewebes. Dies ist durch eine Reduktion bzw. das Fehlen eines optischen Stiels, mit einhergehender Reduktion entsprechender Markergene wie Xvax2, und ausgedehnte Expression von Markergenen distalen retinalen Gewebes wie Xpax6 und insbesondere Xrx 1 gekennzeichnet (s. Kapitel 4.20). Vergleichbares, nämlich eine Reduktion der Xvax2- und eine Verstärkung bzw. Ausdehnung der Xpax6-Expression, tritt als Folge der Xbmp4-Überexpression innerhalb retinalen Gewebes auf (Sasagawa et al., 2002). Die fehlerhafte Verbindung zwischen Diencephalon und Retina ist in Fällen des Xdach1-Funktionsverlustes und der Xbmp4Überexpression zusätzlich durch eine Ausdehnung Retinalen Pigmentepithels nach proximal gekennzeichnet, was den distalen Charakter der beobachteten retinalen Phänotypen unterstreicht. Dass es bei starker Ausprägung von Phänotypen des Xdach1-Funktionsverlustes zur Reduktion von Linsengewebe kommt, kann durch das Ausbleiben der Interaktion zwischen Linsenektoderm und dem in diesem Fall sich abnormal entwickelnden optischen Vesikel erklärt werden. Wechselwirkungen zwischen prospektivem retinalen- und Linsengewebe sind für die Entwicklung und Musterbildung beider Strukturen unerlässlich (Henry und Grainger, 1990). Die beobachteten Defekte in der Musterbildung retinalen Gewebes nach Funktionsverlust von Xdach1 können so zum Teil auch das Resulat dieser unterbliebenen Wechselwirkung, als Resultat der fehlerhaften Evagination des optischen Vesikels, darstellen. Auswirkungen des Xdach1-Funktionsverlustes auf die dorsoventrale Musterbildung der Retina sind, wiederum vergleichbar mit Effekten einer Xbmp4-Überexpression, ebenso denkbar. So kommt es zum Verlust der innerhalb des optischen Vesikels ventral lokalisierten Xvax2-Expression. Es kann jedoch nicht ausgeschlossen werden, dass es sich dabei um einen sekundären Effekt als Auswirkung der fehlerhaften Evagination des optischen Vesikels handelt.

Bezüglich der Augenentwicklung von Xenopus laevis legt dies nahe, dass Xdach1 in diesem in vivo Kontext durch Inhibition bzw. Modifikation der von Xbmp4 vermittelten Signaltransduktion zur Musterbildung in proximodistaler und eventuell auch dorsoventraler Orientierung beiträgt. 

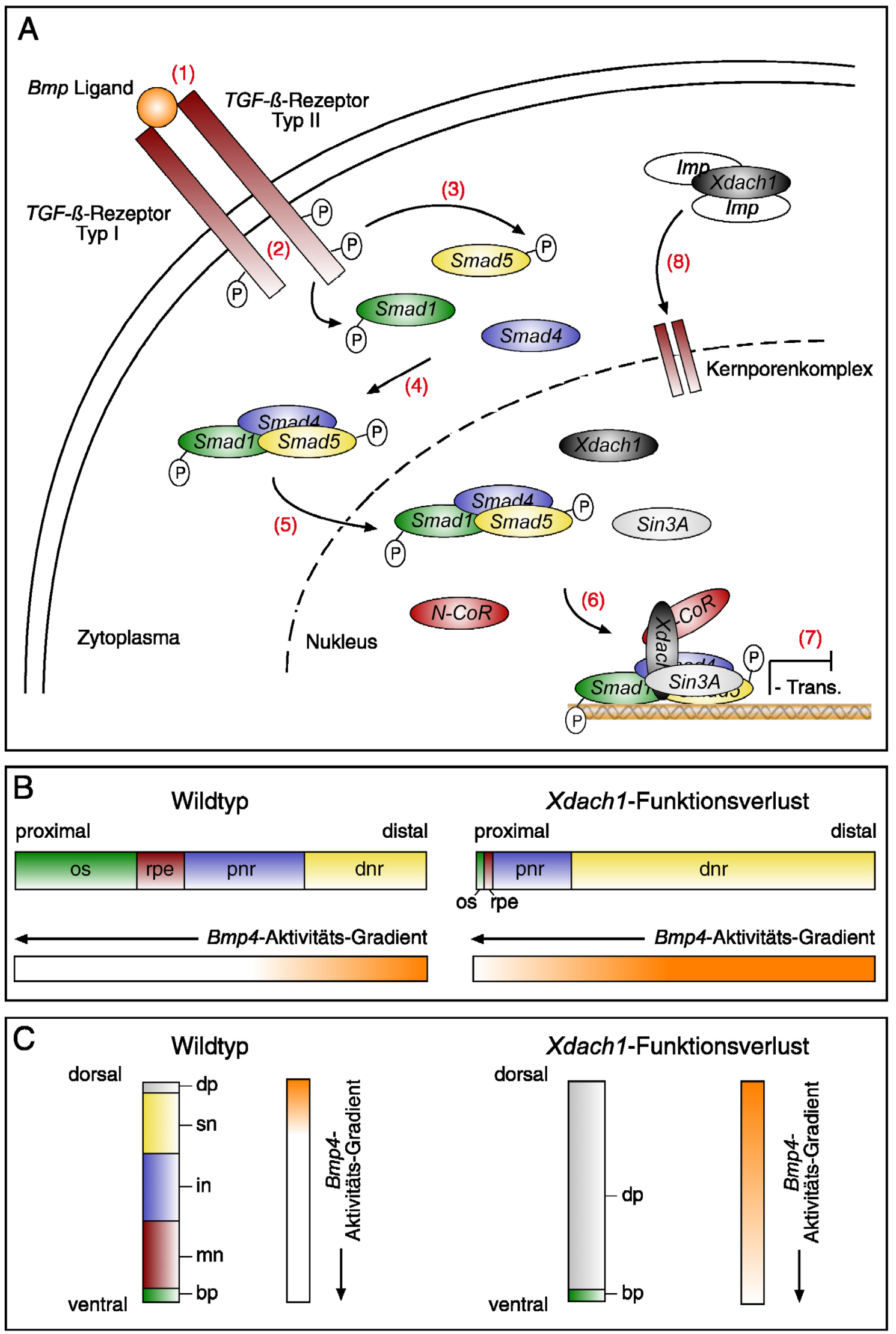

Abb. 5.5: Modell der Wirkungsweise von Xdach1 als Antagonist der Bmp-Signaltransduktion. (A) Repression von Zielgenen der Bmp-Signaltransduktion durch Xdachl-vermittelte Rekrutierung von KoRepressormolekülen. Durch Bindung des Bmp Liganden an den $T G F$ - $\beta$-Rezeptor vom Typ I (1) kommt es 
zur Dimerisierung mit dem $T G F-\beta$-Rezeptor Typ II und dessen Phosphorylierung durch den $T G F-\beta$ Rezeptor Typ I (2). Der TGF- $\beta$-Rezeptor Typ II phosphoryliert seinerseits die zytoplasmatischen Smads 1 und 5 (3), die nach ihrer Aktivierung durch Phosphorylierung zusammen mit Smad4 einen Komplex bilden (4) und in den Zellkern eintreten (5). Ist nukleär lokalisiertes Xdach1 vorhanden, kommt es durch $X d a c h 1$-vermittelte Rekrutierung von Ko-Repressormolekülen wie $N$-CoR und Sin3A zum SmadKomplex zur Bildung eines multimeren transkriptionellen Repressorkomplexes (6). Dieser unterdrückt die Transkription (-Trans.) von Bmp-Zielgenen (7). In Abwesenheit des Xdach1-Proteins werden diese durch die Bmp-induzierte Signaltransduktion in ihrer Transkription aktiviert (s. Abb. 5.4). (8) Die Translokation des Xdachl-Proteins in den Nukleus erfolgt sehr wahrscheinlich über einen Kernrezeptorvermittelten Transport unter Verwendung ubiquitär vorhandener Importfaktoren (Imp). Proximodistale Musterbildung während der Augenentwicklung unter Funktionsverlust von Xdach1. Die bezüglich der Augenentwicklung gemachten Beobachtungen des Verlustes proximaler Strukturen wie optischem Stiel (os) und Retinalem Pigmentepithel (rpe) können Folge einer räumlich ausgedehnten Bmp4-Aktivität sein, die die Ausbildung distaler Strukturen propagiert; dnr, distale neurale Retina; pnr, proximale neurale Retina. (C) Inhibition neuraler Differenzierung und dorsoventrale Musterbildung im Hinterhirn unter Funktionsverlust von Xdach1. Die durch Xdach1-Funktionsverlust möglicherweise nach ventral ausgedehnte Bmp4-Aktivität stimuliert die Differenzierung ektodermaler, epidermaler Zellen der Dachplatte (dp) auf Kosten neuraler Differenzierung; bp, Bodenplatte; in, Interneurone; mn, Motorneurone; sn, sensorische Neurone.

Im Unterschied zu den Verhältnissen während der Augenentwicklung, wo es trotz fehlerhafter Musterbildung $\mathrm{zu}$ Zelldifferenzierungsprozessen kommt, bleiben neurale Differenzierungsprozesse innerhalb des zentralen Nervensystems nach Funktionsverlust von Xdach1 aus. Dies zeigt sich zum einen durch den Verlust der Expression von Markergenen mit Expression in Vorläuferzellen (Xpax3) sowie differenzierten Neuronen (N-Tubulin), zum anderen durch eine bei Vergleich mit neuralen Zellen der nicht betroffenen Hirnhälfte deutlich veränderte Zellmorphologie, die ein anderes Zellschicksal vermuten lässt (s. Kapitel 4.21). Ähnlich dem Augenvesikel wird Xbmp4 auch innerhalb des Hinterhirns bzw. des Neuralrohres räumlich begrenzt exprimiert, in diesem Fall dorsal von Zellen der Dachplatte (s. Kapitel 4.24). Ventral davon gelegen schließt sich die Expressionsdomäne von Xdach1 im dorsalen Hinterhirn bzw. Neuralrohr an.

In Experimenten im Hühnerembryo konnte gezeigt werden, dass eine Verstärkung der Bmpvermittelten Signaltransduktion innerhalb des Hinterhirns durch konstitutiv aktive BmpZellmembranrezeptoren oder die Überexpression des Bmp-Zielgens Msxl eine Differenzierung neuraler Zelltypen des Hinterhirns verhindert (Liu et al., 2004). Als eine Ursache dafür konnte die Repression von Genen identifiziert werden, die im Zusammenhang mit der Regulation neuraler Differenzierungsprozesse stehen. Dies ist in der vorliegenden Arbeit auch im Hinterhirn von Xenopus laevis nach Funktionsverlust von Xdach1 beobachtet worden (s. Kapitel 
4.21). Des Weiteren wurde im Hühnerembyro eine Ausbreitung der Expression von Markergenen spezifisch für Zellen der Dachplatte, wie z.B. Bmp4 selbst, in ventrale Bereiche des Hinterhirns beobachtet. Unter dem Einfluss einer funktionellen Überexpression von Bmp nehmen somit putative Neurone ein nicht-neurales, ektodermales Schicksal an. Durch Wegnahme der Xbmp4-antagonistischen Funktion von Xdach1 im Zuge der hier durchgeführten Funktionsverlustanalysen kommt es in Xenopus laevis möglicherweise zu einem vergleichbaren Prozess, da das parakrin sezernierte Morphogen Xbmp4 einen der Antagonisten seiner Signaltransduktionskaskade verliert. Funktionell entspricht dies einer Steigerung seiner Aktivität innerhalb seines räumlichen Wirkungsspektrums. Die Tatsache, dass für Xbmp4 die Möglichkeit einer positiven Autoregulation über durch seine Signaltransduktionskaskade induzierte Faktoren besteht (Schuler-Metz et al., 2000), lässt vermuten, dass der Verlust des vor allem dorsal agierenden Antagonisten Xdach1 dies neben einer Aktivierung von Xbmp4Zielgenen weiter unterstützt. Somit könnte die beobachtete Inhibition neuraler Differenzierung innerhalb des Hinterhirns von Xenopus laevis neben der Aktivierung von Xbmp4-Zielgenen, wie etwa Xmsxl, zusätzlich durch eine Verstärkung des Xbmp4-Signals im Zuge seiner Autoregulation begründet sein. Dies würde zu einer Ausbreitung von Xbmp4-sezernierenden Zellen über die dorsoventrale Achse des Hinterhirns und in der Folge zur Inhibition von Prozessen der sekundären Neurogenese führen.

Ein Aspekt der Xdach1-Funktion ist somit die Inhibition oder Modifizierung von durch Xbmp4 vermittelten Signalen, was sowohl im Zusammenhang mit der Augenentwicklung als auch der Bildung von Bereichen des zentralen Nervensystems wesentlich zur Musterbildung der entsprechenden Organe beiträgt. Für Dachshundl sind Interaktionen mit einer Vielzahl von Mitgliedern der Smad-Familie von Transkriptionsfaktoren als Teil der TGF- $\beta$ induzierten Signaltransduktion nachgewiesen worden (Kida et al., 2004; Wu et al., 2003). Da bezüglich der im Verlauf der Signaltransduktion rekrutierten Smads zwischen den Mitgliedern der TGF- $\beta$ Familie definierte Unterschiede bestehen, ergeben sich somit bezüglich des Dachshund1Proteins sehr wahrscheinlich eine Vielzahl an Funktionen, die sich z.B. auch auf mesodermale Entwicklungsprozesse, z.T. durch die Aktivität des Morphogens Activin gesteuert, ausdehnen. Ein Modell der Wirkungsweise von Xdach1 als Antagonist der Bmp-Signaltransduktion sowie der Auswirkungen eines Xdach1-Funktionsverlustes auf die Entwicklung des Auges und Hinterhirns sind in Abbildung 5.5 dargestellt.

\subsection{Ausblick}

Für die Zukunft ergeben sich aus der vorgestellten Arbeit eine Reihe weiterer Experimente. Um mögliche Interaktionspartner von Хeya 3 zu identifizieren, sind zunächst zwei experimentelle Ansätze denkbar. (1) Durch einen Yeast-Two-Hybrid-Screen unter Verwendung des vollständigen Xeya3-Proteins und einer entsprechenden Yeast-Two-Hybrid-Bibliothek wäre es 
möglich, direkte Wechselwirkungen mit anderen Proteinen zu untersuchen. (2) In einem Expressionsscreen in Xenopus laevis könnten zudem Proteine identifiziert werden, die zusammen mit Xeya3 synergistisch wirken. Nach (1) und (2) identifizierte Klone könnten anschließend mit der jeweils anderen Strategie auf eine tatsächliche direkte physikalische Interaktion bzw. auf die Ausbildung synergistischer Effekte getestet werden. Außerdem sollte versucht werden, im Hefe-System beobachtete physikalische Interaktionen auch in Xenopus laevis mit Hilfe von Ko-Immunpräzipitationen darzustellen. Dazu werden synthetische mRNAs für Flag- bzw. c-myc-Epitop tragende Proteine in Xenopus laevis Embryonen ko-injiziert, der mögliche Komplex mit Hilfe eines Flag- oder c-myc-spezifischen Antikörpers extrahiert und mittels SDS-PAGE und Western-Blot analysiert. Ein diesbezüglich weiterführender Ansatz wäre die statistische Immunpräzipitation von Proteinen, die mit Xeya3 interagieren, und deren Identifikation mittels 2-D Gelelektrophorese und massenspektroskopischer Analyse (MALDITOF).

Die durch den Yeast-Two-Hybrid- und Expressionsscreen bzw. durch Ko-Immunpräzipitationen erhaltenen Ergebnisse hinsichtlich Wechselwirkungen zwischen Xeya 3 und anderen Proteinen sollten dann mit Blick auf die Xeya3-Primärstruktur weitergehend untersucht werden. So können zunächst Xeya3-Deletionskonstrukte bezüglich der „Eya“- oder „PST“-Domäne hergestellt werden und in den oben beschriebenen Experimenten getestet werden. Bestehende physikalische Interaktionen mitsamt einer möglichen Funktion in vivo könnten so bestimmten Abschnitten des Xeya3-Proteins zugeordnet werden. Die in dieser Arbeit verwendeten Phosphatase-Mutanten können ebenso in der beschriebenen Art und Weise getestet werden, um zu erkennen, ob die Phosphatase-Aktivität die Identität der Interaktionspartner beeinflusst.

Weitergehende Fragestellungen ergeben sich auch im Hinblick auf die Regulation der Xeya3Expression. Mit Hilfe des in naher Zukunft vollständig sequenzierten Genoms des nahe verwandten Xenopus tropicalis werden Promoterbereiche des Eya3-Gens zugänglich sein. Durch Vergleich der potentiellen Promotersequenzen von Xeya 3 mit denen anderer Spezies wie Mensch, Maus und Zebrafisch können möglicherweise evolutionär konservierte Bereiche kartiert werden. Durch Herstellung von Reporterkonstrukten, bestehend aus dem Xeya3Promoter als cis-regulatorischem Element und dem offenen Lesehramen des Green-FluorescentProtein (GFP), könnten entsprechend transgene Tiere erzeugt werden. Durch den Einsatz von Deletionskonstrukten hinsichtlich konservierter Promoterbereiche bei der Erzeugung transgener Tiere können so bestimmte Promoterregionen, die für die räumliche wie auch zeitliche Steuerung der Xeya3-Expression unerlässlich sind, identifiziert werden. Weiterhin kann durch computergestützte Analysen versucht werden, dem gesamten bzw. Abschnitten des Xeya3Promoters bekannte trans-regulatorische Faktoren zuzuordnen. Mittels ChIP (Chromatin Immunpräzipitation) können so erhaltene Kandidaten auf eine tatsächliche Interaktion mit der Promotersequenz des Xeya3-Gens getestet werden. 
Mit Hilfe des Systems der animalen Gewebeexplantate aus Xenopus laevis Embryonen und einer nachgeschalteten Transkriptom-Analyse durch Microarrays könnten potentielle Zielgene von Xeya3 identifiziert werden. Durch Einsatz verschiedener Xeya3-Mutanten könnten hierbei wiederum funktionsrelevante Bereiche des Proteins bestimmt werden.

Wie beschrieben induziert Xeya3 eine Neoplasie neuralen Gewebes bzw. aktiviert das apoptotische Programm bei Funktionsverlust. In diesem Zusammenhang wäre es interessant zu erfahren, ob Eya3 oder Mitglieder der Eya-Familie auch an der Entstehung neuro-ektodermaler Tumore beteiligt sind. Eine Veränderung der Eya3-Aktivität könnte sowohl auf transkriptioneller Ebene, als auch auf Proteinebene erfolgen. Zu diesem Zweck könnten entsprechende Gewebeproben zunächst mit Hilfe der quantitativen RT-PCR auf eine Veränderung der Eya3-Transkription hin untersucht werden. Werden hier Unterschiede zu gesundem Gewebe festgestellt, könnte versucht werden, eventuelle Mutationen innerhalb cisregulatorischer Promoterelemente des jeweiligen Eya3-Gens zu bestimmen. Außerdem könnte Eya3 auf Veränderungen seiner Primärstruktur als Ursache für die Bildung von Tumoren untersucht werden. Besonderer Augenmerk sollte dabei auf den Bereich der PhosphataseDomäne gelegt werden, da diese, wie in dieser Arbeit gezeigt, mit einer Kontrolle der Aktivität des Proteins in Verbindung steht. Mutationen, die möglicherweise eine Verringerung oder den Verlust der Phosphatase-Aktivität zur Folge haben, können nach Klonierung des entsprechenden Allels im in vitro Test unter Verwendung des Substrates p-Nitrophenylphosphat (pNPP) auf ihre Phosphatase-Aktivität hin untersucht werden.

Durch eine weitergehende „WMISH“-Analyse der Funktionsverlust-Phänotypen von Xdach1 sollen detailliertere Ergebnisse hinsichtlich des Charakters der Zellen innerhalb der betroffenen neuralen Gewebe wie Gehirn und Retina erhalten werden. Bezüglich des Gehirns könnten hierbei vor allem Markergene einer aktiven $T G F-\beta$-Signaltransduktion, wie beispielsweise $X m s x 1$ und weitere bekannte $T G F-\beta$-Zielgene, zum Einsatz kommen, um die Expansion der Bmp-Aktivität nach ventral zu verifizieren. In retinalem Gewebe können neben einer „WMISH“ mit weiteren, in spezifischen Bereichen exprimierten Markergenen außerdem Immunfärbungen an Paraffinschnitten mit zelltypspezifischen Antikörpern durchgeführt werden, um Aussagen über den Verlust oder auch eine besondere Anhäufung bestimmter retinaler Zelltypen zu treffen. In diesem Zusamenhang sollen zusätzlich Lipofektionen sowohl des Xdach1-Morpholinos als auch von synthetischer Xdach1-mRNA in retinale Vorläuferzellen der optischen Vesikel zum Zeitpunkt verschiedener Entwicklungsstadien des Auges durchgeführt werden. In Kombination mit der „WMISH“- und proteinchemischen-Analyse könnte so untersucht werden, welchen Einfluss Xdach1 auf das Differenzierungsverhalten retinaler Vorläuferzellen hat.

Zur Umgehung der durch eine Mikroinjektion synthetischer mRNA hervorgerufenen starken Neuralisierung zu Zeitpunkten, an denen noch keine endogene Expression von Xdachl besteht, kann neben dem angesprochenen Verfahren der Lipofektion synthetische mRNA für 
Glucocorticoid-Rezeptor-Konstrukte von Xdach1 in Mikroinjektionsexperimenten verwendet werden. Deren Translationsbeginn lässt sich durch eine Zugabe von Dexamethason in das Kulturmedium zum gewünschten Zeitpunkt der Embryonalentwicklung steuern. Im Fall von Xdach1 wäre dies zum Ende der Neurulation. So können möglicherweise Phänotypen eines Funktionsgewinns von Xdachl erhalten werden, die im Falle der hier durchgeführten Überexpressionsstudien durch die starke Neuralisierung im Zuge der Inhibition der Xbmp4vermittelten Signaltransduktion überlagert werden.

Des Weiteren sollte untersucht werden, ob auch die Signalwege anderer Mitglieder der Bmpbzw. TGF- $\beta$-Familie durch eine Überexpression von Xdachl in vivo betroffen sind. Dazu werden Experimente in animalen Gewebeexplantaten aus Xenopus laevis unter Verwendung von Xdach1 und Faktoren wie beispielsweise Activin oder TGF- $\beta$ und entsprechend ausgewählten, spezifischen Zielgenen durchgeführt. Durch Ko-Injektion von Xdach1 und Mitgliedern der TGF- $\beta$-Familie sowie die anschließende Analyse der Transkription der angesprochenen Zielgene im Zuge einer RT-PCR können so, wie hier im Falle von Xbmp4 gezeigt, eventuelle negative Effekte von Xdach1 herausgearbeitet werden.

Zur Identifikation möglicher Interaktionspartner von Xdach1 soll wie für Xeya3 weiter oben beschrieben verfahren werden (Yeast-Two-Hybrid- und Expressionsscreen, KoImmunpräzipitationen). Im Zusammenhang damit werden auch Deletionskonstrukte bezüglich der beiden konservierten Dachshund-Domänen getestet. Dadurch soll versucht werden, die einzelnen Bereiche des Proteins z.B. mit Hinblick auf ihren Beitrag zur Bindung möglicher Interaktionspartner genauer zu charakterisieren. 



\section{Zusammenfassung}

Xeya 3 aus Xenopus laevis ist als Mitglied der Eya-Famile von Proteinen durch eine hochkonservierte C-terminal gelegene „Eya“-Domäne und eine im Vergleich mit anderen Familienmitgliedern in ihrer Primärstruktur variable, Prolin-, Serin und Threonin reiche, Nterminale „PST“-Domäne gekennzeichnet. Transkripte von Xeya3 können bereits während der Oogenese detektiert werden. Im reifen Ei und in Blastulastadien ist die Xeya3-mRNA in der animalen Hemisphäre lokalisiert. Nach Beginn der zygotischen Transkription beschränkt sich die Xeya3-Expression auf Gewebe anterioren neuralen Charakters wie Hirn- und Augenanlage und bleibt dort bis zum Beginn von Zelldifferenzierungsprozessen bestehen. Zellen der Linsenplakode, primäre Linsenfasern und Zellen der cranialen Neuralleiste exprimieren ebenfalls Хeya3. Ein Funktionsverlust von Xeya3 führt zum vollständigen Verlust des Auges inklusive der Linse sowie der betroffenen Hirnhälfte. Ursache dafür sind die Apoptose neuraler Vorläuferzellen sowie Defekte in der Ausbildung präsumtiven Linsengewebes. Komplementär dazu hat die Überexpression von Xeya 3 eine starke Neoplasie anterioren neuralen Gewebes wie Gehirn und Retina zur Folge. Neben einer Hyperproliferation neuraler Vorläuferzellen trägt die Ausbildung weiterer Zentren sekundärer Neurogenese in Form zusätzlicher Gehirnventrikel zum beobachteten Phänotyp bei. Durch Überexpression von Xeya3 kommt es zudem zur Vergrößerung von Gewebe im Bereich cranialen Neuralleistengewebes. Die Inaktivierung einer im Bereich der „Eya“-Domäne lokalisierten Phosphatase-Aktivität führt zu einer deutlichen Aktivitätssteigerung des Xeya3-Proteins. Möglicherweise besitzt die Phosphatase-Aktivität des Xeya3-Proteins autoregulatorische Funktionen.

Xdach1 aus Xenopus laevis besitzt als Mitglied der Dachshund-Familie zwei konservierte Domänen, die Dachshund Domäne 1 (DD1) und 2 (DD2). Gegen Ende der Neurulation wird Xdach1 von Zellen des optischen Vesikels sowie des zukünftigen dorsalen Hinterhirns exprimiert. In frühen Kaulquappenstadien zeigen neben neuraler Retina und Bereichen des Gehirns auch mesodermale Derivate wie die Nierenanlage und Muskelvorläuferzellen Expression von Xdach1. Die Überexpression von Xdach1 hat stark neuralisierende Effekte, die eine Folge der Inhibition der durch Xbmp4 vermittelten Signaltransduktion sind. Ein Funktionsverlust von Xdach1 führt zur fehlerhaften Musterbildung retinalen Gewebes in proximodistaler Orientierung, die durch das Fehlen eines optischen Stiels sowie die Expansion distal exprimierter Markergene nach proximal gekennzeichnet ist. In Bereichen des zukünftigen Gehirns verhindert der Xdachl-Funktionsverlust den Prozess der Neurogenese. Als Grund für die beobachteten Funktionsverlust-Phänotypen kann eine Ausdehnung des Einflussbereiches des Morphogens Xbmp4 samt seiner nachgeschalteten Signaltransduktionskaskade angeführt werden. Xdach1 und Six6 steuern im Verlauf der Embryogenese von Xenopus laevis die 
Entwicklung retinalen Gewebes. Gemeinsam zugeführte, geringe Mengen an Protein führen zu positiven synergistischen Effekten im Sinne eines starken Größenzuwachses der Retina. 


\section{Literaturverzeichnis}

Abdelhak, S., Kalatzis, V., Heilig, R., Compain, S., Samson, D., Vincent, C., Weil, D., Cruaud, C., Sahly, I., Leibovici, M., Bitner-Glindzicz, M., Francis, M., Lacombe, D., Vigneron, J., Charachon, R., Boven, K., Bedbeder, P., Van Regemorter, N., Weissenbach, J. und Petit, C. (1997) A human homologue of the Drosophila eyes absent gene underlies branchio-oto-renal (BOR) syndrome and identifies a novel gene family. Nat Genet, 15, 157-164.

Acampora, D., Mazan, S., Lallemand, Y., Avantaggiato, V., Maury, M., Simeone, A. und Brulet, P. (1995) Forebrain and midbrain regions are deleted in Otx2-/- mutants due to a defective anterior neuroectoderm specification during gastrulation. Development, 121, 3279-3290.

Akiyoshi, S., Inoue, H., Hanai, J., Kusanagi, K., Nemoto, N., Miyazono, K. und Kawabata, M. (1999) c-Ski acts as a transcriptional co-repressor in transforming growth factor-beta signaling through interaction with smads. J Biol Chem, 274, 35269-35277.

Altmann, C.R., Chow, R.L., Lang, R.A. und Hemmati-Brivanlou, A. (1997) Lens induction by Pax-6 in Xenopus laevis. Dev Biol, 185, 119-123.

Altschul, S.F., Madden, T.L., Schaffer, A.A., Zhang, J., Zhang, Z., Miller, W. und Lipman, D.J. (1997) Gapped BLAST and PSI-BLAST: a new generation of protein database search programs. Nucleic Acids Res, 25, 3389-3402.

Amaravadi, L.S., Neff, A.W., Sleeman, J.P. und Smith, R.C. (1997) Autonomous neural axis formation by ectopic expression of the protooncogene c-ski. Dev Biol, 192, 392-404.

Ashery-Padan, R., Marquardt, T., Andrejewski, N. und Gruss, P. (2001) Unraveling the multiple functions of Pax6 in eye development by conditional mutagenesis. MPIbpc News, 7, 16.

Azuma, N., Hirakiyama, A., Inoue, T., Asaka, A. und Yamada, M. (2000) Mutations of a human homologue of the Drosophila eyes absent gene (EYA1) detected in patients with congenital cataracts and ocular anterior segment anomalies. Hum Mol Genet, 9, 363366.

Behrens, J., von Kries, J.P., Kuhl, M., Bruhn, L., Wedlich, D., Grosschedl, R. und Birchmeier, W. (1996) Functional interaction of beta-catenin with the transcription factor LEF-1. Nature, 382, 638-642.

Bellefroid, E.J., Bourguignon, C., Hollemann, T., Ma, Q., Anderson, D.J., Kintner, C. und Pieler, T. (1996) X-MyT1, a Xenopus C2HC-type zinc finger protein with a regulatory function in neuronal differentiation. Cell, 87, 1191-1202. 
Bernier, G., Panitz, F., Zhou, X., Hollemann, T., Gruss, P. und Pieler, T. (2000) Expanded retina territory by midbrain transformation upon overexpression of Six6 (Optx2) in Xenopus embryos. Mech Dev, 93, 59-69.

Blom, N., Gammeltoft, S. und Brunak, S. (1999) Sequence and structure-based prediction of eukaryotic protein phosphorylation sites. J Mol Biol, 294, 1351-1362.

Bonini, N.M., Bui, Q.T., Gray-Board, G.L. und Warrick, J.M. (1997) The Drosophila eyes absent gene directs ectopic eye formation in a pathway conserved between flies and vertebrates. Development, 124, 4819-4826.

Bonini, N.M., Leiserson, W.M. und Benzer, S. (1993) The eyes absent gene: genetic control of cell survival and differentiation in the developing Drosophila eye. Cell, 72, 379-395.

Borsani, G., DeGrandi, A., Ballabio, A., Bulfone, A., Bernard, L., Banfi, S., Gattuso, C., Mariani, M., Dixon, M., Donnai, D., Metcalfe, K., Winter, R., Robertson, M., Axton, R., Brown, A., van Heyningen, V. und Hanson, I. (1999) EYA4, a novel vertebrate gene related to Drosophila eyes absent. Hum Mol Genet, 8, 11-23.

Brewster, R., Lee, J. und Ruiz i Altaba, A. (1998) Gli/Zic factors pattern the neural plate by defining domains of cell differentiation. Nature, 393, 579-583.

Briscoe, J. und Ericson, J. (1999) The specification of neuronal identity by graded Sonic Hedgehog signalling. Semin Cell Dev Biol, 10, 353-362.

Bullock W.O., Fernandez J.M. und Short J.M. (1987) Biotechniques, 5, 376-379.

Cadigan, K.M. und Nusse, R. (1997) Wnt signaling: a common theme in animal development. Genes Dev, 11, 3286-3305.

Casarosa, S., Andreazzoli, M., Simeone, A. und Barsacchi, G. (1997) Xrx1, a novel Xenopus homeobox gene expressed during eye and pineal gland development. Mech Dev, 61, 187-198.

Caubit, X., Thangarajah, R., Theil, T., Wirth, J., Nothwang, H.G., Ruther, U. und Krauss, S. (1999) Mouse Dac, a novel nuclear factor with homology to Drosophila dachshund shows a dynamic expression in the neural crest, the eye, the neocortex, and the limb bud. Dev Dyn, 214, 66-80.

Chen, R., Amoui, M., Zhang, Z. und Mardon, G. (1997) Dachshund and eyes absent proteins form a complex and function synergistically to induce ectopic eye development in Drosophila. Cell, 91, 893-903.

Chen, Y., Pollet, N., Niehrs, C. und Pieler, T. (2001) Increased XRALDH2 activity has a posteriorizing effect on the central nervous system of Xenopus embryos. Mech Dev, 101, 91-103.

Chitnis, A. und Kintner, C. (1996) Sensitivity of proneural genes to lateral inhibition affects the pattern of primary neurons in Xenopus embryos. Development, 122, 2295-2301. 
Chow, R.L., Altmann, C.R., Lang, R.A. und Hemmati-Brivanlou, A. (1999) Pax6 induces ectopic eyes in a vertebrate. Development, 126, 4213-4222.

Cox, W.G. und Hemmati-Brivanlou, A. (1995) Caudalization of neural fate by tissue recombination and bFGF. Development, 121, 4349-4358.

David, R., Ahrens, K., Wedlich, D. und Schlosser, G. (2001) Xenopus Eyal demarcates all neurogenic placodes as well as migrating hypaxial muscle precursors. Mech Dev, 103, 189-192.

Davidson, L.A. und Keller, R.E. (1999) Neural tube closure in Xenopus laevis involves medial migration, directed protrusive activity, cell intercalation and convergent extension. Development, 126, 4547-4556.

Davis, R.J., Shen, W., Heanue, T.A. und Mardon, G. (1999) Mouse Dach, a homologue of Drosophila dachshund, is expressed in the developing retina, brain and limbs. Dev Genes Evol, 209, 526-536.

Davis, R.J., Shen, W., Sandler, Y.I., Amoui, M., Purcell, P., Maas, R., Ou, C.N., Vogel, H., Beaudet, A.L. und Mardon, G. (2001a) Dach1 mutant mice bear no gross abnormalities in eye, limb, and brain development and exhibit postnatal lethality. Mol Cell Biol, 21, 1484-1490.

Davis, R.J., Shen, W., Sandler, Y.I., Heanue, T.A. und Mardon, G. (2001b) Characterization of mouse Dach2, a homologue of Drosophila dachshund. Mech Dev, 102, 169-179.

Don, R.H., Cox, P.T., Wainwright, B.J., Baker, K. und Mattick, J.S. (1991) 'Touchdown' PCR to circumvent spurious priming during gene amplification. Nucleic Acids Res, 19, 4008.

Duncan, M.K., Kos, L., Jenkins, N.A., Gilbert, D.J., Copeland, N.G. und Tomarev, S.I. (1997) Eyes absent: a gene family found in several metazoan phyla. Mamm Genome, 8, 479485.

Ekker, S.C., Ungar, A.R., Greenstein, P., von Kessler, D.P., Porter, J.A., Moon, R.T. und Beachy, P.A. (1995) Patterning activities of vertebrate hedgehog proteins in the developing eye and brain. Curr Biol, 5, 944-955.

Fainsod, A., Deissler, K., Yelin, R., Marom, K., Epstein, M., Pillemer, G., Steinbeisser, H. und Blum, M. (1997) The dorsalizing and neural inducing gene follistatin is an antagonist of BMP-4. Mech Dev, 63, 39-50.

Falquet, L., Pagni, M., Bucher, P., Hulo, N., Sigrist, C.J., Hofmann, K. und Bairoch, A. (2002) The PROSITE database, its status in 2002. Nucleic Acids Res, 30, 235-238.

Fujiwara, M., Uchida, T., Osumi-Yamashita, N. und Eto, K. (1994) Uchida rat (rSey): a new mutant rat with craniofacial abnormalities resembling those of the mouse Sey mutant. Differentiation, 57, 31-38.

George, D.G., Barker, W.C. und Hunt, L.T. (1990) Mutation data matrix and its uses. Methods Enzymol, 183, 333-351. 
Ghanbari, H., Seo, H.C., Fjose, A. und Brandli, A.W. (2001) Molecular cloning and embryonic expression of Xenopus Six homeobox genes. Mech Dev, 101, 271-277.

Gilbert, S. (2000) Developmental Biology. Sinauer Associates, Inc., Sunderland.

Glaser, T., Jepeal, L., Edwards, J.G., Young, S.R., Favor, J. und Maas, R.L. (1994) PAX6 gene dosage effect in a family with congenital cataracts, aniridia, anophthalmia and central nervous system defects. Nat Genet, 7, 463-471.

Glaser, T., Walton, D.S. und Maas, R.L. (1992) Genomic structure, evolutionary conservation and aniridia mutations in the human PAX6 gene. Nat Genet, 2, 232-239.

Glinka, A., Wu, W., Delius, H., Monaghan, A.P., Blumenstock, C. und Niehrs, C. (1998) Dickkopf-1 is a member of a new family of secreted proteins and functions in head induction. Nature, 391, 357-362.

Glinka, A., Wu, W., Onichtchouk, D., Blumenstock, C. und Niehrs, C. (1997) Head induction by simultaneous repression of Bmp and Wnt signalling in Xenopus. Nature, 389, 517519.

Halder, G., Callaerts, P. und Gehring, W.J. (1995) Induction of ectopic eyes by targeted expression of the eyeless gene in Drosophila. Science, 267, 1788-1792.

Hammond, K.L., Hanson, I.M., Brown, A.G., Lettice, L.A. und Hill, R.E. (1998) Mammalian and Drosophila dachshund genes are related to the Ski proto-oncogene and are expressed in eye and limb. Mech Dev, 74, 121-131.

Hammond, K.L., Hill, R.E., Whitfield, T.T. und Currie, P.D. (2002) Isolation of three zebrafish dachshund homologues and their expression in sensory organs, the central nervous system and pectoral fin buds. Mech Dev, 112, 183-189.

Hammond, K.L., Lettice, L.A., Hill, R.E., Lee, M., Boyle, S. und Hanson, I.M. (1999) Human (DACH) and mouse (Dach) homologues of Drosophila dachshund map to chromosomes $13 \mathrm{q} 22$ and 14E3, respectively. Genomics, 55, 252-253.

Hardcastle, Z. und Papalopulu, N. (2000) Distinct effects of XBF-1 in regulating the cell cycle inhibitor p27(XIC1) and imparting a neural fate. Development, 127, 1303-1314.

Harland, R. (2000) Neural induction. Curr Opin Genet Dev, 10, 357-362.

Harland, R. und Gerhart, J. (1997) Formation and function of Spemann's organizer. Annu Rev Cell Dev Biol, 13, 611-667.

Harris, W.A. und Hartenstein, V. (1991) Neuronal determination without cell division in Xenopus embryos. Neuron, 6, 499-515.

Heanue, T.A., Davis, R.J., Rowitch, D.H., Kispert, A., McMahon, A.P., Mardon, G. und Tabin, C.J. (2002) Dach1, a vertebrate homologue of Drosophila dachshund, is expressed in the developing eye and ear of both chick and mouse and is regulated independently of Pax and Eya genes. Mech Dev, 111, 75-87. 
Heanue, T.A., Reshef, R., Davis, R.J., Mardon, G., Oliver, G., Tomarev, S., Lassar, A.B. und Tabin, C.J. (1999) Synergistic regulation of vertebrate muscle development by Dach2, Eya2, and Six1, homologs of genes required for Drosophila eye formation. Genes Dev, 13, 3231-3243.

Hendzel, M.J., Wei, Y., Mancini, M.A., Van Hooser, A., Ranalli, T., Brinkley, B.R., BazettJones, D.P. und Allis, C.D. (1997) Mitosis-specific phosphorylation of histone H3 initiates primarily within pericentromeric heterochromatin during G2 and spreads in an ordered fashion coincident with mitotic chromosome condensation. Chromosoma, 106, 348-360.

Henry, J.J. und Grainger, R.M. (1990) Early tissue interactions leading to embryonic lens formation in Xenopus laevis. Dev Biol, 141, 149-163.

Hensey, C. und Gautier, J. (1998) Programmed cell death during Xenopus development: a spatio-temporal analysis. Dev Biol, 203, 36-48.

Hill, R.E., Favor, J., Hogan, B.L., Ton, C.C., Saunders, G.F., Hanson, I.M., Prosser, J., Jordan, T., Hastie, N.D. und van Heyningen, V. (1991) Mouse small eye results from mutations in a paired-like homeobox-containing gene. Nature, 354, 522-525.

Hirsch, N. und Harris, W.A. (1997) Xenopus Pax-6 and retinal development. J Neurobiol, 32, 45-61.

Hisano, T., Hata, Y., Fujii, T., Liu, J.Q., Kurihara, T., Esaki, N. und Soda, K. (1996) Crystal structure of L-2-haloacid dehalogenase from Pseudomonas sp. YL. An alpha/beta hydrolase structure that is different from the alpha/beta hydrolase fold. $J$ Biol Chem, 271, 20322-20330.

Hogan, B.L., Hirst, E.M., Horsburgh, G. und Hetherington, C.M. (1988) Small eye (Sey): a mouse model for the genetic analysis of craniofacial abnormalities. Development, 103 Suppl, 115-119.

Hollemann, T., Chen, Y., Grunz, H. und Pieler, T. (1998) Regionalized metabolic activity establishes boundaries of retinoic acid signalling. Embo J, 17, 7361-7372.

Holowacz, T. und Sokol, S. (1999) FGF is required for posterior neural patterning but not for neural induction. Dev Biol, 205, 296-308.

Hsiao, F.C., Williams, A., Davies, E.L. und Rebay, I. (2001) Eyes absent mediates cross-talk between retinal determination genes and the receptor tyrosine kinase signaling pathway. Dev Cell, 1, 51-61.

Ikegami, S., Taguchi, T., Ohashi, M., Oguro, M., Nagano, H. und Mano, Y. (1978) Aphidicolin prevents mitotic cell division by interfering with the activity of DNA polymerase-alpha. Nature, 275, 458-460.

Jonas, E., Sargent, T.D. und Dawid, I.B. (1985) Epidermal keratin gene expressed in embryos of Xenopus laevis. Proc Natl Acad Sci U S A, 82, 5413-5417. 
Kida, Y., Maeda, Y., Shiraishi, T., Suzuki, T. und Ogura, T. (2004) Chick Dach1 interacts with the Smad complex and Sin3a to control AER formation and limb development along the proximodistal axis. Development, 131, 4179-4187.

Kiecker, C. und Niehrs, C. (2001) A morphogen gradient of Wnt/beta-catenin signalling regulates anteroposterior neural patterning in Xenopus. Development, 128, 4189-4201.

Knecht, A.K., Good, P.J., Dawid, I.B. und Harland, R.M. (1995) Dorsal-ventral patterning and differentiation of noggin-induced neural tissue in the absence of mesoderm. Development, 121, 1927-1935.

Koster, M., Plessow, S., Clement, J.H., Lorenz, A., Tiedemann, H. und Knochel, W. (1991) Bone morphogenetic protein 4 (BMP-4), a member of the TGF-beta family, in early embryos of Xenopus laevis: analysis of mesoderm inducing activity. Mech Dev, 33, 191-199.

Kozmik, Z., Pfeffer, P., Kralova, J., Paces, J., Paces, V., Kalousova, A. und Cvekl, A. (1999) Molecular cloning and expression of the human and mouse homologues of the Drosophila dachshund gene. Dev Genes Evol, 209, 537-545.

Lamb, T.M. und Harland, R.M. (1995) Fibroblast growth factor is a direct neural inducer, which combined with noggin generates anterior-posterior neural pattern. Development, 121, 3627-3636.

Lamb, T.M., Knecht, A.K., Smith, W.C., Stachel, S.E., Economides, A.N., Stahl, N., Yancopolous, G.D. und Harland, R.M. (1993) Neural induction by the secreted polypeptide noggin. Science, 262, 713-718.

Leyns, L., Bouwmeester, T., Kim, S.H., Piccolo, S. und De Robertis, E.M. (1997) Frzb-1 is a secreted antagonist of Wnt signaling expressed in the Spemann organizer. Cell, 88, 747756.

Li, X., Oghi, K.A., Zhang, J., Krones, A., Bush, K.T., Glass, C.K., Nigam, S.K., Aggarwal, A.K., Maas, R., Rose, D.W. und Rosenfeld, M.G. (2003) Eya protein phosphatase activity regulates Six1-Dach-Eya transcriptional effects in mammalian organogenesis. Nature, 426, 247-254.

Li, X., Perissi, V., Liu, F., Rose, D.W. und Rosenfeld, M.G. (2002) Tissue-specific regulation of retinal and pituitary precursor cell proliferation. Science, 297, 1180-1183.

Liem, K.F., Jr., Tremml, G. und Jessell, T.M. (1997) A role for the roof plate and its resident TGFbeta-related proteins in neuronal patterning in the dorsal spinal cord. Cell, 91, 127138.

Liem, K.F., Jr., Tremml, G., Roelink, H. und Jessell, T.M. (1995) Dorsal differentiation of neural plate cells induced by BMP-mediated signals from epidermal ectoderm. Cell, 82, 969-979. 
Liu, Y., Helms, A.W. und Johnson, J.E. (2004) Distinct activities of Msx1 and Msx3 in dorsal neural tube development. Development, 131, 1017-1028.

Liu, Y., Lupo, G., Marchitiello, A., Gestri, G., He, R.Q., Banfi, S. und Barsacchi, G. (2001) Expression of the Xvax2 gene demarcates presumptive ventral telencephalon and specific visual structures in Xenopus laevis. Mech Dev, 100, 115-118.

Loosli, F., Mardon, G. und Wittbrodt, J. (2002) Cloning and expression of medaka Dachshund. Mech Dev, 112, 203-206.

Luo, K. (2004) Ski and SnoN: negative regulators of TGF-beta signaling. Curr Opin Genet Dev, $14,65-70$.

Luo, K., Stroschein, S.L., Wang, W., Chen, D., Martens, E., Zhou, S. und Zhou, Q. (1999) The Ski oncoprotein interacts with the Smad proteins to repress TGFbeta signaling. Genes Dev, 13, 2196-2206.

Ma, Q., Kintner, C. und Anderson, D.J. (1996) Identification of neurogenin, a vertebrate neuronal determination gene. Cell, 87, 43-52.

Mardon, G., Solomon, N.M. und Rubin, G.M. (1994) dachshund encodes a nuclear protein required for normal eye and leg development in Drosophila. Development, 120, 34733486.

Martini, S.R., Roman, G., Meuser, S., Mardon, G. und Davis, R.L. (2000) The retinal determination gene, dachshund, is required for mushroom body cell differentiation. Development, 127, 2663-2672.

Mathers, P.H., Grinberg, A., Mahon, K.A. und Jamrich, M. (1997) The Rx homeobox gene is essential for vertebrate eye development. Nature, 387, 603-607.

McGrew, L.L., Lai, C.J. und Moon, R.T. (1995) Specification of the anteroposterior neural axis through synergistic interaction of the Wnt signaling cascade with noggin and follistatin. Dev Biol, 172, 337-342.

Mishima, N. und Tomarev, S. (1998) Chicken Eyes absent 2 gene: isolation and expression pattern during development. Int J Dev Biol, 42, 1109-1115.

Munoz-Sanjuan, I. und Brivanlou, A.H. (2002) Neural induction, the default model and embryonic stem cells. Nat Rev Neurosci, 3, 271-280.

Niederreither, K., McCaffery, P., Drager, U.C., Chambon, P. und Dolle, P. (1997) Restricted expression and retinoic acid-induced downregulation of the retinaldehyde dehydrogenase type 2 (RALDH-2) gene during mouse development. Mech Dev, 62, 6778.

Nieuwkoop P.D., Faber P. (1967) Normal Table of Xenopus laevis (Daudin). 2. Auflage, North-Holland Publ. Co., Amsterdam. 
Ohto, H., Kamada, S., Tago, K., Tominaga, S.I., Ozaki, H., Sato, S. und Kawakami, K. (1999) Cooperation of six and eya in activation of their target genes through nuclear translocation of Eya. Mol Cell Biol, 19, 6815-6824.

Oschwald, R., Richter, K. und Grunz, H. (1991) Localization of a nervous system-specific class II beta-tubulin gene in Xenopus laevis embryos by whole-mount in situ hybridization. Int J Dev Biol, 35, 399-405.

Pannese, M., Polo, C., Andreazzoli, M., Vignali, R., Kablar, B., Barsacchi, G. und Boncinelli, E. (1995) The Xenopus homologue of Otx2 is a maternal homeobox gene that demarcates and specifies anterior body regions. Development, 121, 707-720.

Papalopulu, N., Clarke, J.D., Bradley, L., Wilkinson, D., Krumlauf, R. und Holder, N. (1991) Retinoic acid causes abnormal development and segmental patterning of the anterior hindbrain in Xenopus embryos. Development, 113, 1145-1158.

Papalopulu, N. und Kintner, C. (1993) Xenopus Distal-less related homeobox genes are expressed in the developing forebrain and are induced by planar signals. Development, 117, 961-975.

Paulson, J.R. und Taylor, S.S. (1982) Phosphorylation of histones 1 and 3 and nonhistone high mobility group 14 by an endogenous kinase in HeLa metaphase chromosomes. J Biol Chem, 257, 6064-6072.

Penzel, R., Oschwald, R., Chen, Y., Tacke, L. und Grunz, H. (1997) Characterization and early embryonic expression of a neural specific transcription factor $\mathrm{xSOX} 3$ in Xenopus laevis. Int J Dev Biol, 41, 667-677.

Piccolo, S., Agius, E., Leyns, L., Bhattacharyya, S., Grunz, H., Bouwmeester, T. und De Robertis, E.M. (1999) The head inducer Cerberus is a multifunctional antagonist of Nodal, BMP and Wnt signals. Nature, 397, 707-710.

Piccolo, S., Sasai, Y., Lu, B. und De Robertis, E.M. (1996) Dorsoventral patterning in Xenopus: inhibition of ventral signals by direct binding of chordin to BMP-4. Cell, 86, 589-598.

Pignoni, F., Hu, B., Zavitz, K.H., Xiao, J., Garrity, P.A. und Zipursky, S.L. (1997) The eyespecification proteins So and Eya form a complex and regulate multiple steps in Drosophila eye development. Cell, 91, 881-891.

Pommereit, D., Pieler, T. und Hollemann, T. (2001) Xpitx3: a member of the Rieg/Pitx gene family expressed during pituitary and lens formation in Xenopus laevis. Mech Dev, 102, 255-257.

Rayapureddi, J.P., Kattamuri, C., Steinmetz, B.D., Frankfort, B.J., Ostrin, E.J., Mardon, G. und Hegde, R.S. (2003) Eyes absent represents a class of protein tyrosine phosphatases. Nature, 426, 295-298. 
Roelink, H., Porter, J.A., Chiang, C., Tanabe, Y., Chang, D.T., Beachy, P.A. und Jessell, T.M. (1995) Floor plate and motor neuron induction by different concentrations of the aminoterminal cleavage product of sonic hedgehog autoproteolysis. Cell, 81, 445-455.

Roux, K.H. (1995) Optimization and troubleshooting in PCR. PCR Methods Appl, 4, S185-194.

Ruiz i Altaba, A. und Jessell, T. (1991a) Retinoic acid modifies mesodermal patterning in early Xenopus embryos. Genes Dev, 5, 175-187.

Ruiz i Altaba, A. und Jessell, T.M. (1991b) Retinoic acid modifies the pattern of cell differentiation in the central nervous system of neurula stage Xenopus embryos. Development, 112, 945-958.

Saha, M.S. und Grainger, R.M. (1993) Early opsin expression in Xenopus embryos precedes photoreceptor differentiation. Brain Res Mol Brain Res, 17, 307-318.

Sahly, I., Andermann, P. und Petit, C. (1999) The zebrafish eyal gene and its expression pattern during embryogenesis. Dev Genes Evol, 209, 399-410.

Saka, Y. und Smith, J.C. (2001) Spatial and temporal patterns of cell division during early Xenopus embryogenesis. Dev Biol, 229, 307-318.

Sanger, F., Nicklen, S. und Coulson, A.R. (1977) DNA sequencing with chain-terminating inhibitors. Proc Natl Acad Sci U S A, 74, 5463-5467.

Sasagawa, S., Takabatake, T., Takabatake, Y., Muramatsu, T. und Takeshima, K. (2002) Axes establishment during eye morphogenesis in Xenopus by coordinate and antagonistic actions of BMP4, Shh, and RA. Genesis, 33, 86-96.

Sasai, Y., Lu, B., Steinbeisser, H. und De Robertis, E.M. (1995) Regulation of neural induction by the Chd and Bmp-4 antagonistic patterning signals in Xenopus. Nature, 376, 333336.

Schuler-Metz, A., Knochel, S., Kaufmann, E. und Knochel, W. (2000) The homeodomain transcription factor Xvent-2 mediates autocatalytic regulation of BMP-4 expression in Xenopus embryos. J Biol Chem, 275, 34365-34374.

Shen, W. und Mardon, G. (1997) Ectopic eye development in Drosophila induced by directed dachshund expression. Development, 124, 45-52.

Silver, S.J., Davies, E.L., Doyon, L. und Rebay, I. (2003) Functional dissection of eyes absent reveals new modes of regulation within the retinal determination gene network. $\mathrm{Mol}$ Cell Biol, 23, 5989-5999.

Sive, H.L., Draper, B.W., Harland, R.M. und Weintraub, H. (1990) Identification of a retinoic acid-sensitive period during primary axis formation in Xenopus laevis. Genes Dev, $\mathbf{4}$, 932-942.

Spemann, H. und Mangold, H. (2001) Induction of embryonic primordia by implantation of organizers from a different species. 1923. Int J Dev Biol, 45, 13-38. 
Sun, Y., Liu, X., Eaton, E.N., Lane, W.S., Lodish, H.F. und Weinberg, R.A. (1999) Interaction of the Ski oncoprotein with Smad3 regulates TGF-beta signaling. Mol Cell, 4, 499-509.

Suzuki, A., Ueno, N. und Hemmati-Brivanlou, A. (1997) Xenopus msx1 mediates epidermal induction and neural inhibition by BMP4. Development, 124, 3037-3044.

Tavsanli, B.C., Ostrin, E.J., Burgess, H.K., Middlebrooks, B.W., Pham, T.A. und Mardon, G. (2004) Structure-function analysis of the Drosophila retinal determination protein Dachshund. Dev Biol, 272, 231-247.

Tootle, T.L., Silver, S.J., Davies, E.L., Newman, V., Latek, R.R., Mills, I.A., Selengut, J.D., Parlikar, B.E. und Rebay, I. (2003) The transcription factor Eyes absent is a protein tyrosine phosphatase. Nature, 426, 299-302.

Turner, D.L. und Weintraub, H. (1994) Expression of achaete-scute homolog 3 in Xenopus embryos converts ectodermal cells to a neural fate. Genes Dev, 8, 1434-1447.

Vincent, C., Kalatzis, V., Abdelhak, S., Chaib, H., Compain, S., Helias, J., Vaneecloo, F.M. und Petit, C. (1997) BOR and BO syndromes are allelic defects of EYA1. Eur J Hum Genet, 5, 242-246.

Wang, W., Cho, H.S., Kim, R., Jancarik, J., Yokota, H., Nguyen, H.H., Grigoriev, I.V., Wemmer, D.E. und Kim, S.H. (2002) Structural characterization of the reaction pathway in phosphoserine phosphatase: crystallographic "snapshots" of intermediate states. J Mol Biol, 319, 421-431.

Wang, W., Mariani, F.V., Harland, R.M. und Luo, K. (2000) Ski represses bone morphogenic protein signaling in Xenopus and mammalian cells. Proc Natl Acad Sci U S A, 97, 14394-14399.

Wawersik, S. und Maas, R.L. (2000) Vertebrate eye development as modeled in Drosophila. Hum Mol Genet, 9, 917-925.

Wayne, S., Robertson, N.G., DeClau, F., Chen, N., Verhoeven, K., Prasad, S., Tranebjarg, L., Morton, C.C., Ryan, A.F., Van Camp, G. und Smith, R.J. (2001) Mutations in the transcriptional activator EYA4 cause late-onset deafness at the DFNA10 locus. Hum Mol Genet, 10, 195-200.

Weinstein, D.C. und Hemmati-Brivanlou, A. (1999) Neural induction. Annu Rev Cell Dev Biol, 15, 411-433.

Wilson, P.A. und Hemmati-Brivanlou, A. (1995) Induction of epidermis and inhibition of neural fate by Bmp-4. Nature, 376, 331-333.

Wittbrodt, J., Shima, A. und Schartl, M. (2002) Medaka--a model organism from the far East. Nat Rev Genet, 3, 53-64.

Wolpert, L. (1998) Principles of development. Oxford University Press, New York.

Wu, K., Yang, Y., Wang, C., Davoli, M.A., D'Amico, M., Li, A., Cveklova, K., Kozmik, Z., Lisanti, M.P., Russell, R.G., Cvekl, A. und Pestell, R.G. (2003) DACH1 inhibits 
transforming growth factor-beta signaling through binding Smad4. J Biol Chem, 278, 51673-51684.

Xu, P.X., Adams, J., Peters, H., Brown, M.C., Heaney, S. und Maas, R. (1999) Eya1-deficient mice lack ears and kidneys and show abnormal apoptosis of organ primordia. Nat Genet, 23, 113-117.

Xu, P.X., Woo, I., Her, H., Beier, D.R. und Maas, R.L. (1997) Mouse Eya homologues of the Drosophila eyes absent gene require Pax6 for expression in lens and nasal placode. Development, 124, 219-231.

Zhang, L., Mathers, P.H. und Jamrich, M. (2000) Function of Rx, but not Pax6, is essential for the formation of retinal progenitor cells in mice. Genesis, 28, 135-142.

Zhang, Y., Knosp, B.M., Maconochie, M., Friedman, R.A. und Smith, R.J. (2004) A comparative study of Eya1 and Eya4 protein function and its implication in branchiooto-renal syndrome and DFNA10. J Assoc Res Otolaryngol, 5, 295-304.

Zhou, X., Hollemann, T., Pieler, T. und Gruss, P. (2000) Cloning and expression of xSix3, the Xenopus homologue of murine Six3. Mech Dev, 91, 327-330.

Zimmerman, J.E., Bui, Q.T., Steingrimsson, E., Nagle, D.L., Fu, W., Genin, A., Spinner, N.B., Copeland, N.G., Jenkins, N.A., Bucan, M. und Bonini, N.M. (1997) Cloning and characterization of two vertebrate homologs of the Drosophila eyes absent gene. Genome Res, 7, 128-141.

Zimmerman, L.B., De Jesus-Escobar, J.M. und Harland, R.M. (1996) The Spemann organizer signal noggin binds and inactivates bone morphogenetic protein 4. Cell, 86, 599-606.

Zuber, M.E., Perron, M., Philpott, A., Bang, A. und Harris, W.A. (1999) Giant eyes in Xenopus laevis by overexpression of XOptx2. Cell, 98, 341-352. 



\section{Danksagungen}

Für die gute Betreuung während der Promotionsarbeit möchte ich mich besonders bei Herrn Prof. Dr. Thomas Hollemann bedanken. Seine Anregungen und konstruktive Kritik in den letzten drei Jahren waren jederzeit eine große Hilfe.

Mein Dank gilt Herrn Prof. Dr. Tomas Pieler für die Möglichkeit, die Arbeit in seiner Abteilung durchführen zu können.

Herrn Prof. Dr. Rüdiger Hardeland danke ich für die Übernahme des Korreferates.

Ein Dankeschön an die gesamte Abteilung Entwicklungsbiochemie für ein freundliches und kollegiales Arbeitsumfeld.

Bei Yvonne Cornesse, Marco Winkler, Emmanuel Tadjuidje und Andreas Nolte bedanke ich mich ganz besonders für eine mehr als nur gute, tägliche Zusammenarbeit.

Danke an Katrin, Tiemo und Christine für's Korrekturlesen der Arbeit und die Unterstützung im Kampf mit der deutschen Rechtschreibung.

An die ganze Familie Kriebel in Cuxhaven, Bremen und Trier: DANKESCHÖN EUCH VIER! 



\section{Lebenslauf}

$\begin{array}{ll}\text { Name: } & \text { Martin Kriebel } \\ \text { Geburtsdatum: } & 20.08 .1975 \\ \text { Geburtsort: } & \text { Jane-Furse-Hospital/Südafrika } \\ \text { Nationalität: } & \text { deutsch } \\ \text { Familienstand: } & \text { ledig } \\ \text { Adresse: } & \text { Stumpfe Eiche 1 } \\ & \text { 37077 Göttingen }\end{array}$

Ausbildung:

1981-1985

Grundschule Cuxhaven-Altenbruch

1985-1987

Orientierungsstufe Cuxhaven-Altenbruch

1987-1994

Amandus-Abendroth-Gymnasium Cuxhaven;

Abschluß: Abitur

1994-1995

Zivildienst; Seehospital Sahlenburg der Nordheim-Stiftung

1995-1996

Justus-Liebig-Universität Gießen

1996-1998

Georg-August-Universität Göttingen;

Grundstudium im Fach Biologie

1998:

Vordiplom im Fach Biologie am 16.10.1998

1998-2001:

Georg-August-Universität Göttingen;

Hauptstudium im Fach Biologie; Hauptfach Entwicklungsbiologie,

Nebenfächer Zoologie und Humangenetik

2000-2001:

Diplomarbeit im Fach Biologie, Schwerpunkt Entwicklungsbiologie,

Abteilung Prof. Dr. T. Pieler

Thema: „Vergleichende Expressionsanalyse von Regulatoren der

Augenentwicklung in Xenopus laevis“"

2001:

Hauptdiplom im Fach Biologie am 24.10.2001

seit 11.2001:

Georg-August-Universität Göttingen;

Promotionsarbeit im Fach Biologie, Schwerpunkt

Entwicklungsbiologie, Abteilung Prof. Dr. T. Pieler

2002-2004:

Förderung durch die DFG 